TEEHAHEAL REPGRTS SERHES AO.

$$
478
$$

\title{
Feasibility of Producing
}

Molybdenum-99 on a Small Scale Using Fission of Low Enriched Uranium or Neutron Activation of Natural Molybdenum 


\section{IAEA SAFETY STANDARDS AND RELATED PUBLICATIONS}

\section{IAEA SAFETY STANDARDS}

Under the terms of Article III of its Statute, the IAEA is authorized to establish or adopt standards of safety for protection of health and minimization of danger to life and property, and to provide for the application of these standards.

The publications by means of which the IAEA establishes standards are issued in the IAEA Safety Standards Series. This series covers nuclear safety, radiation safety, transport safety and waste safety. The publication categories in the series are Safety Fundamentals, Safety Requirements and Safety Guides.

Information on the IAEA's safety standards programme is available on the IAEA Internet site

$$
\text { http://www-ns.iaea.org/standards/ }
$$

The site provides the texts in English of published and draft safety standards. The texts of safety standards issued in Arabic, Chinese, French, Russian and Spanish, the IAEA Safety Glossary and a status report for safety standards under development are also available. For further information, please contact the IAEA at: Vienna International Centre, PO Box 100, 1400 Vienna, Austria.

All users of IAEA safety standards are invited to inform the IAEA of experience in their use (e.g. as a basis for national regulations, for safety reviews and for training courses) for the purpose of ensuring that they continue to meet users' needs. Information may be provided via the IAEA Internet site or by post, as above, or by email to Official.Mail@iaea.org.

\section{RELATED PUBLICATIONS}

The IAEA provides for the application of the standards and, under the terms of Articles III and VIII.C of its Statute, makes available and fosters the exchange of information relating to peaceful nuclear activities and serves as an intermediary among its Member States for this purpose.

Reports on safety in nuclear activities are issued as Safety Reports, which provide practical examples and detailed methods that can be used in support of the safety standards.

Other safety related IAEA publications are issued as Emergency Preparedness and Response publications, Radiological Assessment Reports, the International Nuclear Safety Group's INSAG Reports, Technical Reports and TECDOCs. The IAEA also issues reports on radiological accidents, training manuals and practical manuals, and other special safety related publications.

Security related publications are issued in the IAEA Nuclear Security Series.

The IAEA Nuclear Energy Series comprises informational publications to encourage and assist research on, and the development and practical application of, nuclear energy for peaceful purposes. It includes reports and guides on the status of and advances in technology, and on experience, good practices and practical examples in the areas of nuclear power, the nuclear fuel cycle, radioactive waste management and decommissioning. 


\section{FEASIBILITY OF \\ PRODUCING MOLYBDENUM-99 ON \\ A SMALL SCALE USING \\ FISSION OF LOW ENRICHED \\ URANIUM OR \\ NEUTRON ACTIVATION OF \\ NATURAL MOLYBDENUM}


The following States are Members of the International Atomic Energy Agency:

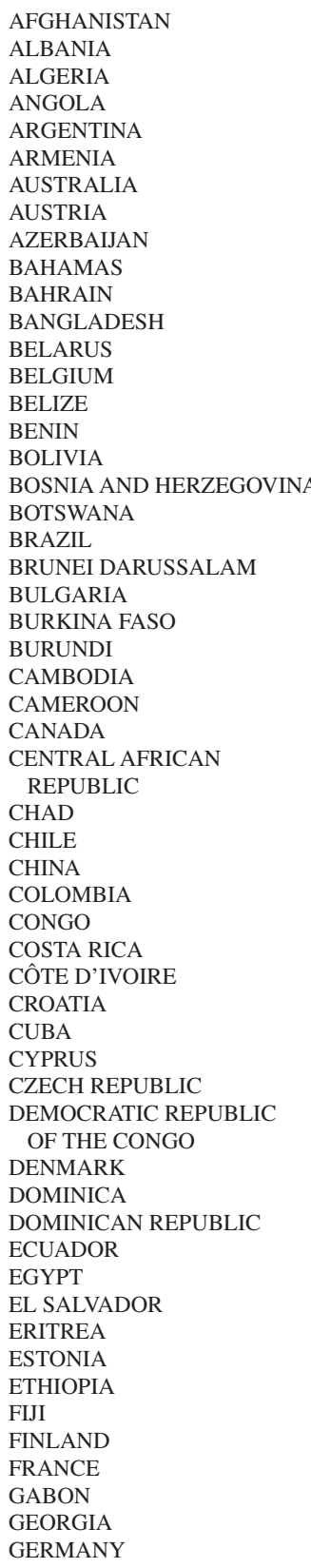

GHANA
GREECE
GUATEMALA
HAITI
HOLY SEE
HONDURAS
HUNGARY
ICELAND
INDIA
INDONESIA
IRAN, ISLAMIC REPUBLIC OF
IRAQ
IRELAND
ISRAEL
ITALY
JAMAICA
JAPAN
JORDAN
KAZAKHSTAN
KENYA
KOREA, REPUBLIC OF
KUWAIT
KYRGYZSTAN
LAO PEOPLE'S DEMOCRATIC
REPUBLIC
LATVIA
LEBANON
LESOTHO
LIBERIA
LIBYA
LIECHTENSTEIN
LITHUANIA
LUXEMBOURG
MADAGASCAR
MALAWI
MALAYSIA
MALI
MALTA
MARSHALL ISLANDS
MAURITANIA, ISLAMIC
REPUBLIC OF
MAURITIUS
MEXICO
MONACO
MONGOLIA
MONTENEGRO
MOROCCO
MOZAMBIQUE
MYANMAR
NAMIBIA
NEPAL
NETHERLANDS
NEW ZEALAND
NICARAGUA
NIGER
NIGERIA
NORWAY

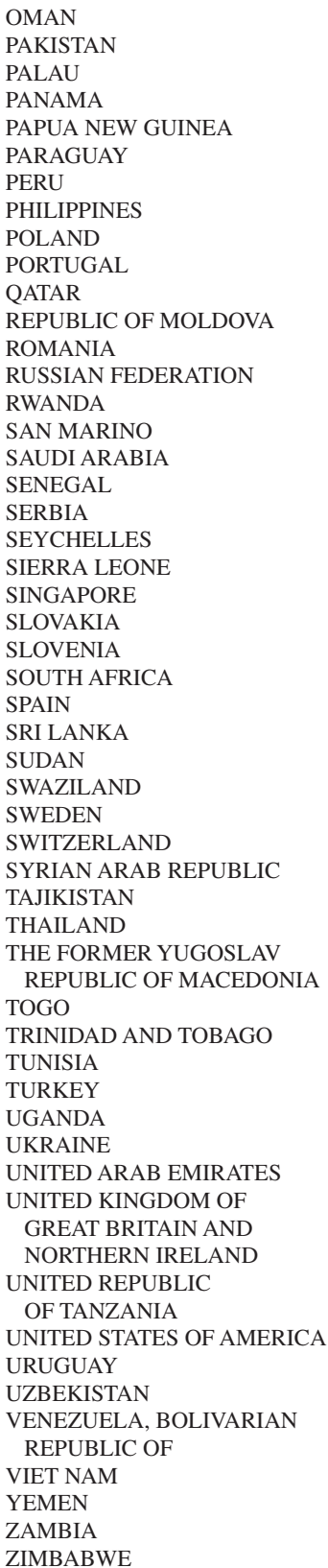

The Agency's Statute was approved on 23 October 1956 by the Conference on the Statute of the IAEA held at United Nations Headquarters, New York; it entered into force on 29 July 1957. The Headquarters of the Agency are situated in Vienna. Its principal objective is "to accelerate and enlarge the contribution of atomic energy to peace, health and prosperity throughout the world". 
TECHNICAL REPORTS SERIES No. 478

\section{FEASIBILITY OF PRODUCING MOLYBDENUM-99 ON A SMALL SCALE USING FISSION OF LOW ENRICHED URANIUM OR NEUTRON ACTIVATION OF NATURAL MOLYBDENUM}




\title{
COPYRIGHT NOTICE
}

All IAEA scientific and technical publications are protected by the terms of the Universal Copyright Convention as adopted in 1952 (Berne) and as revised in 1972 (Paris). The copyright has since been extended by the World Intellectual Property Organization (Geneva) to include electronic and virtual intellectual property. Permission to use whole or parts of texts contained in IAEA publications in printed or electronic form must be obtained and is usually subject to royalty agreements. Proposals for non-commercial reproductions and translations are welcomed and considered on a case-by-case basis. Enquiries should be addressed to the IAEA Publishing Section at:

\author{
Marketing and Sales Unit, Publishing Section \\ International Atomic Energy Agency \\ Vienna International Centre \\ PO Box 100 \\ 1400 Vienna, Austria \\ fax: +43 1260029302 \\ tel.: +431260022417 \\ email: sales.publications@iaea.org \\ http://www.iaea.org/books
}

(C) IAEA, 2015

Printed by the IAEA in Austria

January 2015

STI/DOC/010/478

\section{IAEA Library Cataloguing in Publication Data}

Feasibility of producing molybdenum-99 on a small scale using fission of low enriched uranium or neutron activation of natural molybdenum - Vienna : International Atomic Energy Agency, 2015.

p. ; $24 \mathrm{~cm}$. - (Technical reports series, ISSN 0074-1914; no. 478)

STI/DOC/010/478

ISBN 978-92-0-114713-4

Includes bibliographical references.

1. Molybdenum - Isotopes. 2. Radionuclide generators. 3. Radiopharmaceuticals — Synthesis. 4. Radioisotopes. I. International Atomic Energy Agency. II. Series:

Technical reports series (International Atomic Energy Agency) ; 478.

IAEAL

14-00941 


\section{FOREWORD}

This publication documents the work performed within the IAEA coordinated research project (CRP) on Developing Techniques for Small Scale Indigenous Molybdenum-99 Production Using LEU Fission or Neutron Activation. The project allowed participating institutions to receive training and information on aspects necessary for starting production of molybdenum-99 $\left({ }^{99} \mathrm{Mo}\right)$ on a small scale, that is, to become national level producers of this medical isotope.

Stable production of ${ }^{99} \mathrm{Mo}$ is one of the most pressing issues facing the nuclear community at present, because the medical isotope technetium-99m $\left({ }^{99 \mathrm{~m}} \mathrm{Tc}\right)$, which decays from ${ }^{99} \mathrm{Mo}$, is one of the most widely used radionuclides in diagnostic imaging and treatment around the world. In the past five years, there have been widespread shortages of ${ }^{99} \mathrm{Mo}$ owing to the limited number of producers, many of which use ageing facilities.

To assist in stabilizing the production of ${ }^{99} \mathrm{Mo}$, and to promote the use of production methods that do not rely on the use of highly enriched uranium (HEU), the IAEA initiated the abovementioned CRP on small scale ${ }^{99} \mathrm{Mo}$ production using low enriched uranium (LEU) fission or neutron activation methods. The intention was to enable participating institutions to gain the knowledge necessary to become national level producers of ${ }^{99} \mathrm{Mo}$ in the event of further global shortages. Some of the institutions that participated in the CRP have continued their work on ${ }^{99}$ Mo production, and are enlisting the assistance of other CRP members and the IAEA's technical cooperation programme to set up a small scale production capability.

In total, the CRP was active for six years, and concluded in December 2011. During the CRP, fourteen IAEA Member States took part; four research coordination meetings were held, and four workshops were held on operational aspects of ${ }^{99} \mathrm{Mo}$ production, LEU target fabrication and waste management. Most participants carried out work related to the entire production process, from target assembly to irradiation (most only performed the thermal and hydraulic calculations necessary for irradiation), to planning for target disassembly in hot cells, chemical processing of targets, quality control practices and managing waste streams. However, some participants focused on one particular area, for example, testing new methods for production of LEU foil for targets or the production of gel generators from ${ }^{99} \mathrm{Mo}$ solution. This publication aggregates all of the work undertaken as part of the CRP in order to present the results as a whole; the accomplishments of participating institutions are detailed in individual country reports on the attached CD-ROM.

In addition to presenting the work performed within the CRP, this publication is intended to serve a wide readership that includes nuclear 
authorities, regulators and any institution that may have an interest in becoming a small scale producer of ${ }^{99} \mathrm{Mo}$ using non-HEU production methods. The details presented here could serve as a template for a feasibility study to be carried out by an institution or State wishing to produce ${ }^{99} \mathrm{Mo}$; special care has been taken to note areas that were particularly challenging for participants and therefore may not be feasible for other small scale producers without significant investment in human resources or infrastructure.

The IAEA wishes to thank all of the individual participants in the CRP for their contributions to this publication and all of the participating institutions for taking part. Special thanks are extended to the National Nuclear Security Administration of the Department of Energy of the United States of America, for their contributions throughout the CRP. Special thanks are also due to J.A. Osso Jr. (Brazil) and N. Ramamoorthy (India) for their contributions to the drafting and review of this report. The IAEA officers responsible for the compilation of this report were A. Carrigan, S. Gouzy-Portaix and J. Dix of the Division of Nuclear Fuel Cycle and Waste Technology.

\section{EDITORIAL NOTE}

This report does not address questions of responsibility, legal or otherwise, for acts or omissions on the part of any person.

Although great care has been taken to maintain the accuracy of information contained in this publication, neither the IAEA nor its Member States assume any responsibility for consequences which may arise from its use.

The use of particular designations of countries or territories does not imply any judgement by the publisher, the IAEA, as to the legal status of such countries or territories, of their authorities and institutions or of the delimitation of their boundaries.

The mention of names of specific companies or products (whether or not indicated as registered) does not imply any intention to infringe proprietary rights, nor should it be construed as an endorsement or recommendation on the part of the IAEA.

The authors are responsible for having obtained the necessary permission for the IAEA to reproduce, translate or use material from sources already protected by copyrights. 


\section{CONTENTS}

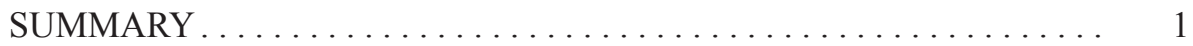

1. INTRODUCTION $\ldots \ldots \ldots \ldots \ldots \ldots \ldots \ldots \ldots \ldots \ldots \ldots \ldots \ldots \ldots, 5$

1.1. Background on ${ }^{99} \mathrm{Mo}$ and ${ }^{99 \mathrm{~m}} \mathrm{Tc} \ldots \ldots \ldots \ldots \ldots \ldots \ldots \ldots \ldots$

1.2. Structure of this publication $\ldots \ldots \ldots \ldots \ldots \ldots \ldots \ldots . \ldots \ldots$

1.3. Summary of the current ${ }^{99}$ Mo market ............. 8

1.4. Transition away from HEU and origins of the IAEA CRP . . . . 9

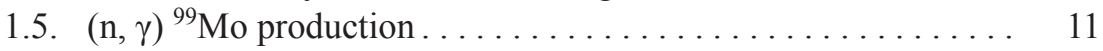

1.6. CRP — Initial planning and consultancies ............ 13

1.7. Participants in the CRP .................... 15

1.7.1. Research agreement holders — roles and work plans... 15

1.7.2. Research contract holders — roles and work plans. .... 17

1.7.3. Observers....................... 20

1.8. Meetings and workshops held under the CRP, 2005-2011 . . . 20

1.8.1. Workshop on operational aspects of ${ }^{99}$ Mo production. . . 20

1.8.2. First research coordination meeting. .......... 20

1.8.3. Workshop on LEU foil target fabrication, irradiation, and chemical processing using the LEU modified Cintichem technique ................... 21

1.8.4. Second workshop on operational aspects of ${ }^{99}$ Mo production...................... 21

1.8.5. Second research coordination meeting .......... 21

1.8.6. Third research coordination meeting............ 21

1.8.7. Workshop on waste management and

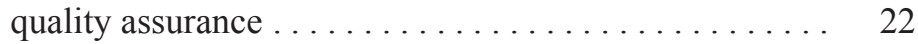

1.8.8. Fourth research coordination meeting. ......... 22

1.9. Overview and summary of non-HEU technologies pursued

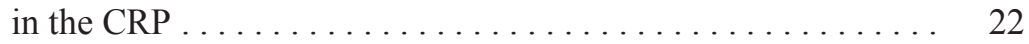

1.9.1. LEU foil target work ................. 22

1.9.2. LEU based $\mathrm{UAl}_{\mathrm{X}}$ dispersion targets. . . . . . . . 24

1.10. Processing and purification — LEU modified

Cintichem process ........................ 24

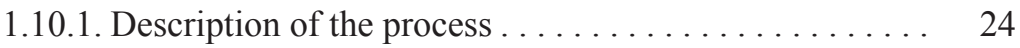

1.10.2. Target disassembly....................... 25

1.10.3. Dissolution. . . . . . . . . . . . . . . . . . 25

1.10.4. Molybdenum-99 separation and purification. . . . . . . 25 


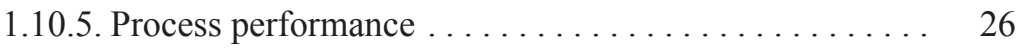

1.10.6. ANL alternative processes................ 26

1.11. $\mathrm{UAl}_{\mathrm{X}}$ dispersion target processing. ............... 26

1.11.1. CNEA process ........................ 26

1.11.2. The ROMOL process.................. 27

1.12. Shipment of bulk ${ }^{99}$ Mo solution for generator production . . . . 27

1.13. Technetium-99m generator production ............. 27

1.14. (n, $\gamma$ ) Molybdenum based gel generators. .............. 28

1.14.1. ${ }^{99}$ Mo production by neutron activation

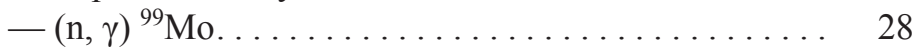

1.14.2. Equipment and methods ................... 29

1.14.3. Gel generator assembly .................. 29

1.14.4. Production trials, analyses and results.......... 30

1.15. Quality control and quality assurance $\ldots \ldots \ldots \ldots \ldots \ldots . \ldots$

1.15.1. Quality control..................... 30

1.15.2. Quality assurance. . . . . . . . . . . . . . . . . 31

1.15.3. Waste management ................... 31

1.16. Recommendations of the CRP members ........... 33

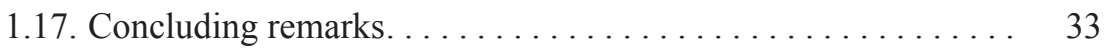

2. TECHNICAL ASPECTS RELATED TO LEU TARGETS FOR MOLYBDENUM-99 PRODUCTION . . . . . . . . . . . . 34

2.1. LEU foil annular target know-how and related aspects....... 34

2.1.1. LEU targets and their irradiation in research reactors... 34

2.1.2. General description of LEU foil annular targets ...... 35

2.1.3. LEU foil production at Y-12 and KAERI . ........ 37

2.1.4. Test irradiations of LEU foils at MURR . . . . . . . . . 43

2.1.5. LEU annular foil target fabrication using the draw die assembly device .............. 43

2.1.6. General observations and lessons from adopting the LEU foil target. ................... 48

2.1.7. Investigation of alternate versions of LEU foil target . . 50

2.2. Dispersion plate LEU target know-how and related aspects.... 51

2.2.1. General description of $\mathrm{LEU}$ based $\mathrm{UAl}_{\mathrm{X}}$ dispersion targets......................... 51

2.3. Planning for and performing irradiation of LEU targets

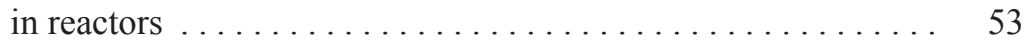

2.4. Summary of LEU target related achievements of the CRP teams . . . . . . . . . . . . . . . . . . . . . 
3.1. Introduction ........................... 55

3.2. LEU foil targets: LEU modified Cintichem process . . . . . . . 64

3.2.1. Description of the process ............... 64

3.2.2. Disassembly of irradiated LEU foil targets . . . . . . . 66

3.2.3. Dissolution. ......................... 75

3.2.4. Chemical processing (Mo precipitation and purification $) \ldots \ldots \ldots \ldots \ldots \ldots \ldots \ldots, 82$

3.3. Alternate methods for processing foil targets .......... 91

3.3.1. ANL method ........................ 91

3.3.2. Gamma Service Group (GSG) . . . . . . . . . . . 91

3.3.3. Other considerations ................... 93

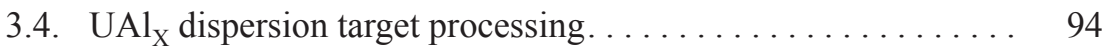

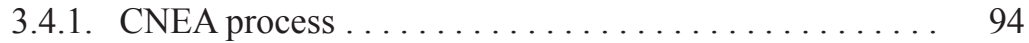

3.4.2. GSG - ROMOL-99 process. . . . . . . . . . . . . 94

3.5. Conclusions on ${ }^{99}$ Mo processes employed in the CRP . . . . . 98

4. $(\mathrm{n}, \gamma)$ MOLYBDENUM-99 BASED GEL GENERATOR $\ldots \ldots \ldots .98$

4.1. Introduction ........................... 98

4.2. Requirements for production of $(\mathrm{n}, \gamma){ }^{99}$ Mo based gel generators. . . . . . . . . . . . . . . . . . 99

4.2.1. Reactor features impacting $(\mathrm{n}, \gamma){ }^{99}$ Mo production .... . 99

4.3. Radiochemical processing. .................... 100

4.3.1. Chemistry aspects ................... 101

4.3.2. Technology development for process scaling up. ..... 101

4.4. Indian production facility . . . . . . . . . . . . . . . . 104

4.4.1. Shielded cells for specific operations ............ 104

4.4.2. Process automation .................... 106

4.4.3. Generator design ...................... 107

4.5. Kazakhstan production facility . . . . . . . . . . . . . 108

4.5.1. Shielded cell and process automation ............ 108

4.6. Facility operations and production experience .......... 112

4.6.1. Indian experience. . . . . . . . . . . . . . 112

4.6.2. Prospects of post-elution concentration of pertechnetate ....................... 115

4.6.3. Kazakhstan experience ................... 117

4.7. Conclusion............................ 117 
5. TRANSPORT ISSUES, WASTE MANAGEMENT AND

QUALITY ASSURANCE . . . . . . . . . . . . . . . . . . . . . . . . . 119

5.1. Transport issues and containers $\ldots \ldots \ldots \ldots \ldots \ldots \ldots \ldots . \ldots . \ldots . \ldots 119$

5.1.1. Transport cask types . . . . . . . . . . . . . 122

5.1.2. Shipment of bulk molybdenum ............... 123

5.2. Quality control and quality assurance ............ 123

5.2.1. Quality control....................... 124

5.2.2. Quality assurance.................... 127

5.3. Waste management ...................... 132

5.3.1. Waste from fission based ${ }^{99}$ Mo production . . . . . . 132

5.3.2. Waste from fission based ${ }^{99}$ Mo production $\mathrm{UAl}_{\mathrm{X}}$ dispersion target processing. ............ 134

5.3.3. Waste from neutron activation based ${ }^{99}$ Mo production. . . . . . . . . . . . . . . . . . . 135

6. CONCLUSIONS OF THE COORDINATED

RESEARCH PROJECT . . . . . . . . . . . . . . . . . . . . . 137

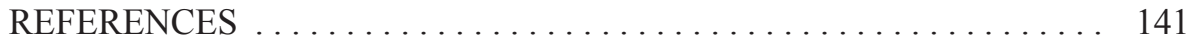

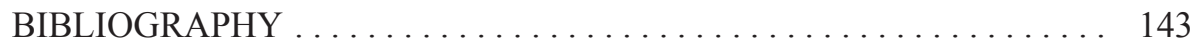

ANNEX I: IDENTIFICATION AND RADIONUCLIDE PURITY

OF FISSION MOLYBDENUM-99 $\left({ }^{99} \mathrm{Mo}\right)$ BASED ON

THE EUROPEAN PHARMACOPOEIA

COMMISSION METHOD FOR SODIUM

MOLYBDATE $\left({ }^{99} \mathrm{Mo}\right)$ SOLUTION FISSION.

ANNEX II: RADIOCHEMICAL PURITY OF FISSION

MOLYBDENUM-99 $\left({ }^{99} \mathrm{Mo}\right)$ BASED ON

THE EUROPEAN PHARMACOPOEIA

COMMISSION METHOD FOR SODIUM

MOLYBDATE $\left({ }^{99} \mathrm{Mo}\right)$ SOLUTION FISSION. . . . . . . . 155

ANNEX III: ALPHA ANALYSIS OF FISSION MOLYBDENUM-99

$\left({ }^{99} \mathrm{Mo}\right)$ BASED ON THE EUROPEAN

PHARMACOPOEIA COMMISSION METHOD FOR

SODIUM MOLYBDATE $\left({ }^{99} \mathrm{Mo}\right)$ SOLUTION FISSION . . . 158 
ANNEX IV: ALPHA ANALYSIS OF FISSION MOLYBDENUM-99 $\left({ }^{99} \mathrm{Mo}\right)$ BASED ON EICHROM TECHNOLOGIES' ANALYTICAL PROCEDURE FOR AMERICIUM, PLUTONIUM AND URANIUM IN WATER . . . . . . . . 160

ANNEX V: DETERMINATION OF RADIOIODINE IN FISSION MOLYBDENUM-99 $\left({ }^{99} \mathrm{Mo}\right)$ BASED ON AUSTRALIAN ATOMIC ENERGY COMMISSION METHOD ............................. 163

ANNEX VI: CD-ROM CONTENTS - INDIVIDUAL COUNTRY REPORTS

ABBREVIATIONS .................................. 165

CONTRIBUTORS TO DRAFTING AND REVIEW . 



\section{SUMMARY}

Technetium-99m $\left({ }^{99 \mathrm{~m}} \mathrm{Tc}, T_{1 / 2} 6 \mathrm{~h}\right)$ is the most widely used radionuclide in diagnostic imaging in nuclear medicine, and is employed in approximately 30 million medical procedures annually worldwide. It is obtained from its parent nuclide molybdenum-99 $\left({ }^{99} \mathrm{Mo}, T_{1 / 2} 66 \mathrm{~h}\right)$, an isotope which can be produced in several different ways. By far the most prevalent of these is through the fission of highly enriched uranium (HEU) targets in research reactors, as the fission yield of the precursor nuclide ${ }^{99} \mathrm{Mo}$ is $6.1 \%$, which has a very high specific activity on the order of $10^{4} \mathrm{Ci} / \mathrm{g}$.

At present, the bulk of global ${ }^{99}$ Mo supply is produced by five industrial producers using eight research reactors for irradiation. While the number of producers and irradiating reactors has grown (from four to five producers and from five to eight reactors in the last decade), several issues have arisen that have caused and may continue to cause critical shortages in global ${ }^{99}$ Mo supply.

There is a need to shift from using HEU targets to using targets made from low enriched uranium (LEU), which stems in part from a dwindling supply of HEU for civilian use, and in part from a political desire to see the reduction in, and eventual elimination of, civilian HEU use. Coordination is required to ensure the stability of the global supply of ${ }^{99} \mathrm{Mo}$, in particular during the period of time in which the HEU to LEU conversion is carried out.

Another issue is that, with a limited number of major producers, any unexpected shutdowns at reactors or processing facilities could create a shortfall in supply. This scenario came to pass at the end of 2007, when the National Research Universal (NRU) reactor in Canada was suddenly forced to shut down for repairs. This was followed over the next two years by a series of other unexpected events, including one production facility finding problems in its management of waste streams, as well as planned extended shutdowns of one or more of the aged reactors used for target irradiation. All these outages resulted in serious disruption of supplies of ${ }^{99} \mathrm{Mo}$, and, in turn, affected prescheduled patient services. Calls for the security of medical isotope supplies were strongly voiced in a number of countries and many international initiatives to stabilize isotope supply were launched.

Against this backdrop, the IAEA's work on fostering small scale ${ }^{99} \mathrm{Mo}$ took on a new urgency. In 2005, prior to the supply shortages, the IAEA had already launched a coordinated research project (CRP), Developing Techniques for Small Scale Indigenous Molybdenum-99 Production Using LEU Fission or Neutron Activation, the aim of which was to prepare interested Member States to adopt LEU based fission ${ }^{99}$ Mo production or $(\mathrm{n}, \gamma){ }^{99} \mathrm{Mo}$ production on a small scale. The project was also intended to foster development of non-HEU production technologies, and was in line with a study being carried out by the 
National Academy of Sciences (NAS) in the United States of America, which was tasked with exploring the feasibility of producing ${ }^{99}$ Mo with LEU targets. ${ }^{1}$

The CRP was active for six years, and concluded in December 2011. During the CRP, fourteen Member States took part as either contract or agreement holders; four research coordination meetings (RCMs) were held and four workshops were held on operational aspects of ${ }^{99}$ Mo production, LEU target fabrication, and waste management, which were of great practical help to participants. Most of the participants carried out calculations or experimental work on all parts of the ${ }^{99}$ Mo production process, including thermal and neutronic calculations; target assembly; irradiation; target disassembly; target processing; and generator manufacture. Some participants focused more on certain aspects of ${ }^{99}$ Mo production, while others were involved as technology holders sharing their knowledge with project participants.

The following publication explains the work performed within the CRP and the results attained. It is hoped that it will serve as a useful compilation of the work performed and lessons learned during this CRP, and as technical guidance outlining the various aspects to be considered when embarking on small scale production of ${ }^{99} \mathrm{Mo}$.

\section{GENERAL COMMENTS ON THE CRP}

- Reliable production of LEU foil was not easily achieved; it requires a complex manufacturing facility and large quantities of materials that are not readily available to most small scale producers. Finding a way to source LEU foil or ready made targets would be necessary to assist small scale producers.

— In addition to producing ${ }^{99} \mathrm{Mo}$ by LEU fission, participants found that there is scope for the small scale co-production of other useful isotopes such as ${ }^{131} \mathrm{I}$.

- Many participants noted that producing ${ }^{99} \mathrm{Mo}$ was one (technical) issue, but being able to qualify and market it, even within their own country, was a different issue for which they might require additional advice or support.

1 The report of this Expert Group was published in 2009 as Medical Isotope Production Without Highly Enriched Uranium, The National Academies Press. 
- IAEA support in arranging workshops and scientific visits for CRP participants was noted as an important component; ensuring the necessary human resources for even a small scale project is an important step in examining the feasibility of small scale production of ${ }^{99} \mathrm{Mo}$.

- The importance of the production related issues such as waste treatment, quality control and quality assurance were an important part of the discussion among the participants.

\section{CONCLUSIONS}

The current demand for ${ }^{99} \mathrm{Mo}$ is likely to remain steady, and may grow in countries that are now low level users, according to research performed by the OCED/NEA's High-Level Group on the Security of Supply of Medical Radioisotopes ${ }^{2}$. Coupled with current impacts of conversion to LEU and ageing infrastructure amongst current major producers of ${ }^{99} \mathrm{Mo}$, there is great potential for setting up small scale, indigenous ${ }^{99}$ Mo production capabilities that can either serve national needs for ${ }^{99 \mathrm{~m}} \mathrm{Tc}$, or act as a reserve capacity in case of global ${ }^{99} \mathrm{Mo}$ supply shortages in the future. Diversifying sources of non-HEU produced ${ }^{99} \mathrm{Mo}$ is beneficial for the stability of supply, especially in States where only a few hundred $\mathrm{Ci}$ a week may be needed.

In the course of this CRP, a large body of information was generated by all the participants, spanning the entire ${ }^{99}$ Mo production spectrum from the initial production of LEU target materials to irradiation calculations (on ${ }^{99}$ Mo yield and heat generation), processing, waste management and quality assurance of the generators produced. Several different target types (all LEU) were used as the basis for calculations; several different dissolution processes were used; and, perhaps most importantly, participants were able to see at first hand the planning and work involved in setting up a small scale, indigenous ${ }^{99}$ Mo production capability, and were able to use the CRP as a feasibility study. For some participants, this CRP assured them that small scale production is something they can achieve; for other participants, the CRP served to identify important areas they need to consider in weighing the costs versus the benefits of small scale ${ }^{99}$ Mo production.

2 See the OECD/NEA's series of studies on The Supply of Medical Radioisotopes, available at http://www.oecd-nea.org/med-radio/supply-series.html. 


\section{RECOMMENDATIONS}

For participants in the CRP, this project served as an extended feasibility study. Some participants will feel that it is feasible for them to serve as small scale producers; those participants should continue with their work, and will approach other CRP participants or the IAEA in instances where they need continued assistance. Some participants may still be undecided about starting ${ }^{99} \mathrm{Mo}$ production, for technical, economic or political reasons. The IAEA recommends that they continue assessing their own technical capability and infrastructure readiness in light of global supply and demand information in order to make the most informed decision about whether or not to pursue a production capability. The IAEA is able to assist some Member States with assessing their ${ }^{99}$ Mo production infrastructure, if they request such assistance.

For readers who were not CRP participants but may be considering a small scale ${ }^{99}$ Mo production capability, it is important to consider the entire production cycle, from making or obtaining targets through interim storage and final disposal of waste streams. This publication is intended to provide initial guidance for Member States interested in examining the feasibility of ${ }^{99}$ Mo production, and the IAEA is able to assist potential small scale producers in assessing their readiness for production, if Member States request assistance. 


\section{INTRODUCTION}

\subsection{BACKGROUND ON ${ }^{99} \mathrm{Mo}$ AND ${ }^{99 \mathrm{~m}} \mathrm{Tc}$}

Technetium-99m $\left({ }^{99 \mathrm{~m}} \mathrm{Tc}, T_{1 / 2}, 6 \mathrm{~h}\right)$ is currently the most widely used radionuclide in nuclear medicine, and is employed in approximately 30 million medical procedures annually worldwide. Technetium- $99 \mathrm{~m}$ is obtained through the beta decay of the precursor nuclide ${ }^{99} \mathrm{Mo}\left(T_{1 / 2}, 66 \mathrm{~h}\right)$; some $88 \%$ of ${ }^{99} \mathrm{Mo}$ decays result in the metastable isotope ${ }^{99 \mathrm{~m}} \mathrm{Tc}$, which in turn decays to the ground state, ${ }^{99 \mathrm{~g}} \mathrm{Tc}$ (Fig. 1).

While ${ }^{99}$ Mo can be produced in several ways (Fig. 2), historically, almost all ${ }^{99}$ Mo for medical use was produced using the neutron fission of ${ }^{235} \mathrm{U}$ (i.e. $\left.{ }^{235} \mathrm{U}(\mathrm{n}, \mathrm{f}){ }^{99} \mathrm{Mo}\right)$ in research reactors. This technology was used because research reactors typically have operational schedules and space available for irradiating multiple targets at high neutron flux rates (usually $10^{13}-10^{14}$ neutrons per square centimetre per second $\left(\mathrm{n} \cdot \mathrm{cm}^{-2} \cdot \mathrm{s}^{-1}\right)$.

However, ${ }^{99} \mathrm{Mo}$ can be produced in a number of other ways, including:

- Fission of ${ }^{235} \mathrm{U}$ with neutrons produced in deuteron and proton accelerators through $(\mathrm{d}, \mathrm{n})$ and $(\mathrm{p}, \mathrm{n})$ reactions on heavy targets.

— Neutron activation of ${ }^{98} \mathrm{Mo}$ (i.e. ${ }^{98} \mathrm{Mo}(\mathrm{n}, \gamma){ }^{99} \mathrm{Mo}$ ). This process is only practical for reactor based production because of the small activation cross-section ( $0.13 \mathrm{~b}$ for thermal neutrons). Also, ${ }^{99} \mathrm{Mo}$ produced through this process has a lower specific activity than neutron fission produced ${ }^{99}$ Mo.

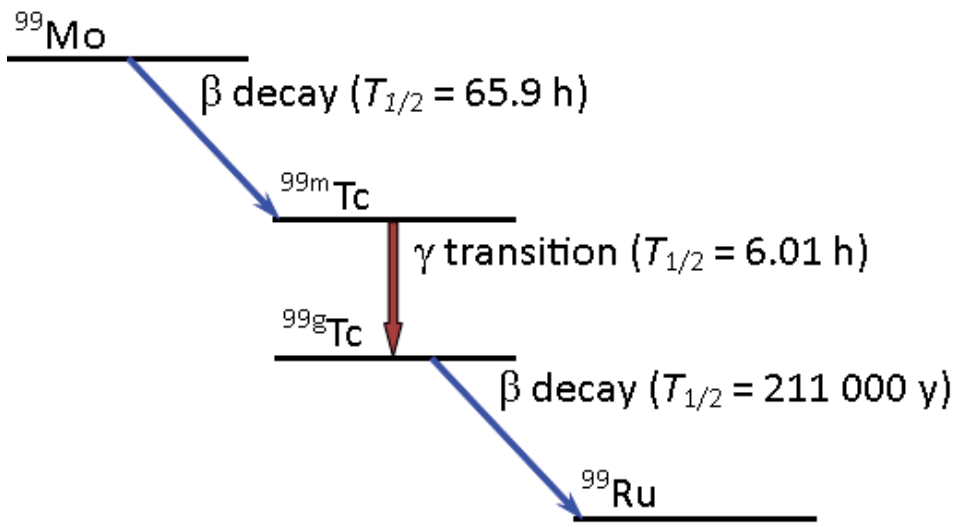

FIG. 1. ${ }^{99}$ Mo decay. 


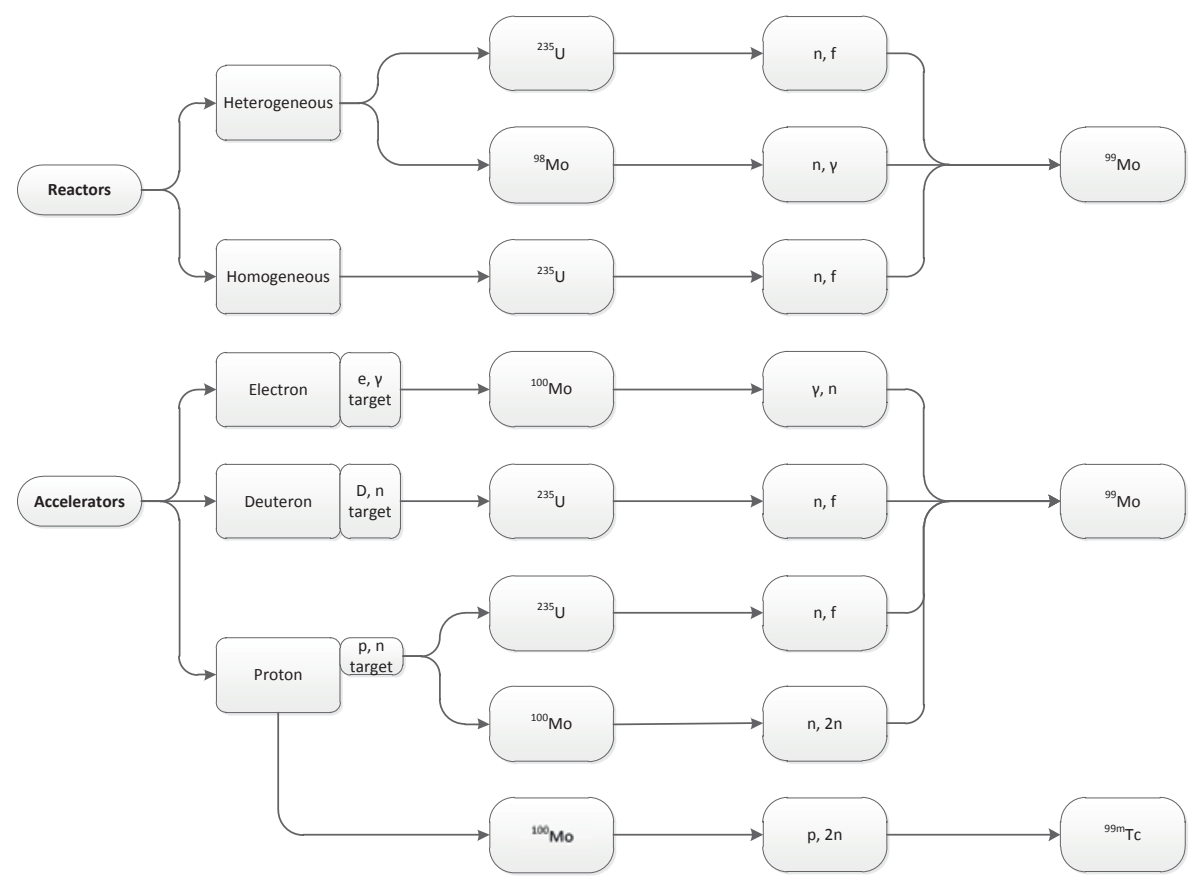

FIG. 2. Schemes for producing ${ }^{99}$ Mo and ${ }^{99 m} T c$.

— Photofission of ${ }^{100} \mathrm{Mo}$ (i.e. ${ }^{100} \mathrm{Mo}(\gamma, \mathrm{n}){ }^{99} \mathrm{Mo}$ ). The energetic photons used in this production scheme are obtained by irradiating heavy targets with electron beams produced by linear accelerators.

- Technetium-99m can also be produced directly through (p, 2n) reactions on targets containing ${ }^{100} \mathrm{Mo}$. This production scheme eliminates the need for intermediate production steps involving the recovery and purification of ${ }^{99} \mathrm{Mo}$. However, it is suitable only for very short supply chains (e.g. city scale) because of the short half-life of ${ }^{99 \mathrm{~m}} \mathrm{Tc}$.

As noted, the majority of major producers ${ }^{3}$ of ${ }^{99}$ Mo use neutron fission of ${ }^{235} \mathrm{U}$, and, in order to maximize their ${ }^{99}$ Mo yield, they have historically used HEU targets. For several reasons detailed below, the international community has called on all producers, both major and small scale, to shift to non-HEU technologies when producing ${ }^{99} \mathrm{Mo}$.

${ }^{3}$ Major producers are defined as entities producing more than 1000 6-day $\mathrm{Ci}$ of ${ }^{99} \mathrm{Mo}$ a week. 
While several methodologies to produce ${ }^{99} \mathrm{Mo}$ are noted here, the CRP on which this publication is based only dealt with neutron fission and (n, $\gamma$ ) methods of ${ }^{99}$ Mo production; this report will therefore focus on those two production methods.

\subsection{STRUCTURE OF THIS PUBLICATION}

The detailed background and design of the CRP are presented in Section 1. This includes an overview of ${ }^{99}$ Mo production techniques using HEU, LEU and non-fission methods. Section 1 also gives further background about the global ${ }^{99}$ Mo market, and how outages and conversion from HEU to LEU have affected the market. Section 1 briefly describes the four RCMs and the four workshops held, and enumerates participants' work plans and roles in the CRP.

Section 2 introduces the work performed on producing the LEU foil targets that were manufactured and used during the CRP. This Section covers LEU foil fabrication in the USA and Republic of Korea, the production and assembly of annular foil targets, the production and use of dispersion type LEU targets, and details of the necessary calculations for irradiation of LEU foil targets.

Section 3 covers the various processing and the purification technologies that were dealt with in the CRP. These include the LEU modified Cintichem process for LEU foil targets; alternate methods for processing foil targets; the CNEA-INVAP method for processing dispersion plate targets; the ROMOL-PINSTECH method for processing dispersion plate targets; and other methods for processing dispersion plate targets.

Section 4 is focused on the production of gel generators from $(n, \gamma)$ produced ${ }^{99} \mathrm{Mo}$. It discusses the requirements for producing gel generators, and offers operation and production experience from facilities in India and Kazakhstan that gained further expertise with gel generator production during the CRP.

Section 5 examines waste management and quality assurance issues. Participants in the CRP were able to attend a workshop in 2010 focusing on ${ }^{99}$ Mo waste issues and strategies, and some of the larger waste issues are addressed in this section. Additionally, quality assurance and quality control issues that are important for successful ${ }^{99}$ Mo production on any scale are addressed.

Section 6 concludes the main body of the publication, recaps the main work performed and its results, and offers some of the most important ideas and lessons learned throughout the course of the CRP. These lessons and ideas are intended to be of assistance both to CRP participants who wish to continue their work on small scale ${ }^{99}$ Mo production, and to any other Member States who may wish to embark on the development of a small scale production capability. 
Finally, the attached CD-ROM includes, in full, the final reports of each participant, by country, and by facility where there were multiple facilities in a State taking part. The data in these reports was used in aggregate for the drafting of the body of this publication. However, each of these reports is also an important record of the work performed and the achievements of each participant in the $\mathrm{CRP}$, and each can be viewed as an individual case study of pursuing a small scale ${ }^{99}$ Mo production capability. Additionally, the detailed calculations that were performed by each participant are presented in these individual reports, as well as step-by-step procedures, results, and their own conclusions and references.

\subsection{SUMMARY OF THE CURRENT ${ }^{99}$ Mo MARKET}

According to estimates made by the OECD/NEA, the weekly global demand for ${ }^{99} \mathrm{Mo}$ is approximately 100006 -day $\mathrm{Ci}^{4}$ [1] and this is largely produced using HEU targets in research reactors (Fig. 3). After irradiation, those targets are then processed in hot cells using acidic or alkaline dissolution methods through a series of radiochemical separation and purification steps that are very complex and require sophisticated technical skills and well equipped hot cells. Purity requirements for ${ }^{99} \mathrm{Mo}$ are very high, and extensive quality controls are essential. The demanding requirements for robust operational systems, a reliable, well trained workforce, and established systems for quality management and waste management, together with the high cost of the required technology, have to date been best met by commercial entities.

At present, there are five major producers of ${ }^{99}$ Mo that use irradiated targets (either HEU or LEU) to produce purified ${ }^{99} \mathrm{Mo}$ solution that is then made into a ${ }^{99} \mathrm{Mo} /{ }^{99 \mathrm{~m}} \mathrm{Tc}$ generator, either within the same company or, more frequently, through one of several separate ${ }^{99 \mathrm{~m}} \mathrm{Tc}$ generator producers.

These five major ${ }^{99}$ Mo processing facilities are Nordion (Canada), the Institute for Radioelements (IRE) (Belgium), Covidien/Mallinckrodt (the Netherlands), NTP Radioisotopes (South Africa) and the Australian Nuclear Science and Technology Organisation (ANSTO) (Australia). The National Atomic Energy Commission (CNEA) in Argentina was the first ${ }^{99}$ Mo producer to deploy LEU targets for national scale production (from 2002). Since 2010, both ANSTO and NTP Radioisotopes have been producing large scale quantities of ${ }^{99}$ Mo using LEU targets.

4 The number of Ci six days after the end of the production process, which is generally 7 or 8 days from the end of reactor irradiation. Any references to $\mathrm{Ci}$ in this publication refer to 6-day $\mathrm{Ci}$, unless specifically stated otherwise. 


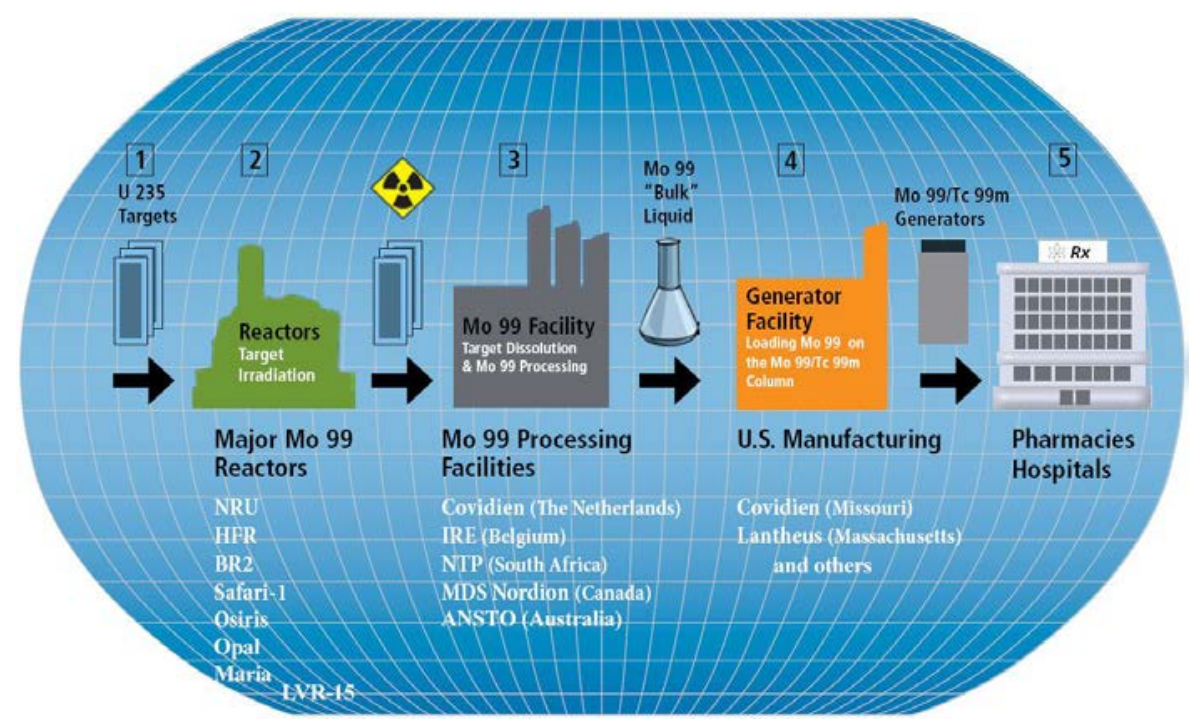

FIG. 3. The global supply chain of ${ }^{99}$ Mo production and subsequent utilization schematics. Source: www.covidien.com

While the number of ${ }^{99} \mathrm{Mo}$ producers has remained limited, the number of ${ }^{99 \mathrm{~m}} \mathrm{Tc}$ generator producers (small and large scale) is considerably larger and also more widely spread across different regions of the world. Thus, the timely and reliable transport of fission produced ${ }^{99} \mathrm{Mo} /{ }^{99 \mathrm{~m}} \mathrm{Tc}$ generators around the globe is an extremely important feature in the supply chain. As a result, transport issues that must be addressed by any potential ${ }^{99 \mathrm{~m}} \mathrm{Tc}$ generator manufacturer or ${ }^{99} \mathrm{Mo}$ producer include securing the approval and registration of transport casks and their recognition by national regulatory authorities, minimizing decay losses due to transit logistics or occasional delays and denials and delays of shipment.

\subsection{TRANSITION AWAY FROM HEU AND ORIGINS OF THE IAEA CRP}

Until very recently, more than $95 \%$ of ${ }^{99}$ Mo production used HEU targets; approximately $40-45 \mathrm{~kg}$ of HEU per year was used to manufacture these targets, and less than $6 \%$ of the original ${ }^{235} \mathrm{U}$ in the targets was consumed during irradiation. Thus a large amount of HEU remained in the waste products. 
In the annual meetings of the programme for Reduced Enrichment for Research and Test Reactors (RERTR), the need to transition to using LEU targets was a regular topic of discussion, along with the need to transition to LEU fuel cores in research reactors. Following the November 2004 RERTR meeting in Vienna, where the topic of ${ }^{99}$ Mo target conversion was again discussed, the IAEA responded by launching the CRP on Developing Techniques for Small Scale Indigenous Molybdenum-99 Production using LEU Fission or Neutron Activation in 2005. The CRP was intended to support Member States interested in adopting non-HEU technologies for the small scale, local production of ${ }^{99} \mathrm{Mo}$; it also complemented the larger goal of fostering minimization of HEU in the civilian nuclear sector.

In December 2007, the CRP took on a new relevance not only in assisting with the spread of non-HEU production technologies, but also in potentially assisting with national and regional self-sufficiency for isotope production in the wake of supply shortages. A series of major supply crises hit the market; the first took place following a sudden, prolonged shutdown of the Canadian National Research Universal (NRU) reactor in order to repair aging components. This was followed over the next two years by a series of other unplanned and unrelated shutdowns, as well as planned extended shutdowns, of several of the aged research reactors used for irradiation and, in one case, owing to operational issues in waste stream processing in a production facility. All of these shutdowns resulted in serious disruptions of supplies of ${ }^{99} \mathrm{Mo}$, and in turn, affected patient services. Calls for ensuring the security of medical isotope supplies were strongly voiced in a number of countries and many international initiatives were launched; the ongoing CRP proved to be a very useful vehicle for leading work to stabilize the supply of ${ }^{99} \mathrm{Mo}$. The regular research coordination meetings (RCMs) of the CRP became mini-seminars, with several observer participants from governments, industry and professional organizations also attending to share information and consider options for increasing the reliability of ${ }^{99}$ Mo supplies.

The ${ }^{99}$ Mo supply crisis was resolved by the third quarter of 2010, when both the NRU reactor and High Flux Reactor (HFR) in Petten, the Netherlands, returned to regular operation. However, several organizations, including the IAEA, continued to recognize the need to address the matter of securing sustainable supplies of ${ }^{99} \mathrm{Mo}$ for users all over the world, since the irradiating reactors continued to age, and the continuing use of HEU targets was neither sustainable nor desirable.

Since 2009, several other events have also had an impact on the ${ }^{99} \mathrm{Mo}$ market. First, the National Research Council of the National Academy of Sciences in the USA published a report on the feasibility of producing supplies of medical 
isotopes from commercial sources that do not use HEU. ${ }^{5}$ The report contains a comprehensive account of all the issues and includes specific recommendations to the United States Congress, including cost sharing for conversion related research and development, a 7-10 year phase-out of HEU exports and continuing government assistance to improve ${ }^{99}$ Mo supply reliability. Most importantly, the report concludes that it is technically feasible and even desirable for ${ }^{99} \mathrm{Mo}$ to be produced from non-HEU sources.

Second, as a result of the supply crisis, in 2009 national regulatory authorities in Canada and the USA approved the use of ${ }^{99}$ Mo produced by LEU fission as an active pharmaceutical ingredient (API). This cleared the way for more producers to enter the market, even on a small scale, and also furthered HEU minimization goals. Around the same time, ANSTO began producing ${ }^{99} \mathrm{Mo}$ using LEU targets, and NTP Radioisotopes began its conversion from HEU to LEU targets.

Third, at the 2010 Nuclear Security Summit in Washington, D.C., several governments agreed to convert their ${ }^{99} \mathrm{Mo}$ production processes from HEU to LEU by the end of 2015. This pledge spurred the remaining major producers to begin planning their conversions from HEU to LEU, and reinforced the need for non-HEU technologies to be deployed, on both a large and small scale.

The CRP was extended for two years beyond its original tenure and concluded in December 2011. The project could not remain insulated from the numerous external events that occurred in the six years it was active, but these events helped to show the importance of pursuing small scale, non-HEU ${ }^{99} \mathrm{Mo}$ production technologies. This publication, which examines the work performed in the CRP, is useful as a compilation of the lessons learned not only on technological aspects, but also on other associated issues that should be taken into account when considering whether to embark on small scale production of ${ }^{99} \mathrm{Mo}$.

\section{5. $(\mathrm{n}, \gamma){ }^{99}$ Mo PRODUCTION}

An alternative to the fission based production of ${ }^{99} \mathrm{Mo}$ is neutron activation of high purity molybdenum trioxide targets in research reactors, also known as $(\mathrm{n}, \gamma){ }^{99}$ Mo production or activation ${ }^{99} \mathrm{Mo}$. The $(\mathrm{n}, \gamma)$ process produces ${ }^{99} \mathrm{Mo}$ of relatively low specific activity, from a low of $3.7 \mathrm{GBq} / \mathrm{g}$ to a high of $74 \mathrm{GBq} / \mathrm{g}$, depending on the neutron flux available in the reactor. Research reactors with

5 The full text of this report, Medical Isotope Production without Highly Enriched Uranium (2009) is available on the NAS website:

http://www.nap.edu/catalog.php?record_id=12569\#toc. 
a large epithermal neutron flux profile are better suited to this approach, since the resonance absorption cross-section is nearly 50 times higher. (n, $\gamma$ ) ${ }^{99} \mathrm{Mo}$ is simple to make, and perhaps most importantly, does not produce large amounts of waste, hence no major waste disposal issues arise.

Activation ${ }^{99}$ Mo has been used in a limited fashion (historically, $1-2 \%$ of global production) for producing ${ }^{99 \mathrm{~m}} \mathrm{Tc}$, but has been used by several states to supply some or all of their national demand for ${ }^{99} \mathrm{Mo}$. This is achieved in one of two ways: either through a process that calls for the production of a zirconium molybdate gel generator (used in China, India and Kazakhstan) or through a process using methyl ethyl ketone (MEK) solvent extraction (used in India and the Russian Federation). A facility in Chengdu, China, was the first large scale producer of zirconium molybdate gel generators and, in the late 1990s, provided up to $25 \%$ of national ${ }^{99 \mathrm{~m}} \mathrm{Tc}$ requirements through this method. Since 2006 , India has produced more than 120 batches of gel generators using over $1200 \mathrm{GBq}$ of ${ }^{99}$ Mo per batch, thus meeting nearly $15 \%$ of India's overall ${ }^{99 m} \mathrm{Tc}$ needs with activation ${ }^{99} \mathrm{Mo}$. India is capable of producing a maximum of 25 generators per batch; the maximum radioactivity capacity per batch is approximately $28 \mathrm{GBq}$. Kazakhstan has also been using gel generators for centralized production of ${ }^{99 \mathrm{~m}} \mathrm{Tc}$ in Almaty. In Uzbekistan, enriched ${ }^{98} \mathrm{Mo}$ targets were used for producing $(\mathrm{n}, \gamma){ }^{99} \mathrm{Mo}$ of relatively higher specific activity, and utilized with a larger alumina bed column generator for obtaining ${ }^{99 \mathrm{~m}} \mathrm{Tc}$; it was possible to recycle the enriched target after recovery and purification.

The aforementioned ${ }^{99} \mathrm{Mo}$ crisis helped increase the interest in alternate (non-HEU and non-fission) technologies for the production of ${ }^{99} \mathrm{Mo}$ and/or ${ }^{99 \mathrm{~m}} \mathrm{Tc}$. As shown in Fig. 2, several technologies have been investigated as methods of production of ${ }^{99} \mathrm{Mo}$, including non-fission and non-reactor based methods. These methods are at different stages of development, from purely conceptual, to proof of principle, to demonstrated potential and to limited deployment. Various methods of producing ${ }^{99} \mathrm{Mo}$ without using HEU are discussed in Ref. [2]. Furthermore, most of these concepts and plans - including activation ${ }^{99} \mathrm{Mo}$ - are meant to be a means of supplementing the well-established method of ${ }^{99} \mathrm{Mo}$ supply (fission based) and are unlikely to replace reactor based fission ${ }^{99} \mathrm{Mo}$ production in the foreseeable future. Table 1 shows some alternatives routes of producing ${ }^{99} \mathrm{Mo}$ in nuclear reactors. Further discussion of these technologies is beyond the purview of the current publication. There are two publications, one from the OECD/NEA [3] and one from the IAEA [2], related to non-HEU technologies, which may be referred to for more details. 
TABLE $1 .{ }^{99}$ Mo PRODUCTION PROCESSES

\begin{tabular}{|c|c|c|c|}
\hline Irradiation & Reaction & Targets & Observation \\
\hline \multirow[t]{2}{*}{ Reactor } & $\mathrm{n}+{ }^{235} \mathrm{U} \rightarrow{ }^{99} \mathrm{Mo}+\mathrm{FP}^{*}+2 \mathrm{n}$ & LEU, HEU & $\begin{array}{l}\text { Research reactor; solution } \\
\text { reactor; power reactor }\end{array}$ \\
\hline & & & $\begin{array}{l}\text { Extensive processing of } \\
\text { irradiated targets followed } \\
\text { by alumina column generator } \\
\text { production }\end{array}$ \\
\hline - & $\mathrm{n}+{ }^{98} \mathrm{Mo} \rightarrow{ }^{99} \mathrm{Mo}+\gamma$ & $\begin{array}{l}\text { Natural Mo, } \\
\text { enriched }{ }^{98} \mathrm{Mo}\end{array}$ & $\begin{array}{l}\text { Simpler processing of irradiated } \\
\text { targets followed by alternate } \\
\text { generator concepts: Gel, } \\
\text { MEK extraction, high capacity } \\
\text { adsorbents }\end{array}$ \\
\hline
\end{tabular}

* $\mathrm{FP}=$ fission product.

\subsection{CRP — INITIAL PLANNING AND CONSULTANCIES}

The CRP on Developing Techniques for Small Scale Indigenous Molybdenum-99 Production Using LEU Fission or Neutron Activation was originally proposed by the IAEA in January 2005, after a consultancy meeting to fully formulate the project was held in November 2004. The specific objectives of the CRP as outlined in the original proposal were:

(a) "To develop and deliver education, awareness, training and coaching activities to provide sufficient information to enable a recipient to make a knowledgeable decision on the technical, regulatory and economic implications of establishing small scale Mo-99 production using the available technology (see below).

(b) "To assist the recipient in development activities to research, test, and evaluate the available technology (LEU modified Cintichem with foil targets or neutron activation of ${ }^{98} \mathrm{Mo}$ with gel generators) and determine the implications of the options to access the available technology, build proprietary technology, or purchase alternate LEU technology.

(c) "To disseminate information on ${ }^{99}$ Mo production using LEU targets or neutron activation obtained from the understanding gained by the experimental evaluation of the available technology." 
The expected output of the CRP was that all the participants would acquire an understanding of available LEU technologies and would be in a position to make a sound decision on whether to proceed with the domestic production of ${ }^{99} \mathrm{Mo}$ or to look for alternative options to satisfy domestic demand. Additionally, work performed within the CRP allowed participants who wanted to proceed with indigenous small scale production to gain the necessary know-how to carry it out. Technology transfer under the CRP included all the necessary production steps: target preparation, irradiation, radiochemical processing, safety, quality control and quality assurance.

The CRP action plan called for the initial evaluation and issuance of five contracts and five agreements under the IAEA's Research Contracts System, to participants who would be able to meet the objectives of the CRP. When the CRP officially began in 2005 , the action plan consisted of the following steps:

- Provision of necessary materials, including mock targets and LEU targets, to undertake experimental activities for the production of ${ }^{99} \mathrm{Mo}$;

- Establishment of procedures and protocols to be employed in the production of ${ }^{99}$ Mo through LEU targets or neutron activation, including quality control and assurance procedures;

- Establishment of an experimental programme for preparation, irradiation, and processing of LEU targets;

(a) Comparison and interpretation of results obtained in the implementation of the technique in order to provide follow-up advice and assistance, and to suggest adaptive changes and modifications;

(b) Provision of expert assistance to the recipient institutions in the form of regular coaching regarding irradiation and processing of targets, assessing and comparing results, and making modifications to improve future efforts.

For recipients who chose to pursue the development of the neutron activation technique for the production of ${ }^{99} \mathrm{Mo}$, a similar approach was followed, including supply of targets (and other related materials), and provision of experts to assist in coaching in regard to target irradiation and gel processing procedures.

Results obtained by participants were shared and compared during the second and third RCMs, including assessment of the product according to purity and other specifications. The experimental set-up and results used by individual participants for each stage of work are available in the annexes to this publication. 


\subsection{PARTICIPANTS IN THE CRP}

\subsubsection{Research agreement holders — roles and work plans}

The IAEA defines research agreement holders as participants in a CRP who do not receive financial support from the IAEA for their work. These agreements may be awarded to institutions that can contribute to the achievement of the objectives of the CRP. However, like all other participants in the CRP, the institution holding a research agreement agrees to provide a report at each RCM on work relating to the CRP and to assist other participants when possible. In return, the institution shares in the results of the work of all other participating institutions. Agreements within a CRP are awarded for the entire duration of the CRP. This CRP involved participation from nine research agreement holders.

\subsubsection{Argentina - National Atomic Energy Commission}

Argentina's National Atomic Energy Commission (CNEA) participated in the CRP in an advisory role. In 2005, CNEA hosted a workshop for potential

${ }^{99}$ Mo producers. At this workshop, different aspects of ${ }^{99}$ Mo production were addressed, such as irradiation conditions, processing, quality control and quality assessment, transport, training of personnel, waste treatment, safety issues, safeguards, and target design and fabrication. CNEA also hosted a Libyan participant in the CRP in 2008, to assist in his training in the production and quality control of ${ }^{99} \mathrm{Mo}$.

\subsubsection{Brazil - Nuclear and Energy Research Institute}

The Nuclear and Energy Research Institute (IPEN) is the largest nuclear research institute of the National Nuclear Energy Commission (Comissão Nacional de Energia Nuclear, or CNEN). IPEN participated in the CRP on behalf of Brazil from 2010 onwards, with the goal of producing ${ }^{99}$ Mo through the fission of LEU ${ }^{235} \mathrm{U}$ targets employing the LEU modified Cintichem process. They experimented with the acid dissolution of metallic uranium targets, the separation of ${ }^{99} \mathrm{Mo}$ from some fission produced impurities, precipitation with alpha-benzoin oxime (ABO), purification in hydrous zirconium oxide (HZO) and activated charcoal columns, and the separation of ${ }^{131}$ I for use as a primary radioisotope. As a participant in the CRP, Brazil participated in the meeting on waste management and quality control held in Chile in 2010, and one researcher went on a visit to Argonne National Laboratory (ANL) and the Y-12 National Security Complex (Y-12) in the USA with the support received under the CRP. 


\subsubsection{India - Board of Radiation and Isotope Technology and Bhabha Atomic Research Centre}

India's Board of Radiation and Isotope Technology (BRIT) participated in the CRP, sharing their design, development and deployment of zirconium molybdate ${ }^{99} \mathrm{Mo}$ gel generators. The generators are a twin column system comprising a primary column containing zirconium molybdate ${ }^{99}$ Mo gel granules and a secondary acidic alumina purification column for adsorption of traces of any co-eluted ${ }^{99} \mathrm{Mo}$. The Indian gel generator system components were exported to Kazakhstan under the CRP, while detailed process know-how is available for technology transfer to interested producers. The Bhabha Atomic Research Centre (BARC) contributed through feasibility studies of radiochemical separation of ${ }^{99} \mathrm{Mo}$ from uranium targets on the one hand and demonstrating two alternate separation schemes for availing pure ${ }^{99 \mathrm{~m}} \mathrm{Tc}$ from $(\mathrm{n}, \gamma)$ produced ${ }^{99} \mathrm{Mo}$ on the other hand.

\subsubsection{Indonesia - National Nuclear Energy Agency}

Indonesia's National Nuclear Energy Agency (BATAN) was involved in the CRP from 2005, and was primarily focused on developing and deploying the LEU foil target for national production. Indonesia hosted a workshop on LEU foil target fabrication, irradiation and chemical processing using the LEU modified Cintichem Technique in 2006. At the time of writing, Indonesia's PT Batan Teknologi was producing ${ }^{99}$ Mo from LEU targets.

\subsubsection{Poland - National Centre for Nuclear Research, Radioisotope Centre POLATOM}

Poland's National Centre for Nuclear Research (NCBJ) Radioisotope Centre POLATOM took part in the CRP, and examined the process of assembling annular LEU foil targets. They experimented with nickel recoil barriers to help keep the uranium target from bonding with the aluminium tubing, and also experimented with using the LEU modified Cintichem process for dissolving targets and studying the chemical process of separating and purifying ${ }^{99} \mathrm{Mo}$.

\subsubsection{Republic of Korea — Korea Atomic Energy Research Institute}

The Korea Atomic Energy Research Institute (KAERI) was involved mainly as a foil fabricator and foil supplier to other participants. As part of the CRP, KAERI experimented with a new method for making LEU foil for targets. The method, involving roll casting, was intended to simplify the process for 
making foil. After 2008, KAERI switched production methods, and began using a gravity assisted casting method. While this process helped with the stabilization of casting and collection of foils to some extent, foil thickness and surface state remained variable.

\subsubsection{USA - Argonne National Laboratory and University of Missouri Research Reactor}

The two institutions from the USA that were involved, ANL and the University of Missouri Research Reactor (MURR), worked to develop foil for targets, and provided assistance to CRP members with assembling and disassembling targets for test purposes. ANL also oversaw the supply of glassware and procedure for using the LEU modified Cintichem process for target dissolution, and has a large scale ambient pressure dissolver under development that would assist small scale producers in dissolving targets.

\subsubsection{Research contract holders — roles and work plans}

The IAEA defines research contract holders as participants in the CRP who receive financial support for activities that involve an essential research element or the development of a technique or specified item of equipment. Research contracts are typically awarded for an initial duration of one year, and can be renewed as the CRP progresses.

\subsubsection{Chile - Chilean Nuclear Energy Commission}

As a recipient of technology through the CRP, Chile's Chilean Nuclear Energy Commission (CCHEN) learned how to fabricate and assemble LEU foil targets. They were also able to disassemble a target in a hot cell, though no test irradiations were carried out in Chile. Chilean participants dissolved the test target and purified the components using the LEU modified Cintchem process, and were able to carry out quality control on the extracts and also evaluated disposition paths for the solid, liquid and gaseous wastes generated. One Chilean scientist received exposure to good manufacturing practices (GMP) through a visit to an industrial facility in the USA engaged in large scale production of ${ }^{99 \mathrm{~m}} \mathrm{Tc}$ generators. Chile later hosted a workshop on waste management and quality assurance in 2010 . 


\subsubsection{Egypt - Egyptian Atomic Energy Authority}

Using new facilities at the ETRR-2 reactor, the work plan of the Egyptian Atomic Energy Authority (EAEA) included carrying out the neutronic and thermohydraulic calculations necessary for irradiation, as well as preparing the safety reports necessary for producing ${ }^{99}$ Mo via neutron activation. Egypt finalized chemical processing steps and quality assurance procedures, and new hot cells were tested and approved. Egypt also modified the core of the ETRR-2 reactor to provide room for target irradiation, carried out calculations for placing targets into the reactor and trained staff on how to process irradiated LEU targets.

\subsubsection{Kazakhstan - Institute of Nuclear Physics, National Nuclear Centre of the Republic of Kazakhstan}

The main objective of research performed by the National Nuclear Centre of the Republic of Kazakhstan's Institute of Nuclear Physics (INP/NNC) from 2005-2011 was development of the technology for portable ${ }^{99 \mathrm{~m}} \mathrm{Tc}$ gel generator production using their own earlier experience in manufacturing and operation of the central type of ${ }^{99 \mathrm{~m}} \mathrm{Tc}$ gel generator. During its time in the CRP, Kazakhstan was able to develop the design of a portable ${ }^{99 \mathrm{~m}} \mathrm{Tc}$ gel generator system; modernize the existing process installation for ${ }^{99} \mathrm{Mo}-\mathrm{Zr}$ gel preparation; develop a technique for the filling of gel generator columns with ${ }^{99} \mathrm{Mo}-\mathrm{Zr}$ gel; develop a ${ }^{99 \mathrm{~m}} \mathrm{Tc}$ gel generator assembly procedure; carry out the production and quality control of cold pilot batches of gel generators; design equipment for the industrial production of portable ${ }^{99 \mathrm{~m}} \mathrm{Tc}$ gel generation; and carry out production of $18-23 \mathrm{GBq}^{99 \mathrm{~m}} \mathrm{Tc}$ gel generators. One scientist made a scientific visit to BRIT, India, and subsequently INP/NNC procured gel generator components and shielding assemblies from BRIT. The gel generator is a product now entered in the Kazakhstan national pharmacopoeia.

\subsubsection{Libya - Tajoura Nuclear Research Centre}

The Tajoura Nuclear Research Centre (TNRC) carried out thermohydraulic analyses of an LEU target, and also prepared three hot cells for the disassembly, dissolution and purification of irradiated targets. Shielding calculations for all three hot cells were completed during the CRP. Two Libyan scientists were trained in chemical processing in Indonesia, and one Libyan scientist visited CNEA, Argentina, for training in quality control aspects of fission produced ${ }^{99} \mathrm{Mo}$. 


\subsubsection{Malaysia - Malaysian Nuclear Agency}

The Malaysian Nuclear Agency joined the CRP in 2010, and they received a technical expert mission sponsored by the IAEA as the main part of their CRP activity. The expert mission examined the available facilities and infrastructure in Malaysia and concluded that with some upgrades to their TRIGA reactor, LEU fission ${ }^{99}$ Mo production would be possible and neutron activation ${ }^{99}$ Mo production might also be feasible for the country, and might satisfy national demand.

\subsubsection{Pakistan - Pakistan Institute of Nuclear Science and Technology}

The Pakistan Institute of Nuclear Science and Technology (PINSTECH) came into the CRP with some experience of producing fission ${ }^{99} \mathrm{Mo}$ from HEU targets. They joined the project to obtain assistance with their plans to convert ${ }^{99}$ Mo production to LEU. Within the CRP, they performed neutronic and thermohydraulic analysis for fission ${ }^{99}$ Mo production at the Pakistan Research Reactor 1 (PARR-1), and this data showed that LEU foil targets can be safely irradiated in PARR-1 for production of the desired amount of fission ${ }^{99} \mathrm{Mo}$ - that is, the amount necessary to meet domestic demand.

\subsubsection{Romania - Institute for Nuclear Research, Pitesti, and Horia Hulubei National Institute of Physics and Nuclear Engineering, Magurele}

Domestic efforts in Romania have been sustained by an existing infrastructure consisting of a 14 MW TRIGA reactor, a hot cell facility, a radioactive waste treatment facility and the Center for Radioisotope Production in Bucharest. The Institute for Nuclear Research (ICN) was able to carry out target fabrication using imported metallic uranium foil, target irradiation, target disassembly and dissolution, product recovery and purification and waste treatment.

There was initially an interest at the Horia Hulubei National Institute of Physics and Nuclear Engineering (IFIN-HH) in being involved in developing and deploying gel generator technology. However, beyond preliminary work performed during the first few years of the CRP, and probably owing to the greater potential of the research reactor in Pitesti to support LEU based fission ${ }^{99}$ Mo production, the gel generator work was not pursued further and the team discontinued participation in the CRP. 


\subsubsection{Observers}

Observers who took part in the CRP included: ANSTO, who shared safety analysis reports; target manufacturer AREVA/CERCA, France; Babcock \& Wilcox $(B \& W)^{6}$, USA; the global healthcare company Covidien/Mallinckrodt; HFR, Netherlands; target manufacturer INVAP, Argentina; IRE, Belgium; Isotope Technologies, Germany, who shared ${ }^{99}$ Mo processing technology; Lantheus Medical Imaging (LMI), USA; NTP Radioisotopes and the South African Nuclear Energy Corporation (NESCA), South Africa; Nordion, Canada; the United States Department of Energy, National Nuclear Security Administration (DOE-NNSA), who provided resources and technology related information; and the Y-12 National Security Complex (Y-12), USA.

These observers were not engaged in an official function, though they often contributed their expertise in one or more meetings and missions. Their role and inputs were vital to the success of the CRP, because without the sharing of experience, knowledge, and advances in the field of ${ }^{99}$ Mo production, CRP participants would have been lacking crucial information.

\subsection{MEETINGS AND WORKSHOPS HELD UNDER THE CRP, 2005-2011}

\subsubsection{Workshop on operational aspects of ${ }^{99}$ Mo production}

A workshop on operational aspects of ${ }^{99} \mathrm{Mo}$ production was held for potential CRP participants in Buenos Aires, Argentina, 17-20 May 2005. During this inaugural workshop, institutes presented information about their national needs and institutional infrastructure available for ${ }^{99}$ Mo production; many of these countries later applied to participate either as contract or as agreement holders.

\subsubsection{First research coordination meeting}

The first RCM was held in Vienna in December 2005. During this meeting, participants gave presentations on their facilities and capabilities. Agreement holders shared information about the materials and expertise they could offer; contract holders described any previous experience on topics related to production of ${ }^{99} \mathrm{Mo}$. Workplans for each of the agreement and contract holders were clearly laid out, including commitments of facilities and human resources. The interest of observers from industry and other stakeholders was evident from

${ }^{6}$ Babcock \& Wilcox were known as BWX Technologies (BWXT) until 2007. 
their participation in the RCM; the following observers attended the first RCM: B\&W, Covidien/Mallinckrodt, DOE/NNSA, HFR, IRE and NECSA.

\subsubsection{Workshop on LEU foil target fabrication, irradiation, and chemical processing using the LEU modified Cintichem technique}

This workshop was held at BATAN in Serpong, Indonesia, in 2006. Participants were taught, step-by-step, how to handle LEU foil targets in order to assemble them for irradiation, and also learned about the chemical processing of foil targets using the LEU modified Cintichem technique.

\subsubsection{Second workshop on operational aspects of ${ }^{99}$ Mo production}

Held at IAEA Headquarters in Vienna in 2006, this workshop brought together experts from the production industry to share their expertise and assist participants in gaining a holistic view of aspects involved in fission based ${ }^{99}$ Mo production. This included advice on targets, through to the final stage of waste management. Experts came from ANL, AREVA/CERCA, B\&W, Covidien/Mallinckrodt, HFR, IRE, MURR, NECSA and Nordion.

\subsubsection{Second research coordination meeting}

The second RCM was held in Bucharest in April 2007. Participants presented updates on the progress of their work since the first RCM in 2005. Participants also visited laboratories in Magurele, Bucharest, to see and discuss the gel ${ }^{99} \mathrm{Mo}$ work being performed, and the ICN, to see the facilities there for fission ${ }^{99}$ Mo production. Various obstacles and challenges that participants were facing were also discussed, including problems with glassware and inability to obtain irradiation time in reactors, and solutions were proposed. An improvement to ANL's target disassembly strategy was also discussed at this meeting. As a consequence, the ICN designed a new annular target disassembly device.

\subsubsection{Third research coordination meeting}

The third RCM was held at MURR, Columbia, MO, in October 2008. Participants presented updates on the progress of their work since the $2007 \mathrm{RCM}$ and discussed additional issues that they were encountering in carrying out the work. The group also visited the MURR facility and had detailed discussions on irradiation planning, thermohydraulic analysis and quality control aspects of 
${ }^{99}$ Mo production. The presence of a large number of observers (more than 20), including several from industry and national governments, meant that participants had unique access to varied expertise. Work plans were updated to be continued until the fourth, and final, RCM.

\subsubsection{Workshop on waste management and quality assurance}

This workshop was held at the La Reina Nuclear Center, in Santiago, in November 2010. The participants presented updates on work, and also presented their planning for waste management and quality control. Presentations were also given by expert representatives from ANSTO and JSC Isotope (Russian Federation). Discussion centred on waste management issues and technologies, and GMP concerns for the whole ${ }^{99}$ Mo production chain, and the experts in attendance offered recommendations for participants.

\subsubsection{Fourth research coordination meeting}

The fourth and final RCM was held in Vienna in December 2011. Participants presented the progress of their work since the $2008 \mathrm{RCM}$, and also presented an overview of all their work for the duration of the project. The meeting was also an opportunity for participants to obtain information about relevant technical activities and developments in ${ }^{99}$ Mo production generally, and to create an action plan for those participants who desired to continue pursuing ${ }^{99}$ Mo production as part of the IAEA's interregional technical cooperation project.

\subsection{OVERVIEW AND SUMMARY OF NON-HEU TECHNOLOGIES PURSUED IN THE CRP}

\subsubsection{LEU foil target work}

For the fission based production of ${ }^{99} \mathrm{Mo}$, the density (or loading) of ${ }^{235} \mathrm{U}$ per target is one of the most important aspects of the target's design, and so any target that uses HEU has a distinct advantage. But as most producers, major and minor, are moving away from HEU use in targets, there is a need to increase the density of uranium in target meat in order to compensate for the lower enrichment of the uranium.

The scientific teams at ANL and MURR recognized that the concept of an LEU metal foil target has great potential, since the uranium metal density in this type of target is potentially very high - approximately $19 \mathrm{~g} / \mathrm{cm}^{3}$, which helps offset the use of LEU instead of HEU in the target. An annular LEU foil target 
design was developed by ANL, who offered to share this technology and the associated radiochemical processing and purification through the CRP.

During the CRP, KAERI's work was focused on manufacturing LEU foil. Their set-up and results are presented in Section 2. Pakistan also performed some work applicable to the development of a flat plate LEU foil target, rather than adopting the annular shape. During the CRP, LEU foil annular targets were successfully irradiated in Argentina (CNEA), Indonesia (BATAN) and the USA (MURR). Based on experimental work performed at ANL, BATAN, CNEA and MURR, participants reported that the LEU foil target has several distinct advantages in comparison with an LEU dispersion type target with the same ${ }^{99}$ Mo yield for small scale ${ }^{99}$ Mo production. These advantages include:

- The time required to dissolve the foil target is less than that required for dissolution of the dispersion target. Because the foil is removed from its aluminium cladding, only the foil component of the target is dissolved in the first stage of the ${ }^{99}$ Mo production process.

- The volume of liquid radioactive waste generated during the target dissolution phase is significantly less for the LEU foil target. This is because only the foil component of the target is dissolved. The LEU foil target's aluminium cladding is removed during target disassembly, allowed to decay, and disposed of as low level solid radioactive waste.

- The uranium loading of a typical LEU dispersion target is in the range of $2.5-3 \mathrm{~g} \mathrm{U} / \mathrm{cm}^{3}$. The density of the LEU metal foil is approximately $19 \mathrm{~g} / \mathrm{cm}^{3}$. As a consequence, a foil target of the same geometry can contain much higher amounts of uranium than an HEU or LEU dispersion type target. The uranium content will be limited by the ability of the target's cooling system to remove heat (target power) during irradiation.

However, it is important to note that no foil target (ANL's or any other) is currently manufactured to an industry accepted standard or specification. As a consequence, each production facility must develop their own standard or specification for LEU foil targets. A corresponding target qualification programme should be established by any small scale producer wishing to manufacture their own LEU targets.

A summary of achievements made in preparing and testing annular LEU foil targets is described in Section 2, as well as in several of the country reports on the CD-ROM. 


\subsection{2. $\mathrm{LEU}$ based $\mathrm{UAl}_{\mathrm{X}}$ dispersion targets}

Uranium aluminide dispersion type targets (commonly referred to as $\mathrm{UAl}_{\mathrm{X}}$ or $\mathrm{UAl}_{2}$ targets) for ${ }^{99}$ Mo production are manufactured to materials testing reactor (MTR) fuel specifications by both AREVA/CERCA and CNEA. As a consequence, dispersion type targets are qualified to a high burnup (i.e. $>30 \%$ ). This burnup is typically greater than three times that which a ${ }^{99}$ Mo production target experiences during irradiation. The uranium density of an LEU based dispersion type target is in the range of $2.5-3.0 \mathrm{~g} / \mathrm{cm}^{3}$. Historically, many thousands of HEU based dispersion type targets were safely irradiated and processed by industry (e.g. Covidien/Mallinckrodt, IRE and NTP Radioisotopes) to produce ${ }^{99}$ Mo of high quality and purity.

LEU dispersion target fabrication begins with LEU $\mathrm{UAl}_{\mathrm{X}}$ particles matrixed with pure aluminium powder. Most of the points cited and discussed regarding LEU foil targets are equally valid and applicable in the case of the $\mathrm{UAl}_{\mathrm{X}}$ dispersion type plate targets. The main difference is that there is significantly more experience and expertise available with $\mathrm{UAl}_{\mathrm{X}}$ targets than there is with foil targets. The vast experience accumulated in the case of the analogous HEU targets, as well as the actual design features of the dispersion type targets (e.g. superior thermal contact) render the analysis and assessment relatively more simple and straight forward in this case. Furthermore, CNEA's expertise was beneficial, and MURR also performed detailed calculations for $\mathrm{UAl}_{\mathrm{X}}$ targets, in addition to their work on annular foil target evaluation as a part of the comparative assessment of possible target options.

\subsection{PROCESSING AND PURIFICATION — LEU MODIFIED CINTICHEM PROCESS}

\subsubsection{Description of the process}

Cintichem was the first producer of fission based ${ }^{99} \mathrm{Mo}$, and the company produced routinely until 1989 , generating approximately $1000 \mathrm{Ci}$ from a few irradiated targets per week, on average. Process yield was consistently $90 \%$.

In 2005, ANL and BATAN developed a chemical process for LEU targets that was based on Cintichem's process - hence, the LEU modified Cintichem process. These modifications consisted of allowing the use of irradiated LEU foil annular targets, and substituting nitric acid for sulphuric acid throughout the process to afford easier radioactive waste treatment and disposal.

The LEU modified Cintichem process can be divided into four steps: (1) disassembly of the irradiated LEU foil target; (2) target meat dissolution; 
(3) ${ }^{99}$ Mo separation and purification and (4) quality testing of the final product. For steps 1-3, there are procedures to be followed to deal with the radioactive waste, and these are described in Section 5 of this publication.

\subsubsection{Target disassembly}

The annular LEU foil target was designed to be disassembled, with the foil and cladding separated, before the LEU foil is dissolved. To disassemble the target, both of its ends are cut off, and a longitudinal cut is made over the length of the target's outer tube. The outer tube is then pulled away from the inner tube, allowing the release of the foil between them. This is performed using a target disassembly device specifically designed for this purpose.

\subsubsection{Dissolution}

After the foil is removed from the target, it is dissolved in nitric acid. The dissolver is a closed unit to capture reaction and fission gases. Once the foil is dissolved, the dissolver is linked to a cold trap held in liquid nitrogen, and the nitric oxide (NOx) gases formed during dissolution and the volatile fission gases (iodine, xenon and krypton) are cryogenically pumped into the cold trap, where they are held for decay storage. Once the dissolved foil solution is drained from the dissolver, it can contain up to $500 \mathrm{~g} \mathrm{U} / \mathrm{L}$.

\subsubsection{Molybdenum-99 separation and purification}

The next step is the precipitation of radioiodide by the addition of a natural iodine carrier, hydrochloric acid $(\mathrm{HCl})$ and silver nitrate $\left(\mathrm{AgNO}_{3}\right)$ to the dissolver solution; the iodide and chloride are precipitated as silver salts and filtered. The second step, and by far the most important, is the precipitation of molybdenum (VI) with ABO. Any other species that remain with the precipitate are present owing to entrainment of the solution in the solid. The precipitate is captured on a glass frit filter containing several layers of glass beads above the frit. The Mo-ABO precipitate is washed many times with small volumes of nitric acid solution; the glass beads facilitate the washing of the precipitate and allow decontamination from all the other dissolver components.

After washing, a solution of hydrogen peroxide $\left(\mathrm{H}_{2} \mathrm{O}_{2}\right)$ in sodium hydroxide $(\mathrm{NaOH})$ is added to the filter and the filter is heated. The molybdenum is dissolved from the precipitate in this stage and then passed sequentially through two columns. After passing through the second column, the molybdenum in $0.2 \mathrm{M} \mathrm{NaOH}$ goes through an extensive quality control procedure to confirm its proper purity and composition, so that it can be fed into ${ }^{99 \mathrm{~m}} \mathrm{Tc}$ generators. 


\subsubsection{Process performance}

The LEU modified Cintichem process technology was made available to participants, and some of them (Brazil, Chile, India, Indonesia, Pakistan, Poland and Romania) performed several studies examining the optimization of process parameters, such as dissolution, Mo precipitation, column purification and the effect of impurities in each step. For this purpose, the studies employed cold materials, radioactive tracers and irradiated LEU foil targets.

During the CRP, demonstrations of the LEU modified Cintichem process on either dummy or irradiated LEU foil targets were performed in India, Indonesia, Romania and in the USA. Results of these demonstrations are included in Section 3.

In conclusion, the LEU modified Cintichem process proved to be a viable process for the small scale production of ${ }^{99} \mathrm{Mo}$. The whole LEU modified Cintichem process technology, including documentation, drawings and expertise, was shared by ANL with all the participants.

\subsubsection{ANL alternative processes}

ANL is working on two schemes that will allow for the use of foil targets with an alkaline process. Both the front end process options under development have two major goals. The first goal is to produce a Mo product solution from the LEU foil that will be compatible with current purification operations and the second that, with the same number of targets irradiated, will provide the same or higher yield of ${ }^{99} \mathrm{Mo}$ at the end of processing. These alternative processes were also shared by ANL during the course of the CRP for the benefit of participants.

\subsection{1. $\mathrm{UAl}_{\mathrm{x}}$ DISPERSION TARGET PROCESSING}

\subsubsection{CNEA process}

CNEA began the production of fission ${ }^{99}$ Mo from HEU targets in 1985 and in 2002 became the first producer to convert to LEU based production. Having established its position as a front runner in LEU based ${ }^{99}$ Mo production, Argentina was able to provide training and expertise for the CRP on the various technologies for producing ${ }^{99} \mathrm{Mo}$ from LEU targets, including the processing aspects.

The CNEA process involves dissolving the irradiated $\mathrm{LEU} \mathrm{UAl}_{\mathrm{X}}$ targets

in a hot concentrated $\mathrm{NaOH}$ solution thus producing precipitate containing aluminium, uranium and some fission products, in particular the actinides. The 
precipitate is washed and together with the filtrate, which contains ${ }^{99} \mathrm{Mo},{ }^{131} \mathrm{I}$ and some fission products, undergoes a purification step.

\subsubsection{The ROMOL process}

The German company Gamma Service Group (GSG) were observers in the CRP, but supplied information for participants on their ROMOL (Rossendorf Molybdenum) process, which was first used on a small scale in Pakistan in 2010. The ROMOL process is based on the basic digestion of $\mathrm{UAl}_{\mathrm{X}} \mathrm{Al}$ clad dispersion targets using a mixture of $\mathrm{NaOH}$ and $\mathrm{NaNO}_{3}$.

\subsection{SHIPMENT OF BULK ${ }^{99}$ Mo SOLUTION FOR GENERATOR PRODUCTION}

After separation and purification, the ${ }^{99} \mathrm{Mo}$ product is in the chemical form of sodium molybdate in dilute sodium hydroxide solution. In this form, it can be loaded onto ${ }^{99 \mathrm{~m}} \mathrm{Tc}$ generators. Because of the short half-life of ${ }^{99} \mathrm{Mo}\left(T_{1 / 2}, 66 \mathrm{~h}\right)$, the transport of the product as quickly as possible to generator manufacturers is vital; approximately $1 \%$ of the ${ }^{99}$ Mo decays per hour. Adequate infrastructure and careful planning are necessary to enable and ensure fast and reliable transport of the product from the ${ }^{99}$ Mo producer to the generator manufacturers. Geographically well distributed ${ }^{99} \mathrm{Mo}$ production centres can also help reduce transport time related decay loss in transporting ${ }^{99}$ Mo to end users. Details of transport considerations, including shipping casks that are suitable for shipment of bulk ${ }^{99} \mathrm{Mo}$, are discussed in Sections 4 and 5.

\subsection{TECHNETIUM-99m GENERATOR PRODUCTION}

A ${ }^{99} \mathrm{Mo} /{ }^{99 m} \mathrm{Tc}$ generator, colloquially called a 'technetium cow', is a device used to extract the metastable isotope of technetium $\left({ }^{99 \mathrm{~m}} \mathrm{Tc}\right)$ from the radioactive decay of ${ }^{99} \mathrm{Mo}$. Most commercial ${ }^{99} \mathrm{Mo} /{ }^{99 \mathrm{~m}} \mathrm{Tc}$ generators use column chromatography, in which ${ }^{99} \mathrm{Mo}$ in the form of molybdate, $\mathrm{MoO}_{4}^{2-}$, is adsorbed onto acidic alumina $\left(\mathrm{Al}_{2} \mathrm{O}_{3}\right)$. A typical column contains 2-3 g of alumina (Fig. 4). When the ${ }^{99}$ Mo decays, it forms pertechnetate $\left(\mathrm{TcO}_{4}^{-}\right)$, which because of its single charge is less tightly bound to the alumina. Passing normal saline solution through the alumina column containing adsorbed ${ }^{99}$ Mo elutes the soluble ${ }^{99 \mathrm{~m}} \mathrm{Tc}$, resulting in an isotonic saline solution containing the ${ }^{99 \mathrm{~m}} \mathrm{Tc}$ as the pertechnetate, with sodium as the counterbalancing cation. The two most important factors for the design of an alumina column based ${ }^{99 \mathrm{~m}} \mathrm{Tc}$ recovery system are that it must exhibit 


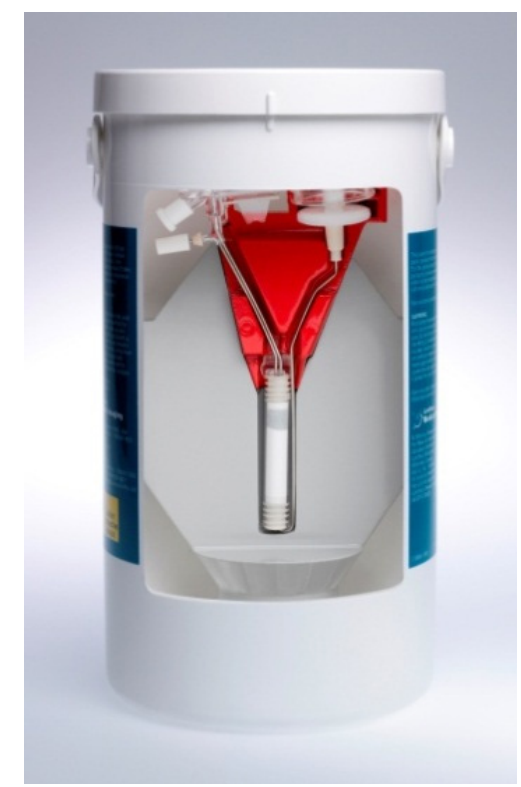

FIG. 4. Cutaway view of a typical ${ }^{99} \mathrm{Mo}{ }^{\rho 9 m} \mathrm{Tc}$ generator (image provided courtesy of Lantheus Medical Imaging, Inc. TechneLite is a registered trademark of Lantheus Medical Imaging, Inc. (C2014 Lantheus Medical Imaging, Inc. All rights reserved).

both a high elution efficiency (typically $85 \%$ ) and minimal Mo breakthrough. All ${ }^{99 \mathrm{~m}} \mathrm{Tc}$ generator systems, regardless of type, must be manufactured to the requirements of an established GMP programme.

Among the CRP participants interested in ${ }^{99}$ Mo production, the facilities and expertise for generator production were already available in the following countries, either on a laboratory or commercial scale: Argentina, Brazil, Chile, Egypt, India, Indonesia, Malaysia, Pakistan, Poland, the Republic of Korea and the USA.

\subsection{4. (n, $\gamma$ ) MOLYBDENUM BASED GEL GENERATORS}

\subsection{1. ${ }^{99}$ Mo production by neutron activation $-(\mathrm{n}, \gamma){ }^{99} \mathrm{Mo}$}

The production of ${ }^{99} \mathrm{Mo}$ via the neutron activation of natural molybdenum targets is a traditional and attractive alternative to the fission of targets containing ${ }^{235} \mathrm{U}$. The main disadvantage of activation ${ }^{99}$ Mo production is the low specific activity of the ${ }^{99} \mathrm{Mo}(3.7-74 \mathrm{GBq} / \mathrm{g} \mathrm{Mo})$ output. However, this specific activity can be increased with the use of highly enriched ${ }^{98} \mathrm{Mo}$ targets and high neutron 
fluxes. The advantages of this method are the generation of very low levels of radioactive waste, because the chemical processing necessary is much simpler; this method also reduces the need for hot cells. The target that is commonly used is a high purity $\mathrm{MoO}_{3}$, either in a powder or compact form. Metallic Mo will provide higher activities, but it is very difficult to dissolve in the processing phase; it also contains traces of tungsten impurity that result in the production of ${ }^{188} \mathrm{~W}$ during the neutron irradiation leading to ${ }^{188} \mathrm{Re}$ impurity in the ${ }^{99 \mathrm{~m}} \mathrm{Tc}$ eluate.

In order to solve the problem of low specific activity from (n, $\gamma)$ produced ${ }^{99} \mathrm{Mo}$, the ${ }^{99 \mathrm{~m}} \mathrm{Tc}$ gel generator makes activation ${ }^{99} \mathrm{Mo}$ into an insoluble zirconium (poly)molybdate ${ }^{99} \mathrm{Mo}$ gel that contains approximately $25 \%$ of molybdenum. The zirconium molybdate gel is predominantly a cation exchanger with an open structure which allows the free diffusion of pertechnetate anion under simple elution by saline. This enables the gel concept approach to retain the advantages of ease and reliability of (alumina) column chromatography generators.

The final product must be certified to meet specified purity standards, and so a quality control laboratory must be a significant part of any production operation. Procedures for performing the quality control analyses must be followed.

\subsubsection{Equipment and methods}

BRIT, in India, has been producing gel generators for several years, and shared its expertise in the CRP. Working mainly with Kazakhstan, participants from the two countries designed and fabricated special process apparatus and other equipment for the production of zirconium molybdate gel; that work is detailed in Section 4.

\subsubsection{Gel generator assembly}

The gel generator is a twin column system, comprising a primary column containing zirconium molybdate ${ }^{99} \mathrm{Mo}$ gel granules and a secondary acidic alumina purification column for adsorption of traces of any co-eluted ${ }^{99} \mathrm{Mo}$. The two most important factors for the design of a column based ${ }^{99 \mathrm{~m}} \mathrm{Tc}$ recovery system are that it must exhibit both a high elution efficiency (80-85\%) and minimal Mo breakthrough. Passing normal saline solution through the column on which ${ }^{99} \mathrm{Mo}$ is immobilized elutes the soluble ${ }^{99 \mathrm{~m}} \mathrm{Tc}$, resulting in an isotonic saline solution containing the ${ }^{99 \mathrm{~m}} \mathrm{Tc}$ as sodium pertechnetate.

All ${ }^{99 \mathrm{~m}} \mathrm{Tc}$ generator systems, regardless of type, must also be manufactured to meet the requirements of GMP. The Geltech system designed and manufactured by India's BRIT was designed and developed according to these principles. Under the CRP, the team from Kazakhstan were able to travel to BRIT's laboratories to 
work on gel generator design and manufacture, and later procured components and subsystems of the gel generator unit from BRIT.

\subsubsection{Production trials, analyses and results}

During the CRP, Kazakhstan produced two types of gel generators: one for centralized use (that is, with a large gel column); and portable units containing 2,4 or $6 \mathrm{~g}$ of gel. India produced only portable units containing between 6 and $9 \mathrm{~g}$ of gel. Gel generators containing ${ }^{99} \mathrm{Mo}$ activity of $14-44 \mathrm{GBq}$ on the date of production were supplied in India to hospitals and diagnostic centres. ${ }^{99 \mathrm{~m}} \mathrm{Tc}$ activity obtained on the first day of use at the hospitals (two days post production) was in the range of 11-22 GBq from the gel generators.

In Kazakhstan, the sodium pertechnetate ${ }^{99 \mathrm{~m}} \mathrm{Tc}$ solution for injection was produced from a centralized ${ }^{99 \mathrm{~m}} \mathrm{Tc}$ gel generator and distributed as a ready to use solution until 2010. From 2010 onwards, nine batches of the ${ }^{99 m}$ Tc portable gel generators were produced and pre-clinical and clinical trials of these ${ }^{99 \mathrm{~m}} \mathrm{Tc}$ gel generators were successfully completed. For its work on the CRP, Kazakhstan's generators were produced using natural molybdenum irradiated for four to five days in a flux of $1 \times 10^{14} \mathrm{n} \cdot \mathrm{cm}^{-2} \cdot \mathrm{s}^{-1}$. On the second day after generator production, three days after irradiation, the ${ }^{99 \mathrm{~m}} \mathrm{Tc}$ solution activity is $0.5-0.6 \mathrm{Ci}$. The same generator can also accommodate a larger gel column to offer a capacity of $1 \mathrm{Ci}$ activity.

\subsection{QUALITY CONTROL AND QUALITY ASSURANCE}

Quality control is of utmost importance in the production of any radiopharmaceutical. All reagents used in the processing of ${ }^{99}$ Mo targets must meet purity specifications laid down by the producer and accepted by national regulatory bodies. Since ${ }^{99} \mathrm{Mo}$ is the raw material for the preparation of ${ }^{99 \mathrm{~m}} \mathrm{Tc}$ generators, it is categorized as an API. Therefore, thorough quality control must be performed on the final solution containing ${ }^{99} \mathrm{Mo}$, and GMP principles must be adhered to throughout the process of manufacturing the ${ }^{99 \mathrm{~m}} \mathrm{Tc}$ generator.

\subsubsection{Quality control}

The final product must be certified to meet specified purity standards, and so a quality control laboratory must be a significant part of any production operation. Procedures for performing the quality control analyses must be 
followed as written. Quality control of fission ${ }^{99} \mathrm{Mo}$, the LEU modified Cintichem process, $\mathrm{UAl}_{\mathrm{X}}$ dispersion targets, $(\mathrm{n}, \gamma){ }^{99} \mathrm{Mo}$ and gel generators is discussed in depth in Section 5.

\subsubsection{Quality assurance}

The importance of maintaining a quality assurance programme that covers all aspects of the ${ }^{99} \mathrm{Mo}$ production chain was one of the important aspects of the CRP. Numerous GMP principles must be taken into account when planning even small scale production of ${ }^{99} \mathrm{Mo}$, and these were highlighted for participants; they are also discussed in depth in Section 5.

It is important to develop detailed step-by-step procedures that provide a means for ensuring controlled and consistent performance. These procedures should $^{7}$ be in written form to prevent misunderstandings and errors; this documentation is also necessary for regulatory compliance and traceability. Additionally, a validation programme should exist to show proof that the production processes are working as designed and that the quality assurance programme is sound. In terms of human resources, the job competencies should be clearly defined, developed and demonstrated, and it is essential to conduct planned and periodic audits for employee compliance and performance.

\subsubsection{Waste management}

The separation of ${ }^{99} \mathrm{Mo}$ from fission products and actinides involves highly radioactive streams of gases, liquids and solids that must be treated according to their radioactivity level and physical form. Thus, the waste management strategy that a facility will need depends on the type of irradiated target and the processing that is carried out.

The $(\mathrm{n}, \gamma)$ method of ${ }^{99}$ Mo production also generates radioactive waste, but typically the levels of waste are much smaller and the level of radioactivity considerably less than those found in the product of the fission route.

Additionally, it is important to have a strategy for other non-radioactive waste (e.g. chemical waste) that is generated.

7 Guidance provided here in the form of 'should' statements, or simply in the present tense indicative, describing good practices, represents expert opinion but does not constitute international consensus recommendations on how to meet the relevant requirements. 


\subsubsection{Treatment for waste streams from fission based ${ }^{99}$ Mo production}

Waste streams from fission based ${ }^{99}$ Mo production include both low and intermediate level solid, liquid and gaseous wastes. These waste streams include general and decontamination waste; caustic scrubber and ammoniacal condensate; cell waste columns; and gaseous wastes, among others.

Treatment for these wastes can be divided into two steps: the first step, treatment of off-gases, is performed on-line during the processing. Gaseous waste, which includes volatile fission products, is removed from the dissolver using a cold trap. The cold trap is stored to allow decay and then eventually vented when the gases have decayed to background levels.

The second step is performed just after the processing, and treats the liquid and solid wastes. Solid waste treatment includes the discarded target tubes after disassembly, and glassware, columns, filters and syringes used during processing. This material is usually all low level waste. Depending on methods used by the producer, there will either be one or two liquid wastes to treat. It is possible to separate the filtrate from the $\mathrm{ABO}$ precipitation by first removing the initial filtrate and the first two rinses. This removed liquid contains the majority of the uranium and fission and activation products from the irradiated target and is a high-activity waste. The second waste results from the remaining rinses and has trace amounts of the same components; it would be low level waste.

Similarly, in treating wastes from alkaline processes, the main concern is the solid waste made up of the filters containing the uranium precipitate. These filters can initially be allowed to accumulate inside the hot cell, and eventually they can be packed and sent to a waste management facility.

\subsubsection{Treatment for waste streams from activation based ${ }^{99}$ Mo production}

The waste management process for $(\mathrm{n}, \gamma){ }^{99} \mathrm{Mo}$ is much simpler than for fission produced ${ }^{99} \mathrm{Mo}$. No gaseous waste is generated; only liquid and solid wastes have to be treated. For gel generator production, approximately $10 \mathrm{~L}$ of liquid waste is generated per $50 \mathrm{~g}$ of molybdenum processed. The waste comprises filtrate of gel precipitate, fine product granules washed down during the gel fragmentation stage, column bed washing and process vessel and tube rinsing. The liquid waste is collected in individual plastic, glass or stainless steel bottles. 


\subsection{RECOMMENDATIONS OF THE CRP MEMBERS}

The need for building diversity in supplies of medical isotopes (such as ${ }^{99} \mathrm{Mo}$ ) based on non-HEU technologies, as well as addressing full cost recovery aspects in the production of radioisotopes, are some of the key requisites to securing sustainable availability of medical isotopes. To that end, this CRP was successful in allowing the participating Member States to see whether producing small quantities of ${ }^{99} \mathrm{Mo}$ would be a feasible activity, especially in the event of another global shortage. For most of the participants, producing a few hundred $\mathrm{Ci}$ of ${ }^{99} \mathrm{Mo}$ a week for a short time would indeed be possible, though for several Member States, there are still outstanding issues to address, including making a careful cost to benefit analysis of undertaking a small scale production project.

There is scope for producing other useful medical isotopes such as ${ }^{131} \mathrm{I}$, along with the fission product ${ }^{99} \mathrm{Mo}$, and this option is of interest to some members.

Coordinated production strategies for LEU foil and preassembled targets are desirable, and work performed during the CRP is valuable in this context. The requirements of many participants, which are now known because of the calculations made during the CRP, can provide useful data for this purpose. The IAEA's support to facilitate access to, or procurement of, some materials and equipment was requested by many participants, and several also requested the IAEA's continued support in facilitating scientific visits and arranging training opportunities.

Other types of need based development, such as processing systems and LEU silicide targets, were cited as potential aspects for further coordinated collaborative efforts, and participants noted that IAEA support would be helpful to accelerate progress on this development.

Participants requested that the IAEA continue to provide support and a forum for further advancing the work of participants in small to medium scale local production of ${ }^{99} \mathrm{Mo}$. One way this might be achieved is through the ongoing technical cooperation project. Many of the CRP participants have already joined, or have expressed interest in joining, the technical cooperation project on small scale ${ }^{99}$ Mo production.

\subsection{CONCLUDING REMARKS}

The concluded CRP has proved to be an extremely important and timely initiative, not only in terms of supporting participating Member States in examining the feasibility of the small scale domestic production of ${ }^{99} \mathrm{Mo}$, but also in terms of raising awareness among the stakeholders on the various aspects involved in the shift to LEU targets. The project also helped address the 
emerging issues surrounding securing sustainable supplies of ${ }^{99}$ Mo for users everywhere. Some of the CRP participants have demonstrated the expertise and resources needed to make them very useful partners, including to commercial entities, to expand the base of ${ }^{99} \mathrm{Mo}$ production and/or irradiation facilities; some others are likely to become small to medium scale producers to meet local and possibly regional needs. The IAEA's new interregional project under the technical cooperation programme on fostering and supporting non-HEU routes of ${ }^{99} \mathrm{Mo}$ production would be an invaluable step in continuing to leverage the considerable capabilities and networking built through the CRP, which has now been concluded.

\section{TECHNICAL ASPECTS RELATED TO LEU TARGETS FOR MOLYBDENUM-99 PRODUCTION}

\subsection{LEU FOIL ANNULAR TARGET KNOW-HOW AND RELATED ASPECTS}

\subsubsection{LEU targets and their irradiation in research reactors}

In order to produce ${ }^{99} \mathrm{Mo}$ by fission, targets containing ${ }^{235} \mathrm{U}$ are placed into a reactor and irradiated for a specific number of hours at a given neutron flux. As ${ }^{99} \mathrm{Mo}$ is one of the major by-products of the fission of ${ }^{235} \mathrm{U}$, the more ${ }^{235} \mathrm{U}$ in the target to begin with (i.e. the higher the loading density), the higher the yield of ${ }^{99}$ Mo per target.

Major producers of ${ }^{99}$ Mo typically use this fission method for production, and most producers use, or have used, an HEU aluminide target with an average density of $2.5 \mathrm{~g} \mathrm{U} / \mathrm{cm}^{3}$, but as much as $93 \%{ }^{235} \mathrm{U}$ [4]. Since the beginnings of ${ }^{99}$ Mo production, many thousands of these HEU based dispersion targets have been safely irradiated and processed by commercial entities to produce ${ }^{99} \mathrm{Mo}$ of high quality and purity.

As noted in the introduction, however, the need to switch to a target based on LEU is imminent, for political, technical and non-proliferation reasons. The simplest technical solution has been to create a LEU-aluminium dispersion target that simply substitutes LEU for HEU. This is the route several major producers are taking as they prepare for their initial target conversion, since this requires the fewest changes to the chemical processes in place, and to irradiation rigs and transport casks. The LEU dispersion target was also used by some of the 
participants in the CRP, and work performed with that target on a small scale is described later in this Section.

The main target that was investigated in the CRP was a higher density annular LEU metal foil target developed at ANL. This target is still largely experimental, but envisaged to be useful for small scale producers as the higher density of uranium in the target will produce more ${ }^{99}$ Mo with fewer target irradiations. Three of the contract holders in the CRP, ANL, MURR and KAERI, worked on developing both a high density LEU metal foil target and the chemical processes for extracting the ${ }^{99} \mathrm{Mo}$ from the target. This work is described below.

The basic elements of LEU target design assessment, for both foil type and dispersion plate type targets, include the following:

- Performance of neutronics calculations to determine the theoretical yield of ${ }^{99} \mathrm{Mo}$ at EOB and target power (i.e. heat generated) during irradiation.

- Performance of thermohydraulic calculations to determine whether the targets can be adequately cooled during irradiation.

- Fabrication of a target draw die assembly device, applicable for the assembly of foil based targets only.

- Evaluation of target assembly procedure and technique by assembling mock targets that use a material other than LEU as a surrogate for the foil component of the target. This activity includes the development of a leak test method to verify the integrity of the welded ends of the targets. Applicable for the assembly of foil based targets only.

- Design and fabrication of the irradiation rig that is used to position the targets in the reactor.

- Manufacture of the actual LEU targets (for ${ }^{99}$ Mo production) suitable for reactor irradiation followed by chemical processing.

While not all of these steps were carried out in this CRP, the work that was completed, and the salient results, are discussed in this Section as reference points for those facilities wishing to undertake small scale ${ }^{99}$ Mo production, since one of the purposes of this publication is to assist future small scale producers.

\subsubsection{General description of LEU foil annular targets}

The scientific teams at ANL and MURR recognized that the concept of an LEU metal foil target has great potential, since the uranium metal density in this type of target is potentially very high, which helps off-set the use of LEU instead of HEU in the target. In order to utilize LEU containing $19.8 \%{ }^{235} \mathrm{U}$ (as opposed to $93 \%{ }^{235} \mathrm{U}$ in HEU targets), scientists at ANL developed a target meat made from LEU metal foil, because the uranium metal density that can be achieved 
with the foil is much higher: approximately $19 \mathrm{~g} / \mathrm{cm}^{3}$, compared to a typical loading of 1.1-1.6 gU/ $\mathrm{cm}^{3}$ in an HEU target. They worked to produce an annular target design, which consists of a thin (typically 100 to $150 \mu \mathrm{m}$ ) uranium foil, wrapped in a $15 \mu \mathrm{m}$ thick nickel foil fission recoil barrier (Fig. 5 and Fig. 6). The fission recoil barrier prevents the uranium foil from bonding to the aluminium tube cladding during irradiation. This is an important feature of this target design, as the foil component of the target is removed from the aluminium cladding for chemical processing.

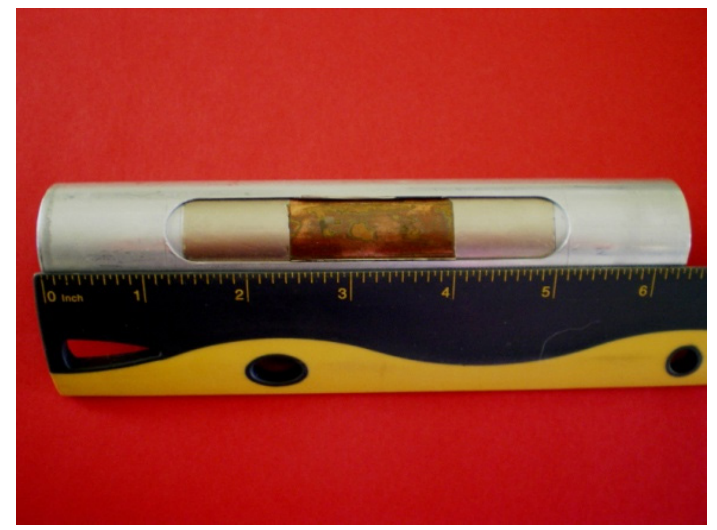

FIG. 5. Mock annular target shown with nickel wrapped $20 \mathrm{~g}$ copper foil exposed.

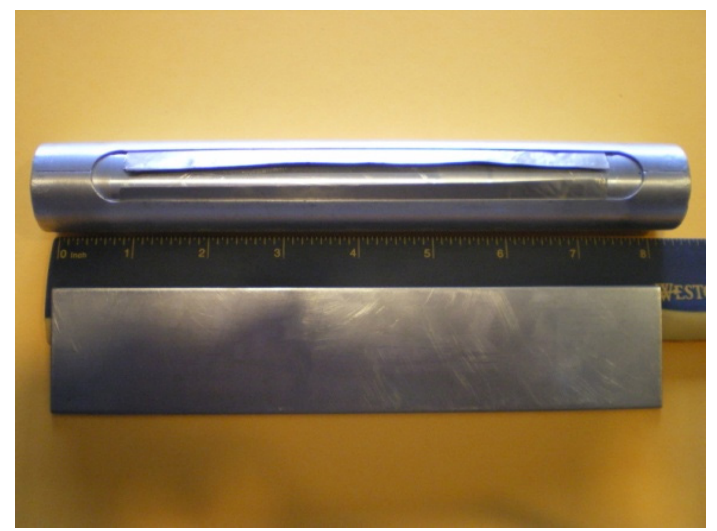

FIG. 6. LEU foil annular target comparison to an HEU based UAl dispersion target used by Covidien/Mallinckrodt. 
The target is assembled by positioning the foil between two concentric aluminium tubes. The tubes are then drawn together in a draw die assembly device. Finally, the ends of the drawn tubes are welded to form a hermetic seal that prevents the release of solid and gaseous fission products into the reactor pool during irradiation. After irradiation, the foil component of the target is removed from the aluminium cladding for chemical processing using the LEU modified Cintichem process also developed by ANL and described in depth in Section 3. The aluminium tubing is allowed to decay and it is discarded as low level solid waste.

Based on experimental work performed at ANL, BATAN, CNEA, and MURR, an LEU foil target offers several distinct advantages in comparison

to an LEU dispersion target offering the same ${ }^{99}$ Mo yield. These advantages include faster dissolution of the metal foil, because the aluminium cladding is removed and disposed of as low level solid waste, and only the thin foil is chemically dissolved. Furthermore, removing the cladding reduces the volume of liquid radioactive waste produced, since only the metal foil is dissolved. Finally, the uranium density of a typical LEU metal foil target can be as high as $19 \mathrm{~g} / \mathrm{cm}^{3}$, whereas typical uranium loading of a LEU dispersion target is in the range of $2.5-3.0 \mathrm{~g} \mathrm{U} / \mathrm{cm}^{3}$. Ultimately, the uranium loading is limited primarily by the target's ability to remove heat (target power) during irradiation.

Though LEU foil annular targets have been successfully irradiated in Argentina (CNEA), Indonesia (BATAN) and the USA (MURR), these targets are not currently manufactured to an industry accepted standard or specification. Work is ongoing at the University of Missouri College of Engineering, ANL and Y-12 to develop the necessary LEU foil target specifications, as well as a manufacturing method for the thin uranium metal foils manufactured by Y-12 and KAERI.

\subsubsection{LEU foil production at $\mathrm{Y}-12$ and KAERI}

The main component of the LEU foil target is the thin uranium foil at the centre of the target. This foil is generally produced by a combination of hot rolling of the LEU foil and cold rolling of cast LEU coupons, as illustrated in Fig. 7.

Figure 8 shows a uranium foil like those fabricated by Y-12 during the course of the CRP, using the hot rolling and cold rolling method. Some of this foil was distributed to CRP participants during the project; Y-12 also assisted KAERI in assessing the quality of the Korean foils produced based on the assessment methodology used at Y-12. 


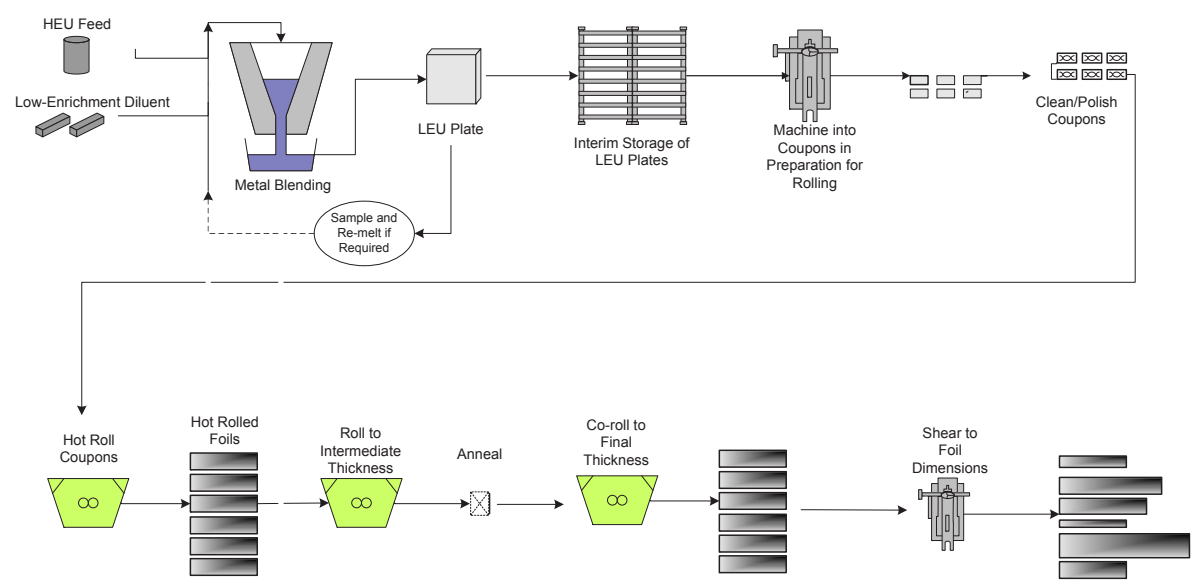

FIG. 7. Fabrication process for LEU foils. Courtesy of Y-12, USA.

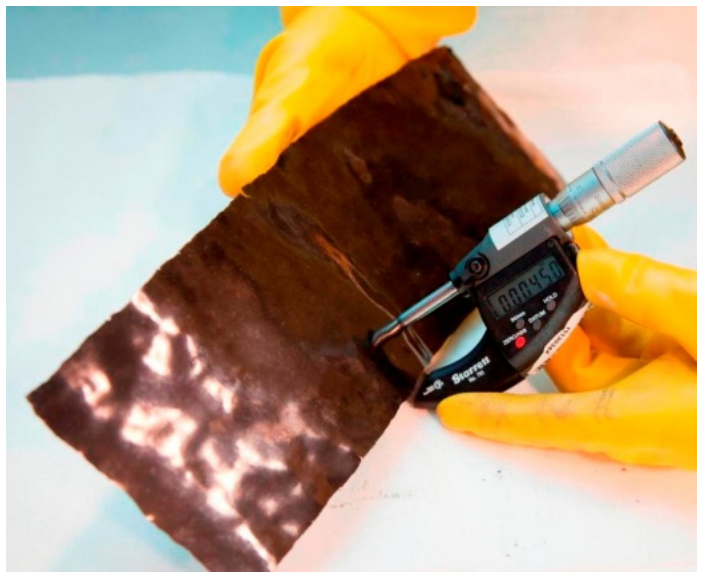

FIG. 8. Uranium metal foil fabricated on a trial basis by Y-12. The thickness of the foil is $\sim 115 \mu \mathrm{m}$.

Before the CRP began, KAERI had already started experimenting with development of an alternative process for foil fabrication. This process entailed directly forming LEU foils from the uranium melt by cool roll casting; the intention was to simplify the fabrication process and reduce the overall cost of foil fabrication. The uranium melt was held in a quartz crucible, and then discharged through an open quartz nozzle with high injection pressure directly onto a rotating cooling roll (in an inert atmosphere) (see Fig. 9). As the roll 


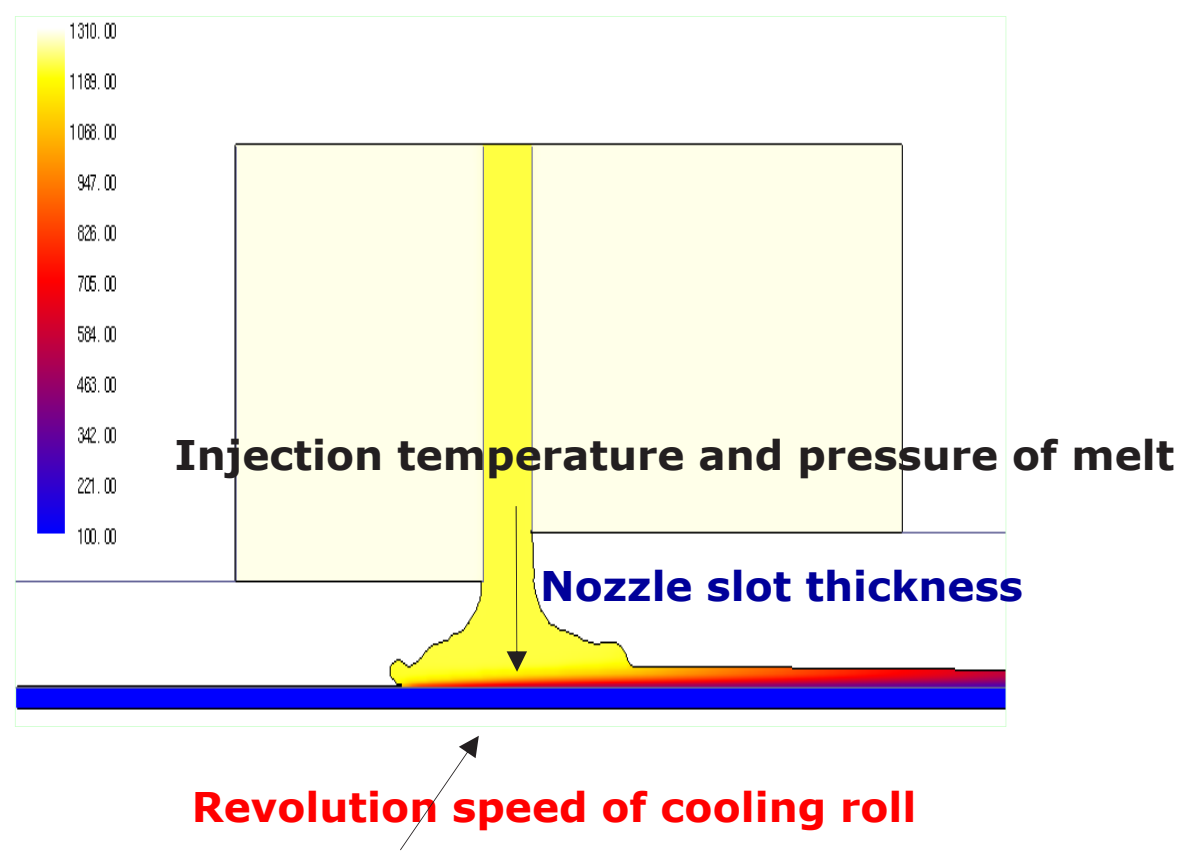

FIG. 9. Diagram of the KAERI method of cold rolling foils. Figure courtesy of KAERI.

rotated at approximately 500 revolutions per min, the metal foils were 'spun off' the roll and collected in a pressure assisted casting apparatus. The foils, which were approximately $50 \mathrm{~mm}$ in width and $135 \mu \mathrm{m}$ in thickness, typically looked crumpled, as shown in Fig. 10, but could then be collected into a single $5 \mathrm{~m}$ long foil roll as shown in Fig. 11.

Through the CRP, some of the KAERI foils were provided to Chile, Indonesia, Poland, Romania and the USA (and also to France, as observers), in order to measure the foil quality and for test irradiations that CRP participants had planned. However, in 2007 KAERI recalled them after discovering that the surface was too inhomogeneous to use the foils as ${ }^{99}$ Mo targets and also finding holes in some of the foils. Figure 12 shows a square of KAERI foil as it looks to the naked eye; Fig. 13 shows a scanning electron micrograph cross-section of a KAERI foil. Figure 12 shows one of the two issues with the foils: the wheel contacted surface (that is, the 'bottom' side of the foil that was poured onto the rolling apparatus, or the right side in Fig. 13) was fairly smooth, but the free surface (the 'top' side of the foil that was in the open air, or the left side of Fig. 13) was rough and pitted and this could make bonding with fission recoil barriers a potential problem. 


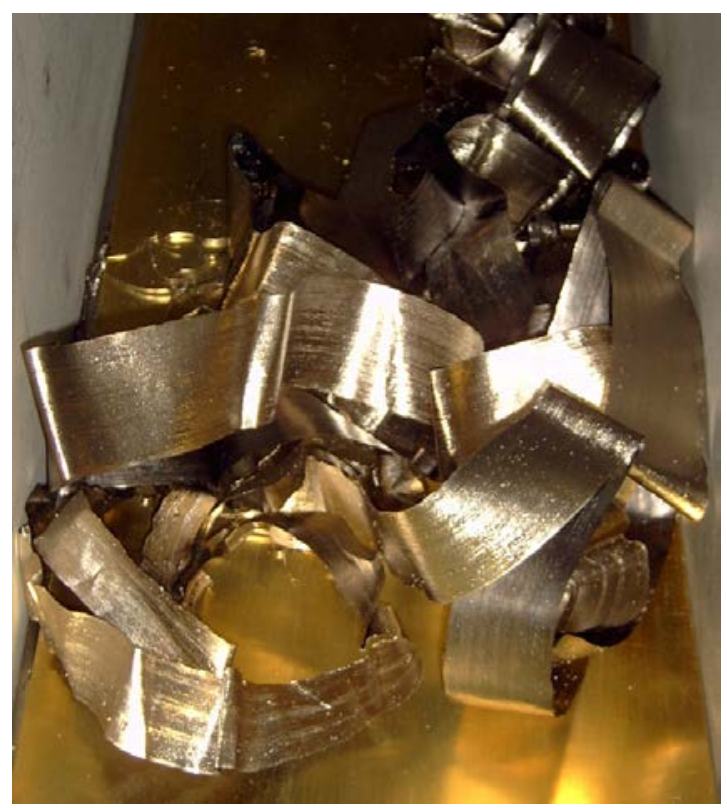

FIG. 10. Foils as they were ejected from the cooling roll. Photograph courtesy of KAERI.

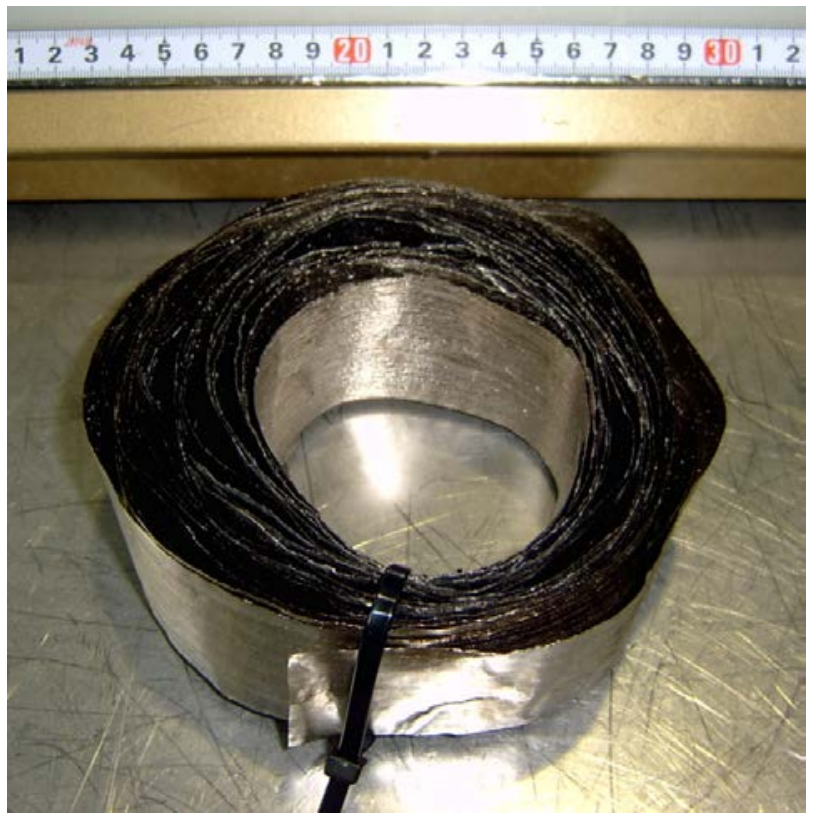

FIG. 11. Foils as they were collected at KAERI. Photograph courtesy of KAERI. 


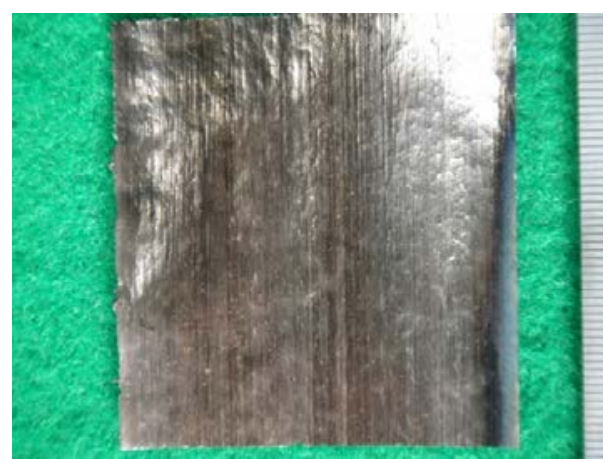

FIG. 12. Uranium metal foil fabricated by KAERI using their cooling roll casting method. The average thickness of the foil is $\sim 140 \mu \mathrm{m}$. Photograph courtesy of KAERI.

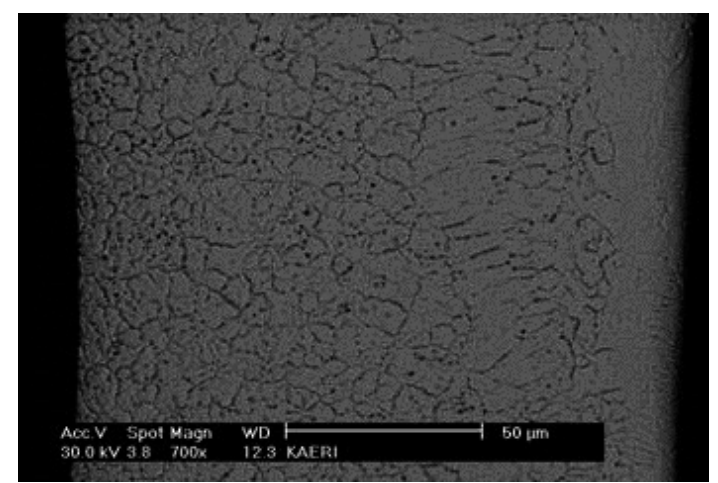

FIG. 13. Uranium metal foil fabricated by KAERI shown as a cross-section of a scanning electron micrograph. Photograph courtesy of KAERI.

Furthermore, studies of the KAERI foils showed variations in the thickness of the foils. KAERI measurements indicated an average standard deviation of $21 \mu \mathrm{m}$ in foil thickness, but there were some points on the foils where thickness fluctuated by as much as $50 \mu \mathrm{m}$ - which again led to concerns at KAERI about being able to use the foils as target material. ${ }^{8}$

8 None of the KAERI produced foils were rolled with a fission recoil barrier or irradiated during the course of the CRP, so it is possible that they would have performed without problems. However, the deviations were sufficiently large that KAERI was concerned about the foils, and so embarked on a different method of production as detailed in the latter half of Section 2.1.3. 
Based on this initial work on fabricating LEU foils, KAERI began using a different approach in 2008 with which they continued for the last three years of the CRP with the intention of improving foil quality. Called 'gravity assisted cooling roll casting', the adapted method used a graphite crucible system, thus avoiding the use of the fragile quartz crucible that had caused problems holding the uranium melt under pressure. The graphite crucible allowed better control of the uranium melt temperature, and the addition of a tun-dish to the system allowed uranium melt to be drawn onto the wheel using gravity, rather than high pressure injection. As a result, KAERI was able to operate the main wheel at $60 \mathrm{rpm}$ (rather than $500 \mathrm{rpm}$ ), and foils were collected in a winding system rather than being spun off the wheel. A schematic of the KAERI designed gravity assisted casting system is shown in Fig. 14.

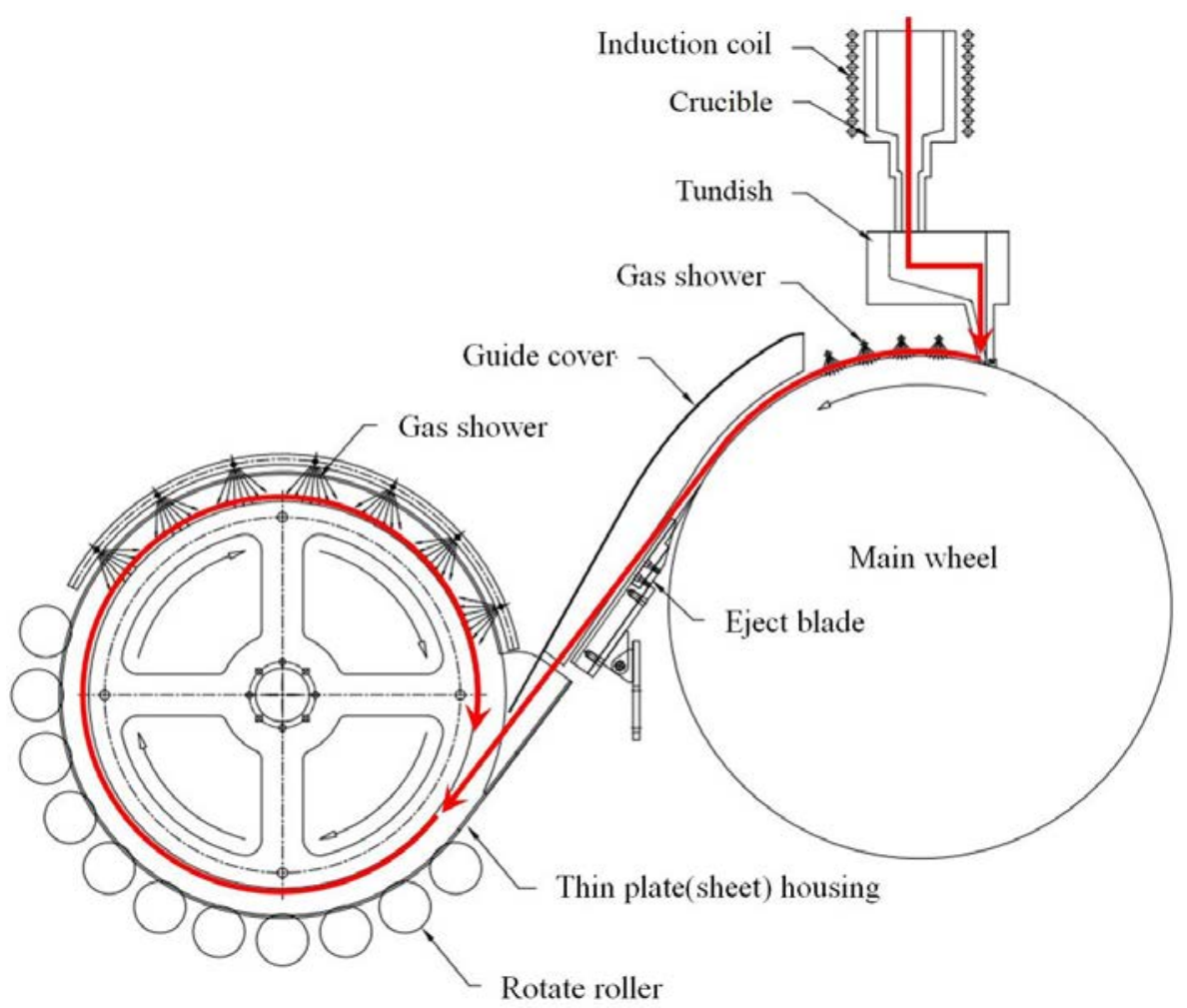

FIG. 14. A schematic of KAERI's gravity-assisted cool-roll casting apparatus. Figure courtesy of KAERI. 
The results of the gravity assisted method marginally improved the foil production. According to KAERI's preliminary analysis, foils could be produced and wound continuously, and no holes were found in the foils. However, while the thickness of the foil remained about the same as when using the pressurized nozzle method (135 $\mu \mathrm{m}$ on average), the average standard deviation in foil thickness actually went up, to $35 \mu \mathrm{m}$. Furthermore, the issues with the roughness of the free, or 'top', surface were not resolved using the new method.

KAERI concluded that making continuous batches of uranium foils of up to $10 \mathrm{~m}$ in length was possible using their two tested methods, and that slowing the main wheel made it easier to collect the foils in a winding system. However, KAERI also found that neither production system made the thickness of the foils more consistent, and neither system made the free (or top) side of the foil significantly less rough. KAERI ultimately concluded that, for the foreseeable future, rolling the foils as Y-12 currently does (Fig. 7) was the best way to ensure a consistent thickness and smooth surface.

\subsubsection{Test irradiations of LEU foils at MURR}

During the CRP, MURR performed two trial demonstrations designed to validate the efficacy of ANL's annular LEU foil target. In both cases, MURR irradiated an annular target with LEU foil meat, and processed it using the LEU modified Cintichem process.

In October 2008, MURR irradiated an annular foil target with LEU foil supplied by ANL (see Fig. 15). The ${ }^{99}$ Mo yield of this first trial irradiation was about $90 \%$. The quality assay of the finished sodium molybdate product was verified to be comparable to the HEU based sodium molybdate supplied to the worldwide market by the major ${ }^{99}$ Mo producers.

MURR performed a second test irradiation in April 2009 using LEU foil supplied by KAERI. Again, the irradiation was successful, and the ${ }^{99}$ Mo yield was approximately $90 \%$, with quality assays also being similar to ${ }^{99}$ Mo produced with HEU based targets. Additionally, MURR reported no issues with the KAERI foil quality, and continued to perform testing with KAERI foils after the end of the CRP.

\subsubsection{LEU annular foil target fabrication using the draw die assembly device}

Once the LEU foil has been procured or fabricated, it must be positioned in between two concentric aluminium tubes. The dimensions of these tubes can vary depending on the size of the irradiation rig, but it is important that the two 


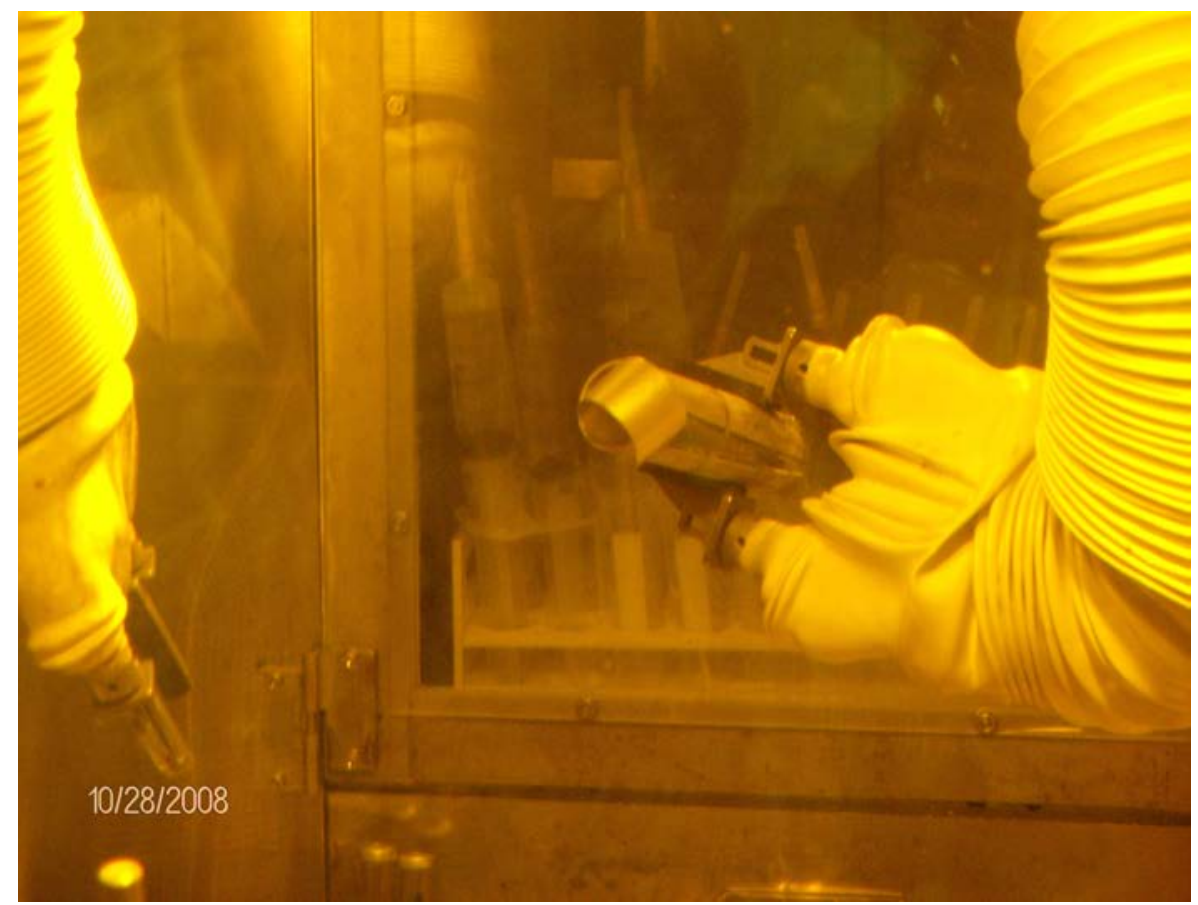

FIG. 15. LEU foil removal from aluminium tubes. Foil is being placed in dissolver unit.

tubes fit together tightly. As an example, the tubes used by Indonesia during the CRP measured as follows:

- Outer tube: inner diameter of $28.27 \mathrm{~mm}$, outer diameter of $30 \mathrm{~mm}$;

— Inner tube: inner diameter of $26.23 \mathrm{~mm}$, outer diameter of $27.978 \mathrm{~mm}$.

The space between the inner and outer tubes, where the foil was placed, measured $0.292 \mathrm{~mm}$ in this case.

Once the foil is positioned between the tubes, these tubes are drawn together in a draw die assembly device. A prototype device, fabricated at ANL, is shown in Fig. 16(a). A cutaway view of this device is shown in Fig. 16(b).

The tubes are placed into the device and drawn together. Once this action has been completed, the ends of the drawn tubes are welded to form a hermetic seal that prevents the release of solid and gaseous fission products into the reactor pool during irradiation. The process for drawing the tubes together and welding them is illustrated in Figs 17-21. 
(a)

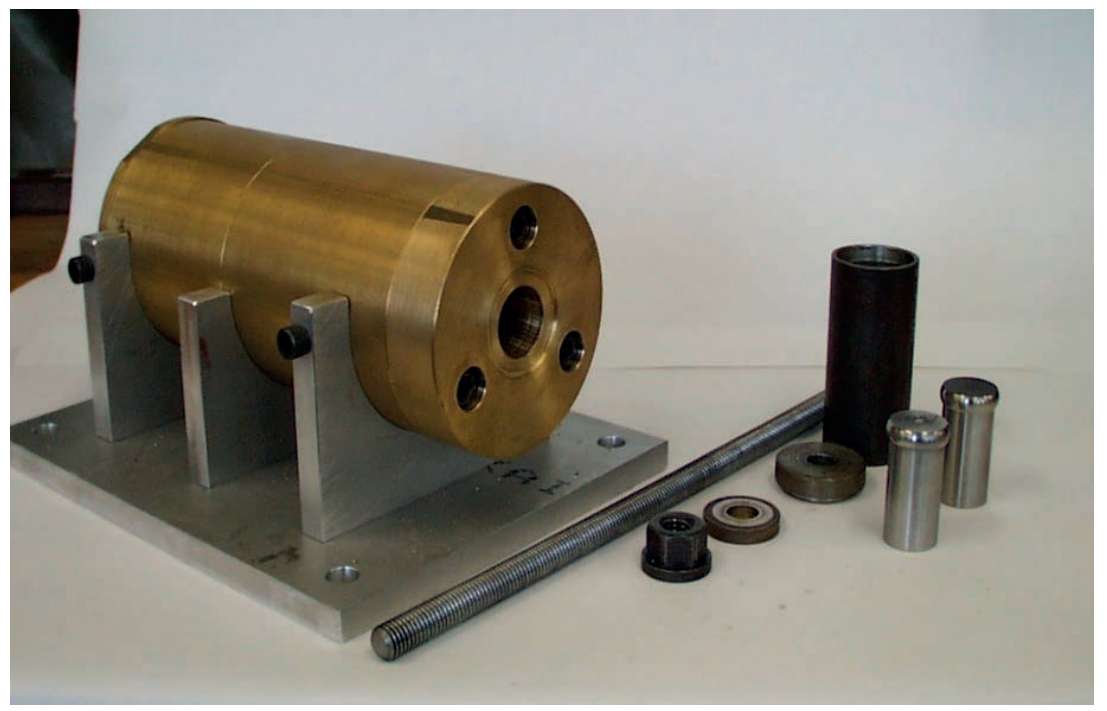

(b)

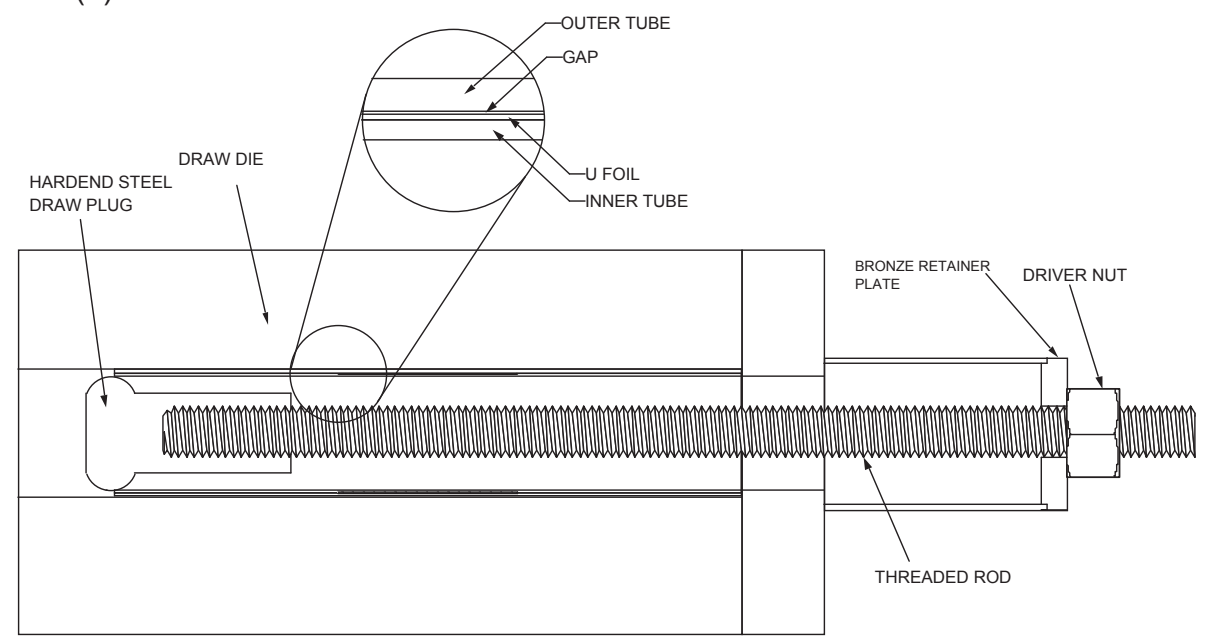

FIG. 16. (a) ANL's prototype target draw die assembly device and (b) cutaway view of the device. Both images courtesy of ANL. 


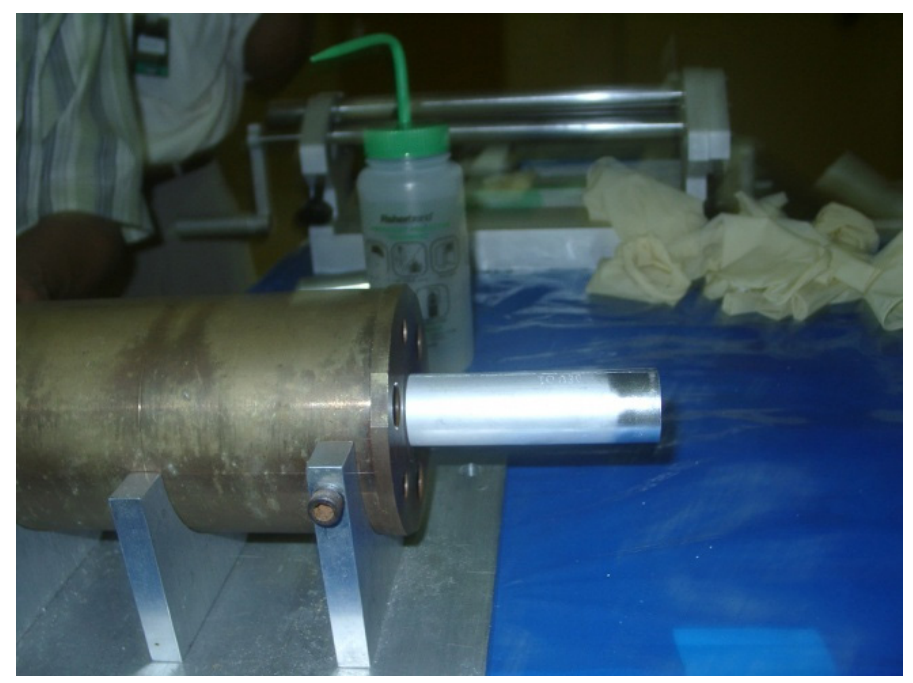

FIG. 17. Draw die assembly with target. Photograph courtesy of BATAN.

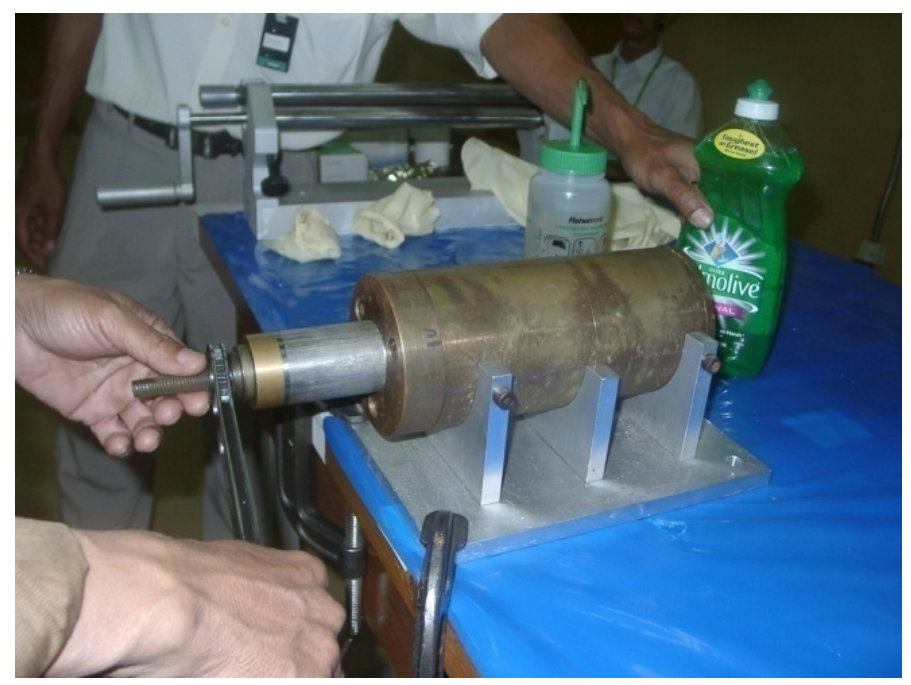

FIG. 18. Assembling the targets with the assembly. Photograph courtesy of BATAN. 


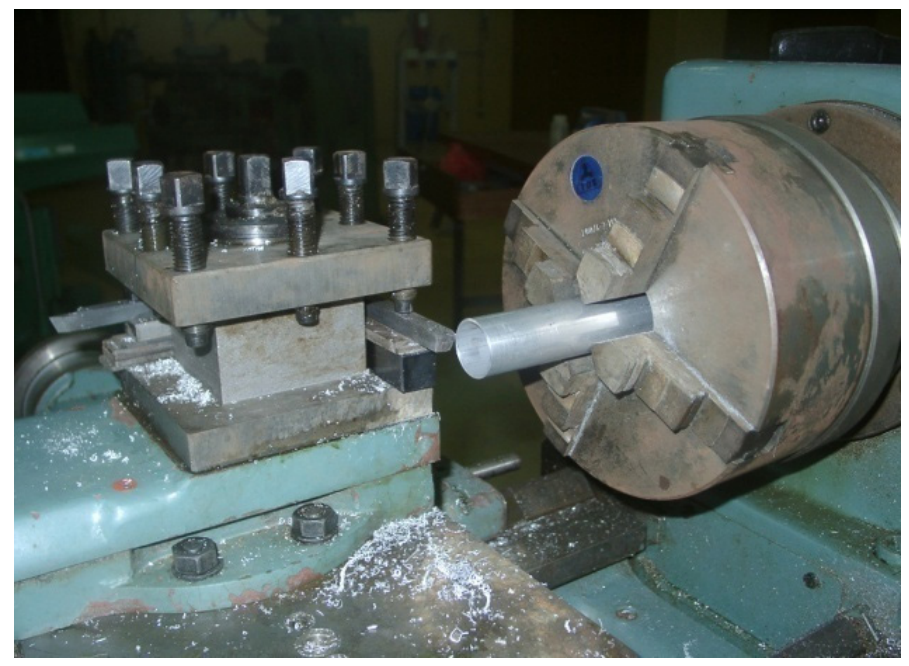

FIG. 19. Machining the ends of the tubes in preparation for the weld. Photograph courtesy of BATAN.

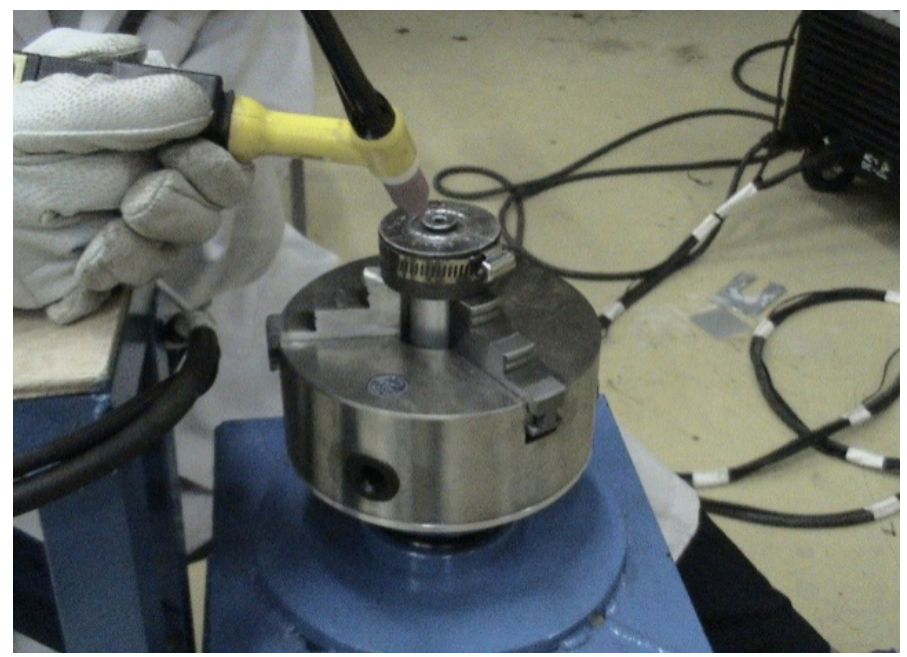

FIG. 20. Performing the welding of the two tubes. Photograph courtesy of BATAN. 


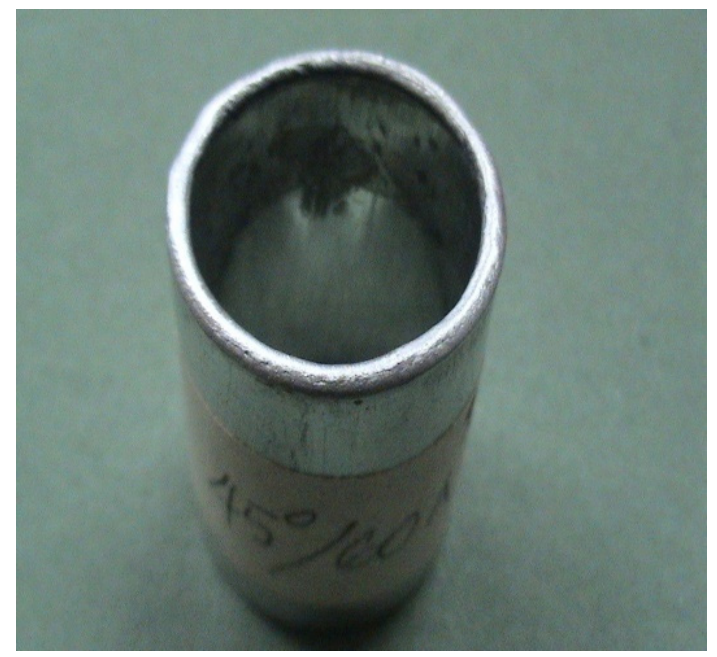

FIG. 21. Final welded target. Photograph courtesy of BATAN.

Testing the welds to ensure the seal, and discount the possibility of major and minor leaks, is an important step in preparing the target. While there are a number of ways that this may be achieved, CRP participants performed one test for major leaks and another for minor leaks. First, they submersed the assembled target in liquid nitrogen, and then transferred it into boiling water, which would cause any major leaks in the welds to become apparent. Secondly, targets were subjected to a helium leak test in order to ensure there were no minor leaks in the welds.

CRP participants noted that machining the inner and outer tubes to the exact specifications necessary was not always successful and took considerable practice; furthermore, participants noted that performing the weld to the exacting standards necessary to ready it for irradiation was difficult.

\subsubsection{General observations and lessons from adopting the LEU foil target}

Throughout the period of the CRP, KAERI had continued development efforts to enhance the quality of uranium foil produced using their cooling roll casting technology. KAERI also supplied uranium foils to Chile, Indonesia, Poland, Romania and the USA, and provided five preassembled targets for Libya.

The development work by the CRP team members engaged in LEU foil related work invariably involved using copper foil as a precursor study, followed by natural uranium foils. After these two 'dummies' were used, participants were able to use actual samples of LEU foil for target assembly and irradiation in 
some cases. Some participants resorted to cold rolling of the foils received from KAERI to reduce heterogeneity in their thickness, from an average thickness of $137.2 \mu \mathrm{m}$ (range 95-207 $\mu \mathrm{m}$ ) to an average thickness of $117 \mu \mathrm{m}$.

Some overall impressions and lessons learned from the CRP work on the LEU foil target should be pointed out:

- Foil fabrication at individual facilities will likely pose challenges in terms of having adequate technology and skill sets available. The infrastructure required for foil fabrication should not be underestimated.

- Assuming that the production of foil is not an option, choosing to work with foil targets requires securing supplies of foil from an industrial level source (with adequate competencies, QA systems, etc.) for successful adoption and propagation of this technology for ${ }^{99}$ Mo production; vendor development considerations merit attention, and the ability to test foils and control for quality are important.

- Safety analysis and regulatory oversight aspects (for reactor irradiation) would also be better addressed if a high degree of quality and reliability of foil targets can be assured from an industrial source.

- For most small scale producers, performing the necessary calculations required for safety analysis reports and regulators is challenge enough, even without considering the other steps that need to be undertaken in order to dissolve and purify their own molybdenum solution. Procuring preassembled targets would be the most expeditious route to setting up a small scale ${ }^{99} \mathrm{Mo}$ production capability; where this is not possible, procuring the component parts to assemble targets as needed would be the next best option.

- At the same time, some serious problems were encountered during the CRP in moving foils from producers to users due to uranium transport logistics. For example, during the CRP, the transport cost estimates received for shipping a few LEU foils to participants turned out to be prohibitively expensive, even though the quantity of uranium being shipped was only a few grams. While professional service providers are available for transporting nuclear and radioactive materials, their general overhead costs may be affordable only when considering bulk consignments of LEU targets. Therefore, cost and difficulty of transport of targets or target materials also needs to be taken into account when considering whether to make or buy targets.

- Similarly, for better management of QA aspects, prefabricated target assemblies that can be slipped into the rig for the calculated reactor position and for the correct time would appear to be an attractive option. The irradiation rig is reactor specific and requires licensing by local safety 
authorities, so internationally harmonized configurations of target holders will require safety analyses and regulatory approval.

\subsubsection{Investigation of alternate versions of $\mathrm{LEU}$ foil target}

Pakistan investigated an alternate target configuration in terms of what was described as an LEU foil plate target design (to produce $100 \mathrm{Ci}$ of ${ }^{99} \mathrm{Mo}$ at the end of irradiation in their reactor PARR-1). The LEU foil plate target selected had the following characteristics.

Uranium foil $\left(19.99 \%{ }^{235} \mathrm{U}\right)$ of $125 \mu \mathrm{m}$ thickness is enveloped in $15 \mu \mathrm{m}$ thick nickel foil and placed between two aluminium plates that are welded from all sides. The geometry of the foil plate target is shown in Fig. 22.

The foil plate target holder is made of reactor grade aluminium metal. It is a rectangular assembly, capable of holding three foil plates vertically and parallel to one other. Three aluminium plates along with two side plates provide the water channels for the cooling of the target plates. Target foil plates will be loaded in the slots of the target holder with the help of tongs while placing the target holder under water in a tray in open pool. At the top of the holder, two collars have

Al plate (upper)
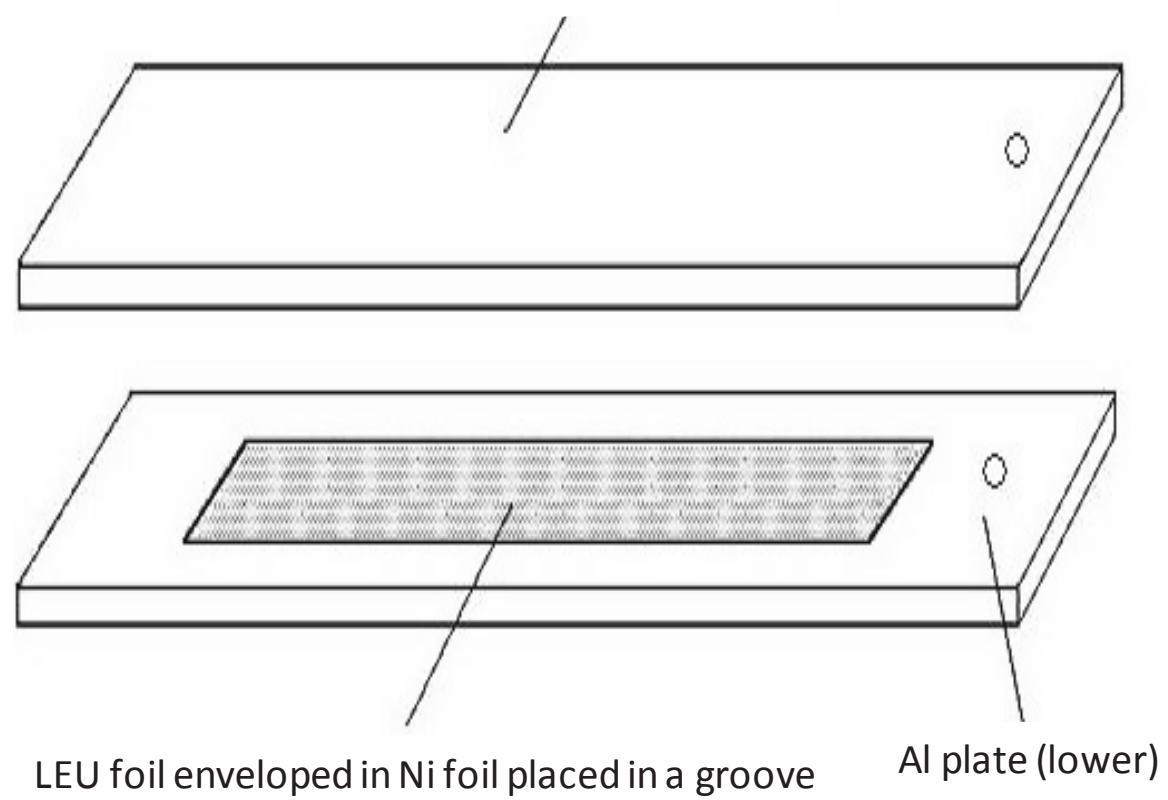

FIG. 22. The geometry of a foil plate target developed in Pakistan. 
been provided to attach it with stainless steel (SS) string of approximately $10 \mathrm{~m}$ which will be used for locking and hanging the target holder for loading in the water box. After loading the required foil plate target, the holder will be loaded into a water box for irradiation purposes. Details and dimensions of the foil plate target holder are depicted in Fig. 23. The main goals of such alternate options are to avoid the need to address certain known disadvantages of the annular foil assembly and yet reap the benefit of the high density of LEU foil as targets. When design and development is complete, this approach could enable the use of LEU foil in a dispersion plate type target configuration.

\subsection{DISPERSION PLATE LEU TARGET KNOW-HOW AND RELATED ASPECTS}

\subsubsection{General description of $L E U$ based $U A I_{X}$ dispersion targets}

This target type is manufactured to MTR fuel specifications by both AREVA/CERCA and CNEA. As a consequence, dispersion type targets are qualified to a high burnup (i.e. $>30 \%$ ). This burnup is typically more than three times that which a ${ }^{99}$ Mo production target experiences during irradiation.

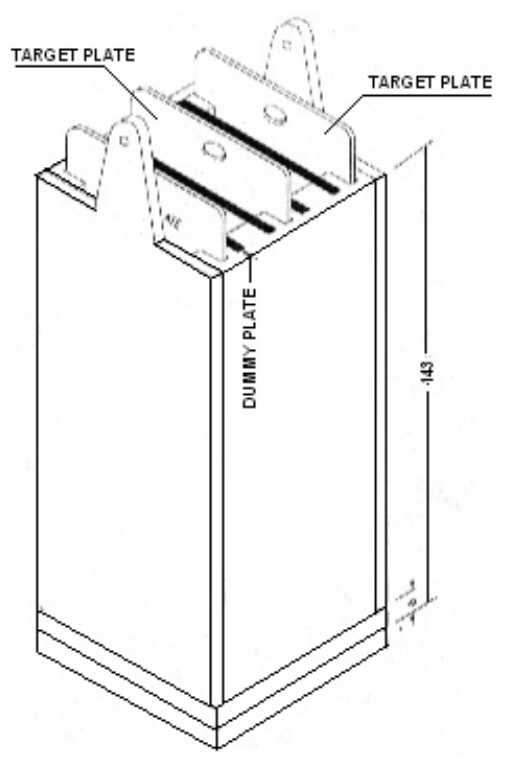

FIG. 23. LEU foil plate target holder developed in Pakistan. Figure courtesy of PINSTECH. 
As mentioned above, the $\mathrm{UAl}_{2}$ dispersion target nomenclature is synonymous with the $\mathrm{UAl}_{\mathrm{X}}$ dispersion target. LEU dispersion target fabrication begins with $\mathrm{LEU} \mathrm{UAl}_{2}$ particles matrixed with pure aluminium powder. The $\mathrm{UAl}_{2}$ to $\mathrm{UAl}_{3} / \mathrm{UAl}_{4}$ phase transformation is inherent to the fabrication process used to manufacture the targets. The various steps of the fabrication process convert all $\mathrm{UAl}_{2}$ to $\mathrm{UAl}_{3} / \mathrm{UAl}_{4}$. As an example, a finished target may consist of $60 \mathrm{wt} \% \mathrm{UAl}_{3}$ and $40 \mathrm{wt} \% \mathrm{UAl}_{4}$. The actual fractions of $\mathrm{UAl}_{3}$ and $\mathrm{UAl}_{4}$ in a finished target will vary from manufacturer to manufacturer depending on the processes and heat treatments that are used in fabricating the powder, core compacts and target plates.

The uranium density of an LEU based dispersion target is in the range of $2.5-3.0 \mathrm{~g} / \mathrm{cm}^{3}$. In the past, many thousands of HEU based dispersion targets have been safely irradiated and processed by Covidien/Mallinckrodt, IRE, and NTP Isotopes to produce ${ }^{99} \mathrm{Mo}$ of high quality and purity.

ETRR-2 (Egypt) will irradiate and process LEU based dispersion plate targets manufactured by CNEA. An LEU based dispersion target manufactured by CNEA is shown in Fig. 24.

Pakistan is considering using an LEU based dispersion target in the future. Pakistan currently fabricates and uses HEU based UAl alloy targets to produce ${ }^{99} \mathrm{Mo}$ for its domestic needs which are estimated to be approximately $150 \mathrm{Ci}(5.6 \mathrm{TBq})$ at EOB. In Pakistan, the UAl alloy targets are processed using

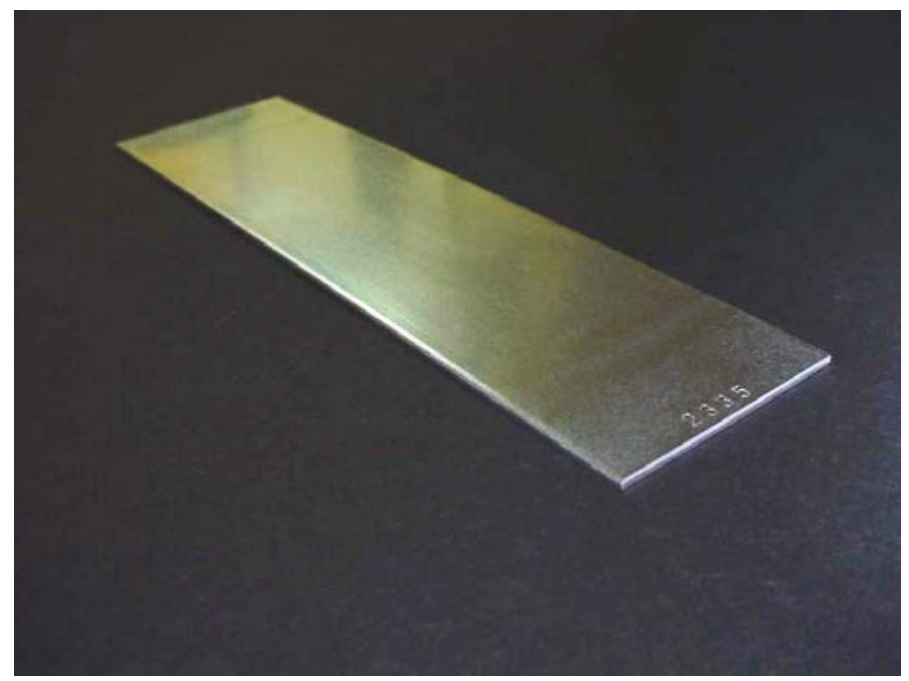

$F I G$. 24. CNEA's LEU aluminium dispersion targets. These targets have been used since 2002 to produce ${ }^{99} \mathrm{Mo}$ in Argentina. The ETRR-2 target is $13.0 \mathrm{~cm}$ in length and $3.5 \mathrm{~cm}$ in width. The thickness of the target is $1.4 \mathrm{~mm}$. Photograph courtesy of CNEA. 
the alkaline based ROMOL process developed by GSG, and PINSTECH has the technology and manufacturing capability to produce LEU based dispersion targets. As an element of their overall HEU to LEU conversion programme strategy, Pakistan has been evaluating the use of LEU foil targets and the LEU modified Cintichem process as an option for ${ }^{99}$ Mo production in the future. Pakistan's progress towards conversion was demonstrated during the period of this CRP.

LEU based $\mathrm{UAl}_{\mathrm{X}}$ dispersion plate targets are currently being irradiated on a routine basis to produce ${ }^{99} \mathrm{Mo}$ in Argentina (RA-3), Australia (OPAL) and South Africa (SAFARI-1). AREVA/CERCA is currently manufacturing LEU based $\mathrm{UAl}_{\mathrm{X}}$ dispersion targets for NECSA. ANSTO has successfully used LEU based $\mathrm{UAl}_{\mathrm{X}}$ dispersion plate targets supplied by both AREVA/CERCA and CNEA. Both Covidien and IRE plan to transition to this LEU based target type as they continue to move forward with their HEU to LEU conversion programme.

The commercial availability of dispersion plate target technology, as well as of finished product LEU target plates, combined with proven operating experience accumulated over the previous several years (for example, by CNEA during participation in the CRP) would render this approach attractive for centres seriously considering an early entry into production of ${ }^{99} \mathrm{Mo}$.

\subsection{PLANNING FOR AND PERFORMING IRRADIATION OF LEU TARGETS IN REACTORS}

Any irradiation of LEU targets for production of ${ }^{99} \mathrm{Mo}$ must be preceded by thorough calculations, to ensure the safety and success of the irradiation. Individual reactors must perform these calculations based on their own core configurations and reactor power and flux. Key parameters for target irradiation include the power developed in the target due to the fission process and temperatures on the target in thermohydraulic conditions existing in the irradiation device. The emphasis in doing the calculations is to ensure that the heat generated due to fission of ${ }^{235} \mathrm{U}$ will not lead to unacceptably high temperatures, that the forced cooling arrangement is adequate, and also that no reactivity issues will be created. Naturally, this phase of development required extensive collaborations; scientific visits, training on calculations and software, and review of completed calculations, and was a feature of this phase of CRP work.

The following temperatures are very important from safety point of view for target irradiation under cooling conditions inside the irradiation device:

- Temperature on the aluminium target inner surface;

- Temperature on the aluminium target outer surface;

- Uranium foil central temperature. 
All these parameters were evaluated starting from the boundary conditions. The analysis was intended to show the influence of gap size on temperatures in uranium foil and near the interface between aluminium and water. Power levels in foil targets and their corresponding irradiation times were initially determined by neutronic analysis, in order to ensure that the required neutron fluence was achieved. Finally, the thermohydraulic analysis was carried out for the proposed design of the target holder using LEU foil targets for fission ${ }^{99}$ Mo production. The main parameter of interest for these calculations was the maximum temperature gained when the reactor was in operation at its full power level (e.g. at $10 \mathrm{MW}$ ). The general conclusion from CRP participants was that the irradiation rig proposed for LEU foil targets would fulfil all the thermohydraulic requirements.

Power density in uranium foil is dependent on the neutron flux $\left(5 \times 10^{13}\right.$ to $\left.2 \times 10^{14} \mathrm{n} \cdot \mathrm{cm}^{-2} \cdot \mathrm{s}^{-1}\right)$ and the energy released per fission, namely $G_{f}=180 \mathrm{MeV} /$ fission. For example, in the case of the TRIGA reactor in Pitesti, Romania, the power density calculated was $16.448 \mathrm{~kW} / \mathrm{cm}^{3}$ and the total on the target was approximately $8 \mathrm{~kW}$. In this case, the positive reactivity induced by the irradiation device and target is $0.43 \Delta \mathrm{K}$ and this positive reactivity is caused mainly by aluminium displacement of the water moderator rather than by the uranium foil itself. The irradiation of LEU foil in the RECH-1 reactor in Chile in an irradiation rig with a thermal neutron flux of $8.0 \times 10^{13} \mathrm{n} \cdot \mathrm{cm}^{-2} \cdot \mathrm{s}^{-1}$ over 48 hours generates $7440 \mathrm{~W}$, which is $3720 \mathrm{~W}$ on each face of the uranium foil. The maximum wall temperature on the target surface will be nearly $89^{\circ} \mathrm{C}$ on the inner face (cf. wall temperature for onset of nuclear boiling is $124^{\circ} \mathrm{C}$ ); this is acceptable from the reactor safety point of view.

A horizontal gap must be maintained between the ends of the foil to facilitate the longitudinal cut of the outer aluminium tube in order to recover the irradiated uranium foil for chemical processing (see Fig. 6 for an example of this horizontal gap in the foil). From a thermal point of view, this unheated gap region provides an asymmetrical temperature gradient.

Also, because the uranium foil thickness varies, calculations needed to be performed that assume a hypothetical uniform gap exists between the Ni foil and uranium foil. For example, Romania assumed hypothetical gaps of $0.003 \mathrm{~mm}$ and $0.005 \mathrm{~mm}$ in their calculations. A uniform gap is not credible. This is because after inserting the foil between the inner and outer aluminium, the tubes are drawn to obtain good thermal contact.

There was extensive use of codes among participants, which involved external expertise in the computational work and verification. For heat transfer computations, RELAP5 was used; for activation calculations, ORIGEN-S code from the SCALE 5 system was used by the participants. 
A summary of achievements in adopting LEU based target development is presented in Tables $2-8$ by country and facility. Their calculation work is also described in detail in each country report in the annexes.

\subsection{SUMMARY OF LEU TARGET RELATED ACHIEVEMENTS OF THE CRP TEAMS}

The basic elements of ${ }^{99}$ Mo production target development include:

- Performance of neutronics calculations to determine the theoretical yield of ${ }^{99} \mathrm{Mo}$ at EOB and target power (i.e. heat generated) during irradiation. See Tables 3-5.

- Performance of thermohydraulic calculations to determine if the targets can be adequately cooled during irradiation. See Tables 6-8.

- Fabrication of a target draw die assembly device (Fig. 16(a) and (b)). This is applicable for the assembly of foil targets only.

- Evaluation of target assembly procedure and technique by assembling mock targets that use a material other than LEU as a surrogate for the foil component of the target. This activity includes the development of a leak test method to verify the integrity of the welded ends of the targets. Again, this is applicable for the assembly foil based targets only.

- Design and fabrication of the irradiation rig that is used to position the targets in the reactor.

- Manufacture of the actual targets for irradiation and chemical processing.

\section{PROCESS AND PURIFICATION OF MOLYBDENUM-99}

\subsection{INTRODUCTION}

After LEU targets have been irradiated, they must be chemically dissolved and processed in order to extract the molybdenum produced through irradiation. This Section will detail the processing of the target after it is removed from the reactor, cooled and disassembled, and the steps involved in the dissolution and further processing. 


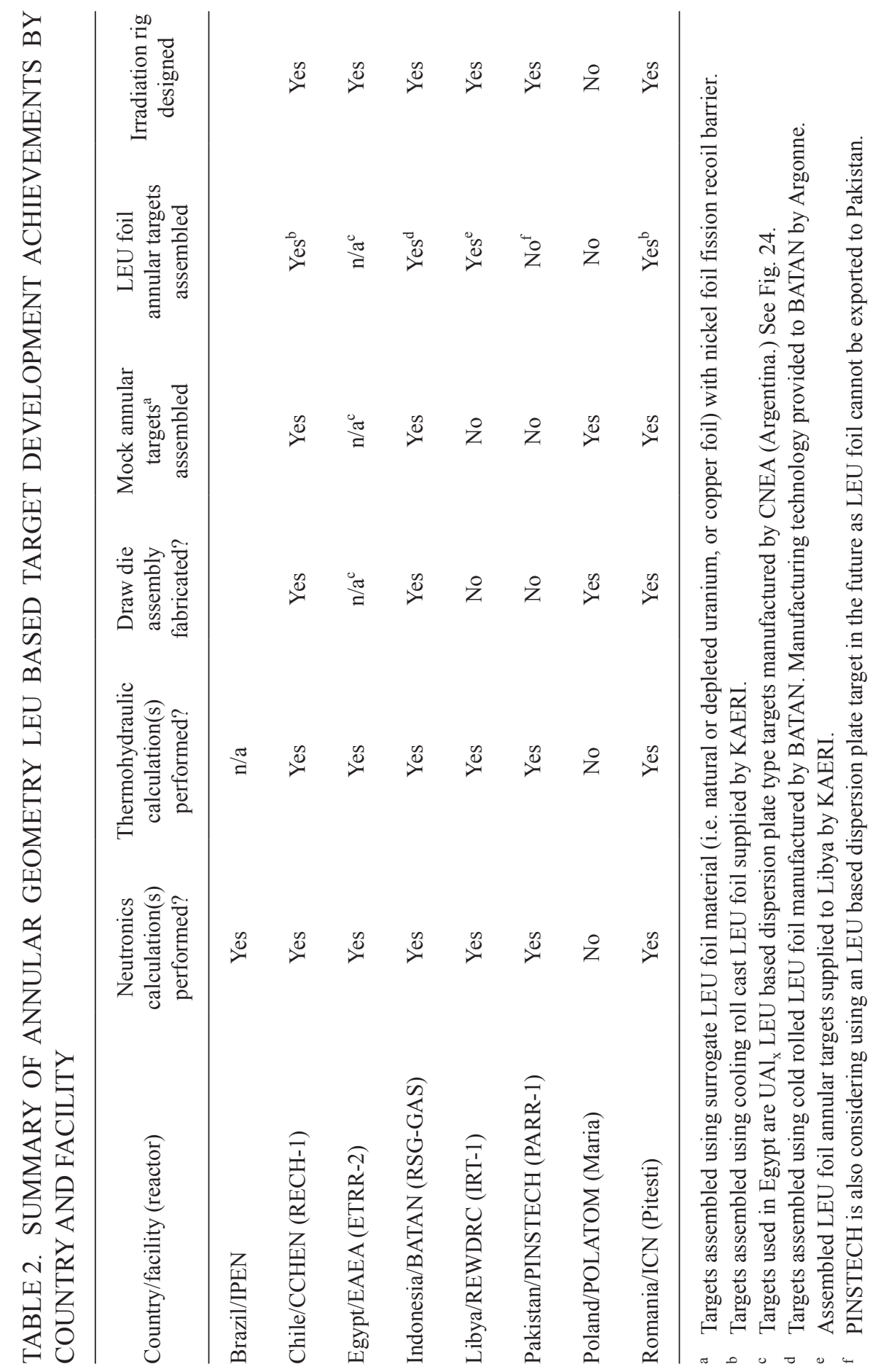




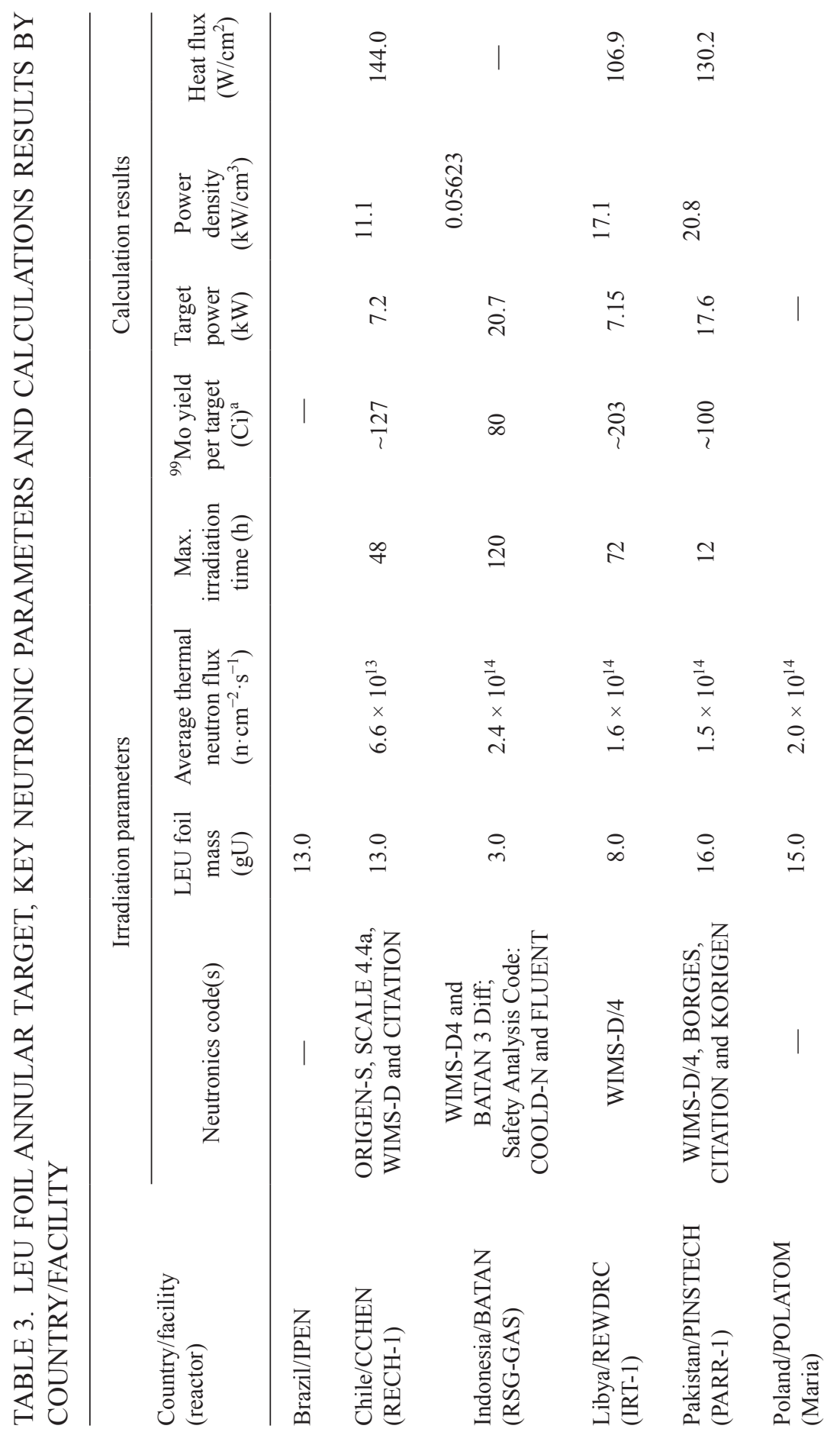




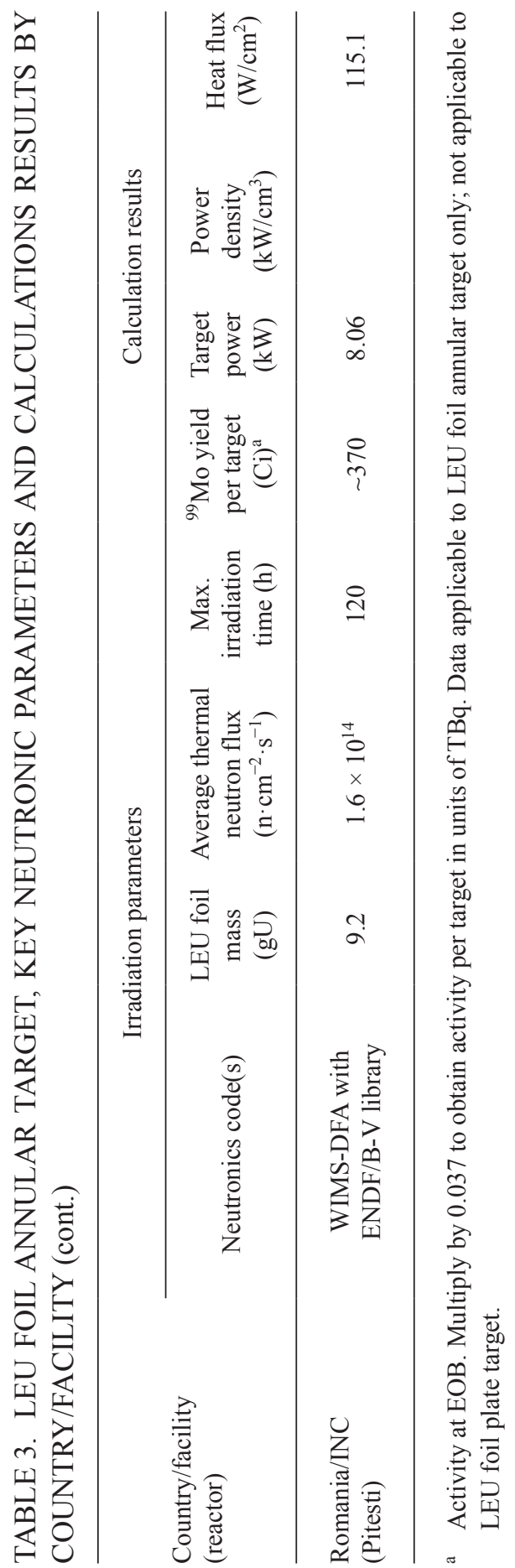




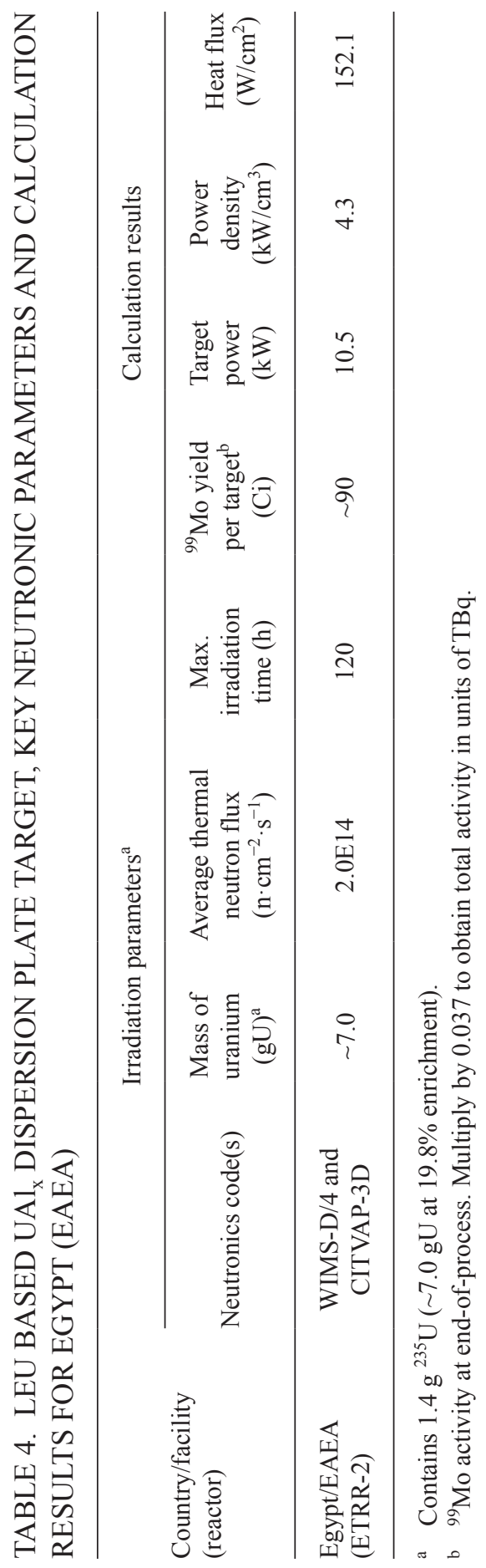




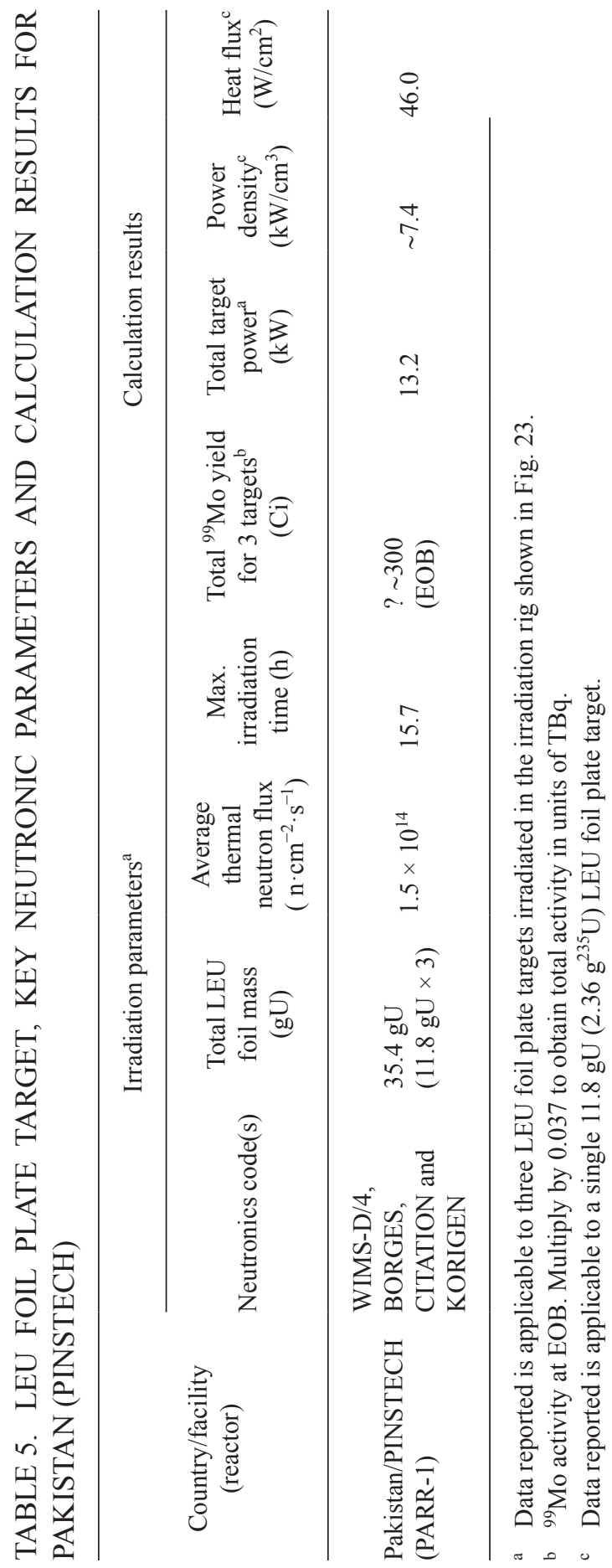




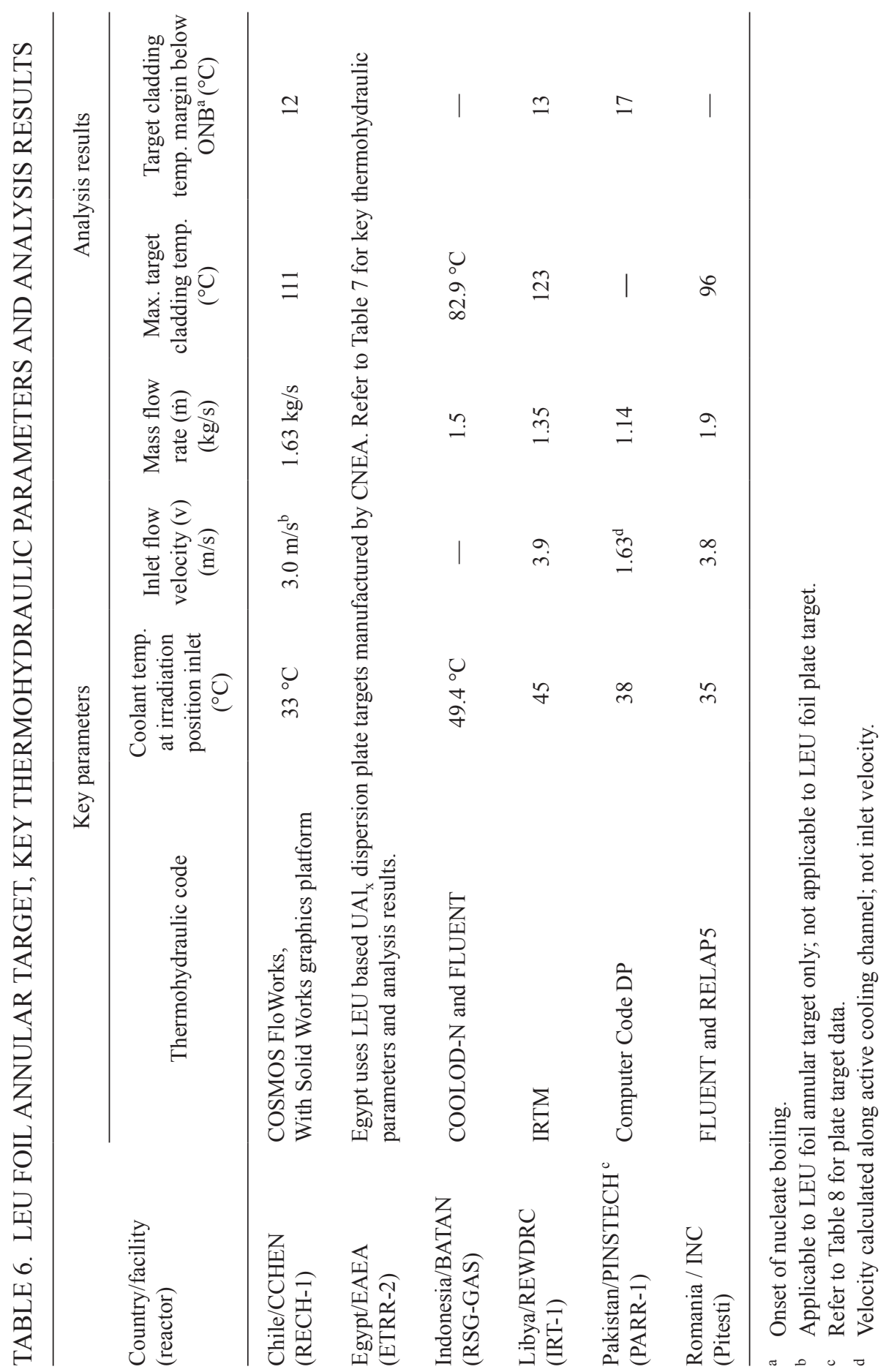




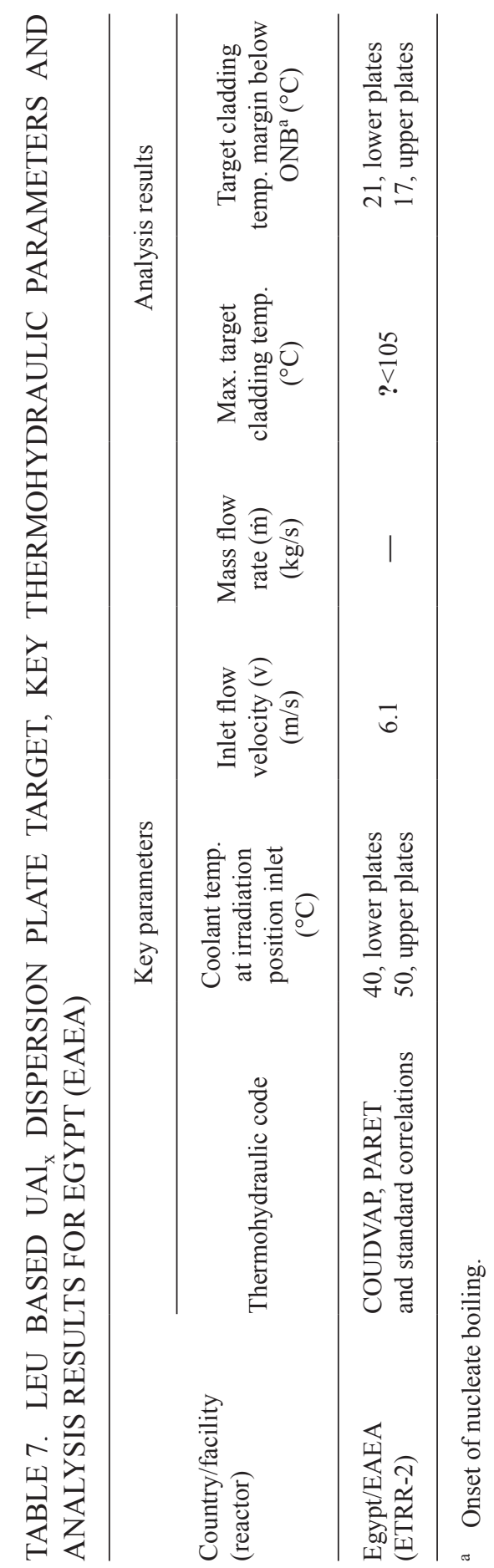




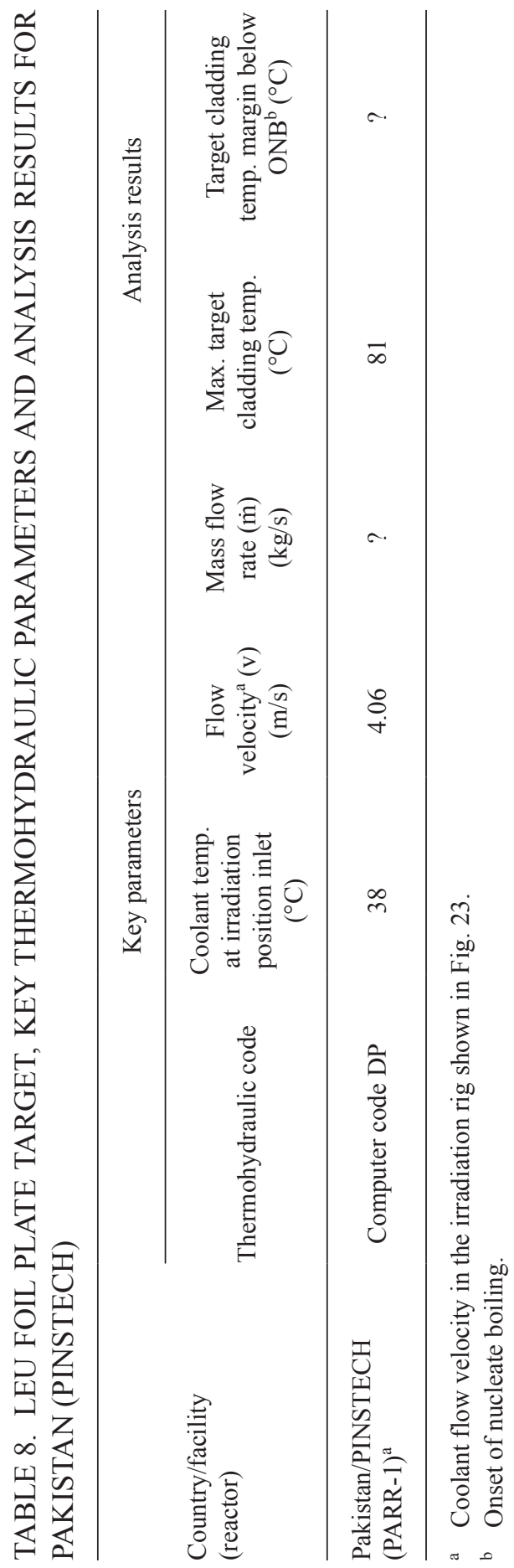


The LEU modified Cintichem process technology was made available to participants, and some of them (Brazil, Chile, India, Indonesia, Pakistan, Poland, Romania) performed several studies examining the optimization of process parameters, such as dissolution, Mo precipitation, column purification and the effect of impurities in each step. For this purpose the studies employed cold materials, radioactive tracers and irradiated LEU foil targets. For small scale producers, the LEU modified Cintichem process is a viable alternative.

Two of the observers in the CRP - INVAP, from Argentina and GSG from Germany - offer commercial scale process and purification technology and hardware, and they were able to provide expertise to participants on processing technologies and issues to keep in mind.

\subsection{LEU FOIL TARGETS: LEU MODIFIED CINTICHEM PROCESS}

\subsubsection{Description of the process}

The first producer of fission based ${ }^{99}$ Mo was Union Carbide; the company used a $5 \mathrm{MW}$ research reactor at the Cintichem facility in New York. The method used to produce ${ }^{99} \mathrm{Mo}$ at this facility employed targets comprised of stainless steel vessels with HEU oxide electroplated on the inside wall of the target. The process was developed from 1968 to 1972 and produced ${ }^{99}$ Mo on a routine basis until 1989. A total of eight processing batches of one to four targets per batch during two days each week generated greater than $1500 \mathrm{Ci}$ per week. The maximum batch size was approximately $1000 \mathrm{Ci}$ of ${ }^{99} \mathrm{Mo}$ at the time of separation ( 200 6-day $\mathrm{Ci}$ per batch). Process yield was consistently 90\%. Cintichem Inc. was the single producer of ${ }^{99}$ Mo in the USA during the 1980s. However, in 1989, tritium contamination of surface waters adjacent to the reactor site was confirmed and led to the reactor's shutdown and decommissioning, putting an end to the commercial production of ${ }^{99} \mathrm{Mo}$ in the USA.

The original Cintichem chemical process can be seen in Fig. 25.

Cintichem Inc. dissolved the target in a mixture of nitric and sulphuric acid and then ${ }^{99} \mathrm{Mo}$ was precipitated with $\mathrm{ABO}$. After filtration, the precipitate was dissolved in a diluted $\mathrm{NaOH}$ solution. This precipitation step could be repeated using an oxidant agent such as permanganate. Further purification was performed by contacting the ${ }^{99}$ Mo solution with adsorbents such as silver coated charcoal and inorganic ion exchangers (zirconium oxide) and activated charcoal. 


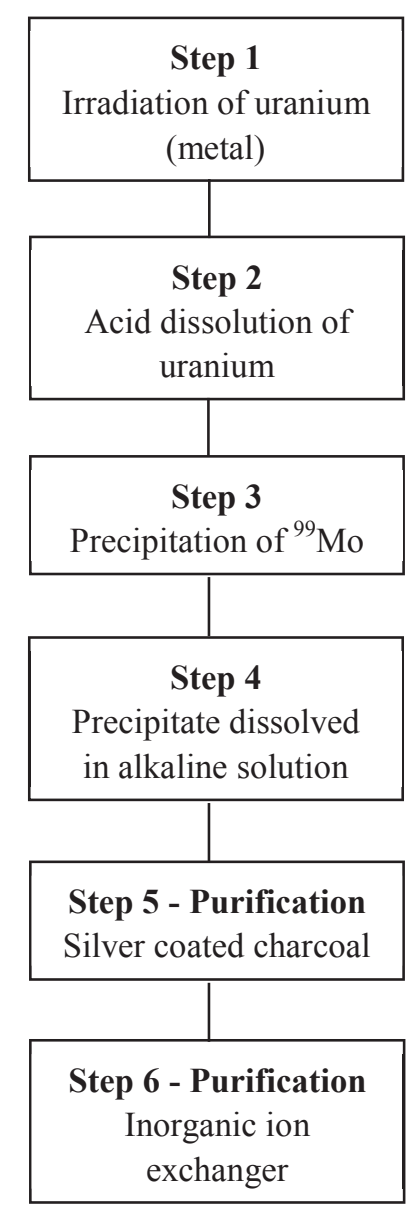

FIG. 25. Original Cintichem process.

ANL developed the LEU modified Cintichem process in cooperation with Indonesia's BATAN. Modifications were made both to allow the use of irradiated LEU foil annular targets and also to substitute nitric acid for sulphuric acid throughout the process to afford easier radioactive waste treatment and disposal.

ANL and BATAN's LEU modified Cintichem chemical process can be seen in Fig. 26. 


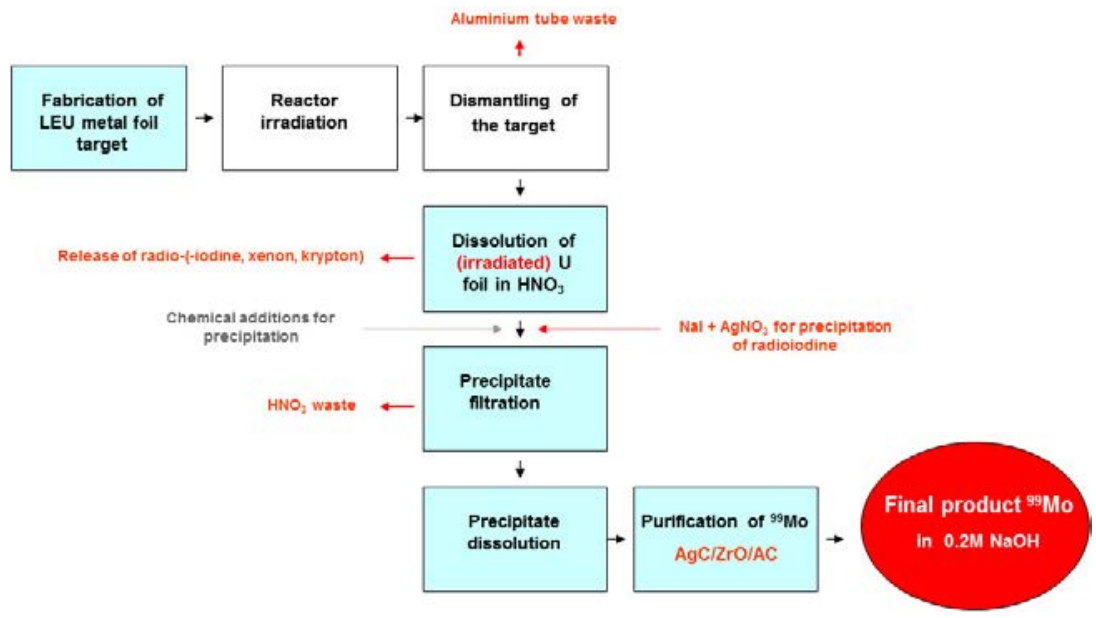

FIG. 26. LEU modified Cintichem process.

The LEU modified Cintichem process can be split into four steps:

(1) Disassembling of irradiated LEU foil target;

(2) Target dissolution;

(3) ${ }^{99}$ Mo separation and purification;

(4) Quality control.

In steps (1)-(3), there are procedures to be followed to deal with the radioactive waste.

\subsubsection{Disassembly of irradiated LEU foil targets}

To disassemble the annular target, both of its ends are cut off, and a longitudinal cut is made over the length of the target. The outer tube is then pulled away from the inner tube, allowing release of the foil between them. This is achieved using a remotely operated cutting tool specifically designed for this purpose, shown in Figs 27 and 28.

Several cutting tool prototypes were suggested and assembled by the CRP members. The first machine was assembled by ANL and can be seen in Figs 29-34. As part of the project, ANL transferred this technology to other CRP participants. Based on the ANL design, other participants designed and manufactured their own cutting devices. These are shown in Figs 35-42. 


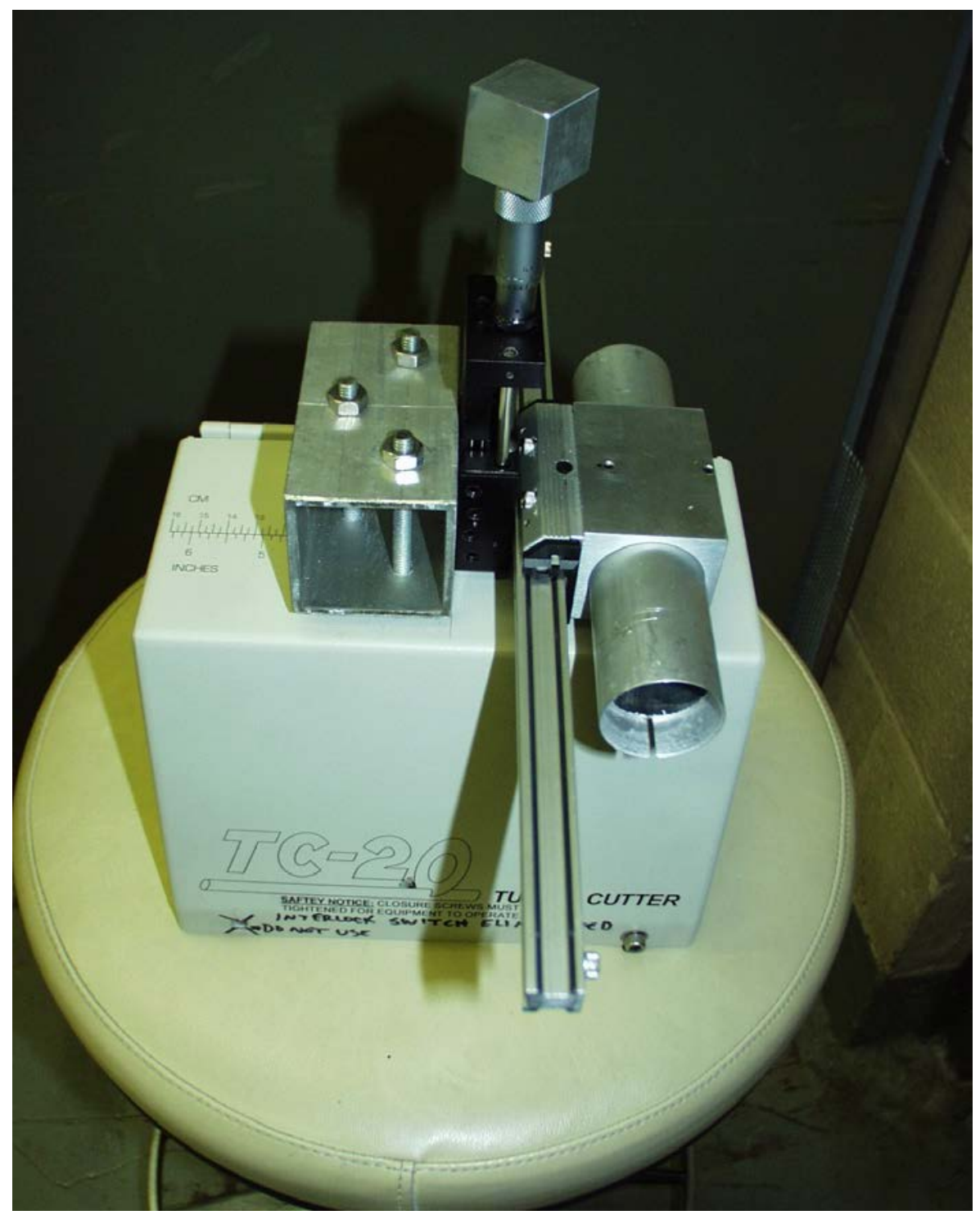

FIG. 27. Remote target cutter. Photograph courtesy of ANL. 


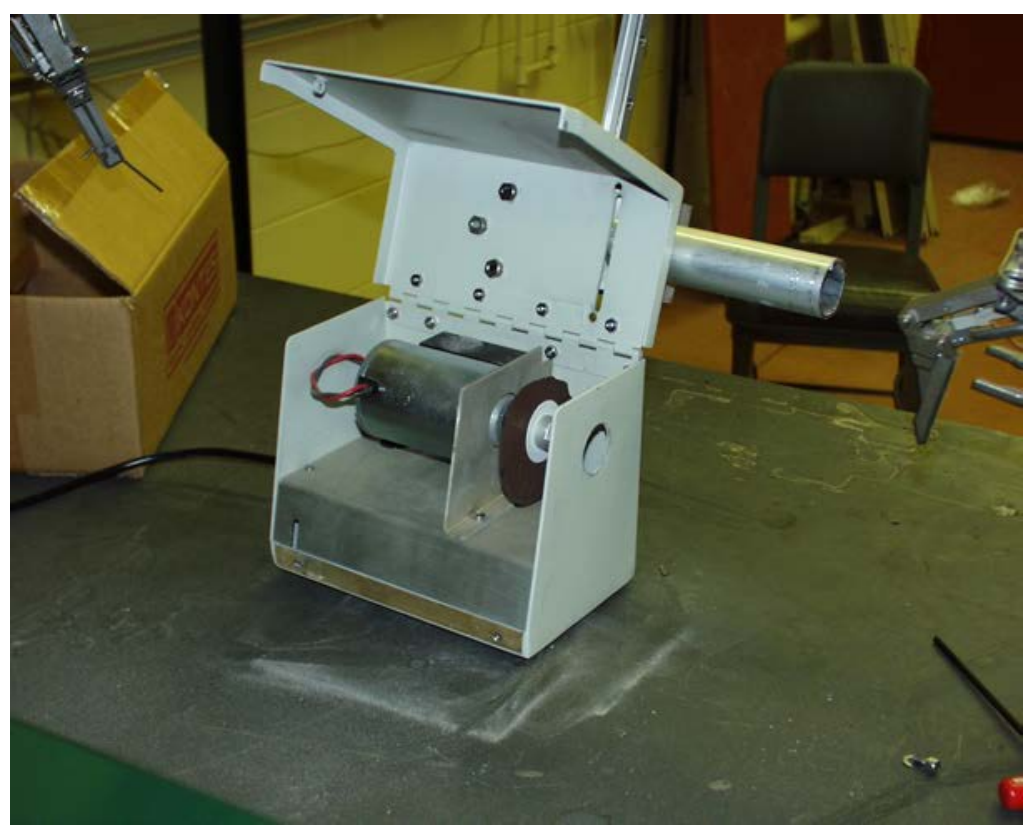

FIG. 28. Remote target cutter. Photograph courtesy of ANL.

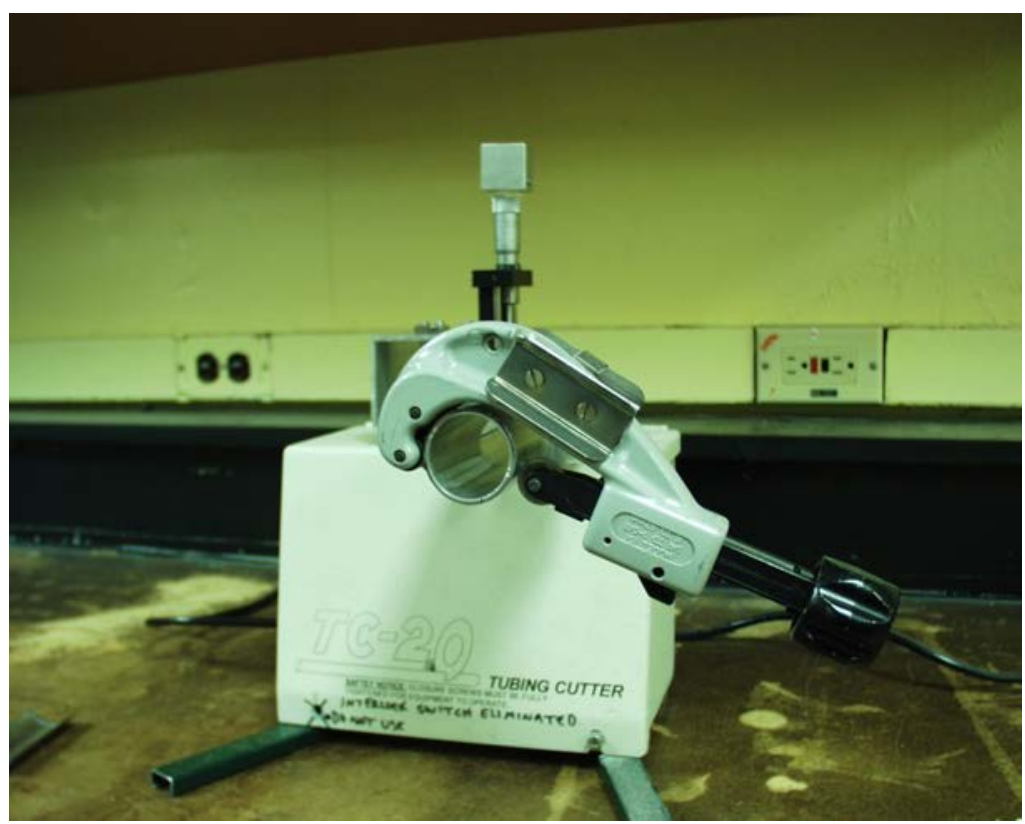

FIG. 29. Manual pipe cutter for making cuts at the ends of the target. Photograph courtesy of $A N L$. 


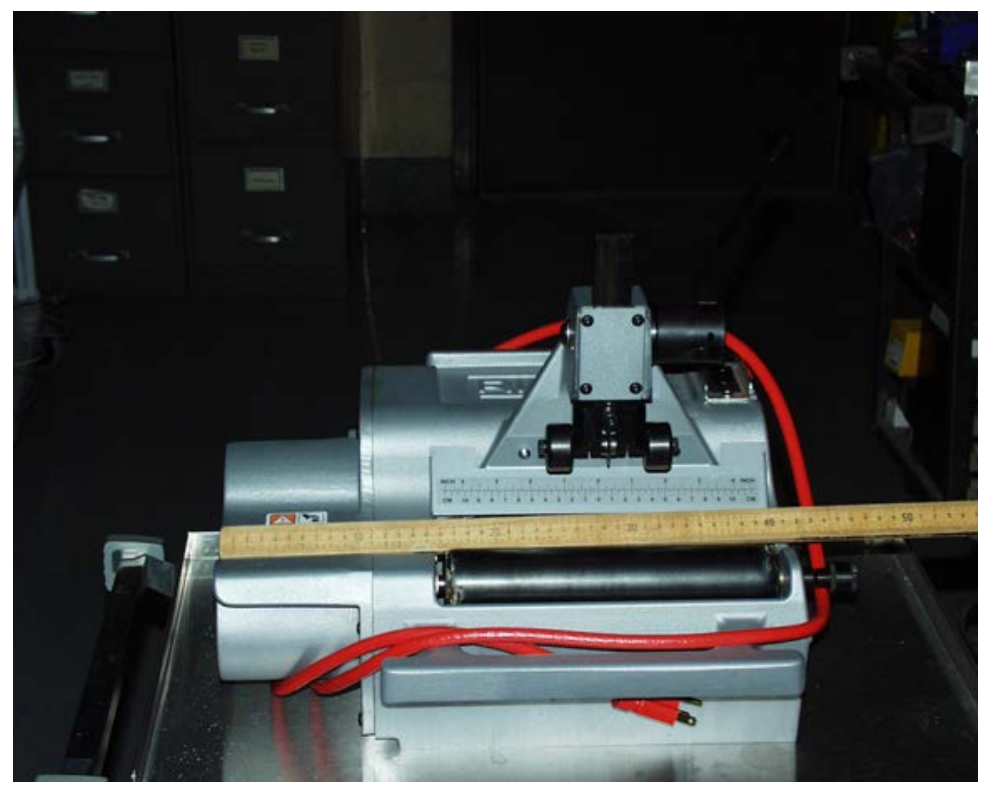

FIG. 30. Power tube cutter for making cuts at the ends of the target. Photograph courtesy of $A N L$.

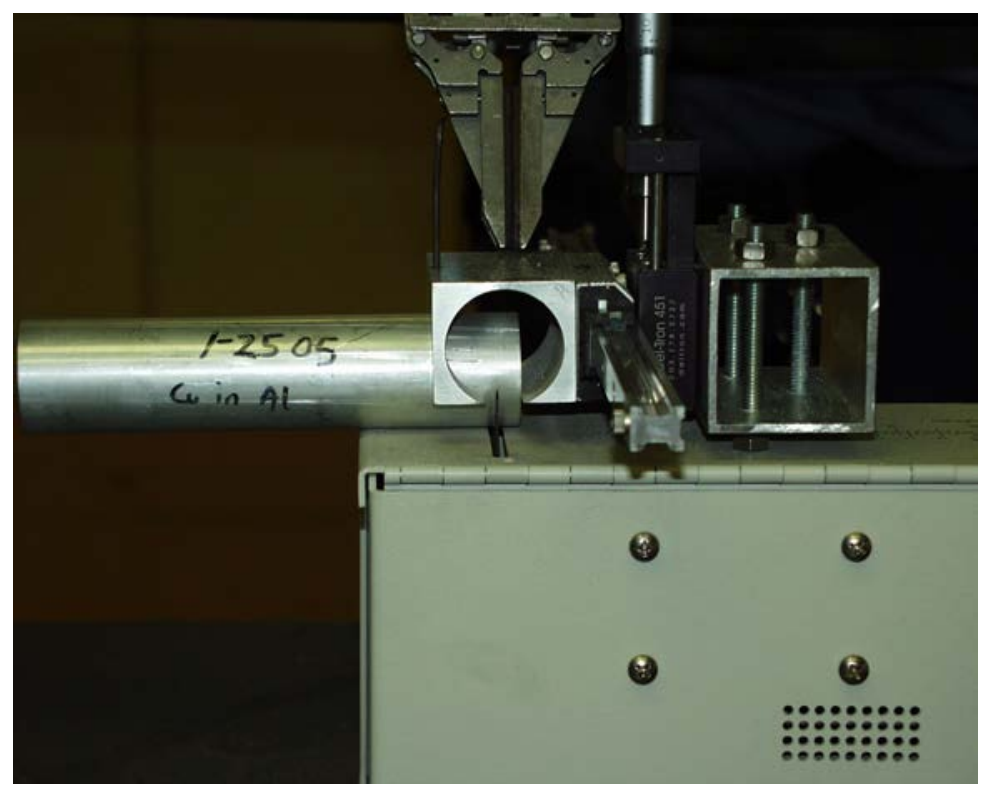

FIG. 31. Remote target cutter for making cuts at the ends of the target. Photograph courtesy of $A N L$. 


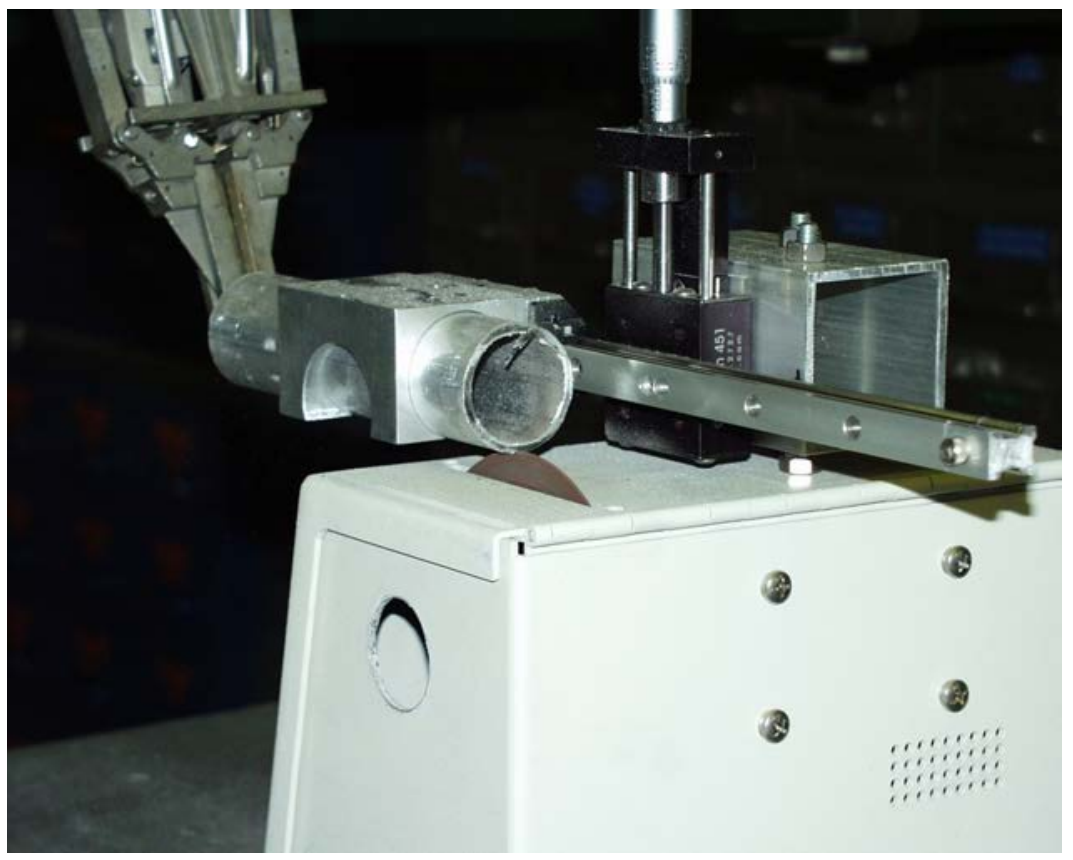

FIG. 32. The remote target cutter used to make the longitudinal cuts. Photograph courtesy of $A N L$.

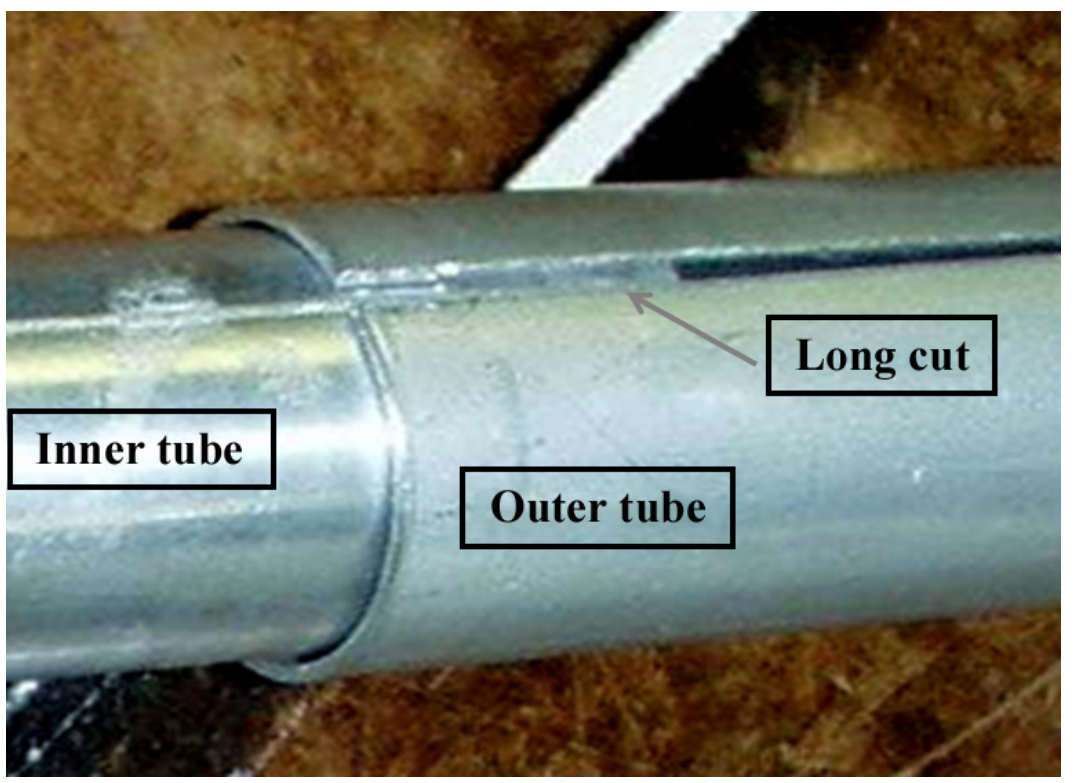

FIG. 33. Target after the longtitudinal cut has been performed. Photograph courtesy of ANL. 


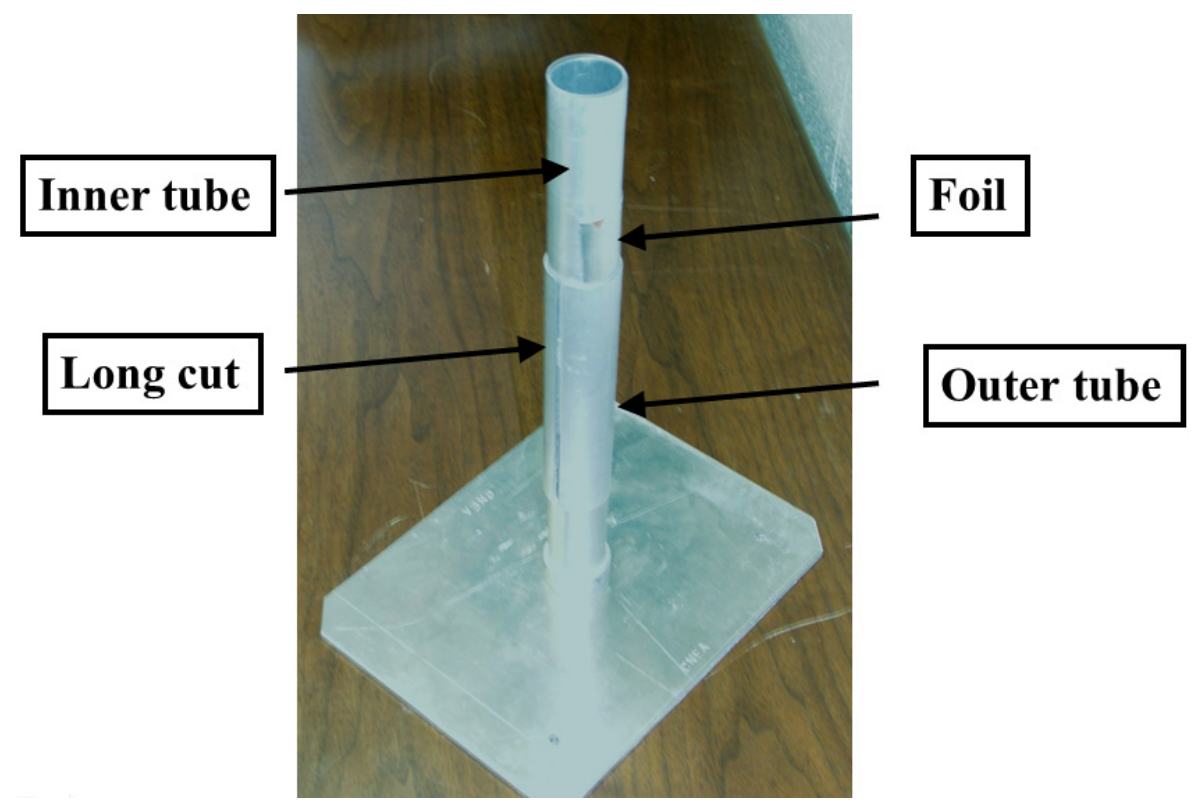

FIG. 34. Separated tubes after target disassembling. Photograph courtesy of ANL.

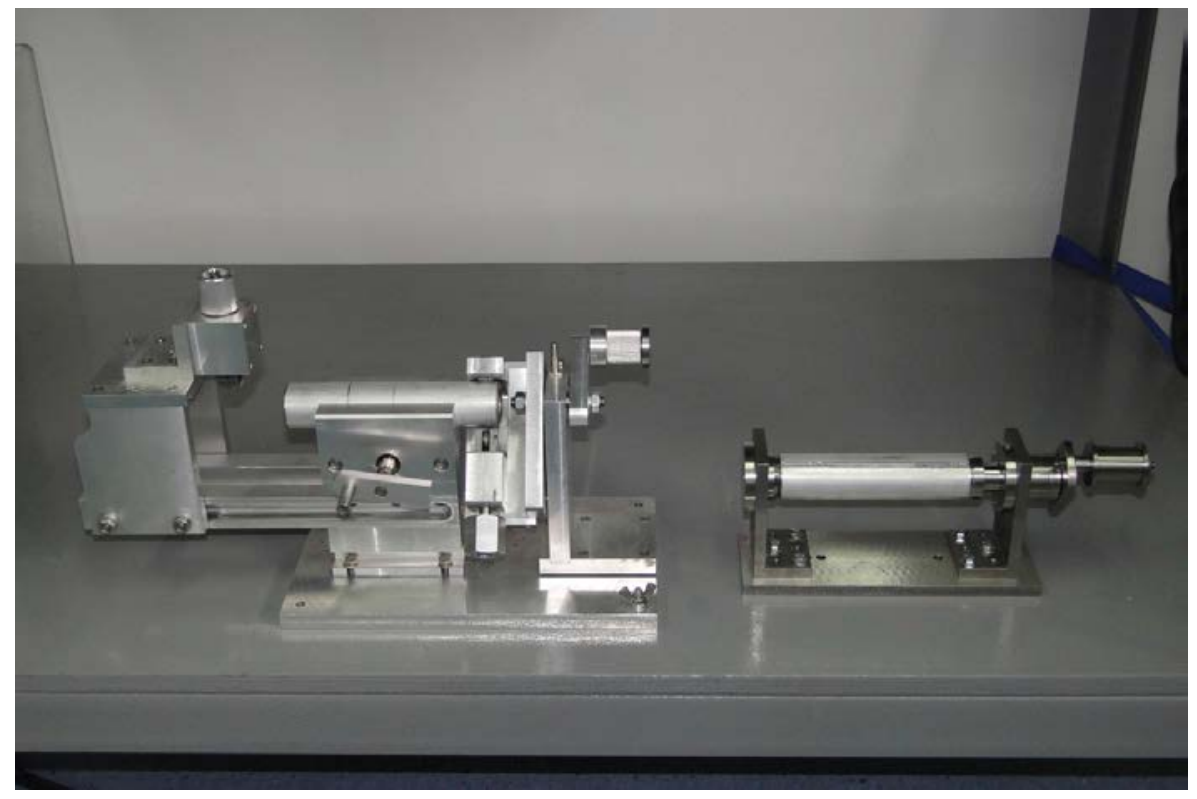

FIG. 35. Target disassembly prototype used in Poland. 


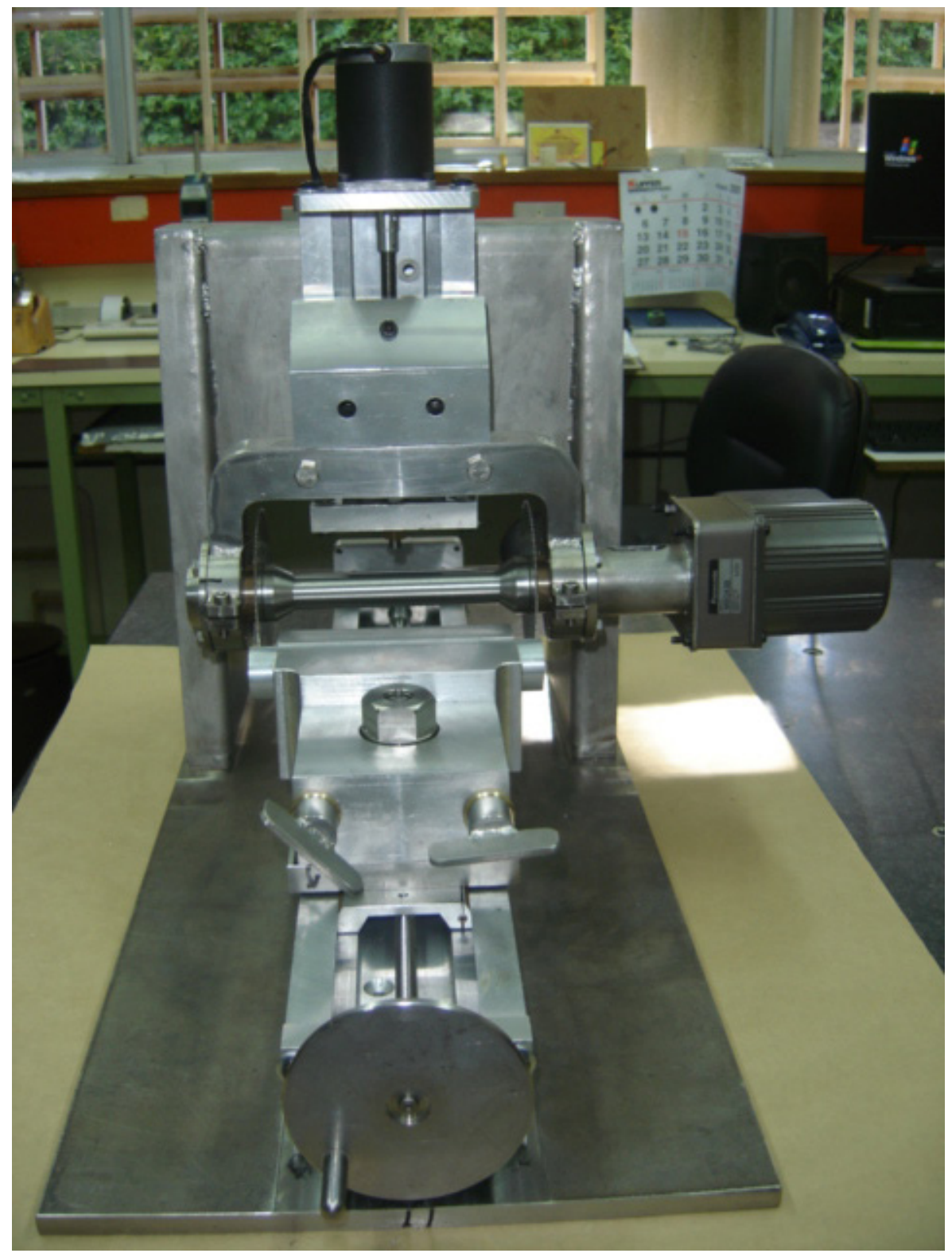

FIG. 36. Target disassembly device used in Chile. 


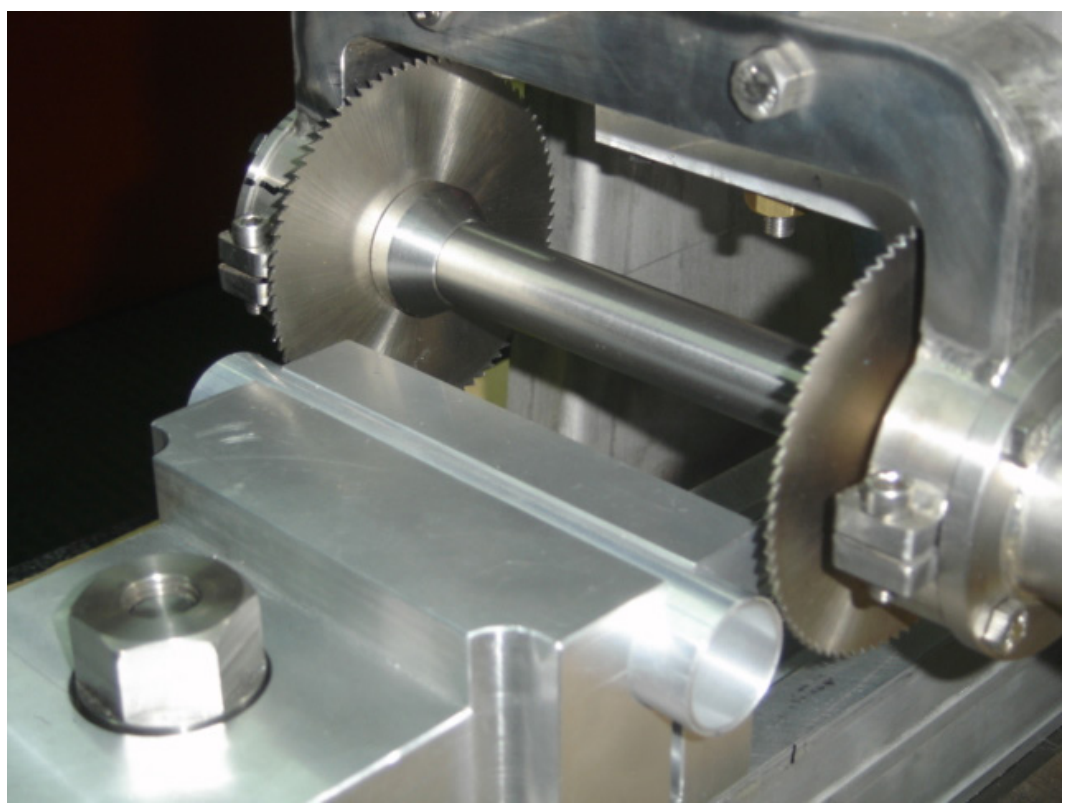

FIG. 37. Target disassembly device used in Chile.

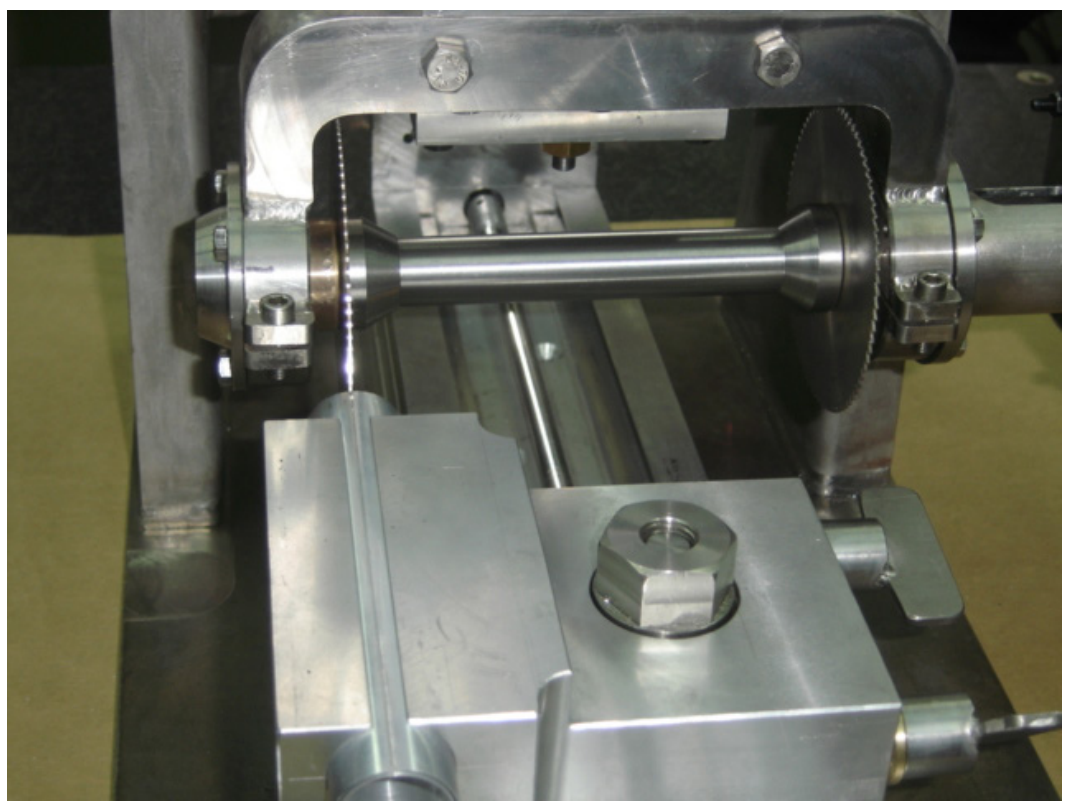

FIG. 38. Target disassembly device used in Chile. 


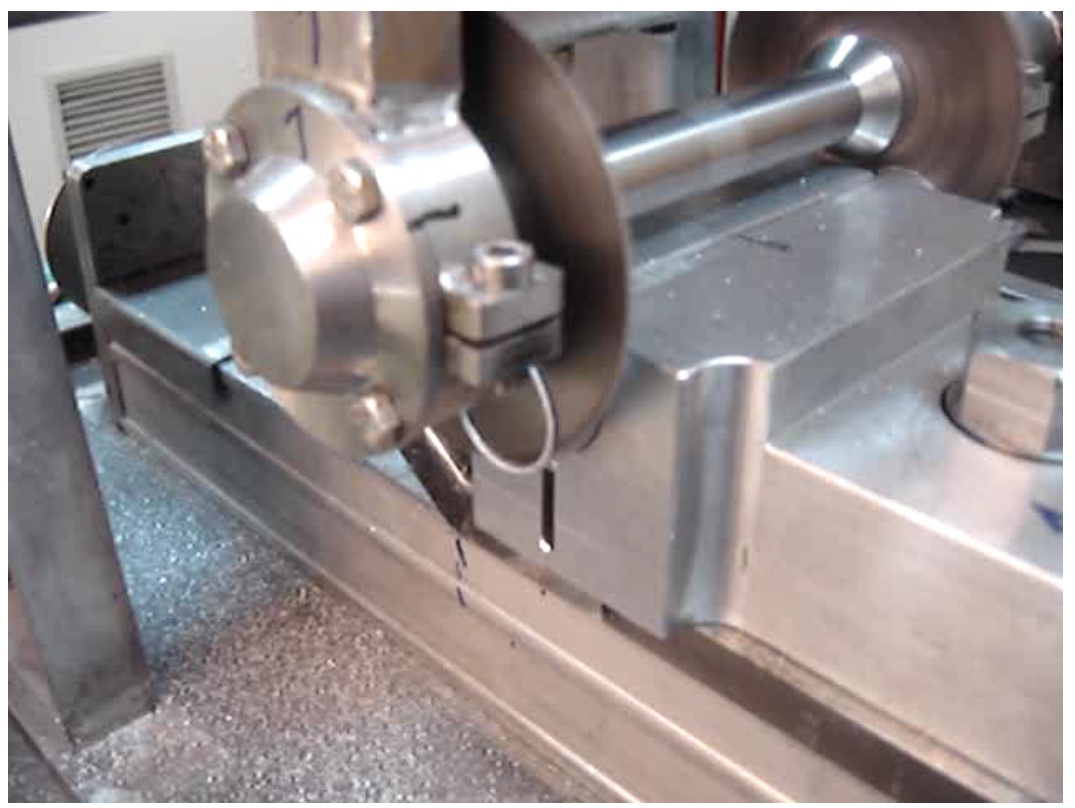

FIG. 39. Target disassembly device used in Chile.

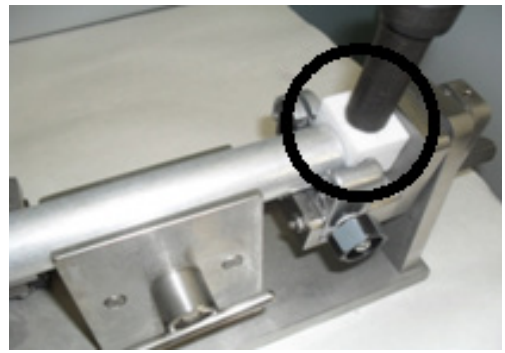

FIG. 40. Special tool to determine the edges of the LEU target during the disassembling, Libya.

The participants from Libya disassembled targets using a special cutter supplied by ANL, and manufactured their own attachment for determining where the edges of the target were during disassembly (Fig. 40, encircled). Another piece of equipment used only in Libya was manufactured for the purpose of the expansion of the sheared longitudinal tube, shown in Fig. 41.

MURR also proposed a new disassembly device shown in Fig. 42. 


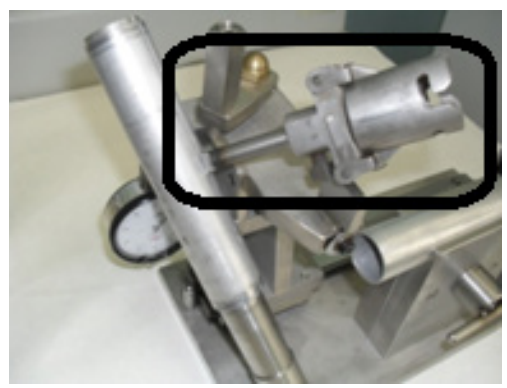

FIG. 41. Tool to expand the sheared longitudinal tube of the target, Libya.

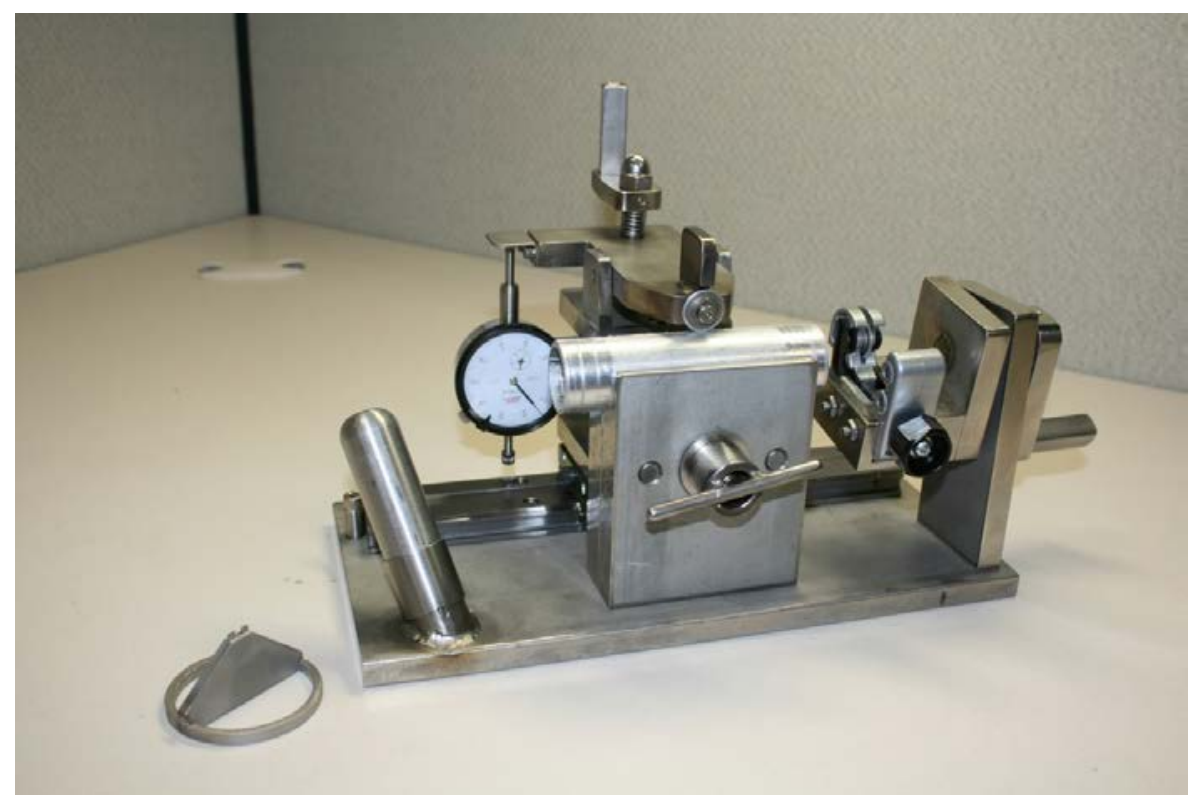

FIG. 42. New disassembly device from MURR.

\subsubsection{Dissolution}

After the foil is removed from the cladding, it is dissolved in nitric acid. Both components of the target material - the uranium foil and the nickel recoil barrier - are dissolved. The concentration of the initial nitric acid is calculated so that the final solution will be $1 \mathrm{M}$ nitric acid. The dissolver is a closed unit so that reaction and fission gases are captured; several atmospheres of pressure are developed during dissolution. After the uranium is dissolved, the gases are pulled from the dissolver using a cold trap immersed in nitric acid. This evacuation 
procedure essentially removes all of the noble fission gases and most of the iodine; a small fraction of the $\mathrm{NO}_{\mathrm{x}}$ gases from the dissolution is also present in the dissolver solution. Once the solution is drained from the dissolver, the dissolver is rinsed with $1 \mathrm{M}$ nitric acid. The dissolver solution can contain up to $500 \mathrm{~g} \mathrm{U} / \mathrm{L}$.

The overall reaction for uranium foil dissolution using nitric acid alone is:

$$
\mathrm{U}+4 \mathrm{HNO}_{3} \rightarrow \mathrm{UO}_{2}\left(\mathrm{NO}_{3}\right)_{2}+2 \mathrm{H}_{2} \mathrm{O}+2 \mathrm{NO}(\uparrow)
$$

This reaction is very similar to that for mixtures of nitric acid and sulphuric acid, except that the uranyl ion now forms a nitrate salt rather than a sulphate salt. In particular, the moles of NO gas generated per mole of uranium foil dissolved are the same. Thus, the final dissolver pressure will be the same for the same mass of uranium. Because there is no sulphuric acid in the dissolver solution, the moles of $\mathrm{HNO}_{3}$ consumed per mole of uranium dissolved are doubled, from two to four.

The use of $10 \mu \mathrm{m}$ metal barriers between the uranium foil and the container walls is necessary because the uranium foil bonds to the container walls owing to fission recoil during irradiation. The barrier metal will be bonded to the uranium foil and has to be dissolved. The overall dissolution reactions for metal barriers of $\mathrm{Cu}$ and $\mathrm{Ni}$, and $\mathrm{Fe}$ using nitric acid alone, are:

$$
\begin{aligned}
& \mathrm{Cu} / \mathrm{Ni}+8 / 3 \mathrm{HNO}_{3} \rightarrow \mathrm{Cu} / \mathrm{Ni}\left(\mathrm{NO}_{3}\right)_{2}+4 / 3 \mathrm{H}_{2} \mathrm{O}+2 / 3 \mathrm{NO}(\uparrow) \\
& \mathrm{Fe}+4 \mathrm{HNO}_{3} \rightarrow \mathrm{Fe}\left(\mathrm{NO}_{3}\right)_{3}+2 \mathrm{H}_{2} \mathrm{O}+\mathrm{NO}(\uparrow)
\end{aligned}
$$

ANL designed and developed an LEU foil dissolver that was provided to several members of the CRP. The dissolver is shown in Figs 43-45.

In a process demonstration in Indonesia, up to $18 \mathrm{~g}$ of uranium were dissolved in $40 \mathrm{~mL}$ of $6 \mathrm{M}$ nitric acid at $\sim 105^{\circ} \mathrm{C}$ with this dissolver device. Complete dissolution of typical foil target meat takes 20-30 min.

Poland performed dissolution studies using rods of natural metal uranium in an apparatus constructed at ANL. The mock-up dissolver solutions were prepared by dissolving a number of natural metal uranium samples in the mass range from $13-18 \mathrm{~g}$ in $40 \mathrm{~mL}$ of nitric acid at approximately $140^{\circ} \mathrm{C}$. Initial nitric acid concentration was calculated to obtain $1 \mathrm{M}$ final concentration of $\mathrm{HNO}_{3}$. The dissolution time was approximately 100 min. During dissolution, the pressure was measured in time intervals of approximately 5 min until a stable value in the range of 965-1654 $\mathrm{kPa}$ was achieved. 


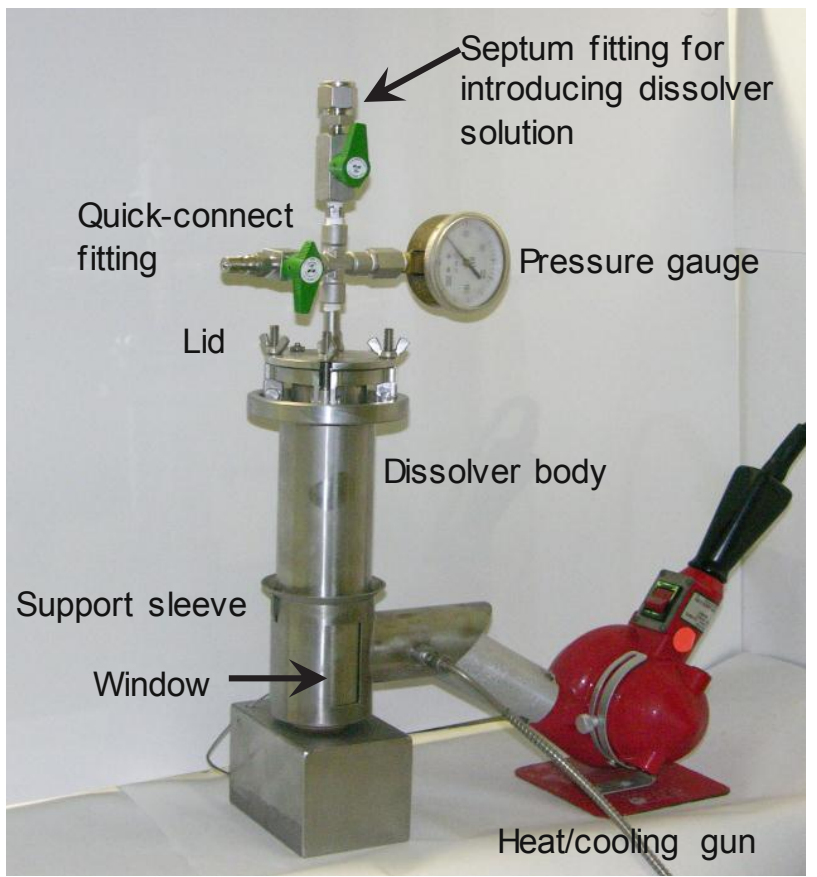

FIG. 43. Dissolver for the LEU modified Cintichem process. Photograph courtesy of ANL.

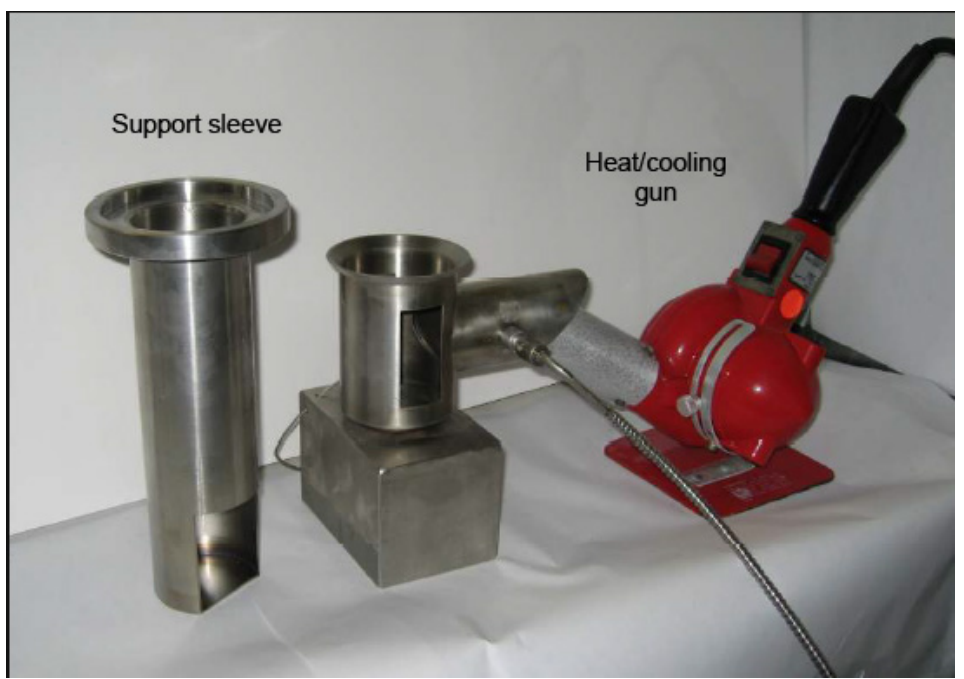

FIG. 44. Dissolver for LEU modified Cintichem heater and support. Photograph courtesy of $A N L$. 


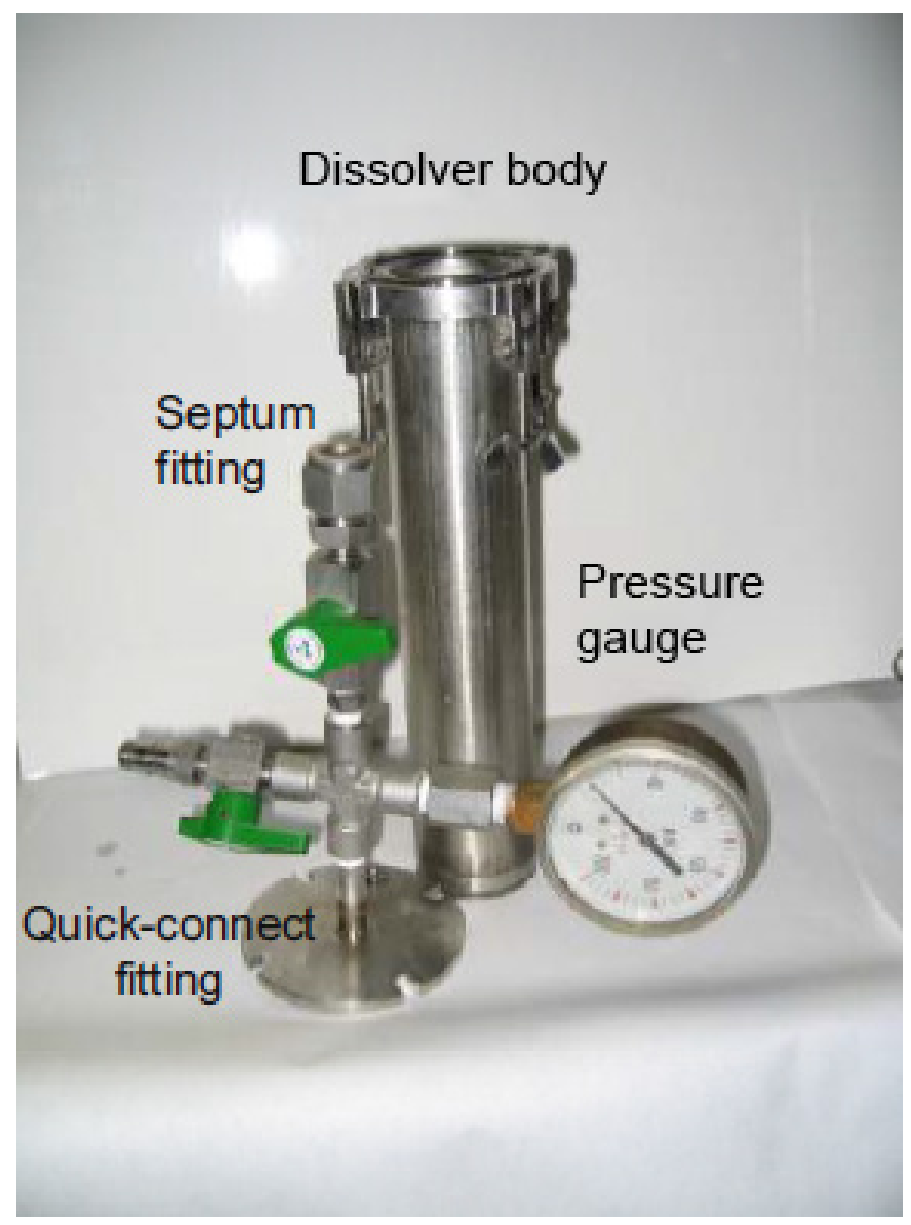

FIG. 45. Dissolver body and lid for LEU modified Cintichem. Photograph courtesy of ANL.

Romania proposed a modification to the dissolver as shown in Figs 46 and 47.

A foil containing $10 \mathrm{~g}$ of LEU was dissolved using this apparatus and the time for complete dissolution was maximum $15 \mathrm{~min}$ followed by a decompression for $20 \mathrm{~min}$.

ANL recently designed a nitric acid dissolution system with the capacity to dissolve up to $250 \mathrm{~g}$ of irradiated LEU target material at near ambient pressure in order to provide a reliable and safe technology to replace the current HEU processes being used by large scale ${ }^{99}$ Mo producers. The main design criteria for this new system are: 


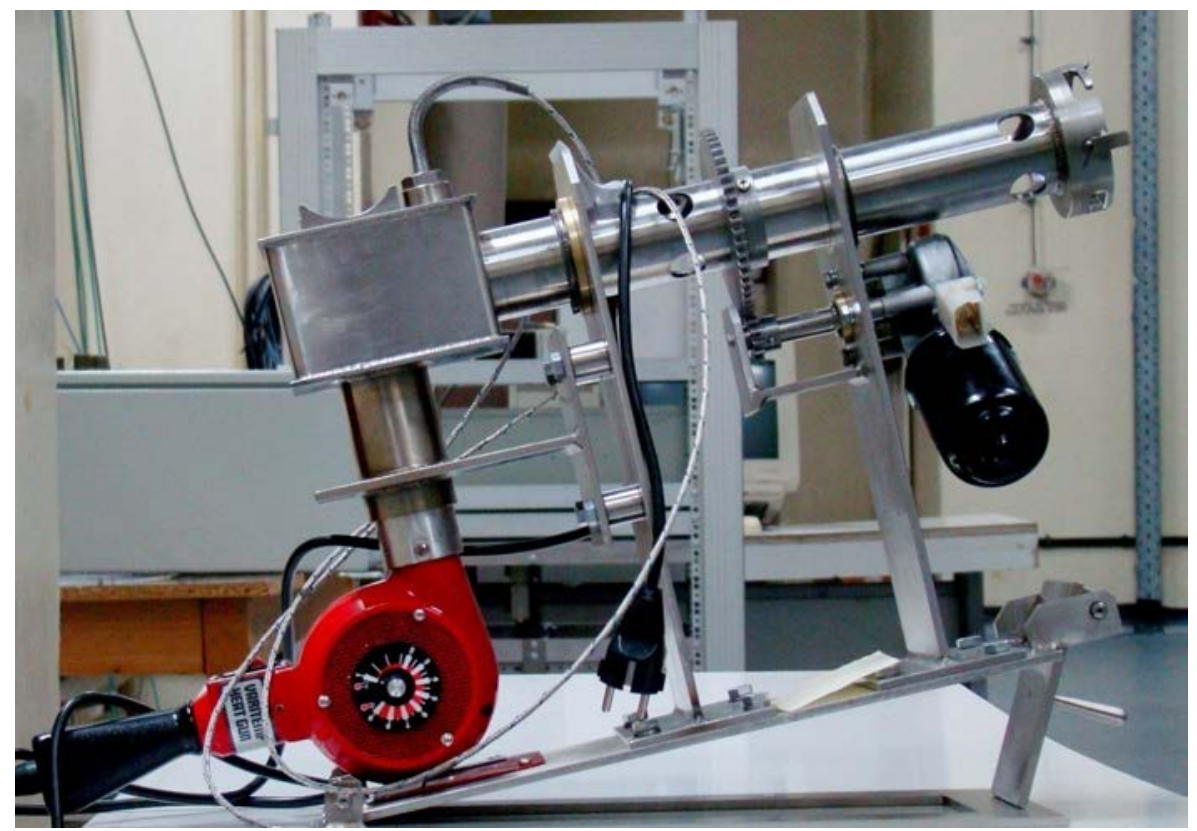

FIG. 46. System built in Romania for positioning, rotary motion and heating of the dissolver.

- Water vapour, reaction products, and fission gases must be contained within the dissolver system at a maximum temperature of $125^{\circ} \mathrm{C}$ and pressure of $203 \mathrm{kPa}$ (absolute) under both normal and off-normal (loss of cooling) conditions.

- To ensure efficient reflux of dissolver solution (minimize loss of acidity), the LEU foil heat of dissolution $(1600 \mathrm{~kJ})$ and continuous decay heat $(\sim 5800 \mathrm{~kJ} / \mathrm{hr})$ must be dissipated by a reliable coolant system at the maximum design temperature $\left(125^{\circ} \mathrm{C}\right)$.

- The acid feed system must be designed so that the thermally hot LEU can be immersed in acid without losing solution owing to instantaneous boiling.

- Gas trap components must be designed to trap or neutralize all nitrogen oxide and acid gases $\left(\mathrm{NO}, \mathrm{NO}_{2}, \mathrm{HNO}_{2}, \mathrm{HNO}_{3}\right)$, as well as to trap iodine for possible extraction of economically important isotopes (noble fission gases will be passively contained).

- Dissolver system components must be designed for remote operation in a hot cell. 


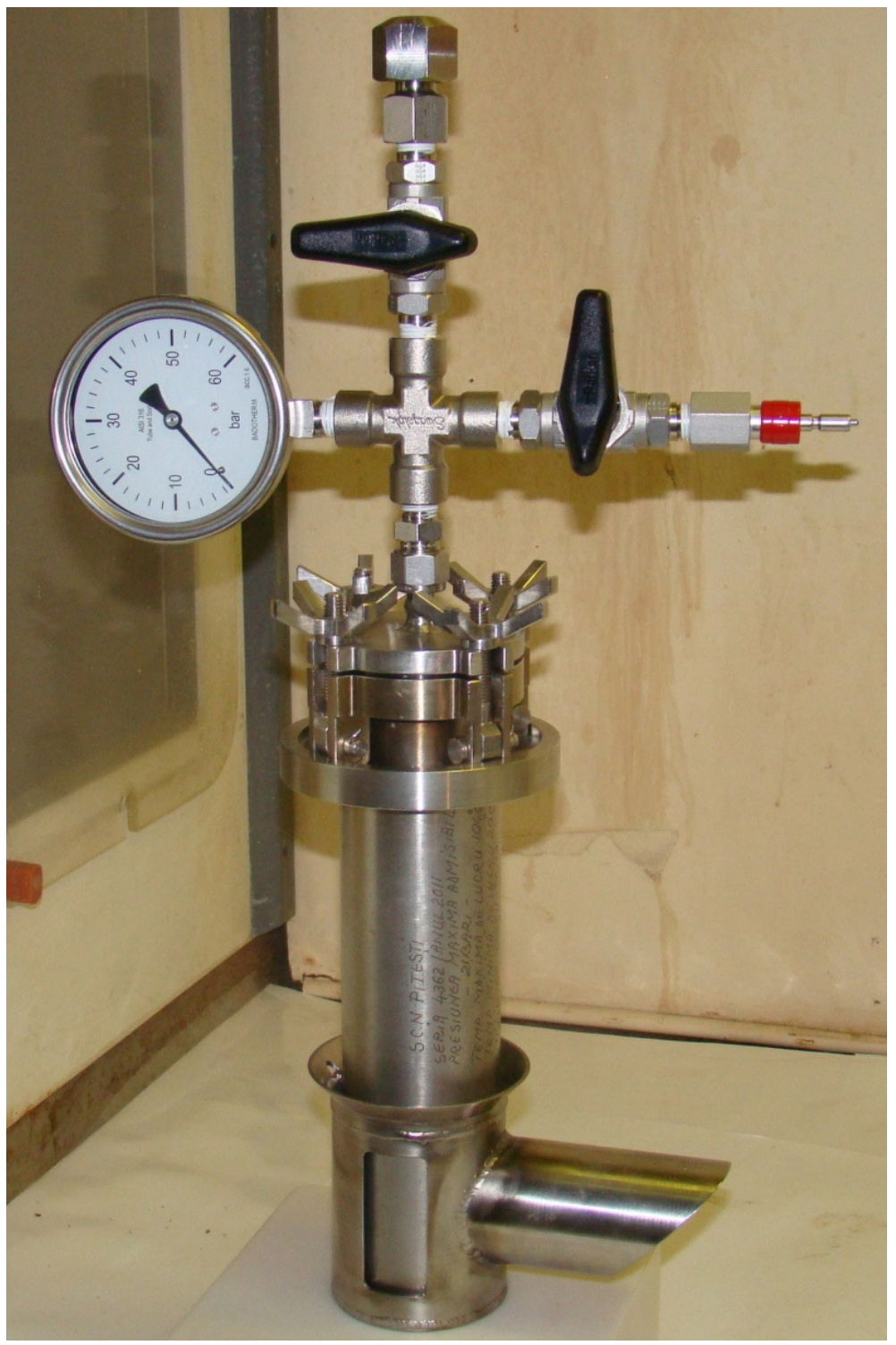

FIG. 47. New foil dissolver, Romania.

The conceptual design can be seen in Fig. 48 and the full scale prototype in Fig. 49. 


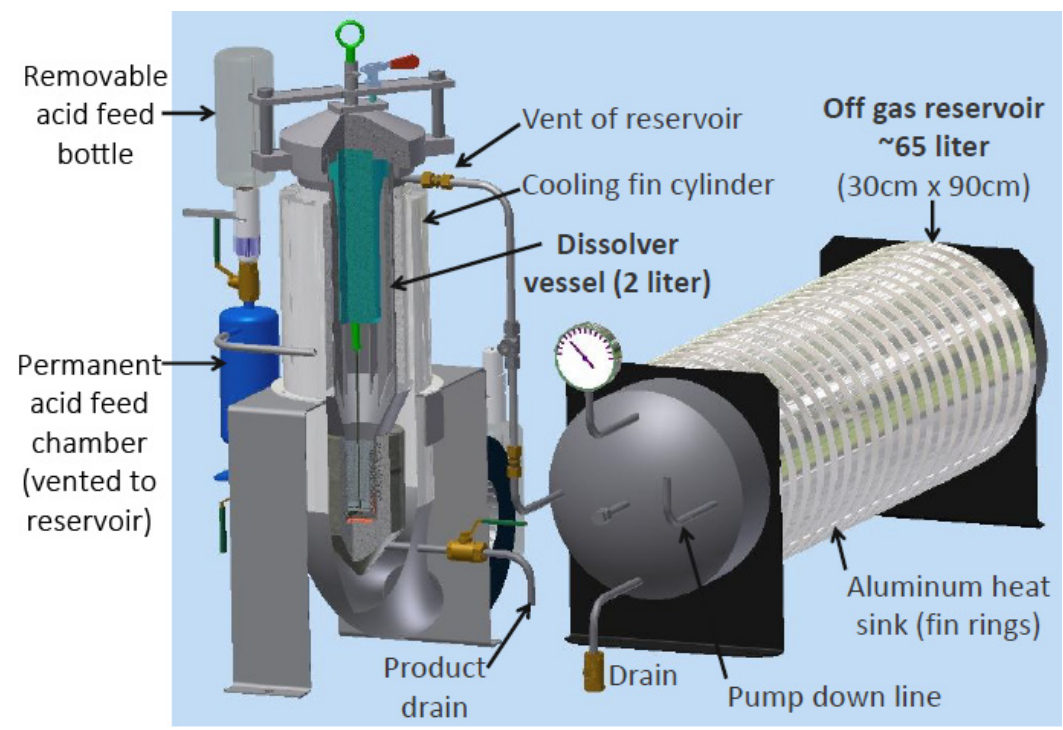

FIG. 48. Conceptual design of the high capacity dissolver developed by ANL.

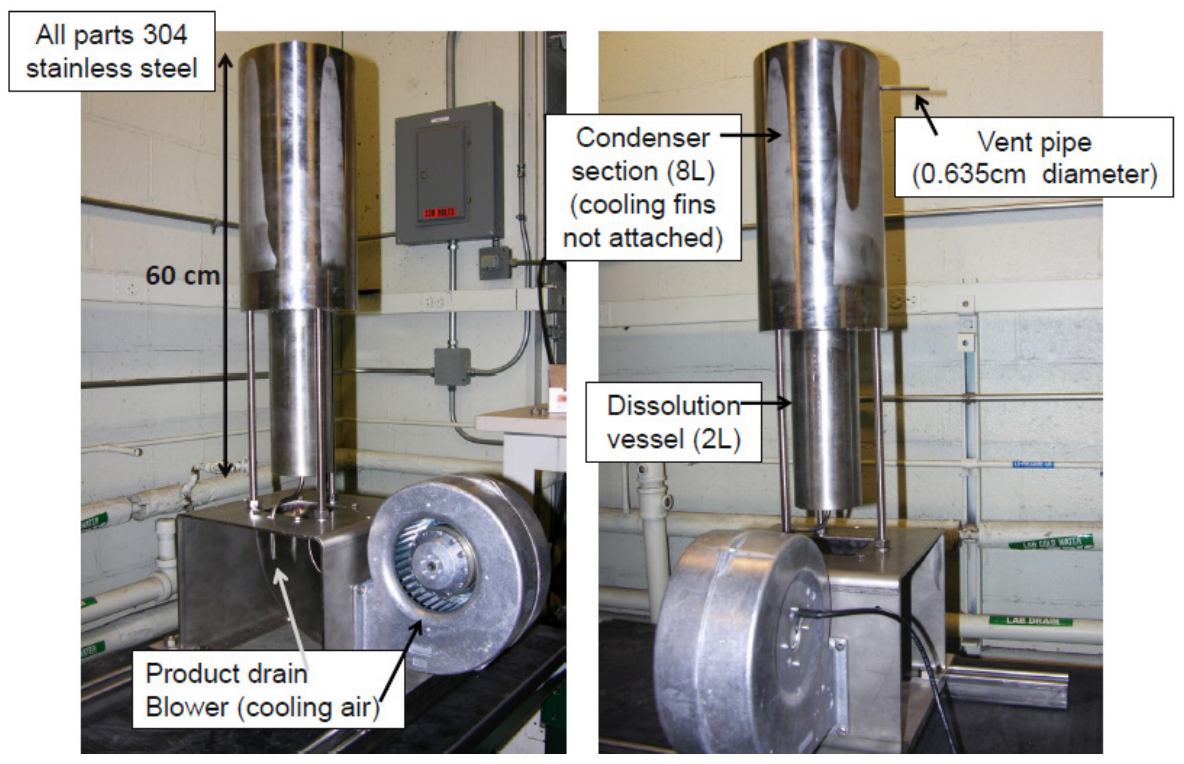

FIG. 49. Full scale prototype of the high capacity dissolver developed by ANL. 


\subsubsection{Dissolution off-gas treatment}

To follow the dissolution of foils in a closed system, ANL proposed an off-gas treatment. The dissolver is linked to a cold trap held in liquid nitrogen, and the $\mathrm{NO}_{\mathrm{x}}$ gases formed during dissolution and the volatile fission gases (iodine, xenon and krypton) are cryogenically pumped into the cold trap, where they are held for decay storage. Most (>95\%) of the iodine is removed from solution during the cold trap evacuation of the dissolver. A copper gauze metal iodine trap can be placed between the dissolver and the cold trap to recover most of the iodine (Fig. 50). The liquid nitrogen cooled cold trap usually contains a molecular sieve (Fig. 51).

Romania improved the design for the off-gas traps that can be seen in Fig. 52. This new design allows the easy release of the iodine and the noble gas traps by using quick release connections for repeated unlockable fastenings and fast assembly.

Several CRP participants were interested in recovering and using the ${ }^{131}$ I produced in the fission of LEU targets. The off-gas method employs ceramic microspheres of alumina containing metals such as $\mathrm{Cu}$ and $\mathrm{Ag}$. The best results were achieved with Ag microspheres giving $42 \%$ of retention and $\sim 100 \%$ of recovery in $0.2 \mathrm{~mol} \cdot \mathrm{L}^{-1} \mathrm{NaOH}$. Good preliminary results with $\mathrm{Cu}$ were also obtained by participants who attempted to recover iodine.

\subsubsection{Chemical processing (Mo precipitation and purification)}

After dissolution, the LEU modified Cintichem process proceeds with ${ }^{131}$ I removal and ${ }^{99}$ Mo precipitation and purification (Fig. 53).

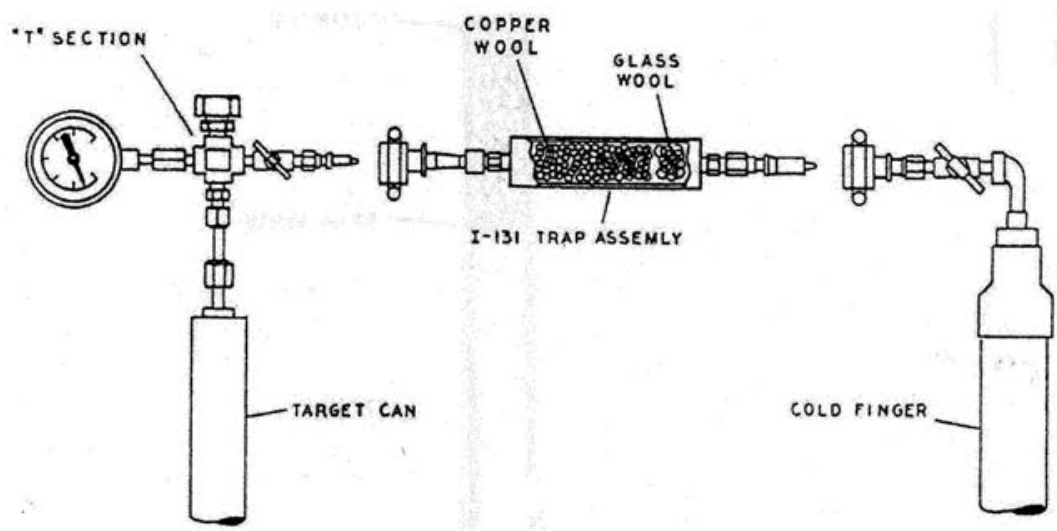

FIG. 50. Off-gas treatment proposed by ANL. 


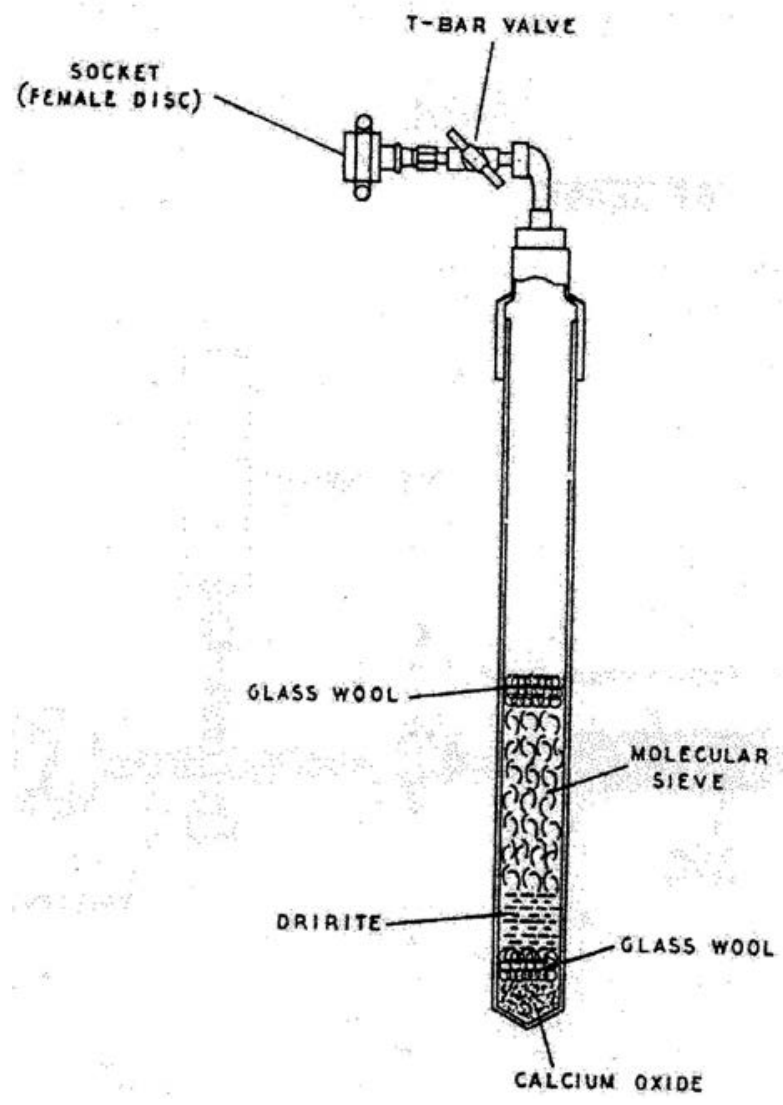

FIG. 51. Cold trap for fission gas trapping proposed by ANL.

\subsubsection{Iodine removal}

After the dissolution and off-gas removal, air is let into the dissolver under vacuum and the dissolver solution is fed into an evacuated bottle. The dissolver vessel is again put under vacuum and a rinse solution $\left(\mathrm{HNO}_{3}\right)$ is pulled into the vessel. The rinse solution is again vacuum pulled into an evacuated bottle. The first step of ${ }^{99} \mathrm{Mo}$ purification is the precipitation of radioiodide by the addition of a natural iodine carrier $(4.0 \mathrm{~mL}$ at $1 \mathrm{mg} / \mathrm{mL})$, hydrochloric acid (1 mL of $1.0 \mathrm{M} \mathrm{HCl})$, and silver nitrate $\left(0.5 \mathrm{~mL}\right.$ of $10 \% \mathrm{AgNO}_{3}$ in $\left.0.1 \mathrm{M} \mathrm{HNO}_{3}\right)$ to the dissolver solution. The iodide and chloride are precipitated as silver salts and are filtered through a $0.3 \mu \mathrm{m}$ and $0.2 \mu \mathrm{m}$ filter assembly. The filter assembly is rinsed with $4 \mathrm{M} \mathrm{HNO}_{3}$. 


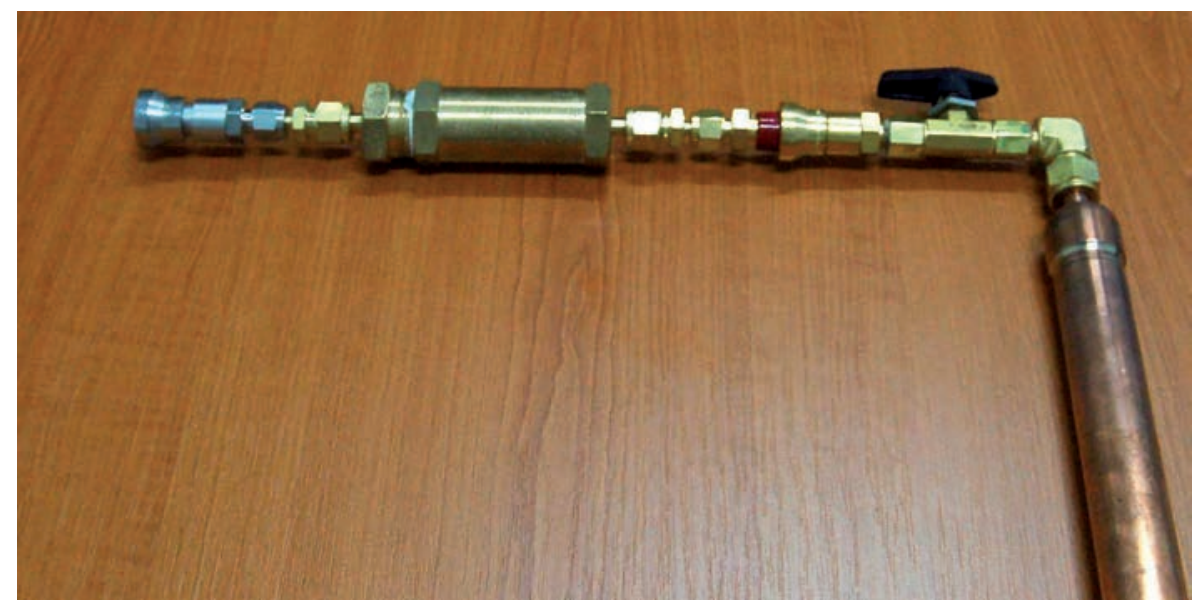

FIG. 52. Iodine and noble gases recovery device built by Romania.

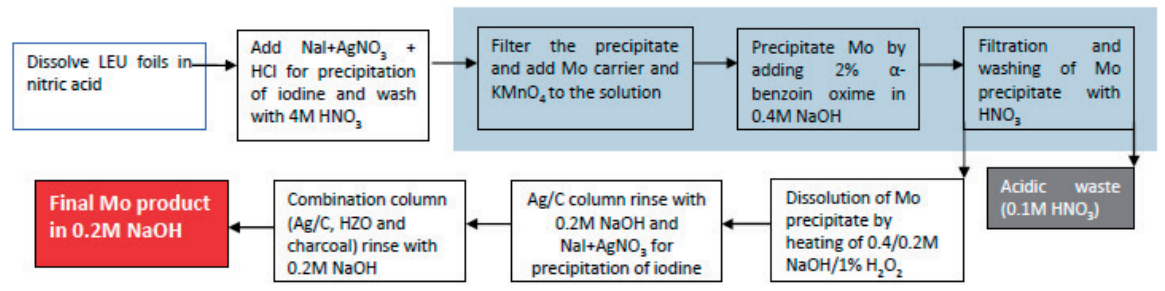

FIG. 53. ${ }^{99}$ Mo processing proposed by ANL.

The participants from India performed some experiments varying some parameters in order to fine tune the removal process of iodine. The effect of inactive carrier concentration of $\mathrm{NaI}$ in the feed solution on the percentage removal of iodine was examined and the result is depicted in Table 9. Ignoring some fluctuation, the percentage of iodine removal was nearly $90 \%$ when the carrier concentration was between 6 and $10 \mathrm{mg} / \mathrm{mL}$. Hence, $10 \mathrm{~mL}$ of NaI solution of a carrier concentration of $6 \mathrm{mg} / \mathrm{mL}$ can be used.

Brazil studied the recovery of ${ }^{131} \mathrm{I}$ in the dissolved solution. Several absorber materials such as ion exchange resins, $\mathrm{Ag}$ and $\mathrm{Cu}$ microspheres, activated charcoal (AC) and commercial cartridges have been employed and reasonable results were achieved with $\mathrm{AC}$. 


\begin{tabular}{lc} 
Amount of NaI carrier $(\mathrm{mg} / \mathrm{mL})$ & $\%$ removal of I-131 \\
\hline 2 & $67.06 \pm 2.3$ \\
4 & $89.03 \pm 2.5$ \\
6 & $90.12 \pm 1.5$ \\
10 & $90.18 \pm 2.1$ \\
\hline
\end{tabular}

\subsubsection{Mo precipitation and column purification}

The second step, and by far the most important, is the precipitation of $\mathrm{Mo}(\mathrm{VI})$ with ABO. Following the silver-iodide precipitation and filtering step to remove additional iodine from the dissolver/rinse solution, specific fissionproduct carriers and an oxidizing agent $\left(\mathrm{KMnO}_{4}\right)$ are added to the solution followed by the addition of $\mathrm{ABO}$, which is a highly selective precipitation agent for $\mathrm{Mo}(\mathrm{VI})$. The precipitate is captured on a glass frit filter containing several layers of glass beads above the frit. The Mo-ABO precipitate is washed many times with small volumes of nitric acid solution; the glass beads facilitate the washing of the precipitate and allow decontamination factors from all other dissolver components (typically 100 000). After washing, a solution of hydrogen peroxide in sodium hydroxide is added to the filter and the filter is heated. The molybdenum is dissolved from the precipitate in this stage.

The precipitation follows the following reaction:

$$
\begin{aligned}
\mathrm{MoO}_{2}^{++} & +2 \mathrm{C}_{6} \mathrm{H}_{5} \mathrm{CH}(\mathrm{OH}) \mathrm{C}: \mathrm{NOHC}_{6} \mathrm{H}_{5} \\
& \leftrightarrow \mathrm{MoO}_{2}\left[\mathrm{C}_{6} \mathrm{H}_{5} \mathrm{CH}(\mathrm{O}) \mathrm{C}: \mathrm{NOHC}_{6} \mathrm{H}_{5}\right]_{2}+2 \mathrm{H}^{+}(\mathrm{ABO})
\end{aligned}
$$

The ANL procedure recommends the addition of $0.5 \mathrm{~mL}$ of Mo carrier $(10 \mathrm{mg} / \mathrm{mL})$, followed by $2.5 \% \mathrm{KMnO}_{4}$ solution added slowly to the raw fission liquor until a deep pink colour holds for $\sim 30$ seconds. Carriers of Ru and Rh can be added in this stage followed by $20 \mathrm{~mL}$ of fresh $2 \% \mathrm{ABO}$ in $0.4 \mathrm{M} \mathrm{NaOH}$, keeping the solution well shaken. After $1 \mathrm{~min}$, the white, flocculent precipitate is filtered through a $51 \mathrm{~mm}$ glass frit column containing glass beads. The precipitate is washed several times with $0.1 \mathrm{M} \mathrm{HNO}_{3}$ and then the precipitate is dissolved with $10 \mathrm{~mL}$ of $0.4 \mathrm{M} \mathrm{NaOH}$ with $\sim 1 \% \mathrm{H}_{2} \mathrm{O}_{2}$. The glass column may be heated to facilitate the dissolution. This dissolution step is repeated using $0.2 \mathrm{M} \mathrm{NaOH}$ with $\sim 1 \% \mathrm{H}_{2} \mathrm{O}_{2}$ to assure the recovery of Mo. 
The dissolved Mo is then passed sequentially through two columns. The first is composed of activated charcoal (AC) and silver coated activated charcoal $(\mathrm{AgC})$. The second also contains hydrated zirconium oxide (HZO) between the $\mathrm{AC}$ and the $\mathrm{AgC}$ adsorbers. The composition of the columns is shown in Fig. 54.

Between the first and second column, any remaining iodine is precipitated by the addition of silver nitrate and carrier sodium iodide; the second column acts as a filter for this precipitate. After passing through the second column, the Mo in $0.2 \mathrm{M}$ sodium hydroxide is ready for shipment to the ${ }^{99 \mathrm{~m}} \mathrm{Tc}$ generator producer. The particular feature of this purification process is that Mo is not retained by any of these adsorbers in the diluted hydroxiyde solution, making the process very fast. The process takes about four hours from beginning of dissolution, and the chemical yield is between 85 and $90 \%$. ANL designed all the glassware and layout for this step. All the glassware and columns are intended to be disposable after processing.

A preliminary test of the LEU modified Cintichem process was performed at the Research Center for Science and Technology (PUSPIPTEK) installation in Indonesia (Figs 55-57) and the contamination level of the ${ }^{99} \mathrm{Mo}$ with impurities is shown in Table 10.

This LEU modified Cintichem process technology was made available to the participants of this CRP and some of them (Brazil, Chile, India, Indonesia, Pakistan, Poland, Romania) performed several studies aiming to optimize several process parameters, such as dissolution, Mo precipitation, column purification and the effect of impurities in each step. For this purpose, the studies employed cold materials, radioactive tracers and irradiated LEU foil targets.

Romania performed three processing tests using small amounts of irradiated metallic uranium (approximately 22,33 and $44 \mathrm{mg}$ ) and non-irradiated uranium to obtain $8 \mathrm{~g}$ for chemical processing. They encountered some difficulties removing Mo from the glass frit column, and their best yield of Mo recovery before the first purification step was 53.5\%. Romania also developed some new metallic supports to be used in and to facilitate the chemical processing in the hot cell.

Indonesia irradiated and processed four LEU foil targets containing $1 \mathrm{~g}$ of ${ }^{235} \mathrm{U}$ (one target) and $3 \mathrm{~g}$ of ${ }^{235} \mathrm{U}$ ( 3 targets) using the LEU modified Cintichem process. Table 10 shows a typical ${ }^{99} \mathrm{Mo}$ analysis of one of the processes performed in Indonesia. The results showed that the four tests of processing irradiated foil targets produced ${ }^{99} \mathrm{Mo}$ with the required radionuclide purity to be used in the manufacture of ${ }^{99} \mathrm{Mo} /{ }^{99 \mathrm{~m}} \mathrm{Tc}$ generators. 


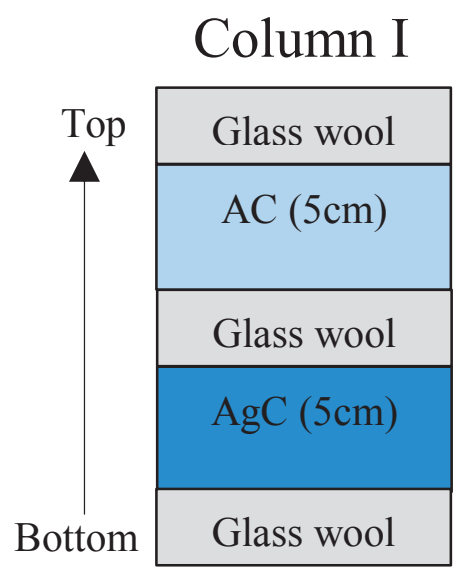

\section{Column II}

\begin{tabular}{|c|}
\hline Glass wool \\
\cline { 1 - 2 } AC \\
\hline Glass wool \\
\hline HZO $(3 \mathrm{~cm})$ \\
\hline Glass wool \\
\hline AgC $(3 \mathrm{~cm})$ \\
\hline Glass wool \\
\hline
\end{tabular}

FIG. 54. ${ }^{99}$ Mo precipitation and column purification proposed by ANL.

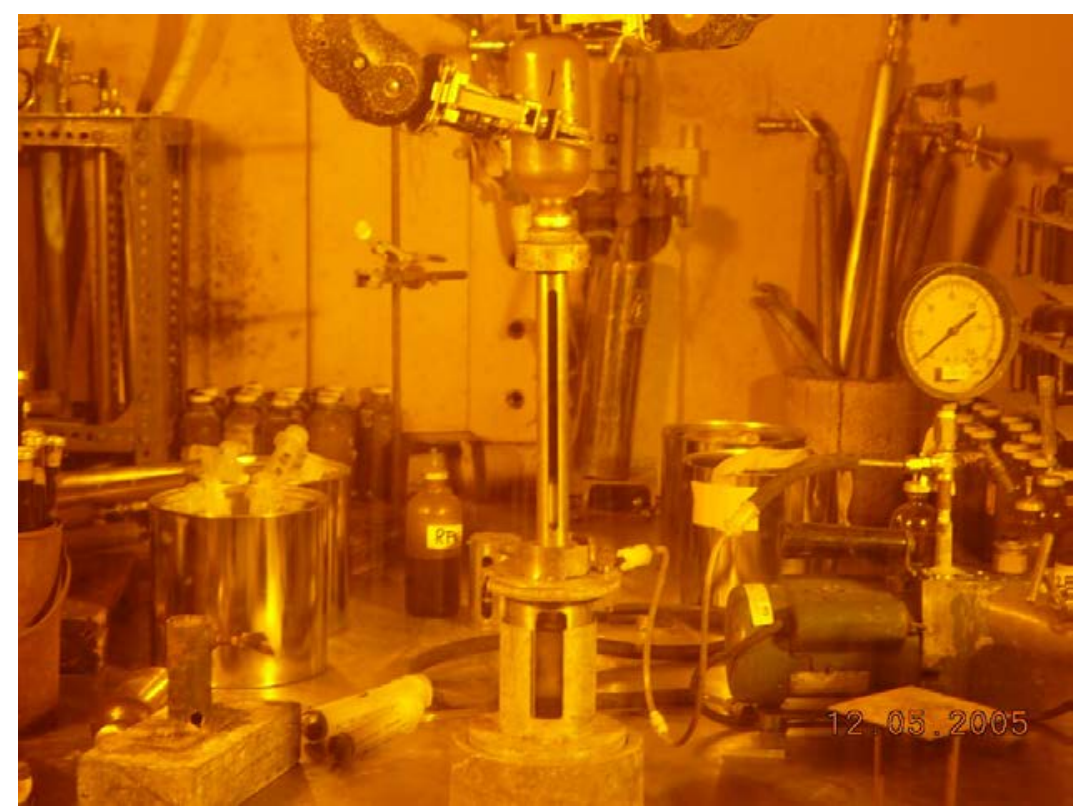

FIG. 55. Purification of ${ }^{99}$ Mo by HZO column at PUSPIPTEK, Indonesia. 


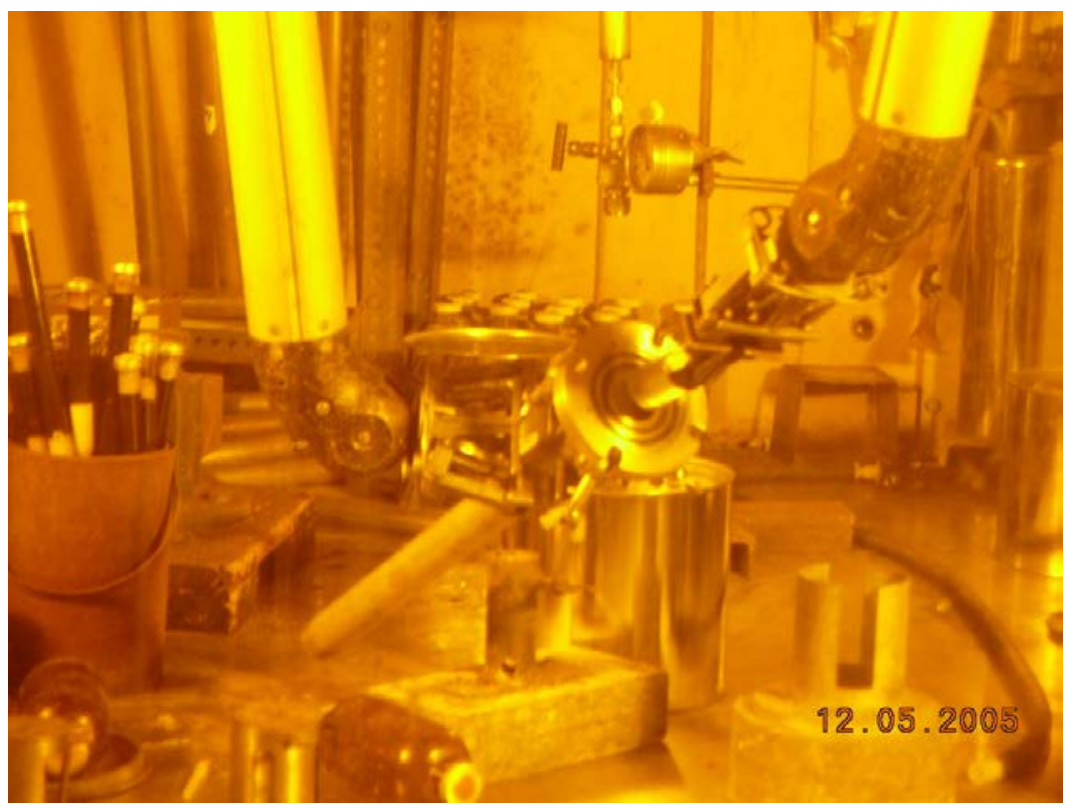

FIG. 56. Foil being placed in the dissolver at PUSPIPTEK, Indonesia.

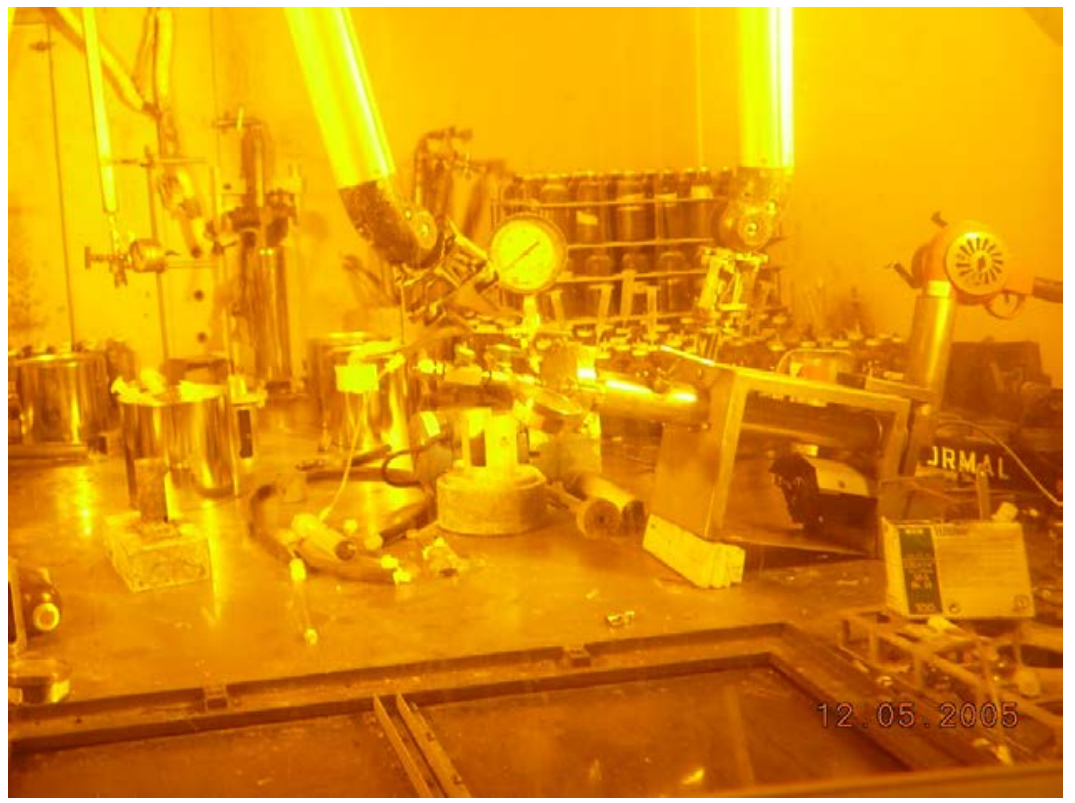

FIG. 57. Dissolver in the heating rig at PUSPIPTEK, Indonesia. 


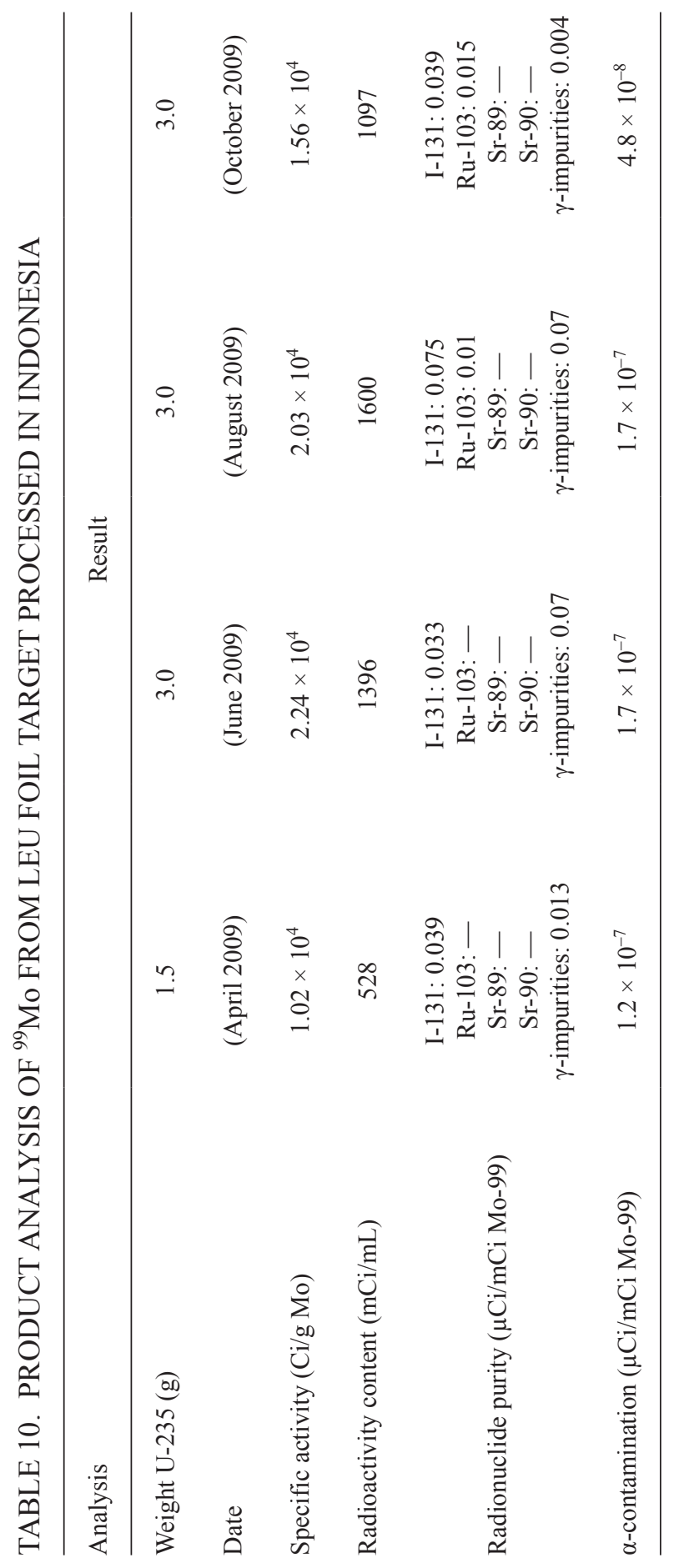


MURR processed an annular target containing $4.59 \mathrm{~g} \mathrm{LEU}\left(19.75 \%{ }^{235} \mathrm{U}\right)$ encased in a $0.776 \mathrm{~g}$ nickel foil fission barrier irradiated at MURR. The total processing time was $8.5 \mathrm{~h}: 1 \mathrm{~h}$ to cut the target and remove the $\mathrm{Al}$, and $7.5 \mathrm{~h}$ for the dissolution and chemical purification of ${ }^{99} \mathrm{Mo}$. The recovery yield of ${ }^{99}$ Mo was $\sim 55 \%$ of the theoretical yield based on safety evaluation calculations.

Several CRP members performed experiments in order to optimize the parameters related to the recovery and purification of ${ }^{99} \mathrm{Mo}$ using the LEU modified Cintichem process and the overall methodology provided by ANL.

The participants from Brazil studied the recovery of Mo through precipitation with $\mathrm{ABO}$. In the column purification they used: $\mathrm{AC}$, homemade $\mathrm{AC}$ containing silver (AC/Ag), commercial and homemade hydrous zirconium oxide (HZO) and commercial Ag cartridges. The effect of some contaminants such as $\mathrm{I}, \mathrm{Zr}, \mathrm{Ru}$ and $\mathrm{Te}$ was also studied using radiotracers from the routine production programme and by producing them in the IEA-R1 reactor. The best overall recovery yield of ${ }^{99}$ Mo was $80.3 \%$.

The participants from Chile performed multiple experiments simulating the conditions and equipment following the LEU modified Cintichem process. Experiments were performed with non-radioactive synthetic solutions (15), with natural uranium (NU) shavings (4) and NU foils (2), but without irradiated uranium. The experiment employing $\mathrm{NU}$ and $\mathrm{Ni}$ foils provided a mean value of Mo recovery of $80.1 \%$, and the presence of uranium was under the detection limit of the NAA technique $(<1 \mathrm{ppm})$.

The participants from India studied several parameters of the Mo precipitation and column purification. The removal of ${ }^{103} \mathrm{Ru}$ was studied by adding different oxidizing agents and performing distillation, so removal yields of greater than $99 \%$ were achieved. The retention of some fission products (I, $\mathrm{Zr}$ and $\mathrm{Sr}$ ) was high in the Mo-ABO precipitate so a carrier precipitation step was suggested. They were precipitated as $\mathrm{AgI}, \mathrm{ZrO}(\mathrm{OH})_{2}$ and $\mathrm{SrCO}_{3}$. A further purification step was added using a final column containing $\mathrm{Al}_{2} \mathrm{O}_{3}$ for the final purification of ${ }^{99} \mathrm{Mo}$. The overall recovery yield of ${ }^{99} \mathrm{Mo}$ was $72.7 \%$.

The participants from Poland performed a procedure to purify tracer ${ }^{99} \mathrm{Mo}$ and carrier added Mo from the dissolver solution containing non-irradiated uranium. The overall recovery yield of ${ }^{99} \mathrm{Mo}$ was $61 \%$. Libya assembled a set-up for the complete LEU modified Cintichem process that was tested in cold conditions (non-irridiated) and was shown to be ready to be assembled in the hot cell.

ANL studied the radiolytic stability of the Mo-ABO precipitate in particular for the expected processing of more than $1000 \mathrm{Ci}$ of ${ }^{99} \mathrm{Mo}$. Their Van der Graaff accelerator was used to irradiate the Mo-ABO precipitate at doses up to the equivalent of $\sim 160 \mathrm{kCi}$ of ${ }^{99} \mathrm{Mo}$ and the stability of the precipitate was examined 
after irradiation. The conclusion was that $\mathrm{ABO}$ radiolysis will not affect yield when processing $\leq 10000 \mathrm{Ci}$ of ${ }^{99} \mathrm{Mo}$.

\subsection{ALTERNATE METHODS FOR PROCESSING FOIL TARGETS}

\subsubsection{ANL method}

ANL is working on two schemes to process foil targets based on an alkaline dissolution process. Both the front end process options have two major goals: the first is to produce a ${ }^{99} \mathrm{Mo}$ product solution from the LEU foil that will be compatible with current purification operations and that will, with the same number of targets irradiated, provide the same or higher yield of ${ }^{99} \mathrm{Mo}$ at the end of processing. The second goal is to deliver a product solution that is of equal or better compatibility than that produced through the current purification process.

In the first alkaline process option, the LEU foil (contained in a thin $(10-15 \mu \mathrm{m}) \mathrm{Ni}$ fission recoil barrier is removed from the target cladding and dissolved in nitric acid. In the dissolution, the uranium, nickel, and all fission and activation products are dissolved. The resultant solution $(\sim 0.5 \mathrm{~L})$ will be $\sim 7 \mathrm{mM} \mathrm{Mo}, \sim 450 \mathrm{~g} \mathrm{U} / \mathrm{L}$, and the nitric acid concentration after dissolution will be $\sim 1$ M. After dissolution, the solution will be fed to a small column of titania sorbent $\left(\mathrm{TiO}_{2}\right)$, where ${ }^{99} \mathrm{Mo}$ will be sorbed on the column with minor amounts of other feed components. The column will be washed with nitric acid and then water, then ${ }^{99} \mathrm{Mo}$ will be stripped into a sodium hydroxide solution.

In the second process, the LEU foil target uses a $40 \mu \mathrm{m}$ aluminium fission recoil barrier. Once the UAl foil is removed from the target, the Al layer is dissolved in base to expose the uranium surface. This is followed by a low temperature, low pressure procedure employing anodic oxidation of the uranium metal into an aqueous bicarbonate solution. After precipitation of uranium, carbonate, and alkaline-insoluble fission and activation products from the solution by the addition of calcium oxide, the ${ }^{99}$ Mo solution can be fed into the current purification processes.

\subsubsection{Gamma Service Group (GSG)}

The LEU modifed Cintichem process requires initial separation of the target cladding from the uranium foil and nickel recoil barrier. Thereafter, the uranium foil is dissolved in a special dissolver vessel with $\mathrm{HNO}_{3}$ under relatively high pressure. There are alternative methods for both steps: for dissolving the uranium foil under normal pressure conditions as well as for the removal of the target cladding by chemical methods. 
The first fission based ${ }^{99}$ Mo production process in Rossendorf, and also in Europe, was based on the digestion of irradiated natural uranium metal pellets in $\mathrm{HCl}$ which can be performed under normal pressure conditions and was in use from 1963 to 1980 . The advantage is that by using $\mathrm{H}_{2}$ as a carrier gas, the Te is eliminated in the first separation step. The fission Xe is trapped in a liquid $\mathrm{N}_{2}$ trap and processed thereafter for medical products (gas and saline solution for intravenous injection). Distilling off the iodine by oxidizing the solution with $\mathrm{HNO}_{3}$ is the second step, and this iodine solution can be used commercially. The uranium fission product solution that is obtained is treated in an $\mathrm{Al}_{2} \mathrm{O}_{3}$ column process. A sublimation step is the last step in the purification of ${ }^{99} \mathrm{Mo}$, as this brings the product to a very high purity standard. The total activity that was typically produced using this process was $15-20 \mathrm{Ci}$ of ${ }^{99} \mathrm{Mo}$ from $180 \mathrm{~g}$ of natural uranium pellets. The drawback of this process was its reliance on $\mathrm{HCl}$, as this created corrosion problems. However, modern materials should stand up to the acid much more readily than materials used 50 years ago. A diagram of this process is shown in Fig. 58.

GSG has developed a process called LITEMOL, which is diagrammed in Fig. 59. LITEMOL is a process for natural uranium or very low enriched uranium metal as a target material, and was derived from the first Rossendorf process. The production capacity is $10-20$ 6-day $\mathrm{Ci}^{99} \mathrm{Mo}$ from $200 \mathrm{~g}$ of natural uranium

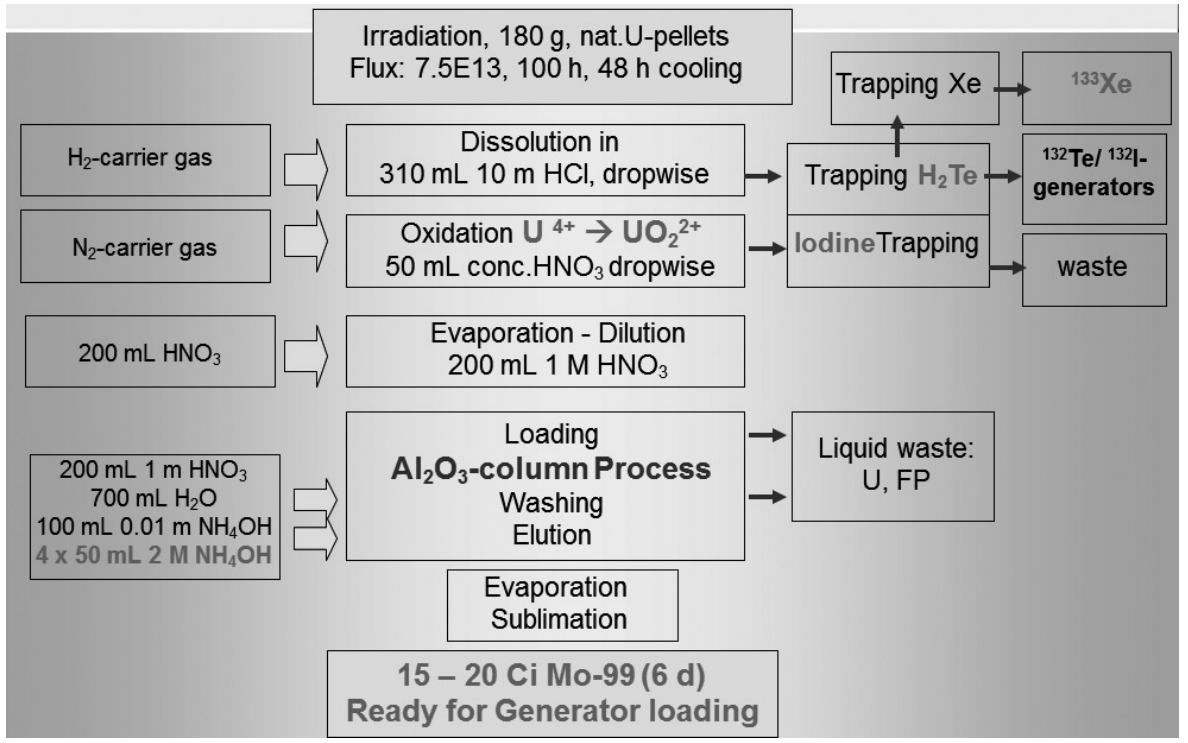

FIG. 58. First fission based ${ }^{99}$ Mo production process in Rossendorf. Figure courtesy of GSG, Germany. 


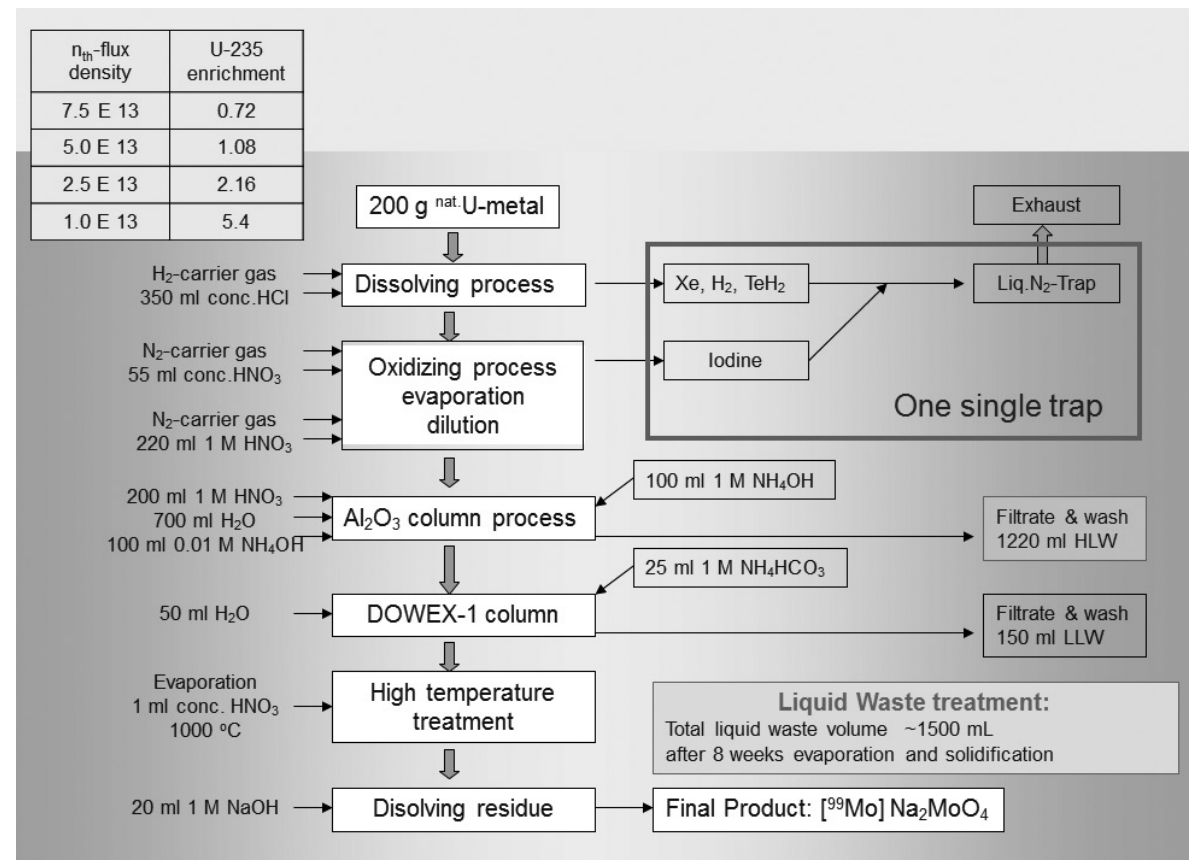

FIG. 59. LITEMOL ${ }^{99}$ Mo production process developed by GSG. Courtesy of GSG, Germany.

pellets. The process is very similar to the Rossendorf process, and the separation and purification is performed by alumina, anion exchange resin and sublimation.

\subsubsection{Other considerations}

There are other alternatives for bringing uranium metal into solution for separating the molybdenum. One very innovative technique is a dry technique, which offers the advantage of generating much less liquid waste. Having separated the uranium foil from the Al cladding, the uranium metal can be oxidized with a controlled $\mathrm{O}_{2}$ gas stream at higher temperatures. The resultant uranium oxide is easy to dissolve in $\mathrm{HNO}_{3}$. There are definitely very different options that can be used for these dry processes, but as they are in the stages of early development, they still require intensive research.

For removing the Al cladding from the uranium foil targets, chemical separation techniques can also be used. In principle, the Al can be distilled off in the form of volatile chloride compounds, and thereafter the uranium foil can be oxidized with a controlled $\mathrm{O}_{2}$ gas stream at higher temperatures. 
Furthermore, any of the basic digestion methods used at present can be used for selectively dissolving the Al cladding, since the uranium foil, even when covered with a Ni fission barrier, will not be attacked by the basic media. However, these techniques require intensive research and development work, since those process options have not been tested.

\section{4. $\mathrm{UAl}_{\mathrm{x}}$ DISPERSION TARGET PROCESSING}

\subsubsection{CNEA process}

CNEA began the production of fission ${ }^{99}$ Mo from HEU targets in 1985; in 2002 they became the first producer to convert to LEU based production. Having established themselves as a frontrunner in LEU based production, Argentina were able to market the technology for LEU based ${ }^{99}$ Mo production and the associated quality control procedures. CNEA were also able to provide training and technical assistance to some CRP members, such as Egypt and Libya.

CNEA's LEU UAl $\mathrm{X}_{\mathrm{X}}$ targets, described in Section 2, are dissolved in alkaline solution (hot concentrated $\mathrm{NaOH}$ solution) producing a precipitate containing $\mathrm{Al}$, uranium and some fission products, in particular the actinides. The precipitate is washed, and together with the filtrate containing ${ }^{99} \mathrm{Mo},{ }^{131} \mathrm{I}$ and some fission products, it undergoes the purification step. The purification consists of three chromatographic columns as follows:

— A strong anion exchange resin AG that retains ${ }^{99} \mathrm{Mo}$ and ${ }^{131} \mathrm{I}$. A differential stripping of the column produces two solutions, one containing ${ }^{131} \mathrm{I}$ that undergoes further purification to meet the required quality standards.

- The solution containing ${ }^{99} \mathrm{Mo}$ is conditioned with thiocyanate to complex $\mathrm{Mo}(\mathrm{V})$ and loaded onto a chelating ion exchange resin (CHELEX).

- The last purification step is performed using a column containing alumina where ${ }^{99} \mathrm{Mo}$ is adsorbed at low $\mathrm{pH}$. The final product is a sodium molybdate solution containing ${ }^{99} \mathrm{Mo}$ with the purity required for use in ${ }^{99 \mathrm{~m}} \mathrm{Tc}$ generators.

CNEA continues with the weekly commercial production of fission ${ }^{99} \mathrm{Mo}$ from LEU targets, and also increased their production volume to help in the mitigation of the supply crisis in 2009 .

\subsubsection{GSG - ROMOL-99 process}

In 1981, ${ }^{99}$ Mo production in Rossendorf changed to the AMOR-1 process because of the need for higher activities of ${ }^{99} \mathrm{Mo}$. The target was dissolved in a 
mixture of $\mathrm{HNO}_{3}$ and $\mathrm{Hg}\left(\mathrm{NO}_{3}\right)_{2}$. The ${ }^{99}$ Mo separation was performed by $\mathrm{Al}_{2} \mathrm{O}_{3}$ adsorption process and the purification by a column process, oxidation $\left(\mathrm{HNO}_{3}\right)$ and sublimation. The batch size was $1200 \mathrm{Ci}$ of ${ }^{99} \mathrm{Mo}$ at the end of the process, from $105 \mathrm{~g}$ of $35 \%{ }^{235} \mathrm{U}$ and $1 \mathrm{~kg} \mathrm{Al}$ (the original fuel element of the reactor). GSG used the AMOR-1 process until 1991.

In 2003, with the expertise acquired through the Rossendorf process, GSG developed a new ${ }^{99}$ Mo production process carrying the registered trade name ROMOL-99. It is used to process $\mathrm{LEU} \mathrm{UAl}_{\mathrm{X}}-\mathrm{Al}$ clad dispersion targets and with a capacity of approximately 1006 -day $\mathrm{Ci}^{99} \mathrm{Mo}$. The process is based on the basic digestion of targets using a mixture of $\mathrm{NaOH}$ and $\mathrm{NaNO}_{3}$. In this case, the $\mathrm{Al}$ reduces the $\mathrm{NO}_{3}^{-}$down to $\mathrm{NH}_{3}$ (with about $84 \%$ fraction) and with the remaining fraction of $16 \%$ to nitrite $\mathrm{NO}_{2}^{-}$. The major advantage of this digestion process is that targets can be dissolved in a closed environment, even under reduced pressure conditions, which makes the process much safer.

After digestion, the target material is found directly in the chemical form of $\mathrm{Na}_{2} \mathrm{U}_{2} \mathrm{O}_{7}$, and ${ }^{99} \mathrm{Mo}$ in the chemical form of $\mathrm{MoO}_{4}^{2-}$. The filter cake collects the actinides, lanthanides, $\mathrm{Zr}$, Nb, most of the $\mathrm{Te}$ and $\mathrm{Sb}$, the $\mathrm{Sr}$ and $\mathrm{Ba}$, a part of the $\mathrm{Ru}$ and others. Iodine remains in solution.

Owing to the high content of $\mathrm{NO}_{3}^{-}$anions, an anion exchange separation cannot be directly applied for ${ }^{99} \mathrm{Mo}$. In the ROMOL-99 process, the basic solution is first acidified by introducing $\mathrm{HNO}_{3}$. Prior to doing so, the filtrate is filtered through an iodine retaining column $\left(\mathrm{Ag}\right.$ coated $\left.\mathrm{Al}_{2} \mathrm{O}_{3}\right)$ that can retain the iodine with close to $100 \%$ efficiency, if freshly prepared. During the acidification process, the nitrite still present is transformed into $\mathrm{N}_{2}$ in the reaction with carbamide.

The acidified solution is then loaded to an $\mathrm{Al}_{2} \mathrm{O}_{3}$ column, which adsorbs the ${ }^{99} \mathrm{Mo}$ with nearly $100 \%$ efficiency. After washing the column, the ${ }^{99} \mathrm{Mo}$ is eluted with $1 \mathrm{M} \mathrm{NH}_{3}$ solution. The recovery rate is of the order of $85 \%$. This eluate is directly loaded to an anion exchange column (Dowex-1). The elution is performed with $\mathrm{NH}_{4} \mathrm{HCO}_{3}$. This eluate is evaporated and the residue formulated to the final product solution.

Figure 60 shows a diagram of the ROMOL-99 process scheme for industrial scale ${ }^{99}$ Mo production based on a hot cell system of seven cells arranged in three separate blocks, enabling operation of the two processes simultaneously.

While this process has been designed for use with LEU targets, the first installation using the ROMOL-99 process was at PINSTECH in Pakistan and used HEU targets. The operation is completed by a touchscreen operation system with partial preprogrammed operation steps. This approach partially avoids operator errors and is more GMP compliant than manually operated processes. GSG also developed a scaled down ROMOL-99 process based on a commercially available

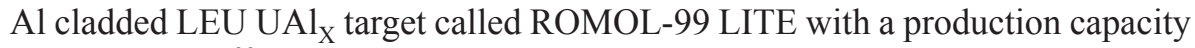
of $10-20 \mathrm{Ci}$ of ${ }^{99} \mathrm{Mo}$. The process can be seen in Fig. 61. 


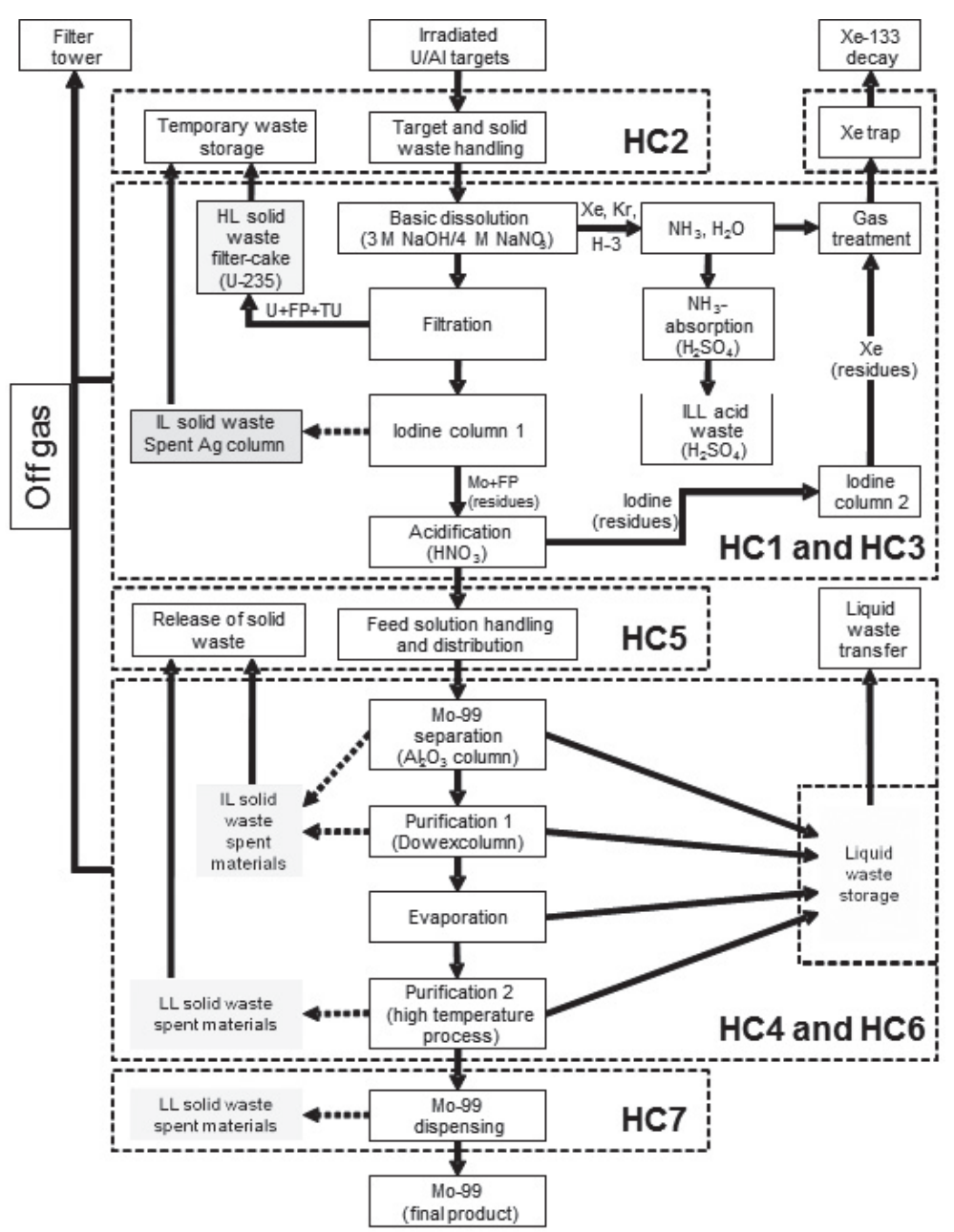

FIG. 60. ROMOL-99 commercial scale Mo production process developed by GSG.

\subsubsection{The experience at PINSTECH}

Pakistan has 39 nuclear medical centres that are using the ${ }^{99} \mathrm{Mo} /{ }^{99 m} \mathrm{Tc}$ generators produced at PINSTECH. At the time of writing, the demand for loading the required quantity of generators is $16 \mathrm{Ci}^{99} \mathrm{Mo}$ at the calibration date. Using the ROMOL-99 process and HEU target plates, the maximum capacity of ${ }^{99} \mathrm{Mo}$ under existing conditions (12 $\mathrm{h}$ irradiation) is $23.63 \mathrm{Ci}$ (4-day $\mathrm{Ci}$ ) ${ }^{99} \mathrm{Mo}$. 


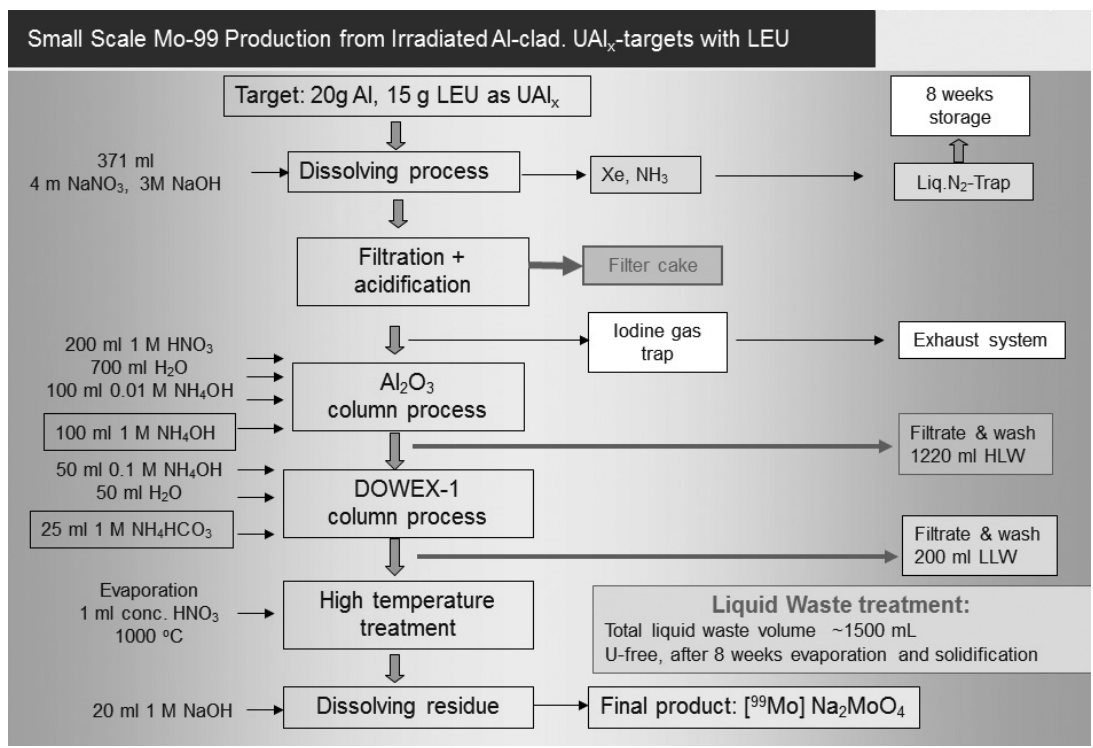

FIG. 61. ROMOL-99 LITE ${ }^{99}$ Mo production process developed by GSG.

The irradiated HEU target plates are dissolved in a mixture of $\mathrm{NaOH}$ and $\mathrm{NaNO}_{3}$. During dissolution, uranium and other actinides are precipitated out, as the liberated xenon is then trapped by liquid nitrogen. The solution produced contains radio-iodine, ${ }^{99} \mathrm{Mo}$ and some fission products such as $\mathrm{Ru}$ and $\mathrm{Rh}$. Ammonia gas produced during dissolution is distilled and trapped in $\mathrm{H}_{2} \mathrm{SO}_{4}$ solution whereas hydrogen is converted to water by action on $\mathrm{CuO}$. Silver coated alumina is used for the removal of radio-iodine from the solution. Nitrates that would interfere with the adsorption of ${ }^{99}$ Mo on alumina are changed to nitrogen by the action of urea. A column chromatography technique using alumina and anion exchange resins is employed for the purification of ${ }^{99} \mathrm{Mo}$ from remaining contaminants. Final purification is performed by the sublimation of ${ }^{99} \mathrm{Mo}$, which is then dissolved in $\mathrm{NaOH}$. Approximately 29 batches of ${ }^{99} \mathrm{Mo}$ have been produced and delivered to the generator loading facility at PINSTECH. These generators have been shipped throughout the country for nuclear medical diagnostic procedures. The quality of the generators and the eluted ${ }^{99 \mathrm{~m}} \mathrm{Tc}$ was identical to that obtained earlier while using imported ${ }^{99}$ Mo from NTP Radioisotopes, South Africa.

The hot cell facility for the production of ${ }^{99} \mathrm{Mo}$, assembled by GSG, is shown in Fig. 62. 


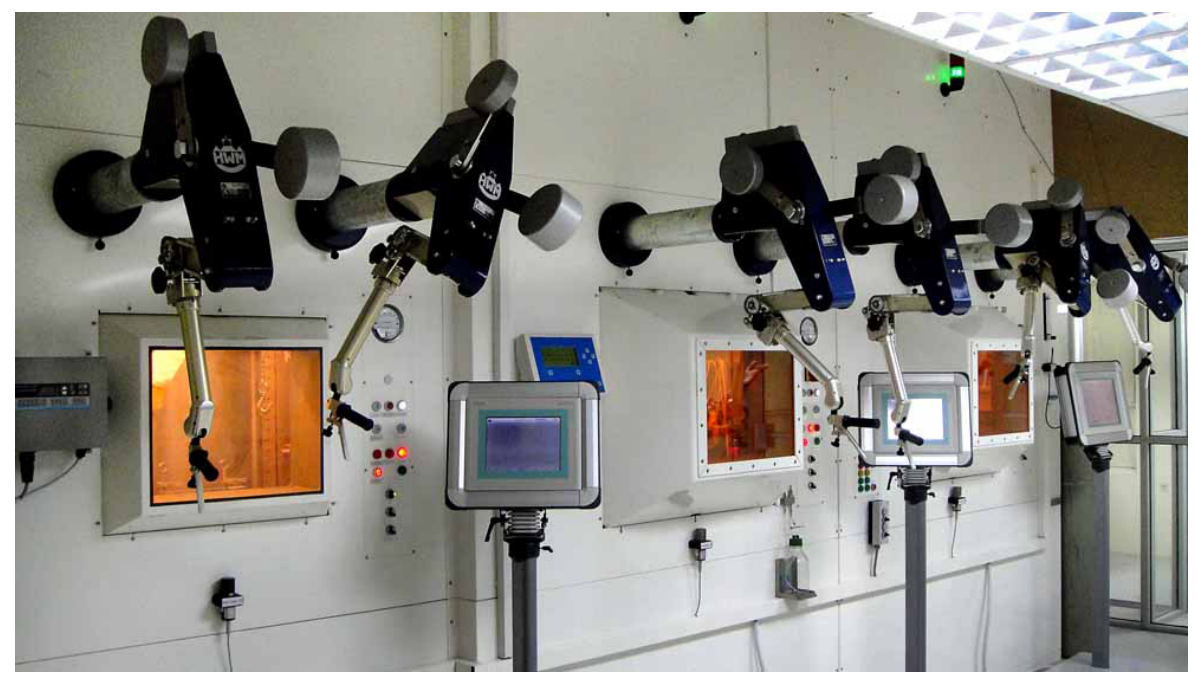

FIG. 62. ${ }^{99}$ Mo production hot cell facility at PINSTECH in Pakistan. Photograph courtesy of $G S G$.

\subsection{CONCLUSIONS ON ${ }^{99}$ Mo PROCESSES EMPLOYED IN THE CRP}

The LEU modified Cintichem process proved to be a viable alternative for small scale production of ${ }^{99} \mathrm{Mo}$ that can be performed in glassware; syringes and septa on the vessels are used for the addition of reagents and for transferring the solution from bottle to bottle, filter and column. The process can take about four hours from beginning of dissolution and the chemical yield is between 85 and $90 \%$. One of the main advantages that allows for a quick separation process is that in the purification steps ${ }^{99} \mathrm{Mo}$ is not adsorbed in any material but the impurities are, so there is no need to separately elute ${ }^{99} \mathrm{Mo}$ from the columns. The whole LEU modified Cintichem process technology, including documentation, drawings and expertise, was shared by ANL with all participants in the CRP.

\section{4. $(n, \gamma)$ MOLYBDENUM-99 BASED GEL GENERATOR}

\subsection{INTRODUCTION}

The valuable potential of $(\mathrm{n}, \gamma){ }^{99} \mathrm{Mo}$ based zirconium molybdate gel generators to deliver sodium pertechnetate ${ }^{99 \mathrm{~m}} \mathrm{Tc}$ of suitable quality for medical 
use has been reiterated ever since their conceptualization by Australian scientists more than three decades ago. Gel generators' widespread acceptability has remained low owing to the perception that the product quality is not as high, and that the production method cannot accommodate larger batch sizes and higher activity generator capacities on account of the inherent specific activity limitation of $(\mathrm{n}, \gamma){ }^{99} \mathrm{Mo} .{ }^{9}$ Furthermore, unlike the established technology of fission ${ }^{99} \mathrm{Mo}$ generator production, no ready-to-use commercial technology exists for gel generators. However, given the investment required for fission ${ }^{99}$ Mo production and ${ }^{99 \mathrm{~m}} \mathrm{Tc}$ generator production, countries with a moderate domestic demand of approximately 25 generators per week might consider the gel generator route using $(\mathrm{n}, \gamma){ }^{99}$ Mo to meet their national requirements. In the last decade, India and Kazakhstan have developed significant expertise in setting up and operating gel generator production facilities in their respective countries to supply or supplement their domestic requirements. The technological inputs required for gel generator manufacture and the production experience gained through the CRP are described in this Section.

\subsection{REQUIREMENTS FOR PRODUCTION OF $(n, \gamma){ }^{99}$ Mo BASED GEL GENERATORS}

\subsubsection{Reactor features impacting $(\mathrm{n}, \gamma){ }^{99}$ Mo production}

Reactor design parameters, operating power level, the neutron flux available for target irradiation, volume available in the reactor for placing targets and reactor operation schedules are some of the key considerations in looking to produce ${ }^{99} \mathrm{Mo}$ by the $(\mathrm{n}, \gamma)$ route. The thermal neutron activation cross-section for ${ }^{98} \mathrm{Mo}(\mathrm{n}, \gamma){ }^{99} \mathrm{Mo}$ is a low $0.13 \mathrm{~b}$, whereas the resonance integral of the reaction is $6.9 \mathrm{~b}$. A neutron flux of $5 \times 10^{13} \mathrm{n} \cdot \mathrm{cm}^{-2} \cdot \mathrm{s}^{-1}$ or higher and irradiation periods of 4-6 d are prerequisites to produce ${ }^{99} \mathrm{Mo}$ of specific activities of practical value. Using enhanced epithermal neutron flux, it is feasible to produce ${ }^{99} \mathrm{Mo}$ with a specific activity of up to $3.4 \mathrm{Ci} / \mathrm{g}$ with samples of natural ${ }^{98} \mathrm{Mo}$ and up to $15 \mathrm{Ci} / \mathrm{g}$ with enriched ${ }^{98} \mathrm{Mo}$ target samples when irradiated in channels with beryllium moderators of appropriate thickness at a neutron flux of $1.7 \times 10^{14} \mathrm{n} \cdot \mathrm{cm}^{-2} \cdot \mathrm{s}^{-1}$.

9 The specific activity in a typical batch of $(\mathrm{n}, \gamma)$, under the best of conditions, reaches a maximum of $37-74 \mathrm{GBq} / \mathrm{g}{ }^{99} \mathrm{Mo}$; this is significantly lower than the specific activity of fission ${ }^{99} \mathrm{Mo}$, which typically reaches $185 \mathrm{TBq} / \mathrm{g}$ or more. 
Targets for $(\mathrm{n}, \gamma)$ production can be made from natural molybdenum (24.13\% natural abundance of ${ }^{98} \mathrm{Mo}$ ) in the form of molybdenum trioxide $\left(\mathrm{MoO}_{3}\right)$ powder or pellets, encapsulated in aluminium or titanium cans or quartz ampoules. Targets in this form make post-irradiation ${ }^{99}$ Mo recovery simple, since dissolution in sodium hydroxide is feasible. However, targets must be of very high purity, and at times, even treated specially to remove any traces of rhenium and tungsten impurities so as to avoid ${ }^{186 / 188} \mathrm{Re}$ and ${ }^{188} \mathrm{~W}$ contaminants. Using targets made from enriched ${ }^{98}$ Mo increases specific activity by $4-8$ times depending upon epithermal flux, and necessitates recycling of the enriched target for reasons of economy through recovery and purification prior to (re)irradiation.

Under the CRP, India and Kazakhstan worked on production of (n, $\gamma$ ) ${ }^{99} \mathrm{Mo}$ and portable gel generators. Currently, Kazakhstan produces ${ }^{99}$ Mo by irradiating $40 \mathrm{~g}$ of $\mathrm{MoO}_{3}$ (natural molybdenum) in a sealed quartz ampoule for 72-200 h at a thermal neutron flux $0.9-1.1 \times 10^{14} \mathrm{n} \cdot \mathrm{cm}^{-2} \cdot \mathrm{s}^{-1}$. Kazakhstan has obtained ${ }^{99} \mathrm{Mo}$ with a specific activity of $800 \mathrm{mCi} / \mathrm{g}$. In India, the practice at the time of writing was to irradiate $135 \mathrm{~g}$ of $\mathrm{MoO}_{3}$ in aluminium cans for $7 \mathrm{~d}$ at a thermal neutron flux of $0.5-0.8 \times 10^{14} \mathrm{n} \cdot \mathrm{cm}^{-2} \cdot \mathrm{s}^{-1}$.

\subsection{RADIOCHEMICAL PROCESSING}

After the target is irradiated, it is cooled and undergoes radiochemical processing. The preparation of zirconium (poly)molybdate ${ }^{99} \mathrm{Mo}$ gel involves multiple radiochemical steps, described in the sections below, carried out through remote operations inside hot cells or shielded gloveboxes. The sequence of steps in preparing the ${ }^{99}$ Mo gel are:

(a) Dissolution of irradiated $\mathrm{MoO}_{3}$ in sodium hydroxide to prepare sodium molybdate ${ }^{99}$ Mo solution;

(b) Reaction with zirconium salt solution of appropriate strength and $\mathrm{pH}$ for quantitative precipitation of zirconium (poly)molybdate ${ }^{99} \mathrm{Mo}$;

(c) Rapid filtration of the insoluble zirconium (poly)molybdate ${ }^{99} \mathrm{Mo}$ gel-like precipitate;

(d) Dehydration/dessication of the filtered cake under carefully controlled conditions of temperature and airflow;

(e) Cake fragmentation and conversion to free flowing granules suitable for dispensing in individual columns. 


\subsubsection{Chemistry aspects}

It is known that the metallic species involved have a complex aqueous chemistry, since both zirconium and molybdenum are known to exist as multiple polymeric species in aqueous solutions. As the predominant polymeric species in solution is dependent on concentration and $\mathrm{pH}$, it follows that variable compositions of zirconium molybdate are possible, not all of which necessarily possess the porous structure so essential to permit the release of ${ }^{99 \mathrm{~m}} \mathrm{Tc}$ upon elution with normal saline or de-ionized water. A thorough optimization of preparatory conditions such as reactant concentration, alkalinity or acidity of reactant solution, mixing time and temperature, $\mathrm{pH}$ of gel formation, filtration rate and controlled desiccation of gel cake are essential to consistently obtain gels with the desirable characteristics for efficient ${ }^{99 \mathrm{~m}} \mathrm{Tc}$ release and minimal ${ }^{99}$ Mo breakthrough.

The Kazakh procedure involves dissolving $\mathrm{MoO}_{3}$ in $2 \mathrm{~N} \mathrm{NaOH}$ and converting to polymolybdate form by adjusting to $\mathrm{pH} 4.0-4.5$ using $3 \mathrm{~N}^{-\mathrm{HNO}_{3}}$. The $\mathrm{pH}$ of the zirconium oxychloride solution is adjusted to $\mathrm{pH} 1.5$ using $\mathrm{Na}_{2} \mathrm{CO}_{3}$. Slow precipitation takes place over 40 min by mixing the above reactants and adjusting the $\mathrm{pH}$ of the resultant gel to 4.5 using $2 \mathrm{~N} \mathrm{NaOH}$. Filtration is followed by the drying of gel cake using heated compressed air at $100^{\circ} \mathrm{C}$.

The Indian procedure involves reacting the sodium molybdate solution having calculated excess alkalinity such that on mixing with a 1.25:1 mole ratio of $\mathrm{Zr}$ :Mo solution, the $\mathrm{pH}$ of the resultant gel is 4.0-4.5. The mixing time is $5-10 \mathrm{~min}$ and, following filtration, the gel cake is dried using domestic microwave ovens under controlled conditions of intensity and duration.

\subsubsection{Technology development for process scaling up}

Technology development for scaling up the process entails four major aspects:

- Erection of a production facility with appropriate shielding;

- Adaptation of chemical process to automation;

- Design, fabrication and installation of operation specific tools;

- Design of appropriate generator assembly for centralized operation or portability.

The general procedure for the generator production process thus entails the various steps shown in Fig. 63. 


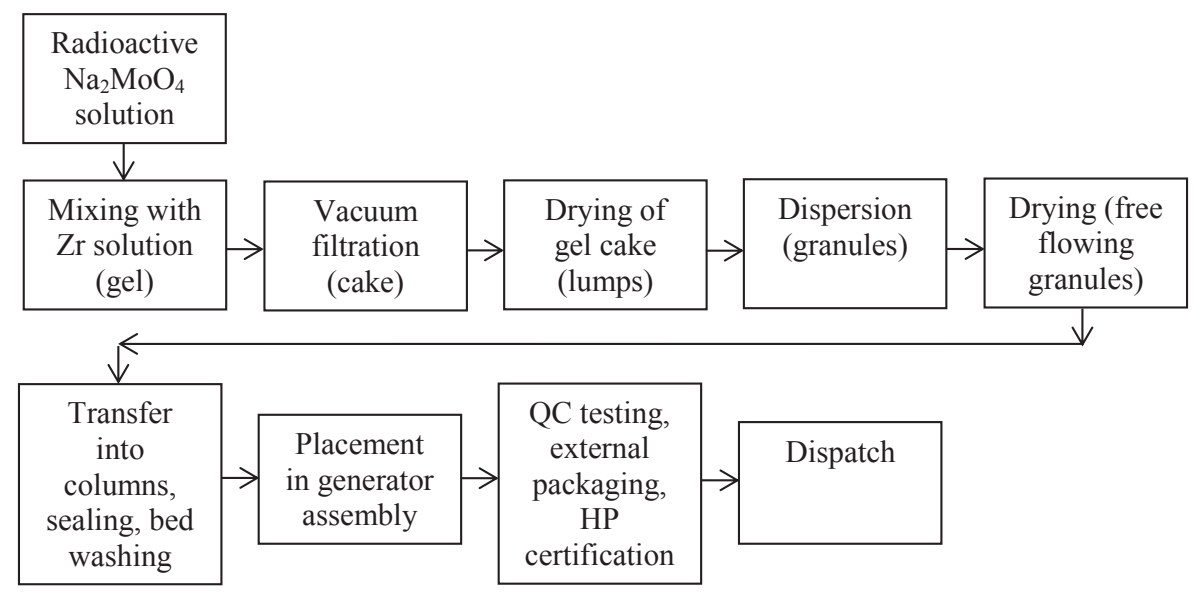

FIG. 63. Flow chart of gel preparation and generator assembly.

\subsubsection{Shielded production facility with operation specific gadgets}

Hot cells specially designed and equipped to suit operational requirements need to be built. This would mean, in general, a series of 3-4 hot cells with appropriate lead shielding and remotely operated tongs or manipulators for performing the required operations. Four sets of operations need to be performed in the hot cells:

— Processing of sodium molybdate ${ }^{99} \mathrm{Mo}$ : In this cell, provisions need to be made for extracting the irradiation container from the transport cask, retrieving the target and dissolving it in the required volume of alkali solution to prepare a sodium molybdate ${ }^{99} \mathrm{Mo}$ of appropriate concentration and $\mathrm{pH}$.

- Preparation of zirconium molybdate ${ }^{99}$ Mo granules: Provisions need to be made for mixing the salt solutions of zirconium and molybdenum resulting in the precipitation of zirconium molybdate ${ }^{99} \mathrm{Mo}$ gel, for the removal of water from the gel $(\sim 85 \%)$ by controlled filtration, for drying and subsequent conversion to granular form to serve as a column matrix.

- Transferring zirconium molybdate ${ }^{99}$ Mo granules to columns: Operations here would depend on the generator type - centralized versus portable. A large bed column would be required for a centralized generator, and small bed (6-12 g) columns for portable generators. A reliable granule dispensing system for portable generators, provisions for insertion of rubber closure, column crimping and column bed conditioning with water or saline need to be made. 
- Placing column in generator shielding: For portable generators, provisions for connecting to inlet and outlet needle assemblies and completing generator assembly are required.

- Custom built processing vessels and equipment such as stirrers, filters and driers would need to be designed depending on the batch size envisaged, and provisions for carrying out all operations remotely must be planned. The production facility should be integrated with workstations for testing eluent flow, QC sampling, final packaging and package certification.

\subsubsection{Adaptation of chemical process to automation}

Reducing the time necessary for processing is one of the keys to success in adapting chemical processing for routine production. The emphasis is on completing processing as early as possible - preferably in a single shift operation of about $8 \mathrm{~h}$ - to minimize decay loss.

Critical steps to determining the processing time are:

- Filtration of the thick, viscous, gelatinous precipitate which undergoes rapid sedimentation and forms an impervious barrier retarding further filtration;

- Drying of gel cake (which contains about $85 \%$ water) in a controlled manner so as to retain the structural integrity necessary to maintain a porous nature and enable ${ }^{99 \mathrm{~m}} \mathrm{Tc}$ elution.

The completion of both of the above steps in as short a time as feasible will determine the process scalability, and generator production capacity, per batch.

\subsubsection{Generator design}

The ${ }^{99} \mathrm{Mo} /{ }^{99 \mathrm{~m}} \mathrm{Tc}$ gel generator has five principal components: (a) a shielded belly to safely house the radioactivity of ${ }^{99} \mathrm{Mo}$; (b) stainless steel thin tubing to extract the ${ }^{99 \mathrm{~m}} \mathrm{Tc}$; (c) outer protective casing; (d) normal saline as eluent and evacuated vials to collect ${ }^{99 \mathrm{~m}} \mathrm{Tc}$; (e) provision for aseptic membrane air filter and solution filter fitted on-line.

There is a need for a second guard column to trap traces of any co-eluted ${ }^{99} \mathrm{Mo}$; this second column can be integrated along with the zirconium molybdate gel bed or kept as a separate entity. For generators operated from a centralized facility, the column need not necessarily be housed in lead shielding, as the generator assembly itself could be placed within a small, well shielded, hot cell. Provision needs to be made for elutions to be performed in a remote manner and for the discharge of the gel bed and replacement of the gel column when it 
expires. For the portable generators, the gel bed dimensions dictate the amount of lead shielding and therefore the overall weight of the generator.

Other essential attributes in the generator system are: user friendliness, sturdiness, radiological safety and cost effectiveness. A generator assembly design which facilitated the recycling of shielding and certain other components would help to bring down costs and also make it environmentally friendly.

\subsection{INDIAN PRODUCTION FACILITY}

\subsubsection{Shielded cells for specific operations}

A $100 \mathrm{~mm}$ lead shielded production facility comprising four interconnected processing cells (referred to as MPC-1 to MPC-4) was designed and erected for the production operations (Fig. 64). Each cell was equipped with specially designed tools and instrumentation to suit operational requirements.

— In the first cell (MPC-1), the sodium molybdate ${ }^{99}$ Mo solution containers are handled. Using a specially designed tool, the contents of the container are transferred to a pooling vessel under suction.

- In the second cell (MPC-2), the entire process from precipitation of zirconium molybdate ${ }^{99} \mathrm{Mo}$ gel to converting the molybdate to free flowing granules is carried out. This cell is equipped with process vessels such as a mixing vessel, specially designed filters, a cake collection dish, a granule receiver vessel, and tools including a microwave oven, an infrared lamp (250W) for drying, a peristaltic pump for solution or slurry transfers and a pneumatic powered material handling system (Figs 65 and 66). The material handling system can be moved to different pre-programmed stations such as the microwave drying station and infrared drying station with three dimensional controlled movement.

- In the third cell (MPC-3), the zirconium molybdate granules are dispensed into individual glass columns using a specially developed dispensing device into which a variable quantity of granules can be dispensed. The rubber closure and aluminium cap are inserted to seal the column using special pick and place devices, and the columns are crimped remotely. The cell also has provisions for washing the column beds with saline under suction.

- In the fourth cell (MPC-4), the glass columns containing activity are transferred into a preassembled cold generator assembly, the top shielding plug is inserted in place and the generator is moved outside the MPC-4 to the elution testing station with a conveyor system. 


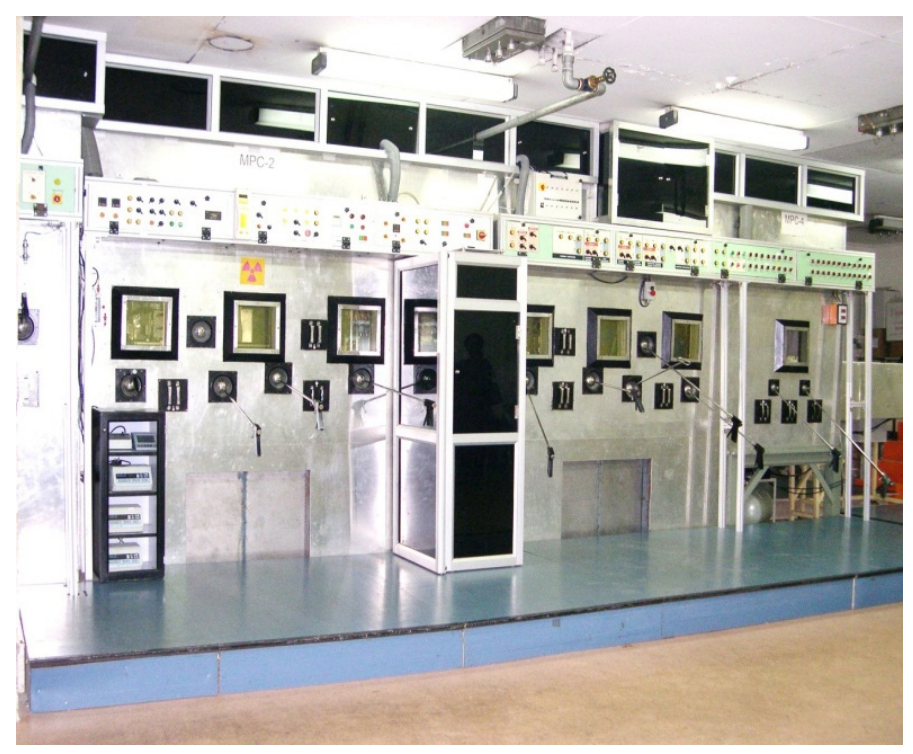

FIG. 64. Gel generator production facility at BRIT, India - the hot cell windows are visible. Photograph courtesy of BRIT, India.

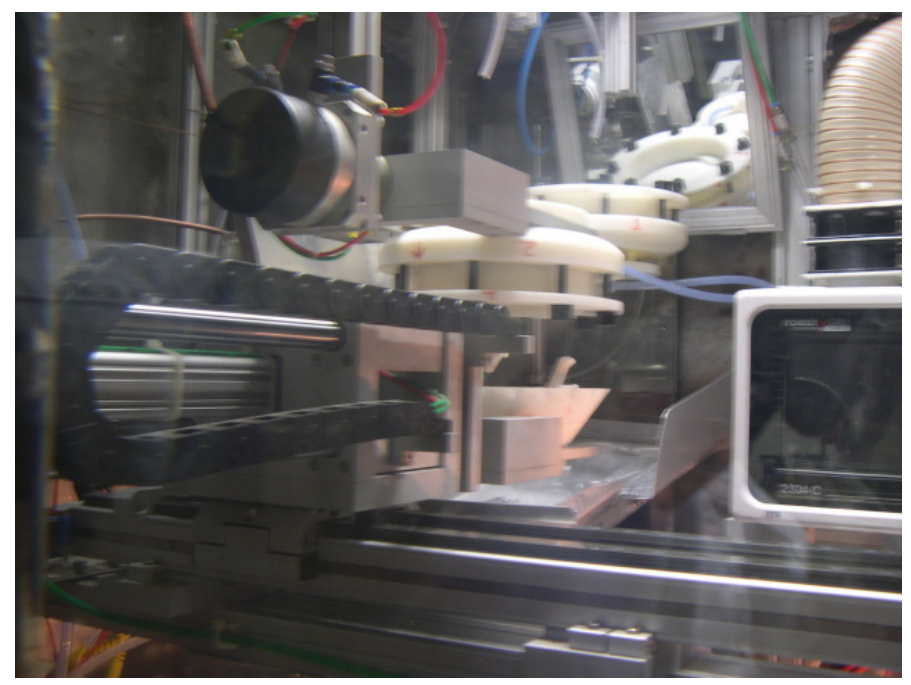

FIG. 65. Special process vessels and material handling systems in the hot cells. Photograph courtesy of BRIT, India. 


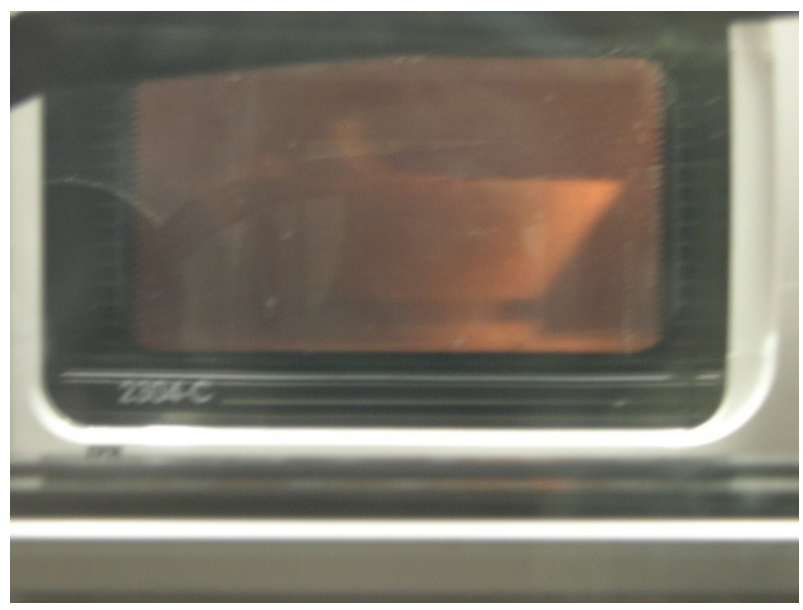

FIG. 66. Gel cake drying in microwave during a remote operation. Photograph courtesy of BRIT, India.

\subsubsection{Process automation}

Special process vessels were designed and fabricated for gel preparation, filtration, drying of filtered cake and granule collection. Solution and slurry transfers were affected using peristaltic pumps. The crucial steps for automation were addressed in the following manner.

\subsubsection{Filtration}

India found that that following precipitation, filtration had to be carried out within 5-10 min. Longer digestion periods of the precipitate with the mother liquor, when the filtration rate was slow, caused changes in the structure and composition of the precipitate. In selecting a filtration technique, two factors had to be considered: the filtration rate and the quantitative recovery of dewatered gel cake.

A special Büchner type filter funnel was designed and polypropylene filter cloth of specific porosity was used. Provision was made for easy replacement of the filter cloth. Zirconium molybdate ${ }^{99} \mathrm{Mo}$ gel slurry was transferred to twin filter assemblies using a peristaltic pump. Filtration was carried out under vacuum using an oil free, moisture free diaphragm type vacuum pump and the filtered cake was recovered by inverting the filter and applying compressed air. Filtration time was $10-15 \mathrm{~min}$ to convert $25 \mathrm{~g}$ Mo to zirconium molybdate ${ }^{99} \mathrm{Mo}$. 


\subsubsection{Drying}

At the end of the filtration stage, the gel cake contains $\sim 85 \%$ water, which needs to be removed. Since it is necessary to leave the structural water undisturbed to enable ${ }^{99 \mathrm{~m}} \mathrm{Tc}$ elution from the matrix, drying has to be carried out in a controlled manner. To reduce the drying time, a domestic microwave oven wired for remote operations was used, and drying was carried out at a controlled intensity.

The gel cake from both filters was discharged after filtration into a collection vessel. The cake collection dish was placed into a domestic microwave oven by pneumatically operated actuators. Special ducting was connected to the oven to exhaust the moisture laden air during drying of the gel cake.

Under optimized conditions, it took $\sim 1 \mathrm{~h}$ to dehydrate approximately $500 \mathrm{~g}$ of gel cake (from $25 \mathrm{~g}$ Mo converted to zirconium molybdate ${ }^{99} \mathrm{Mo}$ ).

\subsubsection{Conversion to granules}

The dried lumps were transferred into another vessel and rendered into granular form using a shower arrangement for spraying normal saline. The granules were converted into free flowing form by further drying under an infrared lamp.

\subsubsection{Dispensing gel powder into glass columns and sealing}

Free flowing gel powder needs to be dispensed into individual glass columns in the desired quantity, and sealed. This was done with special purpose machines designed and developed at BRIT. Each station had one machine which accomplished a specific operation such as powder dispensing, rubber bung insertion, aluminium cap insertion, column crimping and column bed washing.

A variable capacity powder dispenser device was specially designed to dispense $4-10 \mathrm{~g}$ of powder accurately $(+2.5 \%)$ by remote operation. The parameters of the bulk density of the powder and the dispensing time were correlated and the dispensing time was set to achieve variable filling as required.

\subsubsection{Generator design}

The Indian gel generator is a dual column system comprising a primary column containing zirconium molybdate ${ }^{99}$ Mo gel granules and a secondary acidic alumina purification column for adsorption of traces of any co-eluted ${ }^{99} \mathrm{Mo}$. While designing the generator assembly, due consideration was given to the necessity of housing dual columns with provision to disconnect the secondary alumina column 
if needed and render it compatible for applying suitable concentration procedures for availing pertechnetate of a higher radioactive concentration. Other features, such as making the design amenable to recyclability, the ease of dismantling and assembling and the incorporation of on-line sterile membrane filters were taken into consideration while developing the generator assembly.

The compact portable generator assembly has an external casing of ABS plastic and internal components of lead and stainless steel (Figs 67 and 68). The unique design of the 'cold' generator assembly was well appreciated during the $\mathrm{CRP}$, and an order of generator assemblies to Kazakhstan was executed as part of the CRP.

\subsection{KAZAKHSTAN PRODUCTION FACILITY}

\subsubsection{Shielded cell and process automation}

Initially, the gel generator production procedure was adopted for routine operation from a centralized facility with distribution of sodium pertechnetate ${ }^{99 \mathrm{~m}} \mathrm{Tc}$ to individual centres. As experience was gained and the demand for portable generators grew, efforts were initiated to change over to the production of portable generators through revamping existing facilities and processes at INP.

The technological set-up is shown in Fig. 69.

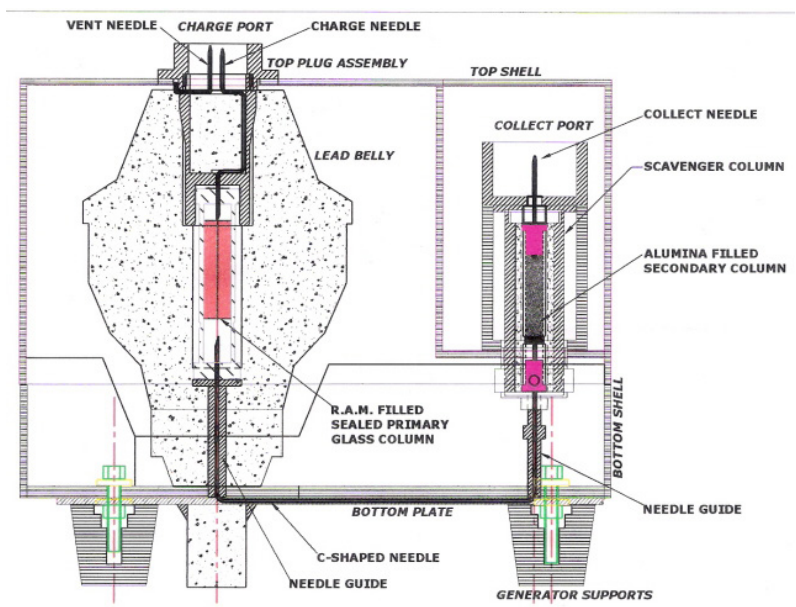

FIG. 67. Sectional view of Geltech generator. Figure courtesy of BRIT, India. 


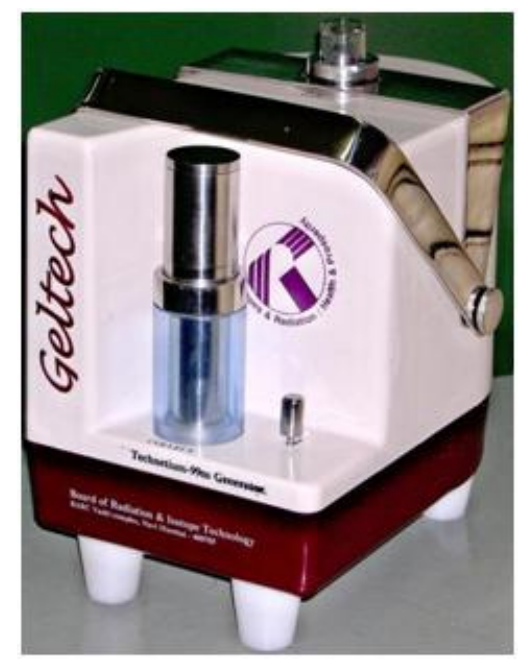

FIG. 68. Geltech generator used by BRIT.

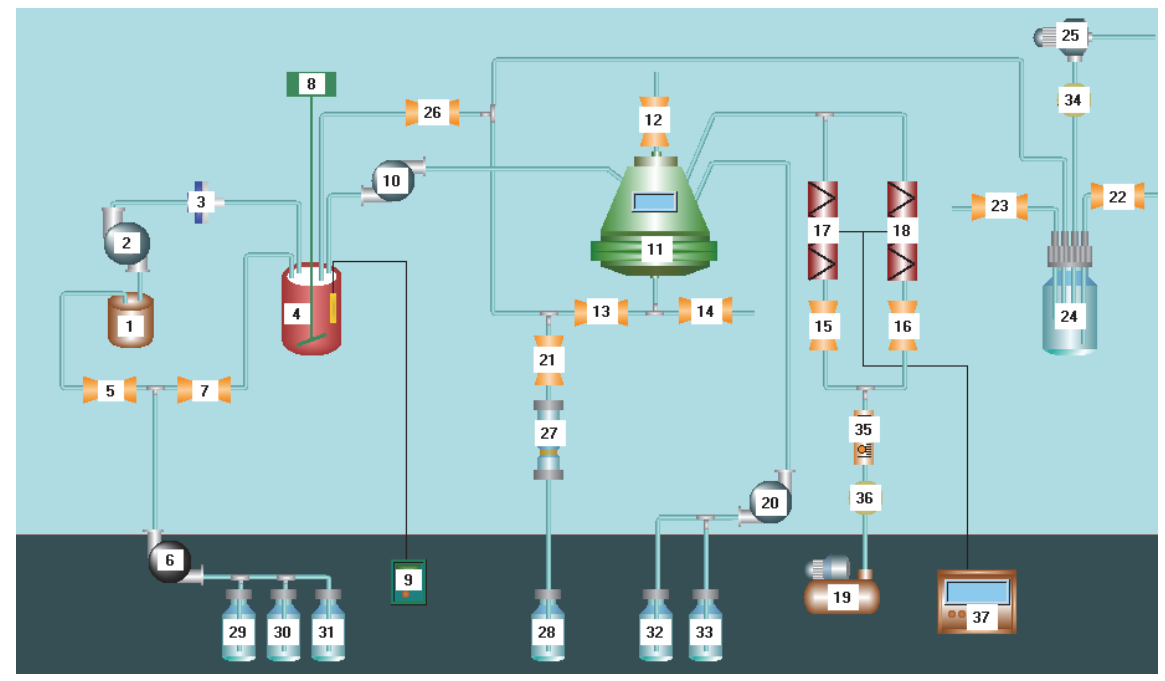

FIG. 69. Symbolic circuit of ${ }^{99} \mathrm{Mo}-\mathrm{Zr}$ gel production process. $(1-$ vessel for dissolution of irradiated $\mathrm{MoO}_{3}$; 2, 6, 10, 20 - pumps; 3 - filter; 4 - vessel for synthesis of ${ }^{99} \mathrm{Mo}-\mathrm{Zr}$ gel; 5, 7, 12,13,14,15,16,21,22, 23, 26-valves; 8-stirrer; 9 - pH meter; 11 -vessel for filtration, drying, decrepitating and dispensing of ${ }^{99} \mathrm{Mo}-Z r$ gel powder; 17, 18 - air heater; 19 - compressor; 24 - vessel for waste; 25 - vacuum pump; 27 - column; 28-33-vessels for reagents; 37 - thermocontroller.) 
Vessels for gel synthesis and an assembly which integrates filtration, gel drying and gel granule dispensing were designed and fabricated in Kazahkstan (Figs 70, 71 and 72).

The gel synthesis equipment (Fig. 70) was used for the dissolution of irradiated $\mathrm{MoO}_{3}$, the synthesis of sodium polymolybdate and the slow precipitation of zirconium polymolybdate over a $30 \mathrm{~min}$ period without stirring. The gel slurry was transferred to the special equipment (Fig. 71) for filtration under vacuum. Water was removed from the gel cake by passing heated compressed air at $\leq 100^{\circ} \mathrm{C}$ for approximately $8 \mathrm{~h}$. Dewatered cake was fragmented using cold water at $3-10^{\circ} \mathrm{C}$ followed by conditioning with saline. Further drying using heated compressed air at $\leq 100^{\circ} \mathrm{C}$ rendered free flowing granules ready for dispensing in columns. For filling of the gel generator columns with dried ${ }^{99} \mathrm{Mo}-\mathrm{Zr}$ gel, the same equipment (Fig. 71) was used after a rotation of $180^{\circ}$.

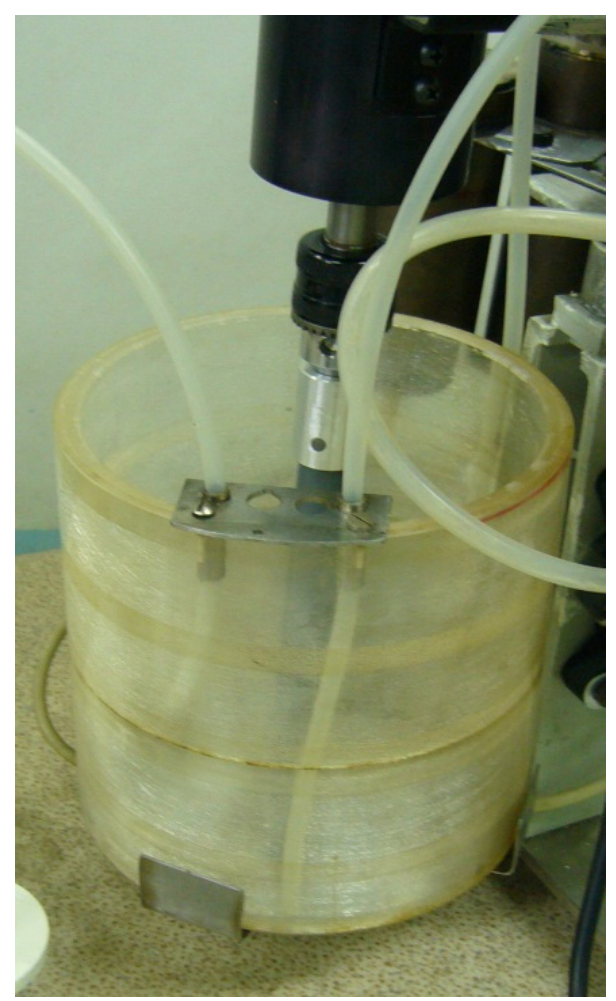

FIG. 70. Gel synthesis equipment. Photograph courtesy of INP, Kazakhstan. 


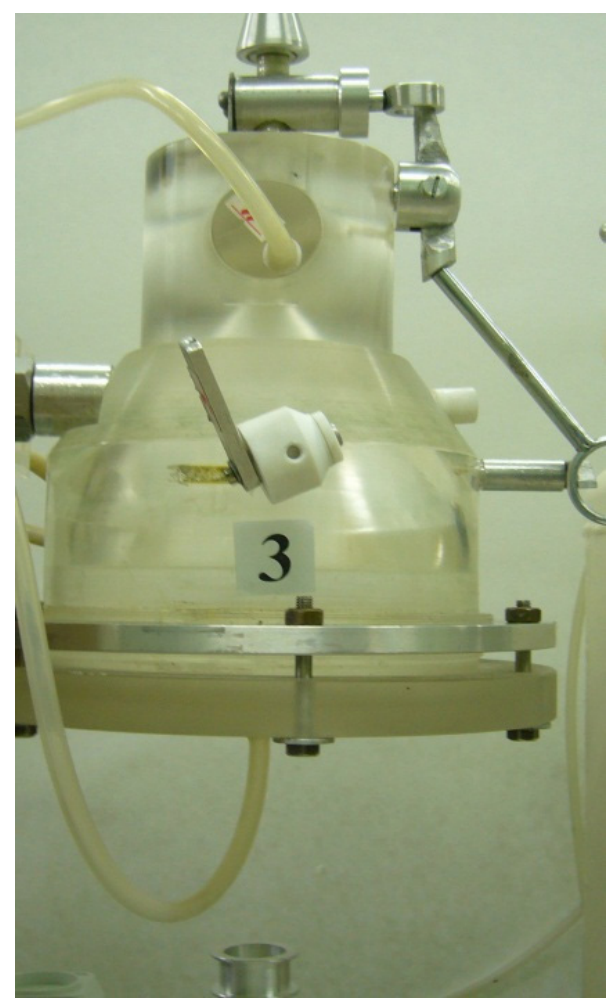

FIG. 71. Equipment for filtration, drying and filling of dried gel granules. Photograph courtesy of INP, Kazakhstan.

For loading 20 generators with gel, $100 \mathrm{~g}$ of dry zirconium molybdate gel need to be processed ( $40 \mathrm{~g}$ irradiated $\mathrm{MoO}_{3}$ ). The most critical steps for synthesis were filtration $(\sim 2 \mathrm{~h})$ and drying $(\sim 8 \mathrm{~h})$ using heated compressed air at $100^{\circ} \mathrm{C}$. Full synthesis time from Mo dissolution to washing of dried gel was $\sim 22 \mathrm{~h}$.

A special transport container of $40 \mathrm{~mm}$ lead (Fig. 72) was designed for housing the filled radioactive gel column during transport to a clean workstation for integration with the generator assembly (Fig. 73). Generator assemblies were procured from BRIT, India. 


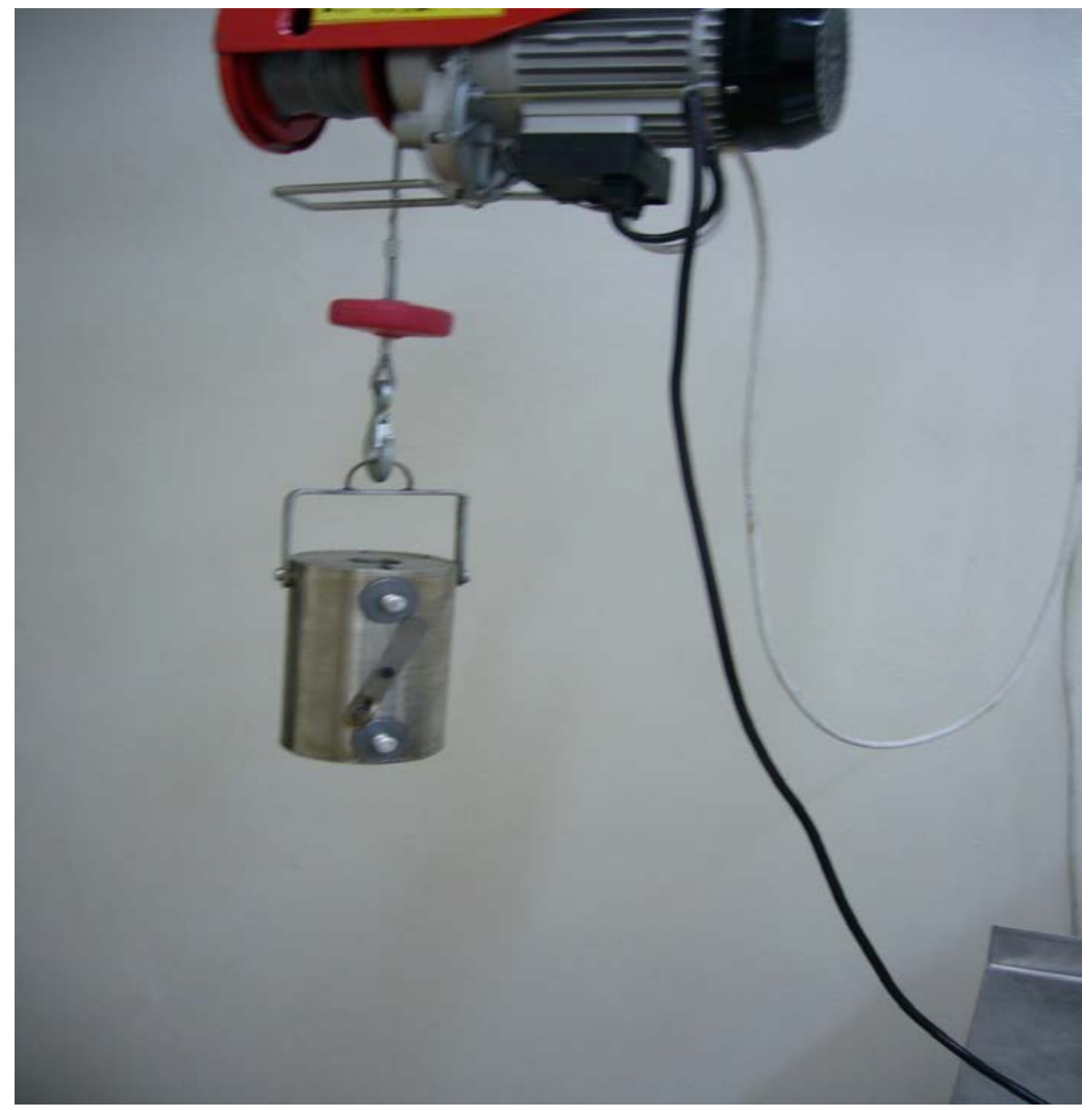

FIG. 72. Transport container for gel column. Photograph courtesy of INP, Kazakhstan.

\subsection{FACILITY OPERATIONS AND PRODUCTION EXPERIENCE}

\subsubsection{Indian experience}

Subsequent to the development of process technology and the facility, a formal review of the safety features was carried out by the regulatory authority in India, the Atomic Energy Regulatory Board (AERB). AERB granted a graded clearance for ${ }^{99} \mathrm{Mo}$ activity handling, progressively increasing from $2 \mathrm{Ci}$ (74 GBq) to $10 \mathrm{Ci}(370 \mathrm{GBq})$ and $30 \mathrm{Ci}(1.1 \mathrm{TBq})$ per batch during the course of the CRP. 


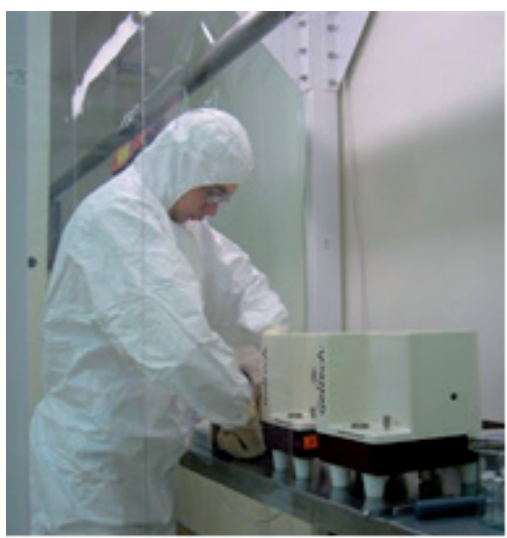

FIG. 73. Assembling of ${ }^{99 m} T c$ gel generators with $Z r^{99}$ Mo gel in the clean module. Photograph courtesy of INP, Kazakhstan.

The production facility in India has been operational for the last five years, initially on a fortnightly and later on a weekly basis. In a single $8 \mathrm{~h}$ working shift, $50 \mathrm{~g}$ of $\mathrm{Mo}\left(75 \mathrm{~g} \mathrm{MoO}_{3}\right)$ are converted to $160-170 \mathrm{~g}$ zirconium molybdate gel granules and used for preparing 15-25 generators.

The process yield is $75-80 \%$. The typical specific activity of indigenous (n, $\gamma$ ) ${ }^{99}$ Mo used for processing is $\sim 11-15 \mathrm{GBq} / \mathrm{g}{ }^{99} \mathrm{Mo}$ and generators with $9 \mathrm{GBq}$ of activity on the calibration date are supplied to radiopharmacies. Generators with between $15 \mathrm{GBq}$ and $28 \mathrm{GBq}$ of activity were occasionally supplied by spiking $(\mathrm{n}, \gamma)$ produced ${ }^{99} \mathrm{Mo}$ with fission moly. Indian production data from 2006-2012 is shown in Table 11. Generators are supplied to all hospitals on a returnable basis. The main radioactive gel glass column, needles and secondary alumina column are removed from the generator assembly, stored and disposed of appropriately, and non-consumable hardware parts of the generator are sanitized and reused. Apart from being an environmentally friendly initiative, recycling generator hardware has helped to make gel generators more cost effective.

The generators are marketed under the name 'Geltech' and 238 batches of generators have been processed. More than 3000 generators have been produced and 2850 generators have been supplied to nuclear medicine hospitals in India at the time of writing. ${ }^{10}$ The ${ }^{99 \mathrm{~m}} \mathrm{Tc}$ elution efficiency when eluted with $10 \mathrm{~mL}$ saline is $\sim 75 \%$. The characteristics of sodium pertechnetate eluted from Geltech generators are shown in Table 12. The eluates were found to be compatible

${ }^{10}$ The other 150 generators were used for in-house evaluations, and research and development. 


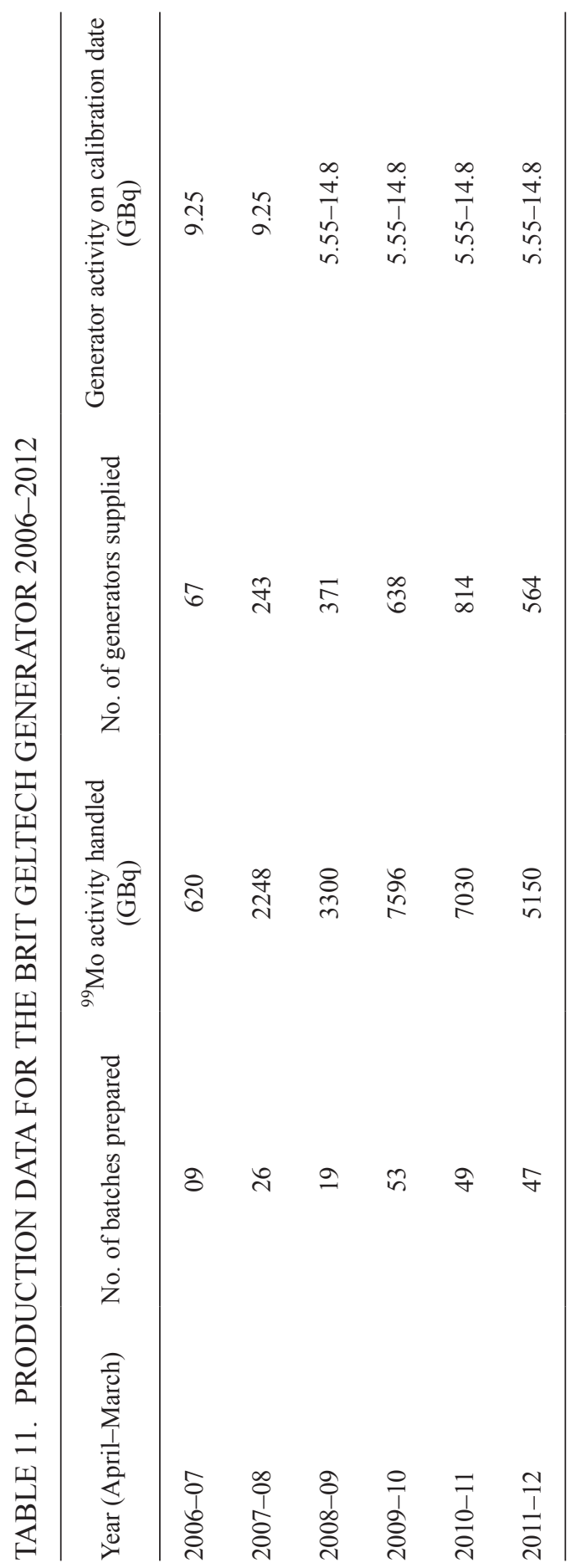


with preparing all ${ }^{99 \mathrm{~m}} \mathrm{Tc}$ radiopharmaceuticals such as ${ }^{99 \mathrm{~m}} \mathrm{Tc}$ MDP, ${ }^{99 \mathrm{~m}} \mathrm{Tc}$ MIBI, ${ }^{99 \mathrm{~m}} \mathrm{Tc} \mathrm{EC},{ }^{99 \mathrm{~m}} \mathrm{Tc}$ ECD and ${ }^{99 \mathrm{~m}} \mathrm{TcDTPA}$; good quality images have been obtained during use in patients.

TABLE 12. CHARACTERISTICS OF SODIUM PERTECHNETATE OBTAINED FROM GELTECH GENERATORS

\begin{tabular}{lc}
\hline Properties & Results \\
\hline${ }^{99 \mathrm{~m}} \mathrm{Tc}$ elution & complete in $\sim 2 \mathrm{~min}$ \\
$\%{ }^{99 \mathrm{~m}} \mathrm{Tc}$ yield & $\sim 75 \%$ in $10 \mathrm{~mL}$ normal saline \\
$\mathrm{pH}$ & $4.5-6$ \\
Radionuclidic purity & $>99.9 \%$ as ${ }^{99 \mathrm{~m}} \mathrm{Tc}$ \\
${ }^{99} \mathrm{Mo} /{ }^{99 m} \mathrm{Tc}$ & $<0.01 \%$ \\
Radiochemical purity & $>95 \%$ as ${ }^{99 \mathrm{~m}} \mathrm{TcO}_{4}^{-}$ \\
Chemical purity & $\mathrm{Mo}^{+6}<10 \mathrm{ppm}, \mathrm{Al}^{+3}<10{\mathrm{ppm}, \mathrm{Zr}^{+4}<10 \mathrm{ppm}}$ \\
\hline
\end{tabular}

\subsubsection{Prospects of post-elution concentration of pertechnetate}

Post-elution concentration (PEC) of pertechnetate would help to enhance the prospects to utilize (n, $\gamma){ }^{99}$ Mo along with larger beds of zirconium molybdate columns. Indian work has shown that the purification trap column of alumina contained in the zirconium molybdate system can be used for the dual purposes of purification and concentration. Use of de-ionized water as a primary eluent, after carefully applying pretreatment procedures on zirconium molybdate granules, enabled trapping traces of ${ }^{99} \mathrm{Mo}$ and having all the ${ }^{99 \mathrm{~m}} \mathrm{Tc}$ eluted; subsequent elution of the alumina trap bed with a few $\mathrm{mL}$ of normal saline releases pure ${ }^{99 \mathrm{~m}} \mathrm{Tc}$. The primary zirconium molybdate gel column, which contains a high concentration of chloride anions, was conditioned by washing with $200 \mathrm{~mL}$ of a solution of equal parts $0.05 \mathrm{M} \mathrm{NH}_{4} \mathrm{OAc}$ and $\mathrm{AcOH}, \mathrm{pH} \sim 5$, followed by $50 \mathrm{~mL}$ of de-ionized water to remove chloride anions. The column effluents were checked for absence of chloride. ${ }^{99 \mathrm{~m}} \mathrm{Tc}$ eluted in $10 \mathrm{~mL}$ de-ionized water was passed through an acidic alumina bed $(2 \mathrm{~g}, 35 \times 8 \mathrm{~mm})$ to trap ${ }^{99 \mathrm{~m}} \mathrm{Tc}$ along with traces 
of co-eluted molybdate ${ }^{99} \mathrm{Mo}$. The pertechnetate retained on the alumina column was selectively re-eluted with $\sim 3 \mathrm{~mL}$ of normal saline.

The post elution concentration procedure standardized in India provides a nearly threefold increase in the radioactive concentration of ${ }^{99 \mathrm{~m}} \mathrm{Tc}$. The duration of this concentration process is approximately $3 \mathrm{~min}$. The critical requirement is to ensure the absence of a macroscopic anionic load in the primary eluate. The prospects of adopting such a scheme in a central radiopharmacy setting, to access pertechnetate of a higher radioactive concentration, especially for preparing ${ }^{99 \mathrm{~m}} \mathrm{Tc}$ MIBI, appear promising. The Geltech generator design has been suitably modified for adopting the post-elution concentration procedure also for the portable generator type (Fig. 74).

\section{Diagram for elution of ${ }^{99 \mathrm{~m}} \mathrm{Tc}$}

Standard elution vs post-concentration elution

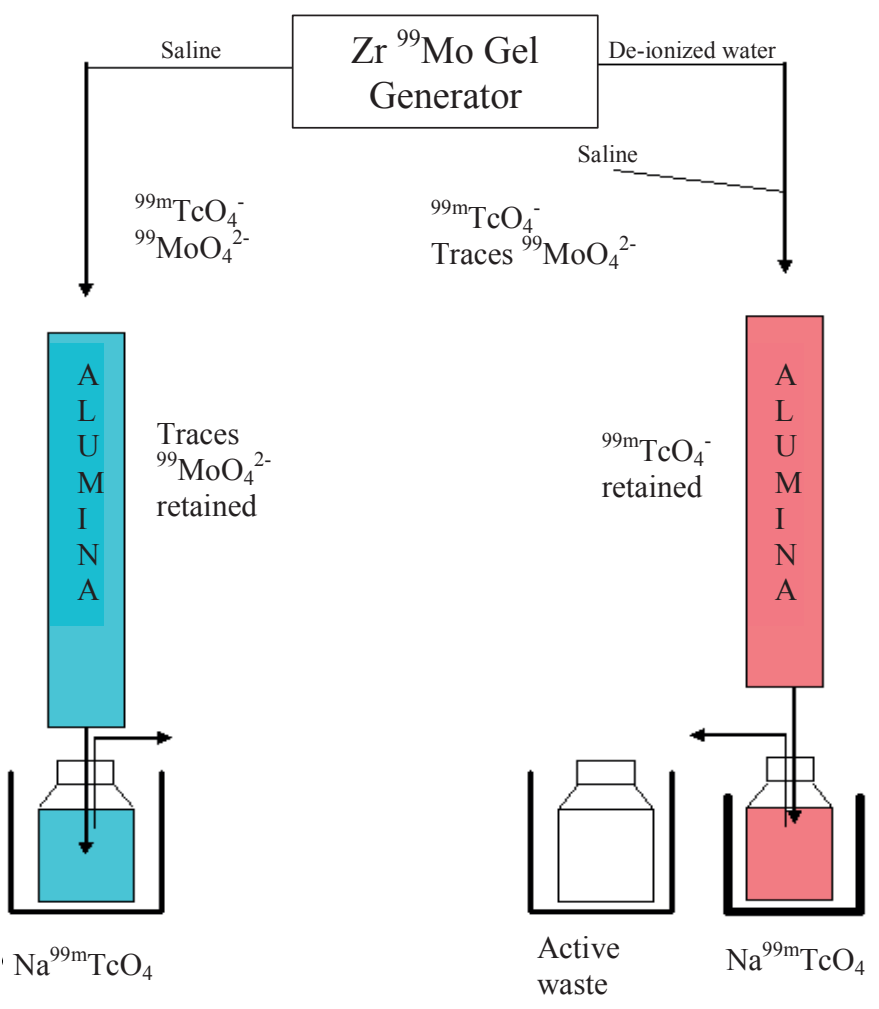

FIG. 74. Diagram of post-elution concentration process developed at BRIT. 


\subsubsection{Kazakhstan experience}

The zirconium molybdate gel based generators were regularly produced for centralized use with a large gel column, and efforts to supply portable units (with 2/4/6 g of gel) are in progress.

During the CRP, the technology for the production of ${ }^{99 \mathrm{~m}} \mathrm{Tc}$ portable gel generators using $(\mathrm{n}, \gamma){ }^{99} \mathrm{Mo}$ with low $(0.8-1.5 \mathrm{mCi} / \mathrm{g})$ specific activity was developed successfully in Kazakhstan. High quality radiopharmaceutical sodium pertechnetate ${ }^{99 \mathrm{~m}} \mathrm{Tc}$ solution for injection from central and portable gel generators was registered and certified and permission was granted to use it in hospitals in the country. Table 13 shows the quality parameters of Kazakhtan's gel generators manufactured under the CRP.

\subsection{CONCLUSION}

The Indian experience of routinely operating a production facility with weekly manufacture, producing more than 3000 generators in the past five years, has established the feasibility and technological viability of gel generator technology for small scale production using $(n, \gamma){ }^{99}$ Mo. The generator activity is a function of the specific activity of ${ }^{99} \mathrm{Mo}$ used for processing and the quantity of zirconium molybdate granules in the column. In the present set-up, this could be varied up to a maximum of $10 \mathrm{~g}$ as defined by the column capacity and with the volume required for elution being kept at $10 \mathrm{~mL}$. Thus when supplying a batch processed using $15 \mathrm{GBq} / \mathrm{g}{ }^{99} \mathrm{Mo}$, the production of generators with a maximum activity of $15 \mathrm{GBq}$, calibrated for two days post-production, is feasible. Additionally, recycling the generator hardware has been demonstrated and makes the process more cost effective and environmentally friendly.

The details available from both the Indian and Kazakh experiences will be of considerable value for other potential small scale producers who may be planning to pursue gel generator production. The gel technology option could very viably serve to meet the needs of states with low to medium ${ }^{99 \mathrm{~m}} \mathrm{Tc}$ demand and local reactor production capability for $(n, \gamma){ }^{99}$ Mo. Kazakhstan's success in adopting gel generator technology through the CRP indicates that this is a feasible route for small scale ${ }^{99 \mathrm{~m}} \mathrm{Tc}$ production. 


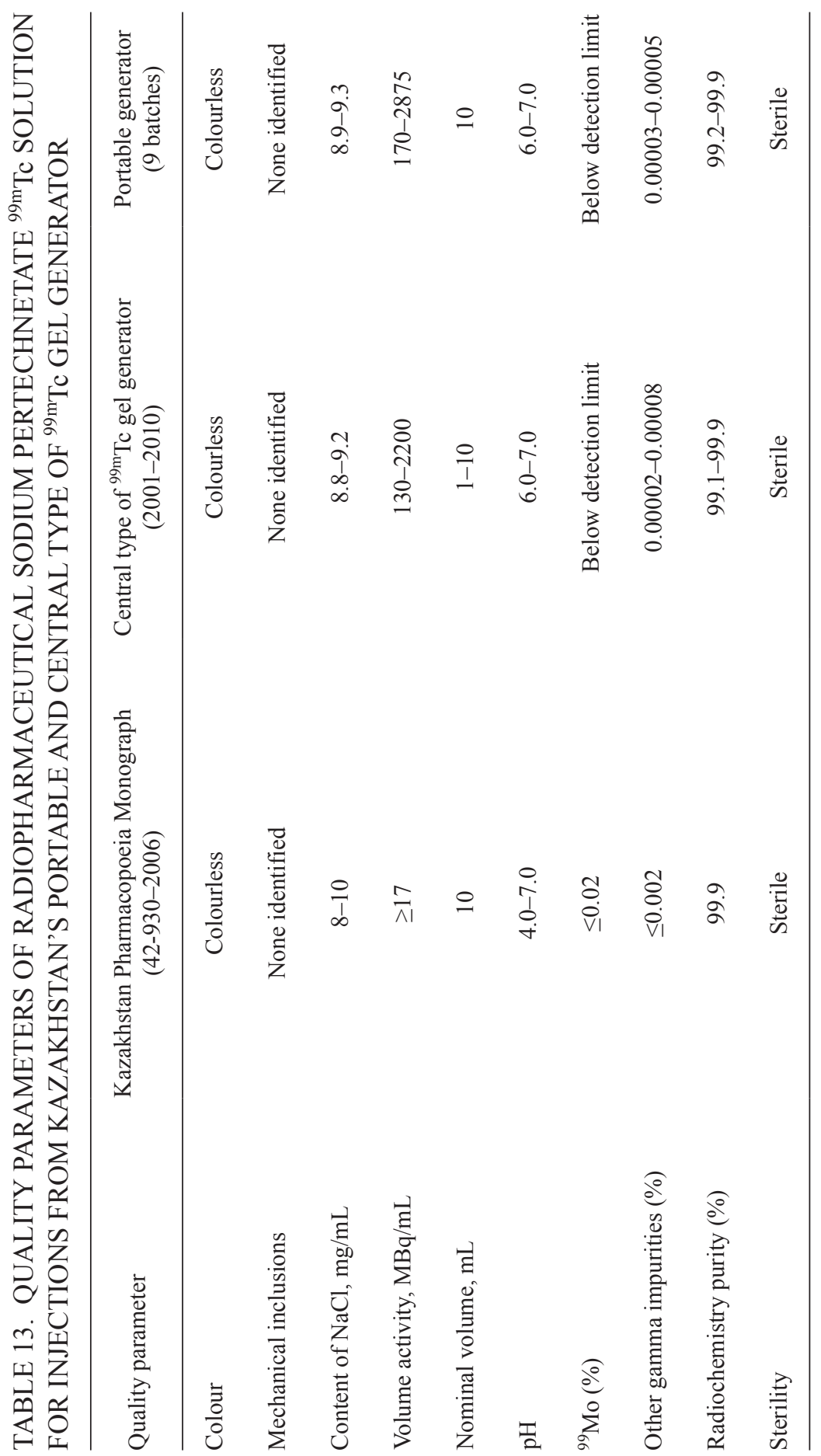




\section{TRANSPORT ISSUES, WASTE MANAGEMENT AND QUALITY ASSURANCE}

\subsection{TRANSPORT ISSUES AND CONTAINERS}

Transportation of ${ }^{99} \mathrm{Mo}$ by-products (targets, solution) is not easily accomplished; there are strict international guidelines about how radioactive materials must be transported. Additionally, because of ${ }^{99} \mathrm{Mo}$ 's short half-life, a strong transport infrastructure is vital to being a feasible supplier.

The CRP did not specifically address transport related issues, though they cannot not be overlooked when planning production facilities and the associated infrastructure. The ${ }^{99} \mathrm{Mo}$ fission production process involves the transport of various materials, including: LEU targets, irradiated targets for processing, ${ }^{99}$ Mo solution and waste products for long term storage. As the materials to be transported at each stage are usually highly radioactive, certified shielded casks must be used for most of these transports. Figure 75 shows examples of one type of transport cask designed and certified to carry radioactive material for internal transport in PINSTECH, Pakistan.

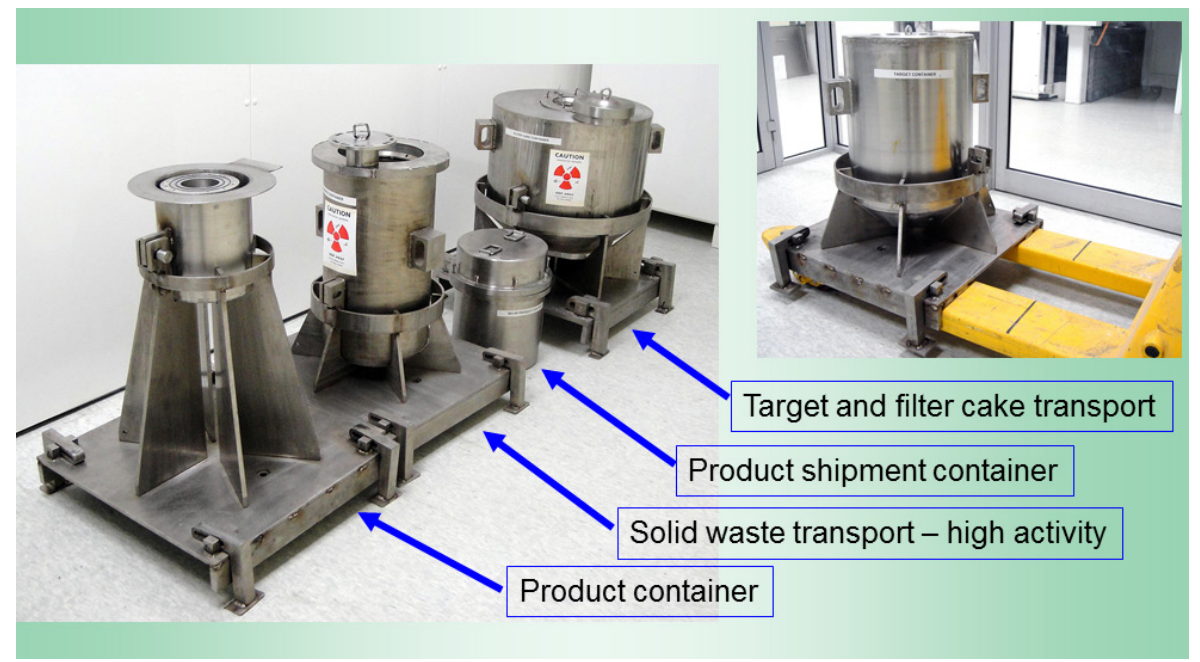

FIG. 75. Transport casks for different duties within the ${ }^{99}$ Mo production process at PINSTECH. Courtesy of GSG. 
Typically, the casks are used as follows: irradiated targets are loaded under water into the target basket of the cask. The basket is inserted into the cask which has been lowered into the pool, and the cask is closed and sealed. Using the reactor crane, the cask is lifted from the reactor pool, dewatered via an inclined borehole which is closed with a special screw, positioned on a fork lift, and after fixation and safety check - transported into the fission ${ }^{99}$ Mo production plant. Once in the production plant, the cask is transported to the dissolution cell of the hot cell complex and positioned for discharge. After another safety check, the lid of the interlock system of the hot cell is opened. The lifting device inside the dissolution cell is used to pull the lid of the cask into the cell. Then the target basket is lifted into the cell where it will remain as solid waste. The lid of the cask is returned to its original position and the lid of the hot cell interlock is closed again. Finally, the cask is removed from the hot cell complex and checked for surface contamination. For security reasons, the target transport cask is typically stored in a separate room. One of Romania's transfer casks is seen in Fig. 76.

Additionally, the same transport cask can be used - and often is - to move the final product. In the hot cell, the vial containing the ${ }^{99} \mathrm{Mo}$ product (after processing and purification) is inserted into a special steel container with a screw-type lid. The production facility's internal transport cask is connected to the hot cell interlock system, and a steel container holding the product vial is inserted into the cask using the hot cell manipulators which have a special magnetic tool. The lid of the transport cask is returned by the cell crane and the lid of the hot cell interlock is closed. The loaded transport cask is ready for removal from the hot cell. After re-inserting the screws of its lid, the transport cask is transferred with the fork lift to the generator production facility. This cask is also used for transfers of filter cakes which are kept in small steel cans.

The most critical step is the transport of the irradiated LEU targets from the reactor to the production premises, as this is very time sensitive. Ideally, the reactor and processing site will be co-located with a built in provision for transport of the irradiated targets directly from the reactor to the production area, for example, by using the same pool or a connected pool for underwater shielded movement of the transport cask. Obviously, many existing reactors that are not co-located with processing facilities will need to find other ways to move targets efficiently. During the CRP, the team from ICN in Romania shared information on their facilities, which were originally built and used for the post-irradiation examination of fuel elements.

Unlike many other CRP members, ICN had the advantage of an existing infrastructure: a $14 \mathrm{MW}$ research reactor with suitable irradiation conditions for producing radioisotopes, a post-irradiation laboratory with the ability to transfer irradiated targets directly from the reactor, and the ability to handle highly radioactive sources in this transfer device. The design specifications for the 


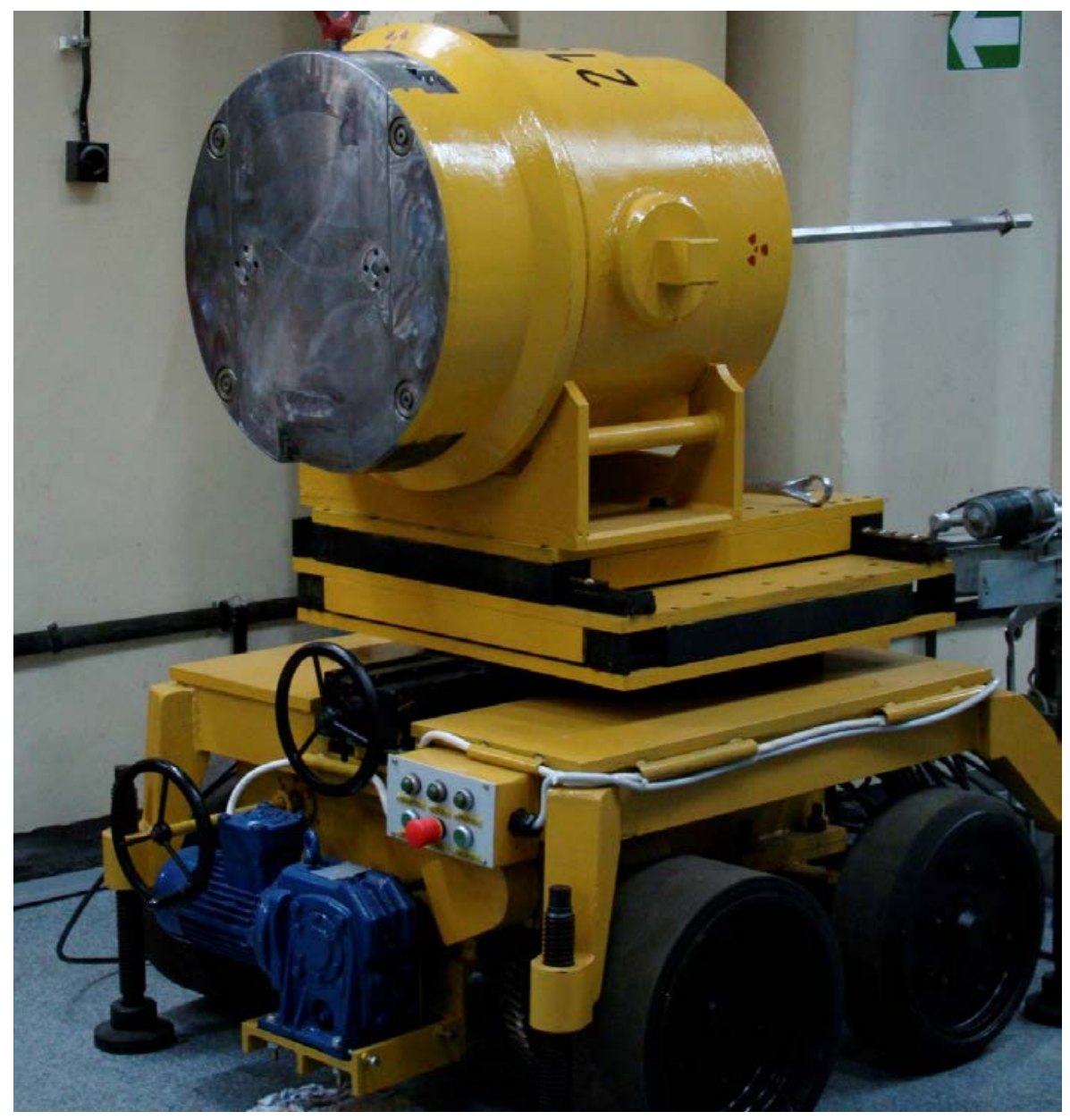

FIG. 76. Transfer cask mounted on transport vehicle developed in Romania. Photograph courtesy of ICN.

transfer device were established in order to ensure the safety and efficiency of the irradiation process without modification of the reactor core structure or the mode of operation. The main feature of the transfer device was its ability to be handled with the same tools as the core components; the irradiated targets can be loaded into the transfer system and transferred under water to the hot cell in the post irradiation examination laboratory without the utilization of a cask or container. Furthermore, all the components of ICN's transfer devices are reusable for every irradiation cycle, thus reducing the amount of radioactive waste generated during target irradiation. 


\subsubsection{Transport cask types}

There are multiple factors that determine the type of packaging used for the transportation of radioactive materials. These are: the quantity of radioactive material shipped, its physical form, its specific radioactivity, the energy of its emissions and their half-life. In general, responsible parties must ensure that the external radiation dose rate is limited to an amount that results in not more than approximately $0.2 \%$ of background radiation.

Two types of containers are used for transportation of radioisotopes: Type A containers and Type B containers.

Type A containers are small packages that may only contain low levels of radioactive material and are designed and tested to withstand the normal rigours of surface and air transportation, such as exposure to rain, rough handling and slight mishaps. Since the radioactive material content is low in these containers, the hazard is generally low, even if the container is badly damaged in an accident. All packaging is leak tested and transported liquids are packaged to limit any spills, in the same manner as any other hazardous liquid being transported. Type A containers are certified by individual national nuclear regulatory authorities, such as the Nuclear Regulatory Commission (NRC) in the USA and the AERB in India. Upper limits are therefore prescribed in the regulations for the activities of individual radionuclides that can be transported in such packages. In order to qualify as Type A packaging, specimens of the design must pass a series of performance tests which are designed to produce the type of damage that would be caused by small mishaps under normal transport conditions.

Highly radioactive material such as large quantities of ${ }^{60} \mathrm{Co}$, bulk ${ }^{99} \mathrm{Mo}$ and even irradiated nuclear fuel is transported in Type B casks that are designed, tested and certified to withstand severe accident conditions in addition to conditions of normal transportation. Type B containers may have as much as $250 \mathrm{~mm}$ of lead shielding or similar amounts of depleted uranium to protect against radioactive emissions, and may weigh hundreds of $\mathrm{kg}$. They are certified to withstand accident conditions that may include, inter alia, a drop of $9 \mathrm{~m}$ onto an unyielding surface, a drop onto a metal pin $150 \mathrm{~mm}$ in diameter, an engulfing fire burning at temperatures of up to $804^{\circ} \mathrm{C}$ that lasts half an hour and immersion in water for $8 \mathrm{~h}$. By meeting the above conditions, authorities can be assured that the container will not release more than the permitted amount of radioactive contents, should it encounter such accidental conditions. The design of a Type B container must be independently approved by national authorities on the basis of a safety analysis report. The amount of radioactive material that can be transported is specified in the approval certificate for each particular type of container. These certified containers, called $\mathrm{B}(\mathrm{U})$ - U for universal — casks, are in extensive use for the transport of bulk radioisotopes around the world. 
The types of casks needed for a specific production set-up - and the authorization procedures for licensing them - vary greatly from one State to another. Transport within the premises of a nuclear centre in an isolated area (e.g. in Egypt or Romania) will be easier to manage, as opposed to transport of the same material between facilities or across State boundaries. Both will involve similar processes of licensing casks, monitoring and reporting transport implementation, tracking and records documentation. Transport security aspects also need to be considered, in addition to complying with transport safety requirements.

Some of the aforementioned points are relevant for the transport of waste products as well, depending upon the location of the waste depository site in relation to the production premises. It may be necessary in many cases to build an adequate storage area for safely storing the waste until it has decayed to a point where it can be moved to a permanent storage or disposal site.

\subsubsection{Shipment of bulk molybdenum}

After its separation and purification, the ${ }^{99}$ Mo product is in the chemical form of sodium molybdate in dilute sodium hydroxide solution, which is appropriate for loading onto ${ }^{99 \mathrm{~m}} \mathrm{Tc}$ generators. As already mentioned, the number of ${ }^{99}$ Mo producers is rather limited, while the number of generator producers (small to large scale) is much larger and also widely distributed across different regions of the world. Because of the short half-life of ${ }^{99} \mathrm{Mo}$, transport of the product to generator manufacturers as quickly as possible is vital; approximately

$1 \%$ of the ${ }^{99}$ Mo decays per $\mathrm{h}$. Adequate infrastructure and careful planning are therefore necessary to enable and ensure fast and reliable transport of the product from the ${ }^{99}$ Mo producer to the generator manufacturers. Geographically well distributed ${ }^{99} \mathrm{Mo}$ production centres also help reduce transport time related decay loss. The transport of the finished product ${ }^{99} \mathrm{Mo}$ solution can be handled following the established procedures and systems for other similar radioactive products. The containers - $\mathrm{B}(\mathrm{U})$ type containers and type A packages - and commercial transport services are easily available and accessible.

\subsection{QUALITY CONTROL AND QUALITY ASSURANCE}

Quality control is of utmost importance in the production of a radiopharmaceutical. All reagents used in the processing must meet purity specifications as cited by the producer and accepted by appropriate regulatory bodies. Since ${ }^{99} \mathrm{Mo}$ is the raw material for the preparation of ${ }^{99 \mathrm{~m}} \mathrm{Tc}$ generators, it is typically categorized by the pharmacopoeial authority as an API, and so a 
thorough quality control must be performed on the final solution containing ${ }^{99} \mathrm{Mo}$. Additionally, the principles of GMP are applicable to the production of ${ }^{99} \mathrm{Mo}$.

\subsubsection{Quality control}

The final product must be certified to meet specified purity standards, and so a quality control laboratory must be a significant part of any production operation. Procedures for performing the quality control analyses must be followed as written. These analyses will require both chemical and radiochemical laboratories, as well as equipment, supplies and instrumentation.

\subsubsection{Quality control of fission ${ }^{99} \mathrm{Mo}$}

There are three monographs available with information on the quality control of ${ }^{99} \mathrm{Mo}$ used in the preparation of ${ }^{99 \mathrm{~m}} \mathrm{Tc}$ generators. One is produced by the United States Pharmacopeial Convention, one by the European Pharmacopoeia and one by the World Health Organization, which deals with international standards. These sources all assume that any ${ }^{99} \mathrm{Mo}$ used will be produced by the fission of ${ }^{235} \mathrm{U}$. There was a recommendation to CRP members to use the specifications from the European Pharmacopoeia (n. 1923), which are outlined in Table 14, because the European Pharmacopoeia regulations are more stringent than the United States Pharmacopeia; meeting European standards ensures that standards for the USA are also met.

TABLE 14. SPECIFICATION OF SODIUM MOLYBDATE $\left({ }^{99} \mathrm{Mo}\right)$ SOLUTION (FROM FISSION) FROM THE EUROPEAN PHARMACOPOEIA

\begin{tabular}{lcc}
\hline Characteristics & Acceptance criteria & Procedures \\
\hline Appearance of the solution & Clear and colourless & Visual inspection \\
Radionuclide identification & $\begin{array}{c}\text { Main emission peaks: } \\
0740 \mathrm{MeV}\end{array}$ & Gamma spectrometry \\
& $\mathrm{pH}>8$ & Indicator paper \\
Alkalinity & &
\end{tabular}




\section{TABLE 14. SPECIFICATION OF SODIUM MOLYBDATE $\left({ }^{99} \mathrm{Mo}\right)$ SOLUTION}

(FROM FISSION) FROM THE EUROPEAN PHARMACOPOEIA (cont.)

\begin{tabular}{lcc}
\hline Characteristics & Acceptance criteria & Procedures \\
\hline Radionuclide impurity & Not more than: & Gamma spectrometry \\
$5 \times 10^{-3} \%{ }^{131} \mathrm{I}$ & \\
$5 \times 10^{-3} \%{ }^{103} \mathrm{Ru}$ & \\
$5 \times 10^{-3} \%{ }^{132} \mathrm{Te}$ & \\
Not more than: & Chromatography / \\
$6 \times 10^{-5} \%{ }^{89} \mathrm{Sr}$ and ${ }^{90} \mathrm{Sr}$ & beta spectrometry \\
& & \\
& Not more than: & Alphaid scintillation counting) \\
$1 \times 10^{-7} \% \alpha$ emitting & impurities & \\
Not more than: & Gamma spectrometry \\
Radiochemical purity & $>95 \%$ & \\
\hline
\end{tabular}

\subsubsection{LEU modified Cintichem process}

In order to perform these quality control tests, it is necessary to have appropriate facilities and competencies. The main issue is how to measure very low levels of radionuclide impurities in the presence of high activities of ${ }^{99} \mathrm{Mo}$. Effective radiochemical separations are needed and should be performed by skilled and well trained operators with a proper infrastructure at their disposal.

ANL provided CRP participants with the Cintichem Quality Control Manual as well as a guidance document on gamma counting samples and a discussion guide for an LEU modified process document originally prepared for BATAN. MURR has also provided a document on quality control method development and testing for LEU Fission ${ }^{99}$ Mo which was originally prepared for the trial run of the process. The MURR document on development of quality control methods is included in Annex I.

Under the CRP, Chile developed quality control processes using gamma and alpha spectrometric methods. Both cold and radioactive synthetic samples were used, always ensuring that the real samples of the final product were emulated. 
Samples including ${ }^{233} \mathrm{U},{ }^{238} \mathrm{U}$ and ${ }^{98} \mathrm{Mo}$, the last one added as a carrier, were prepared to be measured by using alpha spectrometry. Two methods to prepare alpha control samples were tested:

- Drying. The procedure resulted in a non-homogeneous deposit, which was not considered to be useful for the alpha spectrometric measurements.

- Electrodeposition, with sample preparation and sample homogeneity verification in an electrolytic cell. An efficiency of $86 \%$ was obtained for samples prepared with $1 \mathrm{~A}$ of current during 60 min of plating, with the $\mathrm{pH}$ of the solution adjusted to $\mathrm{pH} 2.33$.

An alpha spectrometry system was assembled and calibrated including four PIPS (Passivated Implanted Planar Silicon) detectors for measurement of samples.

\subsubsection{3. $U A l_{\mathrm{X}}$ dispersion target}

Argentina and Egypt routinely perform quality control of ${ }^{99}$ Mo produced by the alkaline dissolution of dispersion LEU targets.

Pakistan was not able to use an LEU foil target for the production of fission ${ }^{99} \mathrm{Mo}$, but ${ }^{99} \mathrm{Mo}$ is being produced by the irradiation of HEI UAl alloy targets in PARR-1. Gamma spectrometric determination of ${ }^{99} \mathrm{Mo},{ }^{131} \mathrm{I}$ and ${ }^{103} \mathrm{Ru}$ activity was performed using a calibrated high purity germanium detector. Beta counting of ${ }^{89} \mathrm{Sr}$ and ${ }^{90} \mathrm{Sr}$ was performed on a calibrated gas flow proportional counter after separation by ion-exchange, and precipitation was performed with the aid of a carrier. Alpha spectrometric determination of the total activity was carried out with a calibrated low background spectrometer after separation by ion exchange and precipitation. The radiochemical purity of ${ }^{99} \mathrm{Mo}$ was determined by means of paper chromatography with a mixture of hydrochloric acid, water, ether and methanol (5:15:50:30) as mobile phase. The distribution of activity on the paper was determined with a scanner, and the specific nuclide content of the relevant areas was measured by gamma spectrometry. Chemical purity was occasionally determined after decay of ${ }^{99}$ Mo by optical emission spectrometry.

\subsubsection{Quality control of $(n, \gamma){ }^{99} \mathrm{Mo}$}

For $(\mathrm{n}, \gamma){ }^{99} \mathrm{Mo}$, special care must be taken concerning the purity of the molybdenum target. Any chemical impurities in the target will be present in the processed solution, and products of the neutron activation may also be present. It is necessary to ensure that the total gamma impurities are less than $0.01 \%$ of 
the total activity of the ${ }^{99 \mathrm{~m}} \mathrm{Tc}$ eluted from the gel generator or any other generator prepared with $(\mathrm{n}, \gamma){ }^{99} \mathrm{Mo}$.

\subsubsection{Quality control of gel generator}

Quality parameters of sodium pertechnetate ${ }^{99 \mathrm{~m}} \mathrm{Tc}$ solution for injection obtained from portable generators have been compared to those from a large column gel generator. The results are shown in Tables 13 and 15. The methods used for quality control tests are those described in the European Pharmacopoeia and in Kazakhstan's national pharmacopoeia. Every generator from every batch has its identity verified and is checked for $\mathrm{pH}$, radionuclide impurities, radiochemical purity, chemical impurities, $\mathrm{NaCl}$ content, radioactivity content and concentration, sterility and apyrogenicity.

India and Kazakhstan routinely perform quality control measures on their ${ }^{99} \mathrm{~m}$ Tc eluted from gel generators. Kazakhstan is the first country to include a monograph on the sodium pertechnetate ${ }^{99 \mathrm{~m}} \mathrm{Tc}$ solution obtained from a gel generator in its national pharmacopoeia. The 2014 version of the Indian Pharmacopoeia will also contain a monograph on gel generator produced sodium pertechnetate ${ }^{99 \mathrm{~m}} \mathrm{Tc}$ solution.

\subsubsection{Quality assurance}

The importance of sustaining a quality assurance programme covering all aspects of the ${ }^{99}$ Mo production chain was discussed at length during this CRP. Some GMP principles to be taken into account when planning a full scale production of ${ }^{99}$ Mo were highlighted.

Firstly, it is important to develop detailed step by step procedures that provide a roadmap for controlled and consistent performance. These written procedures are intended to prevent contamination, mix-ups and errors and are also necessary for compliance and traceability. A validation programme should exist to prove that the system does what it is designed to do, and should also include the validation of general cleaning aspects.

A major concern is to integrate productivity, product quality and employee safety into the design and construction of all facilities and equipment, which should also have a maintenance programme. The purpose is to build quality into products by systematically controlling process components and product related processes such as manufacturing, packaging and labelling, testing, distribution and marketing.

In terms of human resources, competencies for each position should be clearly defined, developed and demonstrated. Finally, it is essential to conduct planned and periodic audits for compliance and performance. 


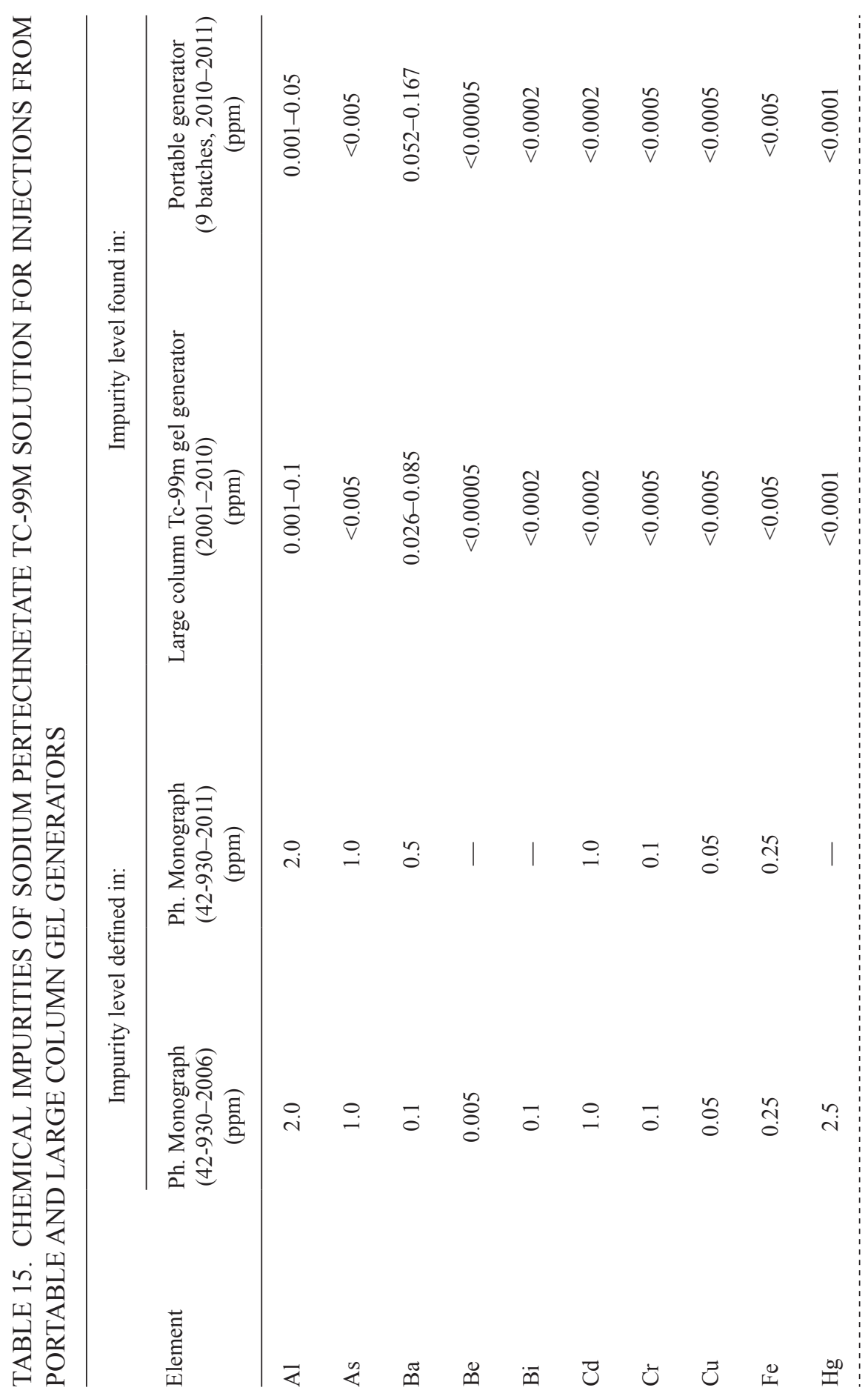




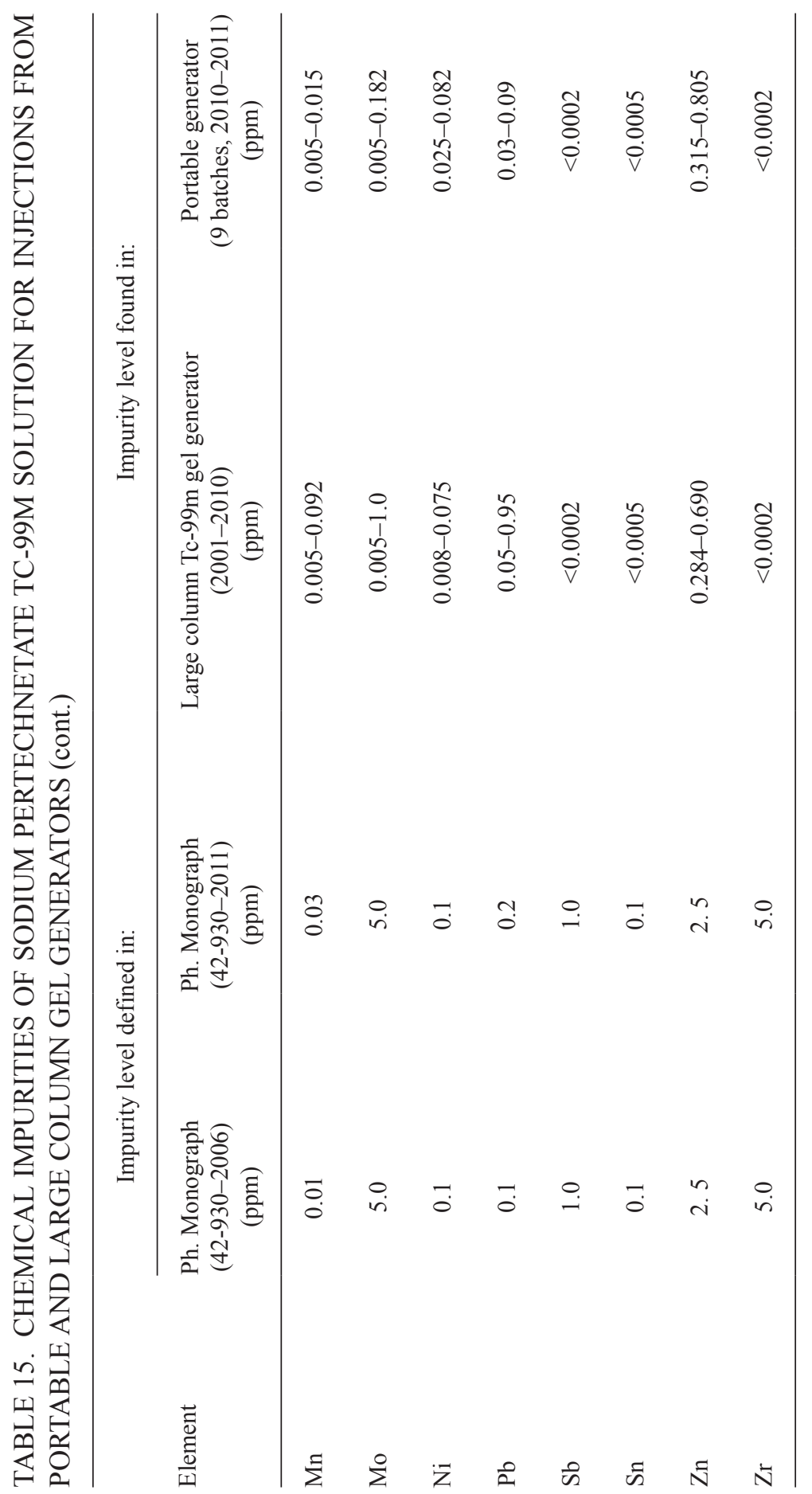


The implementation of these basic principles is necessary to meet regulatory requirements for the production of ${ }^{99} \mathrm{Mo}$. Some recommendations were given to CRP members by ANSTO, MURR, and by institutions in Brazil, Malaysia and Poland, all of which have a well-established quality assurance programme. These recommendations include:

- Develop a general flow chart;

- Create a generic Corrective Action Programme (CAP);

- Develop a basic training programme;

- Develop generic validation master file;

- Use the European Pharmacopoeia monograph system;

- Exchange information between CRP members and other companies by technical support visits;

- Perform cross audits between CRP members.

Some more detailed aspects of a GMP approach were discussed and are listed as follows:

- Quality assurance programme:

- Flow chart approach;

- Responsibility chain.

- Vendor qualification:

- Order;

- Order system;

- Interaction with the purchasing group;

- Stock items (inventory control process);

- Reliability;

- Testing samples.

- Master file for reagents, raw materials, etc:

- QC for raw materials, specifications;

- Definition from R\&D.

- Targets for Mo production (activation or fission);

- Proper specification of all materials to be purchased/prepared;

- Procedures for receiving the materials:

- QC programme (sampling accepted quality limit);

- Storage (quarantine);

- According to the manufacturer.

- Shelf life.

- Water:

- Buy or purify;

- Not so critical for ${ }^{99}$ Mo production. 
— Training and qualification programme:

- GMP;

- Requalification;

- Records, documentation;

- On the job training; documentation;

- Production, target preparation, QC, etc;

- General programme;

- Control of areas.

- Equipment qualification:

- Validation.

- Area classification:

- Mo production: Class D;

- Sterilization after production.

- Documentation:

- Procedures (whole system);

- Rework procedures;

- Checklist;

- Batch records, calibration, maintenance, etc;

- Quality control;

- Validation procedures;

- Record keeping;

- Area monitoring;

- Document control;

- Deviations (planned/unplanned);

- Periodically review.

- Change control process:

- Corrective and preventive action programme;

- Customer complaints;

- Define level of changes.

- Quality control testing:

- Analytical methodology validation;

- Number of samples;

- Chemical, radiochemical, radionuclide quality controls;

- US and EU pharmacopoeias;

- Retention samples $\left({ }^{99} \mathrm{Mo}\right)$;

- Equipment calibration.

- Target characterization and quality control;

- Housekeeping/cleaning validation.

MURR and ANSTO in particular gave some very useful presentations and information during the 2010 workshop in Chile. ANSTO gave details of their 
quality programme for the routine production of ${ }^{99} \mathrm{Mo}$, paying special attention to operator training and accreditation. MURR gave details of its corrective and preventative action programme guidelines.

\subsection{WASTE MANAGEMENT}

The separation of ${ }^{99} \mathrm{Mo}$ from fission products and actinides involves very high level waste streams in three forms: gases, liquids and solids. These must be treated according to their radioactive level and physical form. The waste management strategy employed by a small scale producer will depend on the kind of irradiated uranium target and processing it employs. The (n, $\gamma$ ) production routes also generate radioactive waste, but the levels and volumes are significantly smaller than waste streams generated through the fission route.

The radioactive waste management strategy has to meet the criteria of discharge limits established by each country, as well as national licensing requirements. It is also important to pay attention to the non-radioactive waste that is generated during processing. One example is the waste treatment of MEK, a toxic and flammable solvent, if the solvent extraction procedure is employed for the separation of ${ }^{99 \mathrm{~m}} \mathrm{Tc}$ from $(\mathrm{n}, \gamma){ }^{99} \mathrm{Mo}$.

In general, any waste management plan must consider the following aspects: handling, treatment, conditioning, storage, transport and disposal.

\subsubsection{Waste from fission based ${ }^{99} \mathrm{Mo}$ production}

Use of the LEU modified Cintichem process will generate solid, liquid and gaseous waste. Solid waste will include the discarded target tubes after disassembly, and glassware, columns, filters and syringes used during processing. This material should all be low level solid waste. Treatment for these wastes can be divided into two steps: the first step, treatment of off-gases, is performed on-line during the processing. Gaseous waste, which includes volatile fission products, is removed from the dissolver using a cold trap. The cold trap is stored to allow decay and then eventually vented when the gases have decayed to background levels.

Depending on how the producer decides to carry out processing, there will be one or two types of liquid wastes. It is possible to separate the filtrate from the $\mathrm{ABO}$ precipitation into two fractions. The first fraction is from the initial filtrate and the first two rinses. This essentially contains all the uranium and fission and activation products from the irradiated target and is high level liquid waste. The second waste is from the remaining rinses and has trace amounts of the same components; it would be low level liquid waste. Cintichem selected 
these two fractions because the first fraction was calcined, decay stored and then sent to Savannah River for recycling of the HEU. If no recycling is planned, the fractions could be combined into a single liquid waste stream. The gaseous waste and volatile fission products are removed from the dissolver using a cold trap. The cold trap is stored to allow decay and then eventually vented when the gases have decayed to background.

Figure 77 shows the waste streams for the LEU modified Cintichem process that will generate liquid, solid and gaseous waste.

There is currently no facility producing ${ }^{99}$ Mo by this route. The biggest challenge in dealing with these waste streams would likely be the off-gas treatment of the acidic dissolution of LEU foils and the treatment of the liquid waste containing dissolved uranium and all actinides. However, Chile, Poland and Romania all planned to use the LEU modified Cintichem process, and presented their planned waste management programme during the workshop on waste management in 2010. All three participants intended to separate their waste streams - solid waste (mainly cladding or disposables such as syringes and glassware) was classed as medium or low level and would be stored on-site in a hot cell for several months, and then moved to a longer term storage facility to continue its radioactive decay. Gaseous wastes would be trapped and condensated or trapped in adsorber vessels before being allowed to decay and being released. Liquid waste containing nitric acid, uranium, magnesium, iron, ammonium ions

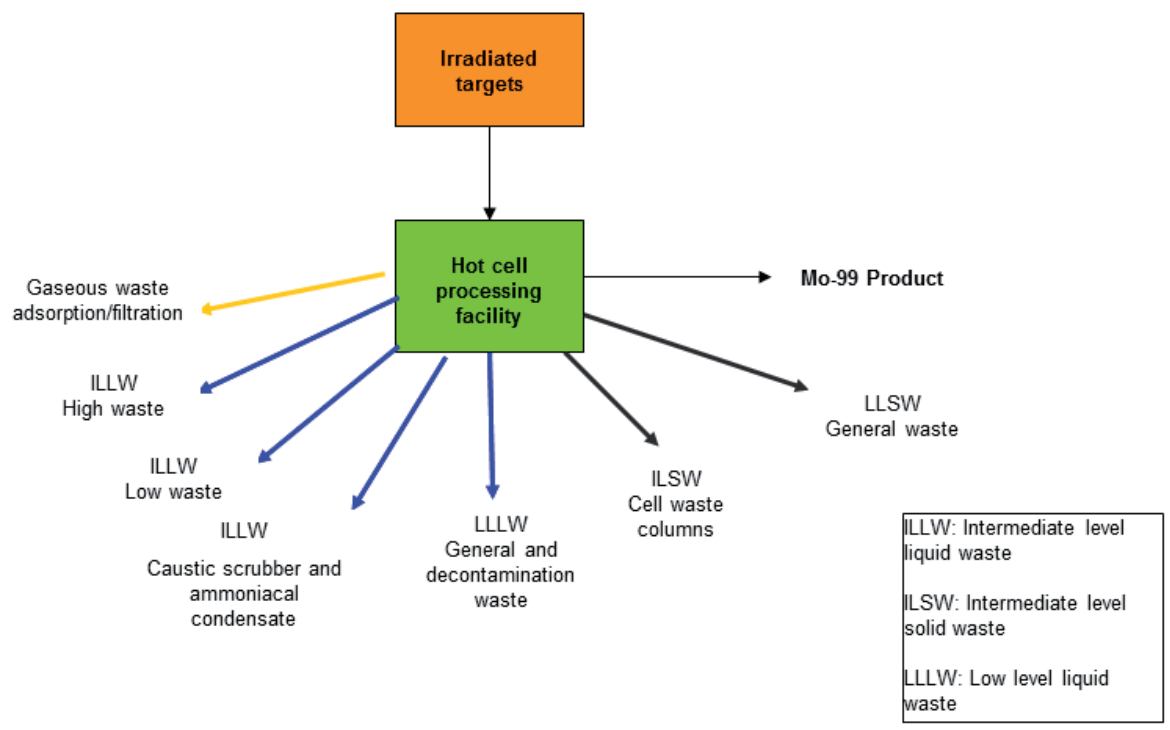

FIG. 77. Flow sheet of the production and waste for the LEU modified Cintichem process. 
and the radioisotopes ${ }^{137} \mathrm{Cs},{ }^{144} \mathrm{Cs},{ }^{106} \mathrm{Ru},{ }^{155} \mathrm{Eu},{ }^{95} \mathrm{Zr},{ }^{95} \mathrm{Nb},{ }^{103} \mathrm{Ru},{ }^{141} \mathrm{Ce},{ }^{134} \mathrm{Cs}$ and ${ }^{60} \mathrm{Co}$ would be stored in the hot cell for approximately one year. After this year, the liquid waste could be classified as a medium level waste and moved to a long term storage facility.

\subsubsection{Waste from fission based ${ }^{99} \mathrm{Mo}$ production $-\mathrm{UAl}_{\mathrm{X}}$ dispersion target processing}

The basic differences between the wastes generated by the acid dissolution of LEU foil targets and those generated by the alkaline dissolution of dispersion LEU UAl $\mathrm{X}_{\mathrm{X}}$ targets are the presence of iodine and $\mathrm{NO}_{\mathrm{x}}$ in the acid and $\mathrm{H}_{2}$ or $\mathrm{NH}_{3}$ in the alkaline and that the uranium and transuranic species remain in the liquid waste in the acid method and in the solid waste in the alkaline one.

Figure 78 shows the production and waste flow sheet for the LEU alkaline process that will also generate liquid, solid and gaseous waste.

In the alkaline process, the main concern is the solid waste, i.e. the filters containing the uranium precipitate. Initially, these filters can be accumulated inside the hot cell; with time, they can be packed and sent to a waste operation facility.

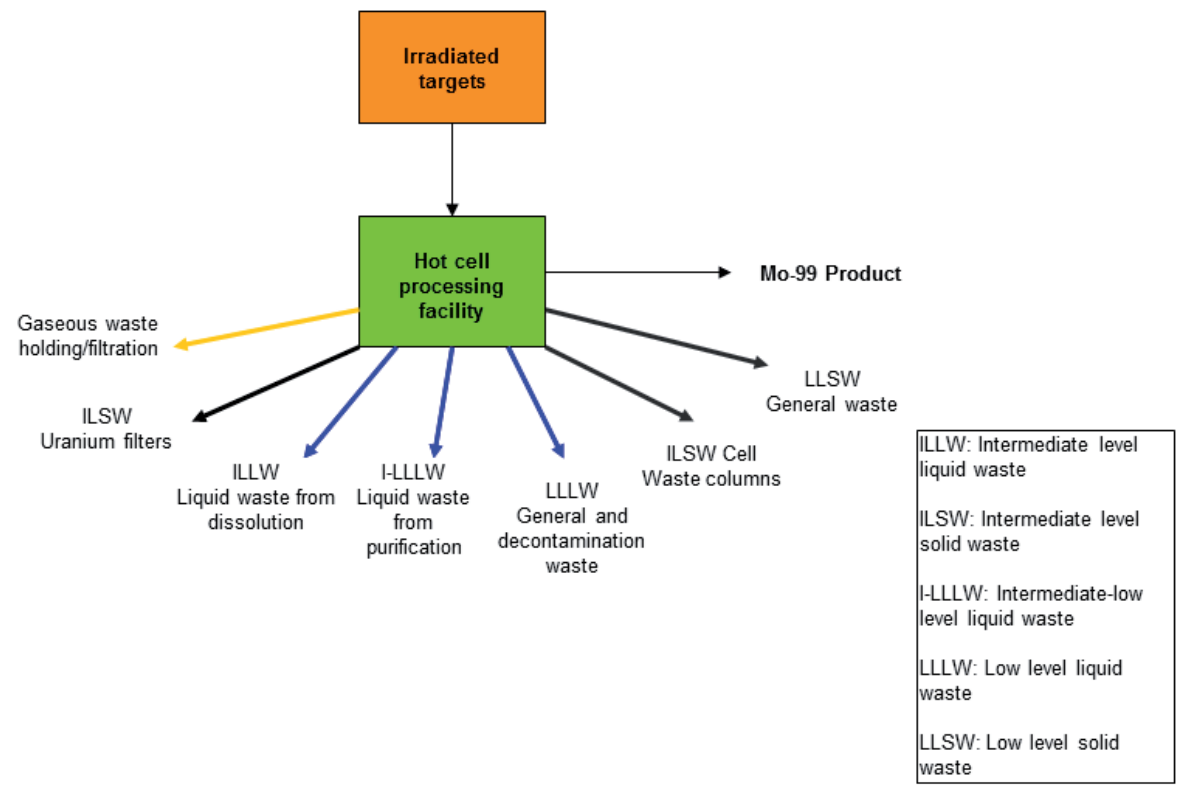

FIG. 78. Flowchart of the production and waste for the LEU alkaline process. 
As a commercial producer of ${ }^{99} \mathrm{Mo}$, CNEA has a proven programme for waste treatment as a part of the management of its ${ }^{99}$ Mo production facility. ANSTO is also an international producer of ${ }^{99} \mathrm{Mo}$ and gave a comprehensive presentation on waste management in the workshop in 2010. As Pakistan currently produces ${ }^{99}$ Mo through the alkaline process (and Egypt stated in their final CRP report that they plan to do so), Pakistan shared their waste management strategy through the CRP.

PINSTECH generates solid waste from a variety of sources, including filter cakes, columns and glassware. Most of this solid waste is considered medium to low level, and is disposed of shortly after its use in ${ }^{99} \mathrm{Mo}$ production. However, the filter cakes - used for filtering the alkaline suspension after dissolution and distillation - are left in the closed dissolver in the hot cell for up to a week to decay further and until the hot cell is being prepared for the next production batch. At this point the filter cake is removed and placed in a special filter box to contain the radiation and for longer term storage. After compacting, all solid waste is placed in a storage drum, which is then sealed and moved out of the hot cell. Both acidic and alkaline liquid waste is generated in processing; the total volume per batch of ${ }^{99} \mathrm{Mo}$ is approximately $15 \mathrm{~L}$. PINSTECH uses two interim storage tanks for acidic and alkaline liquid waste, for a period of six months. After that time, the liquid waste is cemented in a concrete barrel and stored at a waste management facility off-site. Gaseous wastes are trapped in a liquid nitrogen trap and transferred to decay cylinders for storage for seven weeks. After eight weeks of decay in the storage cylinders, the noble gases are released. Figures 79 and 80 show the waste management set-up at PINSTECH.

\subsubsection{Waste from neutron activation based ${ }^{99}$ Mo production}

Waste management for $(\mathrm{n}, \gamma){ }^{99} \mathrm{Mo}$ is much simpler than waste management for the fission production route. No gaseous waste is generated during processing; only liquid and solid wastes have to be treated.

In India, $10 \mathrm{~L}$ of liquid waste is generated per $50 \mathrm{~g}$ of molybdenum processed. The waste comprises a filtrate of gel precipitate, product granules washed down during the gel fragmentation stage, column bed washing and process vessel and tube rinsings. The liquid waste is collected in glass bottles in the processing cells and then transferred by gravity, through pneumatic drain valves, to a high density polyethylene (HDPE) carboy situated in the bottom compartment of the processing cells. A new carboy is used for each batch of molybdenum processed. After allowing for a decay period of approximately 6 months, aliquots from each batch are assayed to determine the radioactive concentration $(\mathrm{Bq} / \mathrm{mL})$, and to identify and quantify the presence of any long lived radionuclide contaminants. Thereafter, the carboys are transferred to the 


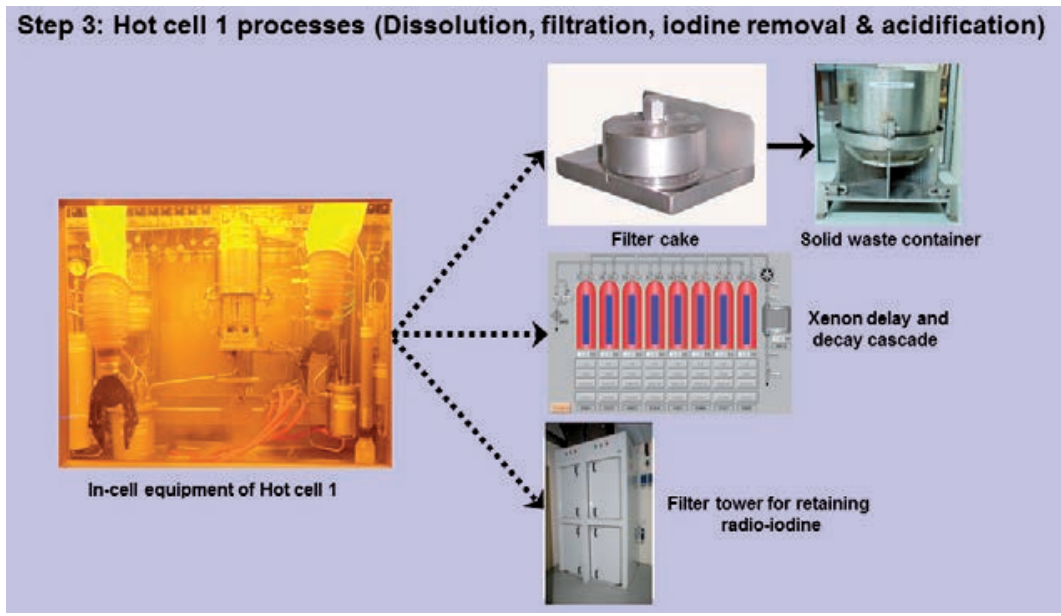

FIG. 79. View of hot cell and gaseous and solid waste treatment at PINSTECH.

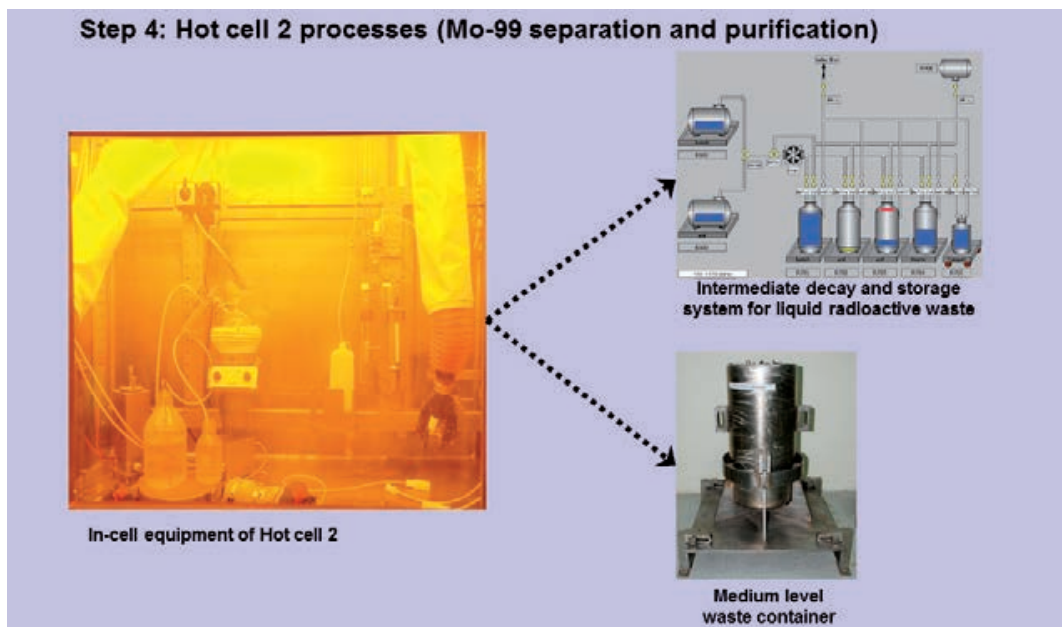

FIG. 80. View of hot cell and liquid waste treatment at PINSTECH.

Waste Management Division of BARC for appropriate handling prior to disposal. The radionuclidic impurities arising in the wastes of the treatment of $(n, \gamma){ }^{99} \mathrm{Mo}$ is directly affected by the chemical purity of the target, in general $\mathrm{MoO}_{3}$. India has been treating the waste generated in the gel production and a typical profile of radioactivity content in the waste stream is shown in Table 16. 

FROM THE TREATMENT OF $(n, \gamma)$ 99-Mo

\begin{tabular}{lcc}
\hline Radionuclide & Activity $(\mathrm{mCi})$ & Half-life (h) \\
\hline $\mathrm{W}-187$ & 0.3 & $24 \mathrm{~h}$ \\
$\mathrm{Nb}-92 \mathrm{~m}$ & 0.3 & $10 \mathrm{~d}$ \\
$\mathrm{Na}-24$ & 0.3 & $15 \mathrm{~h}$ \\
Mo-99 & 50 & $66 \mathrm{~h}$ \\
Tc-99m & 50 & $6 \mathrm{~h}$ \\
\hline
\end{tabular}

\section{CONCLUSIONS OF THE COORDINATED RESEARCH PROJECT}

Technetium-99m products and diagnostic nuclear medicine imaging have remained synonymous over the past several decades. Experts predict that there is very little likelihood of demand for ${ }^{99 \mathrm{~m}} \mathrm{Tc}$ diminishing significantly in the foreseeable future - currently, approximately 30 million diagnostic procedures are performed each year, and this number will likely grow as more procedures are performed in more countries around the world [1]. It is therefore imperative to ensure secure, sustainable supplies of ${ }^{99} \mathrm{Mo}$, so that the benefits of diagnostic imaging are not hampered or denied to patients.

The IAEA commenced the CRP detailed in this publication in 2005, in order to support interested Member States embarking on domestic, small scale ${ }^{99}$ Mo production, at a time when there was no sign of the impending crisis in ${ }^{99}$ Mo supply. There was, however, concern about the fact that fission based ${ }^{99}$ Mo production was almost exclusively dependent on the use of HEU targets. Even as the CRP participants were acquiring information about non-HEU technologies and assessing the resources required for adopting non-HEU based ${ }^{99}$ Mo production, the international supply crisis struck and forced the ${ }^{99}$ Mo production community to reconsider their supply chain. Consequently, the CRP assumed a much greater significance because it was able to address not only HEU minimization, but also to assist with the stability of ${ }^{99} \mathrm{Mo}$ supply. The CRP participants continued to pursue their stated work plans, although it was inevitable that the overall course and progress of the CRP was strongly influenced 
by the crisis itself and other measures taken to address it. One of the outcomes that directly impacted the CRP was an increase in participants: Egypt, Malaysia and Poland all joined the CRP after it had begun.

The CRP concluded in December 2011. Fourteen Member States took part as either contract or agreement holders; four RCMs and four workshops were held, on operational aspects of ${ }^{99} \mathrm{Mo}$ production, LEU target fabrication and waste management.

The majority of CRP members focused on examining the feasibility of using LEU targets for ${ }^{99}$ Mo production. Some participants focused primarily on foil production and target assembly (Indonesia, Republic of Korea) and others on processing of foil targets (Chile, Libya); a few other members gave attention to both areas. The CRP clearly illuminated the technical challenges associated with the fabrication of LEU foil targets and the annular target holder assembly, although participants made many achievements and continued to make progress for the duration of the project. As noted in the recommendations in Section 2, finding a way to purchase LEU foil, or ready made targets, would be necessary to assist most small scale producers. Having a target qualification programme for foil targets is also an important step, so that small scale producers can procure a qualified target, rather than having to perform testing and qualification on their own. One of the main conclusions to come out of the CRP is the need to encourage industrial scale producers to make and sell supplies of target foil, or ready assembled targets, for sustained availability. In the case of other target types such as the LEU dispersion target, commercial sources are currently available for their regular procurement, and will hopefully remain so.

The CRP members also had the benefit of ANL's technology and expertise on the LEU modified Cintichem process for recovery of ${ }^{99} \mathrm{Mo}$. Considerable work was performed on: the extraction of LEU foil after irradiation in a reactor; dissolver assembly; processing conditions; specific purification steps to take care of volatile ${ }^{131} \mathrm{I}$; waste handling; in-process monitoring; and evaluation of purity.

A large amount of experience and information was generated through the work of the participants, ranging from examining different ways to produce LEU foil, carrying out irradiation calculations, processing and purification, waste management and quality assurance of ${ }^{99} \mathrm{Mo}$ as well as of the ${ }^{99 \mathrm{~m}} \mathrm{Tc}$ generators produced. Several different target types (all LEU) were used as the basis for irradiation calculations, and several different dissolution processes were explored as well. Participants were able to see at first hand the planning and work involved in setting up a small scale, indigenous ${ }^{99}$ Mo production capability, and to use the CRP as a feasibility study. 
In addition to deliberations on the various technical aspects of ${ }^{99} \mathrm{Mo}$ production, the CRP served as an excellent forum for current and future cooperation, including linking small scale producers with counterparts in industry and business. Understanding the business side of ${ }^{99} \mathrm{Mo}$ production is also important, as any producer needs to understand the requirement of minimum infrastructure, which is independent of the magnitude of production capacity envisaged. After completing the feasibility study through the CRP, it would be technologically manageable for most participants to embark on the production of fission based ${ }^{99} \mathrm{Mo}$; however, it would be in their institutional and national interest to analyse and understand the entire economic implications of such an undertaking. The economic analyses performed by the OECD/NEA are an excellent reference for all stakeholders and policy makers [5].

The CRP objectives also included examining the feasibility of producing ${ }^{99}$ Mo via neutron activation, principally using gel generator technology. India and Kazakhstan were actively engaged in this part of the CRP, and Kazakhstan was able to adopt the technology with excellent results. The gel generator technology is able to handle approximately $100 \mathrm{~g}$ of $\mathrm{MoO}_{3}$ target per batch, but scaling up further may pose challenges in processing zirconium molybdate gel and ensuring acceptable quality.

Some of the participants demonstrated expertise and resources that will lead to them becoming very useful partners in global ${ }^{99}$ Mo production, including with commercial entities; others are likely to become small to medium scale producers in their own right for meeting local and regional needs. On the other hand, some other participants were undecided about proceeding with production at the end of the CRP, for technical, economic or political reasons. Most of those participants plan to continue assessing their technical capability and infrastructure readiness in light of global supply and demand information in order to make the most informed decision about whether or not to pursue a domestic production capability. The IAEA remains ready to assist Member States in assessing their production infrastructure if they request such assistance. For Member States who were not participants, but may be interested or are even already considering a small scale ${ }^{99}$ Mo production capability, the current publication would serve as vital guidance on examining feasibility. It is, however, important to consider the entire production cycle, from making or obtaining targets through to disposal and storage of waste generated by ${ }^{99}$ Mo production. 
Regarding the IAEA's continued work on creating a sustainable ${ }^{99}$ Mo supply, there are several other initiatives already under way; some of these would benefit the CRP members who wish to pursue ${ }^{99}$ Mo production in the next several years. An Interregional Project (Supporting Non-Highly Enriched Uranium (HEU) Molybdenum-99 Production Capacity for Nuclear Medicine Applications) has recently been launched under the IAEA's technical cooperation programme; this is a valuable step in continuing to leverage the considerable capabilities and networking offered by the IAEA. The IAEA is also able to undertake fact finding missions to facilities in participating Member States that will objectively assess production capabilities, infrastructure and demand, among other factors. These expert missions can help Member States determine whether or not small scale ${ }^{99} \mathrm{Mo}$ production is a viable, cost effective option. The IAEA is also running another accelerator based CRP, Alternatives to Non-HEU Production of ${ }^{99} \mathrm{Mo} /{ }^{99 \mathrm{~m}} \mathrm{Tc}$, to review and assess the potential of accelerator and cyclotron based production of ${ }^{99} \mathrm{Mo}$ and ${ }^{99 \mathrm{~m}} \mathrm{Tc}$. When completed, the results of that CRP will complement the findings from the CRP described in this publication.

The concluded CRP has proved to be an extremely important and timely initiative, not only in terms of supporting participating Member States in examining the feasibility of the small scale domestic production of ${ }^{99} \mathrm{Mo}$, but also in terms of raising awareness among the global ${ }^{99}$ Mo community about the various aspects involved in the transition to LEU targets. The project has also helped address the emerging issues surrounding securing sustainable supplies of ${ }^{99}$ Mo for users everywhere. 


\section{REFERENCES}

[1] OECD NUCLEAR ENERGY AGENCY, A Supply and Demand Update of the Molybdenum-99 Market (2012),

http://www.oecd-nea.org/med-radio/docs/2012-supply-demand-update-molybdenum99-market.pdf

[2] INTERNATIONAL ATOMIC ENERGY AGENCY, Non-HEU Production Technologies for Molybdenum-99 and Technetium-99m, IAEA Nuclear Energy Series. No. NF-T-5.4, IAEA, Vienna (2013).

[3] OECD NUCLEAR ENERGY AGENCY, The Supply of Medical Radioisotopes: Review of Potential Molybdenum-99/Technetium-99m Production Technologies, OECD Publishing, Paris (2010).

[4] ATOMIC ENERGY OF CANADA, HIGH FLUX REACTOR, INSTITUTE FOR RADIOELEMENTS, STUDIECENTRUM VOOR KERNENERGIE - CENTRE D'ETUDE DE L'ENERGIE NUCLÉAIRE, unpublished data.

[5] OECD NUCLEAR ENERGY AGENCY, Documents and Reports (2013), http://www.oecd-nea.org/med-radio/docs/ 



\section{BIBLIOGRAPHY}

ABD EL-HADY, A., ABOU EL-MAATY, T, Thermal analysis model for $\mathrm{MoO}_{3}$ ampoules irradiated in a high neutron flux, Kerntech. 74 1-2 (2009) 47-50.

BDELRAZEK, I.D., GAHEEN, M.A., Thermohydraulic Design Verification of LEU Plates Irradiation in Research Reactor Core (Proc. Mtg. on Reduced Enrichment for Research and Test Reactors, Lisbon, 2010) (2011), http://www.rertr.anl.gov/RERTR32/pdf/S11-P3_Abdelrazek.pdf

BEYER, G.-J., "German experiences in fission based Mo-99 and recent revitalization by GSG”, paper presented at Tech. Mtg on Developing Techniques for Small Scale Indigenous Molybdenum-99 (Mo-99) Production using Low Enriched Uranium (LEU) Fission or Neutron Activation, Santiago, 2010.

BONET, H., DAVID, B., PONSARD, B., "Production of ${ }^{99}$ Mo in Europe: status and perspectives", paper presented at 9th Int. Topical Mtg on Research Reactor Fuel Management, Budapest, 2005.

BOYD, R.E., The gel generator option: a viable alternative source of technetium-99m for nuclear medicine, Appl. Radiat. Isot. 48 (1997) 1027-1033.

BRADLEY, E., ALLDRED, K., ADELFANG, P., RAMAMOORTHY, N., RIDIKAS, D., IAEA Activities to Support the Transition of Molybdenum-99 Production Away From the Use of Highly Enriched Uranium, International RERTR Meeting Proceedings (Proc. Mtg. on Reduced Enrichment for Research and Test Reactors, Lisbon, 2010), (2011), http://www.rertr.anl.gov/RERTR32/pdf/S7-P2_Bradley.pdf

BSEBSU, F.M., ABOTWEIRAT, F., ELWAER, S., Feasibility Study Part-1, Thermal Hydraulic Analysis of LEU Target for ${ }^{99}$ Mo Production in Tajoura Reactor (Proc. Mtg. on Reduced Enrichment for Research and Test Reactors, Prague, 2007), (2008), http://www.rertr.anl.gov/RERTR29/PDF/9-2_Bsebsu.pdf

ECKELMAN, W.C., COURSEY, B.M., Eds., Special issue on ${ }^{99 \mathrm{~m}} \mathrm{Tc}$ generators, chemistry and preparation of radiopharmaceuticals, Int. J. Appl. Radiat. Isot. 3310 (1982) 793-951.

EVANS, J.V., MOORE, P.W., SHYING, M.E., SODEAU, J.M., "A new generator for technetium-99m", Nuclear Medicine and Biology (Proc. 3rd Congress of World Fed. of Nucl. Med. \& Biol., Paris, 1982) Vol. 2, (RAYNAUD, C. Ed.) Pergamon Press, Paris (1982) 1592-1595.

- Zirconium molybdate gel as a generator for technetium-99m-I. The concept and its evaluation, Int. J. Rad. Appl. Instrum. A. 38 (1987) 19-23. 
GOLDMAN, I., RAMAMOORTHY, N., ADELFANG, P., The IAEA Coordinated Research Project: Production of ${ }^{99}$ Mo using LEU Fission or Neutron Activation (Proc. Mtg. on Reduced Enrichment for Research and Test Reactors, Boston, MA, 2005), (2008),

http://www.rertr.anl.gov/RERTR27/PDF/S8-6_Goldman.pdf

— The IAEA Coordinated Research Project: Production of ${ }^{99}$ Mo using LEU Fission or Neutron Activation (Proc. Mtg. on Reduced Enrichment for Research and Test Reactors, Cape Town, 2006), (2008),

http://www.rertr.anl.gov/RERTR28/PDF/S10-1_Goldman.pdf

- The IAEA Coordinated Research Project: Production of ${ }^{99}$ Mo using LEU Fission or Neutron Activation (Proc. Mtg. on Reduced Enrichment for Research and Test Reactors, Prague, 2007), (2008),

http://www.rertr.anl.gov/RERTR29/PDF/6-3_Goldman.pdf

— "Fostering new sources of Mo-99 for international nuclear medicine needs - the contribution of the IAEA coordinated research project on molybdenum-99 production from LEU or neutron activation", paper presented at Mtg. on Reduced Enrichment for Research and Test Reactors, Washington, D.C, 2008.

— "Fostering Additional Sources of Molybdenum-99 Production for Supporting Nuclear Medicine Services and Progress in the IAEA CRP on Molybdenum Production from LEU or Neutron Activation", paper presented at Mtg. on Reduced Enrichment for Research and Test Reactors, Beijing, 2009.

\section{INTERNATIONAL ATOMIC ENERGY AGENCY (Vienna)}

Fission Molybdenum for Medical Use (Proc. Tech. Mtg Karlsruhe, Germany, 1987), IAEA-TECDOC-515, IAEA (1989).

Alternative Technologies for ${ }^{99} \mathrm{Tc}^{\mathrm{m}}$ Generators, IAEA-TECDOC-852, IAEA (1995).

Management of Waste from ${ }^{99}$ Mo Production, IAEA-TECDOC-1051, IAEA (1998).

Production Technologies for ${ }^{99} \mathrm{Mo}$ and ${ }^{99 \mathrm{~m}} \mathrm{Tc}$, IAEA-TECDOC-1065, IAEA (1999).

Homogeneous Aqueous Solution Nuclear Reactors for the Production of Mo-99 and other Short Lived Radioisotopes, IAEA-TECDOC-1601, IAEA (2008).

Optimization of Research Reactor Availability and Reliability: Recommended Practices, IAEA Nuclear Energy Series No. NP-T-5.4, IAEA (2008).

Research Reactor Modernization and Refurbishment, IAEA-TECDOC-1625, IAEA (2009). 
MUSHTAQ, A., et al., Neutronic and thermohydraulic analysis for production of fission molybdenum-99 at Pakistan Research Reactor-1, Ann. Nucl. Energy 35 (2007) 345-352.

- Specifications and qualification of uranium/aluminum alloy plate target for the production of fission molybdenum-99, Nucl. Eng. Des. 241 (2011) 163-167.

MUSHTAQ, A., IQBAL, M., BOKHARI, I.H., TAYYB, M., Low enriched uranium foil plate target for the production of fission molybdenum-99 in Pakistan Research Reactor-1, Nucl. Instrum. Method Phys. Res. B 267 (2009) 1109-1114.

NARASIMHAN, D.V.S., VANAJA, K.P., MANI, R.S., Preparation of sterile closed System ${ }^{99 \mathrm{~m}} \mathrm{Tc}$ generator based on zirconium molybdate, J. Radioanal. Nucl. Chem. 85 (1984) 163-172.

NATIONAL RESEARCH COUNCIL, Medical Isotope Production without Highly Enriched Uranium, The National Academies Press, Washington, D.C. (2009).

\section{RAMAMOORTHY, N.,}

"Production and availability of ${ }^{99 \mathrm{~m}} \mathrm{Tc}$ generators and of ${ }^{99} \mathrm{Mo}$ : Technology considerations and the IAEA contributions", Proceedings of DAE-BRNS Symposium on Nuclear and Radiochemistry (PUJARI, P.K., SAWANT, R.M., JEYAKUMAR, S., GOSWAMI, A., VENUGOPAL, V., Eds), Bhabha Atomic Research Centre, Mumbai, India (2007).

Editorial commentary: Supplies of Molybdenum-99: Need for sustainable strategies and enhanced international cooperation, Nucl. Med. Commun. 30 (2009) 899-905.

RYABCHIKOV, A.I.; SKURIDIN, V.S.; NESTEROV, E.V.; CHIBISOV, E.V.; GOLOVKOV, V.M., Obtaining molybdenum-99 in the IRT-T research reactor using resonance neutrons, Nucl. Instrum. Methods Phys. Res. B 213 (2004) 364-368.

SARASWATHY, P., Studies on the Separation, Characterization and Evaluation of Technetium 99m: Applicability to ${ }^{99} \mathrm{Mo}-{ }^{99 \mathrm{~m}} \mathrm{Tc}$ generator for medical use, PhD Thesis, Univ. Mumbai, India (2002).

— "Chemical process related technology development for production of Zirconium Molybdate${ }^{99}$ Mo based ${ }^{99 \mathrm{~m}} \mathrm{Tc}$ gel generators: Indian experience", Proceedings of DAE-BRNS Symposium on Nuclear and Radiochemistry (PUJARI, P.K., SAWANT, R.M., JEYAKUMAR, S., GOSWAMI, A., VENUGOPAL, V., Eds), Bhabha Atomic Research Centre, Mumbai, India (2007).

SARASWATHY, P., SARKAR, S.K., ARJUN, G., NANDY, S.K., RAMAMOORTHY, N., ${ }^{99 \mathrm{~m}} \mathrm{Tc}$ gel generators based on zirconium molybdate- ${ }^{99} \mathrm{Mo}$ : III: Influence of preparatory conditions of zirconium molybdate- ${ }^{99} \mathrm{Mo}$ gel on generator performance, Radiochim. Acta 92 (2004) 259-264. 
SARASWATHY, P., SARKAR, S.K., NARASIMHAN, D.V.S., PATEL, R.R., RAMAMOORTHY, N., Microwave oven drying of zirconium molybdate- ${ }^{99}$ Mo for use in ${ }^{99 \mathrm{~m}} \mathrm{Tc}$ Gel generator, Appl. Radiat. \& Isot. 50 (1999) 227-281.

SARASWATHY, P., SARKAR, S.K., PATEL, R.R., ARORA, S.S., NARASIMHAN, D.V.S, ${ }^{99 \mathrm{~m}} \mathrm{Tc}$ Gel generators based on zirconium molybdate $-{ }^{99} \mathrm{Mo}$ : I: Process standardization for production Radiochim. Acta, (1998) 83, 97-102.

SARASWATHY, P., SARKAR, S.K., RAMAMOORTHY, N., ARJUN, G., PATEL, R.R., “99m Tc Gel generators based on zirconium molybdate- ${ }^{99} \mathrm{Mo}$ : II: Evaluation of preparation and performance, Radiochim. Acta 83 (1998) 103-108.

SARKAR, S.K., Studies on the Preparation and Evaluation of Novel Delivery System for ${ }^{99 \mathrm{~m}}$ Tc Based on Ion-exchanger Columns in Tandem", PhD Thesis, Univ. Mumbai, India (2004).

SARKAR, S.K., SARASWATHY, P., ARJUN, G., RAMAMOORTHY, N., High radioactive concentration of ${ }^{99 \mathrm{~m}} \mathrm{Tc}$ from zirconium molybdate- ${ }^{99} \mathrm{Mo}$ gel generator using an acidic alumina column for purification and concentration, Nucl. Med. Commun. 25 (2004) 609-614.

SARASWATHY, P., et al., Tc-99m Generators for Clinical Use Based on Zirconium Molybdate Gel and $(\mathrm{n}, \gamma)$ Produced Mo-99: Indian Experience in the Development and Deployment of Indigenous Technology and Processing Facilities (Proc. Mtg. on Reduced Enrichment for Research and Test Reactors, Prague, 2007), (2008), http://www.rertr.anl.gov/RERTR29/PDF/9-5_Saraswathy.pdf

SARASWATHY, P., et al., "Evaluation of preparation and performance of gel column ${ }^{99} \mathrm{Tc}^{\mathrm{m}}$ generators based on zirconium molybdate - ${ }^{99} \mathrm{Mo}$ ", Modern Trends in Radiopharmaceuticals for Diagnosis and Therapy (Proc. Symp. Lisbon, 1998), IAEA-TECDOC-1029, IAEA, Vienna (1998).

SOLBREKKEN, G., TURNER, K., ALLEN, C., Engineering of LEU-foil Based Mo-99 Target for High Volume Production (Proc. Mtg. on Reduced Enrichment for Research and Test Reactors, Beijing, 2009), (2009),

http://www.rertr.anl.gov/RERTR31/pdf/S12-P1_Solbrekken.pdf

TURNER, K., SOLBREKKEN, G., ALLEN, C., "Thermal-Mechanical Analysis of Annular Target Design for High Volume Production of Molybdenum-99 Using Low Enriched Uranium", Proceedings of the ASME 2009 International Mechanical Engineering Congress and Exposition, 13-19 November 2009, Lake Buena Vista, Florida, USA, American Society of Mechanical Engineers, New York (2010).

UNION CARBIDE, ARINO, H., KRAMER, H., McGOVERN, J., THORNTON, A.

Production of high purity fission product Molybdenum-99, Union Carbide, US Patent No. 3799883 (1974). 
Production of high purity fission product Molybdenum-99, Canadian Patent No. 969373 (1975).

Production of high purity fission product Molybdenum-99, UK Patent No. 1389905 (1975).

UNITED STATES DEPARTMENT OF ENERGY, NATIONAL NUCLEAR SECURITY ADMINISTRATION, AUSTRALIAN NUCLEAR SCIENCE AND TECHNOLOGY ORGANISATION, GICNT Workshop Report on the Production of ${ }^{99}$ Mo using LEU, ANSTO, Sydney (2007).

VANDEGRIFT, G.F., Facts and Myths concerning ${ }^{99}$ Mo Production with HEU and LEU Targets (Proc. Mtg. on Reduced Enrichment for Research and Test Reactors, Boston, MA, 2005), (2008),

http://www.rertr.anl.gov/RERTR27/PDF/S8-1_VandeGrift.pdf

VON HIPPEL, F.N., KAHN, L.H., Feasibility of estimating the use of Highly Enriched Uranium in the production of medical radioisotopes, Sci. Glob. Secur. 14 (2006) 151-162. 



\section{Annex I}

\section{IDENTIFICATION AND RADIONUCLIDE PURITY OF FISSION MOLYBDENUM-99 $\left({ }^{99} \mathrm{Mo}\right)$ BASED ON THE EUROPEAN PHARMACOPOEIA COMMISSION METHOD FOR SODIUM MOLYBDATE $\left({ }^{99} \mathrm{Mo}\right)$ SOLUTION FISSION}

This Annex has been provided in its entirety by the University of Missouri Research Reactor as an example procedure. Alternatives to brand name products mentioned may be available.

\section{I-1. SPECIAL TOOLS, EQUIPMENT AND REAGENTS}

- Sodium molybdate $\left(\mathrm{Na}_{2} \mathrm{MoO}_{4} \cdot 2 \mathrm{H}_{2} \mathrm{O}\right)$ American Chemical Society reagent, 99.99\%;

- Glacial acetic acid, ACS reagent;

- 30\% hydrogen peroxide, ACS reagent;

- Hydrochloric acid, ACS reagent;

- Nitric acid, ACS reagent;

- $0.10 \mathrm{M}$ sodium hydroxide $\mathrm{NaOH}$ solution;

- Sodium hypochlorite solution, reagent grade (10-13\% available $\mathrm{Cl}_{2}$ );

- Strontium chloride hexahydrate, ACS reagent;

- Sodium sulphate, ACS reagent;

- Sulphuric acid, ACS reagent;

— ${ }^{125}$ I stock solution $(2.0 \mu \mathrm{Ci} / \mathrm{mL}$ as $\mathrm{NaI}$ in $0.0001 \mathrm{M} \mathrm{NaOH})$;

- ${ }^{106} \mathrm{Ru}$ stock solution $\left(0.5 \mu \mathrm{Ci} / \mathrm{mL}\right.$ as $\mathrm{RuCl}_{3}$ in $50 / 50$ acetic acid/water $)$;

- ${ }^{85} \mathrm{Sr}$ stock solution $\left({ }^{85} \mathrm{SrCl}_{2}\right.$ in $\left.0.5 \mathrm{M} \mathrm{HCl}\right)$;

— ${ }^{85} \mathrm{Sr}$ spike solution $\left(0.27 \mu \mathrm{Ci} / \mathrm{mL}\right.$ in $\left.0.001 \mathrm{M} \mathrm{SrCl}_{2}-0.01 \mathrm{M} \mathrm{HCl}\right)$;

- $\mathrm{pH}$ test strips;

- Strong base anion exchange resin; Maxi-clean IC-OH or Dowex $1 \times 8$;

- Strontium selective resin (Eichrom Sr Resin — 2.0 mL columns SR-C20-A).

\section{I-2. PROCEDURE}

Note: Reagent preparation documentation will be maintained in a bound laboratory notebook. 


\section{I-2.1. 0.118 M sodium molybdate solution}

(a) Weigh $28.40 \pm 0.05 \mathrm{~g}$ of $\mathrm{Na}_{2} \mathrm{MoO}_{4} \cdot 2 \mathrm{H}_{2} \mathrm{O}$ and transfer to a $1 \mathrm{~L}$ volumetric flask equipped with a magnetic stir bar and containing approximately $800 \mathrm{~mL}$ of water.

(b) Stir the mixture until the solid is completely dissolved. Remove the stir bar and dilute to volume with water.

(c) Transfer to a 1 L HDPE bottle and label with identification, concentration, notebook reference number, preparation date and an expiration date of one year from preparation.

\section{I-2.2. 0.0118 M sodium molybdate solution}

(a) In a $1.0 \mathrm{~L}$ volumetric flask, dilute $100.0 \mathrm{~mL}$ of $0.118 \mathrm{M}$ sodium molybdate to volume with water.

(b) Transfer to a 1 L HDPE bottle and label with identification, concentration, notebook reference number, preparation date and an expiration date of one year from preparation.

\section{I-2.3. ${ }^{99}$ Mo analyte solution}

(a) Obtain approximately $50 \mathrm{mCi}$ of the ${ }^{99} \mathrm{Mo}$ product. Transcribe the MURR ID, volume, nominal activity and time of measurement to the quality control data sheet.

(b) Measure the dose rate 6 in. (approximately $15 \mathrm{~cm}$ ) above the sample and record on the data sheet.

(c) Measure the activity of the sample in the dose calibrator and enter the result on the data sheet. If the activity is greater than $60 \mathrm{mCi}$, contact Health Physics.

(d) Place $2 \mu \mathrm{L}$ of the sample on a $\mathrm{pH}$ test strip. Record the result on the data sheet. The $\mathrm{pH}$ must be $>7.0$ to proceed.

(e) Dilute the ${ }^{99}$ Mo sample to an activity concentration of $10 \pm 1 \mathrm{mCi} / \mathrm{mL}$ with $0.0118 \mathrm{M}$ sodium molybdate solution.

$m L_{\text {carrier }}=\frac{(m C i / m L)\left(m L_{\text {Sample }}\right)}{2.3 .3 \quad 2.3 .1}-m L_{\text {Sample }}$

where $m L_{\text {sample }}=$ init $\mathrm{mL}($ step (a) $)-0.002 \mathrm{~mL}$ 


\section{I-2.4. Identification}

(a) Transfer $10 \mu \mathrm{L}$ of ${ }^{99}$ Mo analyte solution to an LSC vial containing $10 \mathrm{~mL}$ of $0.0188 \mathrm{M}$ sodium molybdate solution.

(b) Count the sample for $10 \mathrm{~min}$ on an HPGe detector at an appropriate geometry to accumulate at least 10000 counts for the major emission. The dead time should not exceed 10\%. Dominant emissions should be 181.1 and $739.4 \mathrm{keV}$ from ${ }^{99} \mathrm{Mo}$ and $140.5 \mathrm{keV}$ from ${ }^{99 \mathrm{~m}} \mathrm{Tc}$.

\section{I-2.5. ${ }^{131} \mathrm{I},{ }^{103} \mathrm{Ru}$ and ${ }^{132} \mathrm{Te}$ by gamma spectroscopy}

(a) Prepare $2.5 \mathrm{~mL}$ of ${ }^{125} \mathrm{I} /{ }^{106} \mathrm{Ru}$ spike by combining $2.365 \mathrm{~mL}$ of ${ }^{106} \mathrm{Ru}$ stock solution with $135 \mu \mathrm{L}$ of ${ }^{125}$ I stock solution.

(b) Prepare a test solution by combining and mixing the following in a $10 \mathrm{~mL}$ Hollister-Stier vial.

- $0.1 \mathrm{~mL} 0.118 \mathrm{M}$ sodium molybdate solution;

- $0.5 \mathrm{~mL} \mathrm{30 \%} \mathrm{hydrogen} \mathrm{peroxide;}$

$-2.5 \mathrm{~mL}$ acetic acid;

$-1.0 \mathrm{~mL}{ }^{125} \mathrm{I} /{ }^{106} \mathrm{Ru}$ spike solution;

$-1.0 \mathrm{~mL}$ analyte solution.

(c) Thoroughly mix the solution and allow to stand at ambient temperature for $30 \mathrm{~min}$.

(d) Dilute $7.5 \mathrm{~mL}$ of acetic acid with $7.5 \mathrm{~mL}$ of water in an LSC vial.

(e) Condition a Maxi-Clean IC-OH $1.5 \mathrm{~mL}$ column or equivalent with $5 \mathrm{~mL}$ of 1:1 acetic acid/water.

(f) Prepare a reference solution by combining $1.0 \mathrm{~mL}{ }^{125} \mathrm{I} /{ }^{106} \mathrm{Ru}$ spike solution and $9.0 \mathrm{~mL}$ of water in an LSC vial.

(g) Apply the test solution to the column and collect the eluate in a tared LSC vial. Add $6.0 \mathrm{~mL}$ of 1:1 acetic acid/water to the test solution vial. Just before the disappearance of the liquid from the top of the column, apply the 1:1 acetic acid/water rinse to the column and collect the eluate in the LSC vial. (Total eluate $\sim 12.0 \mathrm{~mL}$.)

(h) Weigh the vial and compute the total mass of eluate. Transfer $10.0 \mathrm{~mL}$ of the eluate to a second tared LSC vial for counting and weighing. Compute the fraction of the total eluate in the counting vial.

(i) Count the sample on an HPGe detector in an appropriate geometry to accumulate at least 10000 counts for the major emission. Dead time should not exceed $10 \%$.

(j) Record the activities for the following radionuclides. 
(k) Note: ${ }^{106} \mathrm{Ru}$ has no gamma emission and therefore is measured by the short lived ${ }^{106} \mathrm{Rh}$ daughter which is in secular equilibrium with the parent:

- ${ }^{125} \mathrm{I}(35.5 \mathrm{keV})$;

- ${ }^{131} \mathrm{I}(364.5 \mathrm{keV})$;

- ${ }^{103} \mathrm{Ru}(497 \mathrm{keV})$;

- ${ }^{106} \mathrm{Ru}\left(511.8\right.$ and $\left.621.7 \mathrm{keV}{ }^{106} \mathrm{Rh}\right)$;

- ${ }^{132} \mathrm{I}(668 \mathrm{keV})$.

(1) Count the reference solution on an HPGe detector at an appropriate geometry to accumulate at least 10000 counts for the major emission. Dead time should not exceed $10 \%$.

(m) Record the activities for ${ }^{125} \mathrm{I}$ and ${ }^{106} \mathrm{Ru}$.

(n) Correct all measured activities to reference time;

(o) Calculate the fractional recoveries of the ${ }^{125} \mathrm{I}$ and ${ }^{106} \mathrm{Ru}$ in the combined eluates. Note: Need to correct these calculations for the fraction of total eluate counted;

(p) ${ }^{123}$ I fractional recovery $=\frac{\mu C i{ }^{125} \mathrm{I}_{\text {eluates }}}{\mu C i{ }^{125} \mathrm{I}_{\text {reference }}}$

(q) ${ }^{106} \mathrm{Ru}$ fractional recovery $=\frac{\mu C i{ }^{106} \mathrm{Ru}_{\text {eluates }}}{\mu C i{ }^{106} \mathrm{Ru}_{\text {reference }}}$

(r) Calculate the activities of ${ }^{131} \mathrm{I},{ }^{132} \mathrm{I}$ and ${ }^{103} \mathrm{Ru}$ in the combined eluates at reference time using the fraction of eluate used and the fractional recovery of like radionuclides.

(s) e.g. ${ }^{131} \mathrm{I}$ total $=\left(\mu C i{ }^{131} \mathrm{I}\right)\left(\frac{\mathrm{g} \text { total eluate }}{\mathrm{g} \text { counted }}\right)\left(\frac{1}{125 \mathrm{I} \text { fract. recovery }}\right)$

(t) From the activity of ${ }^{132} \mathrm{I}$, calculate the activity of ${ }^{132} \mathrm{Te}$ at reference time.

$$
\mu C i^{132} \mathrm{Te}=\mu C i^{132} \mathrm{I} \cdot\left(\frac{\lambda_{I 132}-\lambda_{T e 132}}{\lambda_{I 132}}\right)\left(\frac{1}{e^{-\lambda_{T e 132} \Delta t}}\right)
$$


where:

$\mu \mathrm{Ci}{ }^{132} \mathrm{I}=$ activity at reference time

$\lambda_{\mathrm{Te}-132}=7.978 \times 10^{-3} \mathrm{~h}^{-1}$

$\lambda_{\text {I-132 }}=0.3040 \mathrm{~h}^{-1}$

$\Delta \mathrm{t}=$ Reference time - Count time

(u) Compute the levels of ${ }^{131} \mathrm{I},{ }^{103} \mathrm{Ru}$ and ${ }^{132} \mathrm{Te}$ as a percentage of the total activity

e.g $\%{ }^{131} \mathrm{I}=100\left(\frac{{ }^{131} \mathrm{I}}{{ }^{99} \mathrm{Mo}+{ }^{99 \mathrm{~m}} \mathrm{Tc}+{ }^{131} \mathrm{I}+{ }^{103} \mathrm{Ru}+{ }^{132} \mathrm{Te}}\right)$

Limits are as follows:

$\begin{array}{ll}{ }^{131} \mathrm{I} & \leq 5 \times 10^{-3} \% \\ { }^{103} \mathrm{Ru} & \leq 5 \times 10^{-3} \% \\ { }^{132} \mathrm{Te} & \leq 5 \times 10^{-3} \%\end{array}$

\section{I-2.6. ${ }^{89} \mathrm{Sr}$ and ${ }^{90} \mathrm{Sr}$ by LSC}

(a) Connect two Maxi-Clean IC-OH $1.5 \mathrm{~mL}$ columns or equivalent in series and condition them with $10.0 \mathrm{~mL}$ of $0.10 \mathrm{M} \mathrm{NaOH}$.

(b) Note: Elution flow rates in this procedure should not exceed $1.0 \mathrm{~mL} / \mathrm{min}$.

(c) In a microcentrifuge tube, prepare a test solution by adding in order $1.0 \mathrm{~mL}$ ${ }^{99} \mathrm{Mo}$ analyte, $50 \mu \mathrm{L}{ }^{85} \mathrm{Sr}$ spike solution and $50 \mu \mathrm{L}$ sodium hypochlorite $(\mathrm{NaOCl})$ solution. Agitate the mixture and allow to stand at ambient temperature for $10 \mathrm{~min}$. Volume: $1.10 \mathrm{~mL}$.

(d) Prepare a reference solution by mixing $50 \mu \mathrm{L}$ of ${ }^{85} \mathrm{Sr}$ spike solution to $9.95 \mathrm{~mL}$ of $0.10 \mathrm{M} \mathrm{HNO}_{3}$ in an LSC vial.

(e) Apply the test solution to the upper ion exchange column and allow to elute into an LSC vial. Immediately before the disappearance of the liquid from the top of the upper column, elute additionally with $3.0 \mathrm{~mL}$ of $0.10 \mathrm{M} \mathrm{NaOH}$, used to rinse the analyte vial, until the columns are dry, collecting the additional eluate in the same vial. Volume: $4.1 \mathrm{~mL}$.

(f) Add $5.9 \mathrm{~mL}$ of $8.9 \mathrm{M} \mathrm{HNO}_{3}$ to the combined eluates. Volume: $10.0 \mathrm{~mL}$.

(g) Count the diluted eluate sample on an HPGe detector. The ${ }^{99}$ Mo activity should be less than $1 / 1000$ of that in the analyte solution.

(h) Prepare a $2.0 \mathrm{~mL}$ column of $\mathrm{Sr}$ resin by conditioning with $5.0 \mathrm{~mL}$ of $5.25 \mathrm{M} \mathrm{HNO}_{3}$. 
(i) Apply the diluted eluate to the column and elute. Just before the disappearance of the liquid from the top of the column, elute additionally with $18.0 \mathrm{~mL}$ of $5.25 \mathrm{M} \mathrm{HNO}_{3}$ and allow the column to reach dryness. Discard the eluates.

(j) Rinse the column with $2.0 \mathrm{~mL}$ of $0.10 \mathrm{M} \mathrm{HNO}_{3}$ and discard the eluate.

(k) Elute the column with $10.0 \mathrm{~mL}$ of $0.10 \mathrm{M} \mathrm{HNO}_{3}$ and collect the eluate in an LSC vial.

(1) Count the eluate and the reference samples on an HPGe detector.

(m) Transfer $5.0 \mathrm{~mL}$ each of the final eluate and the reference sample to LSC vials containing $10.0 \mathrm{~mL}$ of LSC cocktail.

(n) Count each of the samples on a liquid scintillation counter.

(o) Calculate the recovery efficiency of the ${ }^{85} \mathrm{Sr}$ spike in the eluate based on the gamma spectral result.

(p) ${ }^{85} \mathrm{Sr}$ fractional recovery $=\left(\frac{\mu C i{ }^{85} \mathrm{Sr}_{\text {test }}}{\mu C i{ }^{85} \mathrm{Sr}_{\text {reference }}}\right)$

(q) Compute the total ${ }^{89} \mathrm{Sr} /{ }^{90} \mathrm{Sr}$ activity in the eluate using $99.6 \%$ counting efficiency and correcting for ${ }^{85} \mathrm{Sr}$ LSC counts.

(r) $\quad{ }^{89 / 90} \mathrm{Sr}_{\text {total }}=\frac{\left(c p s_{\text {total }}-c p s_{\mathrm{Sr}-85 \mathrm{Re} f} \cdot \text { fract }_{\mathrm{Sr}-85 \text { recover. }}\right)}{0.996} \cdot\left(\frac{1}{\text { fract }_{S r-85 \text { recover. }}}\right) \cdot 37000$

(s) Limit for ${ }^{89 / 90} \mathrm{Sr}$ is $6 \times 10^{-5} \%$ of the total activity.

\section{I-2.7. Total $\gamma$ emitting radionuclide impurities other than ${ }^{131} I$, ${ }^{103} \mathrm{Ru}$ and ${ }^{132} \mathrm{Te}$}

(a) Allow a sample of the ${ }^{99}$ Mo product to decay for 4-6 weeks.

(b) Dilute an appropriate aliquot of the sample to $10.0 \mathrm{~mL}$ with $0.0118 \mathrm{M}$ sodium molybdate solution and count on an HPGe detector. Dead time should be $\leq 10 \%$ and the major emission should have greater than 10000 counts.

(c) Back decay each activity to reference time and compute the total.

(d) Limit for $\gamma$ emitting impurities other than ${ }^{131} \mathrm{I},{ }^{103} \mathrm{Ru}$ and ${ }^{132} \mathrm{Te}: 5 \times 10^{-3} \%$ of total activity $\left(5 \times 10^{-2} \mu \mathrm{Ci} / \mathrm{mCi}{ }^{99} \mathrm{Mo}\right)$. 


\section{Annex II}

\section{RADIOCHEMICAL PURITY OF FISSION MOLYBDENUM-99 $\left({ }^{99} \mathrm{Mo}\right)$ BASED ON THE EUROPEAN PHARMACOPOEIA COMMISSION METHOD FOR SODIUM MOLYBDATE $\left({ }^{99} \mathrm{Mo}\right)$ SOLUTION FISSION}

This Annex has been provided in its entirety by the University of Missouri Research Reactor as an example procedure. Alternatives to brand name products mentioned may be available.

\section{II-1. SPECIAL TOOLS, EQUIPMENT AND REAGENTS}

- Sodium molybdate $\left(\mathrm{Na}_{2} \mathrm{MoO}_{4} \cdot 2 \mathrm{H}_{2} \mathrm{O}\right)$ ACS reagent, $99.99 \%$;

- $1.0 \mathrm{M}$ sodium hydroxide, ACS reagent;

- $0.1 \mathrm{M}$ sodium hydroxide, ACS reagent;

- Sodium carbonate, ACS reagent;

- Acetic acid, ACS reagent;

- Phenylhydrazine $\geq 99 \%$;

— iTLC-SG TLC plates $(5 \times 16 \mathrm{~cm})$;

- TLC sprayer and spray box.

\section{II-2. PROCEDURE}

\section{II-2.1. Reference solution $-0.243 \mathrm{M}$ sodium molybdate / $0.10 \mathrm{M} \mathrm{NaOH}$}

(a) Weigh $5.88 \pm 0.01 \mathrm{~g}$ of $\mathrm{Na}_{2} \mathrm{MoO}_{4} \cdot 2 \mathrm{H}_{2} \mathrm{O}$ and transfer to a $100 \mathrm{~mL}$ volumetric flask equipped with a magnetic stir bar and containing approximately $70 \mathrm{~mL}$ of water.

(b) Add $10.0 \mathrm{~mL}$ of $1.0 \mathrm{M}$ sodium hydroxide and stir the mixture until the solid is completely dissolved. Remove the stir bar and dilute to volume with water.

(c) Transfer to a $100 \mathrm{~mL}$ HDPE bottle and label with identification, concentration, notebook reference number, preparation date and an expiration date of one year from preparation. 


\section{II-2.2. 0.10 M sodium carbonate}

(a) Weigh $10.60 \pm 0.05 \mathrm{~g}$ of sodium carbonate and transfer to a $1 \mathrm{~L}$ volumetric flask equipped with a magnetic stir bar and containing approximately $900 \mathrm{~mL}$ of water.

(b) Stir the mixture until the solid is completely dissolved. Remove the stir bar and dilute to volume with water.

(c) Transfer to a 1 L HDPE bottle and label with identification, concentration, notebook reference number, preparation date and an expiration date of one year from preparation.

\section{II-2.3. 0.0185 M phenylhydrazine}

Note: Phenylhydrazine is a toxic material. Wear gloves and handle with care.

(a) Weigh $0.200 \mathrm{~g}$ of phenylhydrazine and transfer to a $100 \mathrm{~mL}$ volumetric flask equipped with a magnetic stirrer and containing approximately $60 \mathrm{~mL}$ of acetic acid.

(b) Stir the mixture until completely dissolved. Remove the stir bar and dilute to volume with acetic acid.

\section{II-2.4. ${ }^{99}$ Mo analyte solution}

(a) Dilute the ${ }^{99} \mathrm{Mo}$ product with $0.10 \mathrm{M} \mathrm{NaOH}$ to an activity concentration of $\sim 0.2 \mu \mathrm{Ci} / \mu \mathrm{L}$.

\section{II-2.5. Analysis}

(a) Mark two $10 \times 12 \mathrm{~cm}$ ITLC-SG plates with origin lines $1 \mathrm{~cm}$ from one end and a stop line $1 \mathrm{~cm}$ from the other on the long axis. Mark three equidistant spots along each origin line.

(b) Spot one of the plates in triplicate with $3 \mu \mathrm{L}$ of analyte. Spot the second plate with $2 \mu \mathrm{L}$ of reference solution.

(c) Develop both plates with $0.10 \mathrm{M}$ sodium carbonate to the stop line.

(d) Mount the analyte plate and count on the Bioscan.

(e) Dry the reference plate with warm air (hair dryer), then spray with phenylhydrazine visualization reagent and heat with hot air until spots are visible. 
(f) Measure and record the retention factors for the major peaks. The retention factor should be $0.9-1.0$ for both analyte and reference.

(g) Integrate the major peak on the analyte TLC and record as the radiochemical purity. Acceptance criterion: $\geq 95 \%$ RCP. 


\section{Annex III}

\section{ALPHA ANALYSIS OF FISSION MOLYBDENUM-99 $\left({ }^{99} \mathrm{Mo}\right)$ BASED ON THE EUROPEAN PHARMACOPOEIA COMMISSION METHOD FOR SODIUM MOLYBDATE $\left({ }^{99} \mathrm{Mo}\right)$ SOLUTION FISSION}

This Annex has been provided in its entirety by the University of Missouri Research Reactor as an example procedure. Alternatives to brand name products mentioned may be available.

\section{III-1. SPECIAL TOOLS, EQUIPMENT AND REAGENTS}

- ${ }^{242} \mathrm{Pu}$ solution;

— ${ }^{243}$ Am solution;

- Nitric acid $\left(\mathrm{HNO}_{3}\right)$;

- Hydrochloric acid ( $\mathrm{HCl})$;

- $\mathrm{HCl}$ solutions - 9.15 M, 0.10 M;

- Sulphuric acid;

- Sodium sulphate $\left(\mathrm{Na}_{2} \mathrm{SO}_{4}\right)$;

- $0.30 \mathrm{M} \mathrm{Na}_{2} \mathrm{SO}_{4}$ solution;

- Thymol blue solution;

- Lanthanum chloride heptahydrate $\left(\mathrm{LaCl}_{3} \cdot 7 \mathrm{H}_{2} \mathrm{O}\right)$;

— ${ }^{242} \mathrm{Pu}$ spike solution $\left(50 \mathrm{~Bq} / \mathrm{L}^{242} \mathrm{Pu}, 134 \mathrm{~g} / \mathrm{L} \mathrm{LaCl}_{3} \cdot 7 \mathrm{H}_{2} \mathrm{O}\right.$ in $\left.284 \mathrm{~g} / \mathrm{L} \mathrm{HNO}_{3}\right)$;

— ${ }^{243} \mathrm{Am}$ spike solution $\left(50 \mathrm{~Bq} / \mathrm{L}^{243} \mathrm{Am}, 134 \mathrm{~g} / \mathrm{L} \mathrm{LaCl}_{3} \cdot 7 \mathrm{H}_{2} \mathrm{O}\right.$ in $103 \mathrm{~g} / \mathrm{L} \mathrm{HCl}$;

- TEVA anion exchange resin;

- Electrodeposition cell and controlled power supply;

- Stainless steel planchet.

\section{III-2. PROCEDURE}

(a) Prepare analyte by combining a ${ }^{99} \mathrm{Mo}$ sample with $1.0 \mathrm{~mL}{ }^{242} \mathrm{Pu}$ spike solution, $1.0 \mathrm{~mL}{ }^{243} \mathrm{Am}$ spike solution and $9.0 \mathrm{~mL} 9.15 \mathrm{M} \mathrm{HCl}$.

(b) Evaporate to dryness with heat.

(c) Dissolve residue in $2.0 \mathrm{~mL} 9.15 \mathrm{M} \mathrm{HCl}$.

(d) Evaporate to dryness with heat.

(e) Dissolve residue in $2.0 \mathrm{~mL} 0.10 \mathrm{M} \mathrm{HCl}$.

(f) Apply solution to a column containing $0.7 \mathrm{~g}$ of TEVA anion exchange resin.

(g) Collect eluate and wash the column with $1.0 \mathrm{~mL} 0.10 \mathrm{M} \mathrm{HCl}$.

(h) Evaporate the combined eluates to dryness. 
(i) Dissolve residue in $2.0 \mathrm{~mL} 0.10 \mathrm{M} \mathrm{HCl}$.

(j) Apply the solution to a second column containing $0.7 \mathrm{~g}$ TEVA anion exchange resin.

(k) Collect the eluate and wash the column with $1.0 \mathrm{~mL} 0.10 \mathrm{M} \mathrm{HCl}$.

(l) Evaporate the combined eluates to dryness.

(m) Dissolve the residue in $1.0 \mathrm{~mL} \mathrm{HNO}_{3}$.

(n) Evaporate to dryness with heat.

(o) Again dissolve the residue in $1.0 \mathrm{~mL} \mathrm{HNO}_{3}$.

(p) Add $1.0 \mathrm{~mL}$ of $0.30 \mathrm{M} \mathrm{Na}_{2} \mathrm{SO}_{4}$ and evaporate to dryness.

(q) Add $0.3 \mathrm{~mL}$ of $\mathrm{H}_{2} \mathrm{SO}_{4}$ and warm until the residue dissolves.

(r) Add $4.0 \mathrm{~mL} \mathrm{H}_{2} \mathrm{O}$ and $10 \mu \mathrm{L}$ of Thymol blue solution.

(s) Add concentrated ammonia dropwise until the colour changes from red to yellow ( $\mathrm{pH} 1.2-2.8)$.

(t) Prepare the electrodepostion cell (rinse planchet with acetone, then water before start).

(u) Transfer the solution to the electrodeposition cell and rinse with $5.0 \mathrm{~mL}$ of $0.10 \mathrm{M} \mathrm{H}_{2} \mathrm{SO}_{4}$ to assist transfer (solution becomes pink).

(v) Adjust the $\mathrm{pH}$ to 2.1-2.4 with concentrated $\mathrm{NH}_{4} \mathrm{OH}$ or $2.0 \mathrm{M} \mathrm{H}_{2} \mathrm{SO}_{4}$.

(w) Electrolyse at $1.2 \mathrm{~A}$ for $75 \mathrm{~min}$.

(x) Add $1.0 \mathrm{~mL}$ of concentrated $\mathrm{NH}_{4} \mathrm{OH} 1 \mathrm{~min}$ prior to switching off the current.

(y) Rinse the planchet with $0.50 \mathrm{M} \mathrm{NH}_{4} \mathrm{OH}$.

(z) Rinse the planchet with acetone and remove residual solvent by blotting with a Kimwipe.

(aa) Heat the planchet on a hot plate at $180^{\circ} \mathrm{C}$ for $10 \mathrm{~min}$.

(ab) Measure the planchet in an alpha spectrometer, correcting for the recovery of the ${ }^{242} \mathrm{Pu}$ and ${ }^{243} \mathrm{Am}$ tracers. 


\section{Annex IV}

\section{ALPHA ANALYSIS OF FISSION MOLYBDENUM-99 $\left({ }^{99} \mathrm{Mo}\right)$ BASED ON EICHROM TECHNOLOGIES' ANALYTICAL PROCEDURE FOR AMERICIUM, PLUTONIUM AND URANIUM IN WATER}

This method separates americium, plutonium and uranium using Eichrom resins. Resultant analytes are then electroplated or co-precipitated with $\mathrm{CeF}_{3}$ and counted by alpha spectroscopy.

This Annex has been provided in its entirety by the University of Missouri Research Reactor as an example procedure. Alternatives to brand name products mentioned may be available.

\section{IV-1. SPECIAL TOOLS, EQUIPMENT AND REAGENTS}

— UTEVA resin prepacked columns (100-150 $\mu \mathrm{m})$;

- TRU resin prepacked columns (100-150 $\mu \mathrm{m})$;

- Resolve filters, $25 \mathrm{~mm}$ polypropylene, $0.1 \mu \mathrm{m}$;

- Vacuum filtration system;

- Electrodeposition cell assembly;

- Stainless steel planchets;

- $\mathrm{M} \mathrm{HNO}_{3}$ - $1.0 \mathrm{M} \mathrm{Al}\left(\mathrm{NO}_{3}\right)_{3}$ solution;

- Ferrous sulphamate solution (prepared from iron and sulphamic acid);

- M ammonium thiocyanate solution;

- $\mathrm{M}$ ascorbic acid solution;

- $\mathrm{M} \mathrm{HCl}$;

- 9.0 M HCl;

- $\mathrm{M} \mathrm{HCl}-0.05 \mathrm{M}$ oxalic acid;

$-0.5 \mathrm{M} \mathrm{HNO}_{3}$;

- $2.0 \mathrm{M} \mathrm{HNO}_{3}$;

- $3.0 \mathrm{M} \mathrm{HNO}_{3}$;

- $2.0 \mathrm{M} \mathrm{HNO}_{3}$;

$-0.1 \mathrm{M} \mathrm{NaNO}_{2}$. 


\section{IV-2. PROCEDURE}

\section{IV-2.1. Analyte preparation}

(a) Dilute sample to $10.0 \mathrm{~mL}$ with $3.0 \mathrm{M} \mathrm{HNO}_{3}-1.0 \mathrm{M} \mathrm{Al}\left(\mathrm{NO}_{3}\right)_{3}$.

(b) Add $2.0 \mathrm{~mL}$ of $0.6 \mathrm{M}$ ferrous sulphamate and mix.

(c) Add 1 drop of $1.0 \mathrm{M} \mathrm{NH}_{4} \mathrm{SCN}$ and mix.

(d) Add $1.0 \mathrm{~mL}$ of $1.0 \mathrm{M}$ ascorbic acid solution.

\section{IV-2.2. U Separation from Pu and Am using UTEVA Resin}

(a) Precondition a UTEVA resin column with $5.0 \mathrm{~mL}$ of $3.0 \mathrm{M} \mathrm{HNO}_{3}$;

(b) Transfer the analyte to the column, collect the eluate and set aside;

(c) Place new collection vessel beneath the column;

(d) Rinse the column with $5.0 \mathrm{~mL}$ of $3.0 \mathrm{M} \mathrm{HNO}_{3}$ and collect the eluate;

(e) Rinse again with $5.0 \mathrm{~mL}$ of $3.0 \mathrm{M} \mathrm{HNO}_{3}$ and collect the eluate in the same vessel as in step (d);

(f) Set aside all of the above eluates for $\mathrm{Am}$ and $\mathrm{Pu}$ separations;

(g) Add $5.0 \mathrm{~mL}$ of $9.0 \mathrm{M} \mathrm{HCl}$ to the column, allow to drain and discard eluate;

(h) Add $20.0 \mathrm{~mL}$ of $5.0 \mathrm{M} \mathrm{HCl}-0.05 \mathrm{M}$ oxalic acid to the column, allow to drain and discard eluate;

(i) Place a clean receptacle beneath the column;

(j) Add $15.0 \mathrm{~mL}$ of $1.0 \mathrm{M} \mathrm{HCl}$ to the column to strip the uranium;

(k) Collect the eluate and set aside for $\mathrm{CeF}_{3}$ precipitation or electrodeposition.

\section{IV-2.3. Pu, Am Separation Using TRU Resin}

(a) Equilibrate a TRU resin column with $5.0 \mathrm{~mL}$ of $2.0 \mathrm{M} \mathrm{HNO}_{3}$.

(b) Transfer the solution from IV-2.2(b) to the column and allow to drain.

(c) Transfer the solution from IV-2.2(d) and IV-2.2(e) to the column and allow to drain.

(d) Rinse the sample vessels with $5.0 \mathrm{~mL} 2.0 \mathrm{M} \mathrm{HNO}_{3}$, transfer to the column and allow to drain.

(e) Add $5.0 \mathrm{~mL}$ of $2.0 \mathrm{M} \mathrm{HNO}_{3}-0.1 \mathrm{M} \mathrm{NaNO}_{2}$ to the column and allow to drain.

(f) Add $5.0 \mathrm{~mL}$ of $0.5 \mathrm{M} \mathrm{HNO}_{3}$ to the column and allow to drain.

(g) Discard all loading and rinse solutions.

(h) Place a clean receptacle beneath the column.

(i) Add $3.0 \mathrm{~mL}$ of $9.0 \mathrm{M} \mathrm{HCl}$ to the column, allow to drain and collect eluate.

(j) Add $20.0 \mathrm{~mL}$ of $4.0 \mathrm{M} \mathrm{HCl}$ to elute the americium in the same vessel as in step (i). 
(k) Evaporate the eluates (steps (i) and (j) combined) to near dryness (do not over heat).

(1) Proceed to electrodepostion procedure or prepare for $\mathrm{CeF}_{3}$ precipitation by dissolving in $0.5 \mathrm{~mL} \mathrm{HCl}$ and $10.0 \mathrm{~mL}$ of water.

(m) Rinse the column with $25 \mathrm{~mL}$ of $4.0 \mathrm{M} \mathrm{HCl}-0.1 \mathrm{M} \mathrm{HF}$ and discard eluate (removes any residual $\mathrm{Th}$ ).

(n) Place a clean receptacle beneath the column.

(o) Add $10.0 \mathrm{~mL}$ of $0.1 \mathrm{M} \mathrm{NH}_{4} \mathrm{HC}_{2} \mathrm{O}_{4}$ to the column to elute the plutonium.

(p) Set the plutonium eluate aside for electrodeposition or $\mathrm{CeF}_{3}$ precipitation. 


\section{Annex V}

\section{DETERMINATION OF RADIOIODINE IN FISSION MOLYBDENUM-99 $\left({ }^{99}\right.$ Mo) BASED ON AUSTRALIAN ATOMIC ENERGY COMMISSION METHOD}

This Annex has been provided in its entirety by the University of Missouri Research Reactor as an example procedure. Alternatives to brand name products mentioned may be available.

\section{V-1. SPECIAL TOOLS, EQUIPMENT AND REAGENTS}

- $25 \mathrm{~mL}$ micro still with air condenser connected to a $2 \mathrm{~mL}$ bubbler;

- Aquarium pump;

- Electric heating mantle and power controller;

- 6.0 M NaOH;

— KI solution $(10 \mathrm{mg} / \mathrm{mL})$;

- $\mathrm{KIO}_{3}$ solution $(10 \mathrm{mg} / \mathrm{mL})$;

- Ammonium molybdate $\left(\mathrm{NH}_{4}\right)_{2} \mathrm{MoO}_{4}$ solution $(100 \mu \mathrm{g} / \mathrm{mL})$;

$-1.0 \mathrm{M} \mathrm{HNO}_{3}$.

\section{V-2. PROCEDURE}

(a) Add 2 drops of $6.0 \mathrm{M} \mathrm{NaOH}$ to the still flask.

(b) Add $1.0 \mathrm{ml}$ of ${ }^{99} \mathrm{Mo}(50-100 \mathrm{MBq}), 1.0 \mathrm{~mL} \mathrm{KI}$ solution, $0.3 \mathrm{~mL}$ $\mathrm{KIO}_{3}$ solution and $1.0 \mathrm{~mL}\left(\mathrm{NH}_{4}\right)_{2} \mathrm{MoO}_{4}$ solution and mix with air sparge from the pump.

(c) Add $1.5 \mathrm{~mL}$ of $6.0 \mathrm{M} \mathrm{NaOH}$ to the trap.

(d) Rapidly add 1-2 $\mathrm{ml}$ of $1.0 \mathrm{M} \mathrm{HNO}_{3}$ to the mixture and seal the still.

(e) Gently heat the still while continuously sparging with air.

(f) After complete transfer of the iodine to the trap $(-20 \mathrm{~m})$ empty the trap solution to an LSC vial and rinse with sufficient water to a final volume of $10.0 \mathrm{~mL}$.

(g) Count the sample in a calibrated HPGe detector. 


\section{Annex VI}

\section{CD-ROM CONTENTS - INDIVIDUAL COUNTRY REPORTS}

See attached CD-ROM for the following reports:

- Country report: Argentina

- Country report: Brazil

- Country report: Chile

- Country report: Egypt

- Country report: India (Gel Gen)

- Country report: India (Tech99)

- Country report: Indonesia

- Country report: Kazakhstan

- Country report: Libya

- Country report: Malaysia

- Country report: Pakistan

- Country report: Poland

- Country report: Republic of Korea

- Country report: Romania

- Country report: United States of America (Argonne National Laboratory)

- Country report: United States of America (University of Missouri Research Reactor) 


\section{ABBREVIATIONS}

AECL

ANSTO

AREVA/CERCA

ANL

BARC

BATAN

BRIT

B\&W

CCHEN

CNEA

CNEN

CRP

DOE

EAEA

EOB

GMP

GSG

HEU

HFR

HLG-MR

ICN

INVAP

IPEN

INP/NNC

IRE

KAERI

LEU

LMI

MEK

MTR
Atomic Energy of Canada Limited

Australian Nuclear Science and Technology Organisation

Compagnie pour l'etude et la réalisation de combustibles atomiques, France

Argonne National Laboratory, USA

Bhabha Atomic Research Centre, India

National Nuclear Energy Agency, Indonesia

Board of Radiation and Isotope Technology, India

Babcock \& Wilcox, USA

Chilean Nuclear Energy Commission

National Atomic Energy Commission, Argentina

National Nuclear Energy Commission, Brazil

coordinated research project

Department of Energy, United States of America

Egyptian Atomic Energy Authority

End-of-bombardment (synonymous with end-ofirradiation (EOI))

good manufacturing practice (also cGMP, current good manufacturing practice)

Gamma-Service Group

highly enriched uranium, uranium enriched in the isotope ${ }^{235} \mathrm{U}$ to $20 \%$ or more

High Flux Reactor, Netherlands

High-level Group on the Security of Supply of Medical Radioisotopes

Institute for Nuclear Research - Pitesti reactor facility, Romania

Investigaciones Aplicadas, Argentina

Nuclear and Energy Research Institute, Brazil

Institute of Nuclear Physics' National Nuclear Centre of the Republic of Kazakhstan

Institute for Radioisotopes, Belgium

Korea Atomic Energy Research Institute, Republic of Korea

low enriched uranium, uranium enriched in the isotope

${ }^{235} \mathrm{U}$ to less than $20 \%$

Lantheus Medical Imaging, USA

methyl ethyl ketone

materials testing reactor 
MURR

NAS

OECD/NEA

NESCA

NNSA

NRG

NRU

NTP

NU

PINSTECH

POLATOM

PUSPIPTEK

RCM

RERTR

ROMOL

$\mathrm{SCK} \cdot \mathrm{CEN}$

TNRC

$\mathrm{Y}-12$
University of Missouri Research Reactor, USA

National Academy of Sciences, USA

Nuclear Energy Agency of the Organisation for Economic Cooperation and Development/Nuclear Energy Agency South African Nuclear Energy Corporation

National Nuclear Security Administration, United States of America

Nuclear Research and Consultancy Group, Netherlands

National Research Universal Reactor, Canada

NTP Radioisotopes; subsidiary of the South African

Nuclear Energy Corporation (NECSA)

natural uranium

Pakistan Institute of Nuclear Science and Technology

Institute of Atomic Energy, Radioisotope Centre, Poland

Research Centre for Science and Technology, Pakistan

research coordination meeting

Reduced Enrichment for Research and Test Reactors

Rossendorf Molybdenum

Belgian Nuclear Research Centre

Tajoura Nuclear Research Center, Libya

Y-12 National Security Complex, USA 


\section{CONTRIBUTORS TO DRAFTING AND REVIEW}

Allen, C.W.

Alwaer, S.M.

Bradley, E.

Briyatmoko, B.

Carrigan, A.

Cieszykowska, I.

Chakrova, Y.

Cristini, P.

Dahalan, R.

Dash, A.

Duran, O.

Dix, J.

Gaheen, M.A.

Goldman, I.N.

Janiak, T.

Kim, C.K.

Kim, K.H.

Mielcarski, M.

Mikolajczak, R.

Mushtaq, A.
University of Missouri Research Reactor Center, USA

Tajoura Nuclear Research Center (TNRC), Libya

International Atomic Energy Agency

National Nuclear Energy Agency (BATAN), Indonesia

International Atomic Energy Agency

NCBJ Radioisotope Centre POLATOM, Poland

Institute of Nuclear Physics (INP), Kazakhstan

National Atomic Energy Commission

(CNEA), Argentina

Malaysian Nuclear Energy Agency, Malaysia

Bhabha Atomic Research Centre (BARC), India

Chilean Nuclear Energy Commission (CCHEN), Chile

International Atomic Energy Agency

Egyptian Atomic Energy Agency Research Reactor (ETRR-2), Egypt

Lantheus Medical Imaging, USA

NCBJ Radioisotope Centre POLATOM, Poland

Korea Atomic Energy Research Institute

(KAERI), Korea

Korea Atomic Energy Research Institute

(KAERI), Korea

NCBJ Radioisotope Centre POLATOM, Poland

NCBJ Radioisotope Centre POLATOM, Poland

Pakistan Institute of Nuclear Science and Technology (PINSTECH), Pakistan 
Osso, J.

Parus, J.L.

Pawlak, D.

Piasecki, A.

Ramamoorthy, N.

Saraswathy, P.

Schrader, R.

Shaat, M.K.

Staples, P.

Toma, C.

Vandegrift, G.F.

Venugopal, V.

Wojdowska, W.

Zoltowska, M.
Nuclear and Energy Research Institute (IPEN), Brazil

NCBJ Radioisotope Centre POLATOM, Poland

NCBJ Radioisotope Centre POLATOM, Poland

NCBJ Radioisotope Centre POLATOM, Poland

Bhabha Atomic Research Centre and Department of Atomic Energy (BARC), India

Board of Radiation and Isotope Technology (BRIT), India

Chilean Nuclear Energy Commission (CCHEN), Chile Egypt Atomic Energy Authority (EAEA), Egypt

Department of Energy (DOE), USA

Institute for Nuclear Research Pitesti (ICN), Romania

Argonne National Laboratory (ANL), USA

Bhabha Atomic Research Centre (BARC), India

NCBJ Radioisotope Centre POLATOM, Poland

NCBJ Radioisotope Centre POLATOM, Poland 


\title{
ORDERING LOCALLY
}

In the following countries, IAEA priced publications may be purchased from the sources listed below or from major local booksellers.

Orders for unpriced publications should be made directly to the IAEA. The contact details are given at the end of this list.

\author{
AUSTRALIA \\ DA Information Services \\ 648 Whitehorse Road, Mitcham, VIC 3132, AUSTRALIA \\ Telephone: +61 392107777 • Fax: +61 392107788 \\ Email: books@dadirect.com.au •Web site: http://www.dadirect.com.au

\section{BELGIUM} \\ Jean de Lannoy \\ Avenue du Roi 202, 1190 Brussels, BELGIUM \\ Telephone: +32 25384308 - Fax: +3225380 841 \\ Email: jean.de.lannoy@euronet.be •Web site: http://www.jean-de-lannoy.be
}

\section{CANADA}

Renouf Publishing Co. Ltd.

5369 Canotek Road, Ottawa, ON K1J 9J3, CANADA

Telephone: +1613745 2665• Fax: +16437457660

Email: order@renoufbooks.com • Web site: http://www.renoufbooks.com

\section{Bernan Associates}

4501 Forbes Blvd., Suite 200, Lanham, MD 20706-4391, USA

Telephone: +1 8008653457 • Fax: +1 8008653450

Email: orders@bernan.com•Web site: http://www.bernan.com

\section{CZECH REPUBLIC}

\section{Suweco CZ, spol. S.r.o.}

Klecakova 347, 18021 Prague 9, CZECH REPUBLIC

Telephone: +420 242459202 • Fax: +420 242459203

Email: nakup@suweco.cz•Web site: http://www.suweco.cz

\section{FINLAND}

\section{Akateeminen Kirjakauppa}

PO Box 128 (Keskuskatu 1), 00101 Helsinki, FINLAND

Telephone: +358912141 • Fax: +35891214450

Email: akatilaus@akateeminen.com•Web site: http://www.akateeminen.com

\section{FRANCE}

\section{Form-Edit}

5 rue Janssen, PO Box 25, 75921 Paris CEDEX, FRANCE

Telephone: +331420149 49 • Fax: +33142019090

Email: fabien.boucard@formedit.fr •Web site: http://www.formedit.fr

\section{Lavoisier SAS}

14 rue de Provigny, 94236 Cachan CEDEX, FRANCE

Telephone: +33147406700 • Fax: +33147406702

Email: livres@lavoisier.fr•Web site: http://www.lavoisier.fr

\section{L'Appel du livre}

99 rue de Charonne, 75011 Paris, FRANCE

Telephone: +331430750 80 • Fax: +33143075080

Email: livres@appeldulivre.fr•Web site: http://www.appeldulivre.fr

\section{GERMANY}

\section{Goethe Buchhandlung Teubig $\mathrm{GmbH}$}

Schweitzer Fachinformationen

Willstätterstrasse 15, 40549 Düsseldorf, GERMANY

Telephone: +49 (0) 211498740 • Fax: +49 (0) 2114987428

Email: s.dehaan@schweitzer-online.de • Web site: http://www.goethebuch.de

\section{HUNGARY}

Librotrade Ltd., Book Import

PF 126, 1656 Budapest, HUNGARY

Telephone: +3612577777• Fax: +361257 7472

Email: books@librotrade.hu •Web site: http://www.librotrade.hu 


\section{Allied Publishers}

$1^{\text {st }}$ Floor, Dubash House, 15, J.N. Heredi Marg, Ballard Estate, Mumbai 400001, INDIA

Telephone: +9122 2261 7926/27 • Fax: +9122 22617928

Email: alliedpl@vsnl.com•Web site: http://www.alliedpublishers.com

\section{Bookwell}

3/79 Nirankari, Delhi 110009, INDIA

Telephone: +91 112760 1283/4536

Email: bkwell@nde.vsnl.net.in •Web site: http://www.bookwellindia.com

\section{ITALY}

\section{Libreria Scientifica "AEIOU"}

Via Vincenzo Maria Coronelli 6, 20146 Milan, ITALY

Telephone: +390248954552• Fax: +390248954548

Email: info@libreriaaeiou.eu•Web site: http://www.libreriaaeiou.eu

\section{JAPAN}

Maruzen Co., Ltd.

1-9-18 Kaigan, Minato-ku, Tokyo 105-0022, JAPAN

Telephone: +8136367 6047• Fax: +8136367 6160

Email: journal@maruzen.co.jp • Web site: http://maruzen.co.jp

\section{NETHERLANDS}

\section{Martinus Nijhoff International}

Koraalrood 50, Postbus 1853, 2700 CZ Zoetermeer, NETHERLANDS

Telephone: +31793684 400• Fax: +31793615698

Email: info@nijhoff.nl•Web site: http://www.nijhoff.nl

\section{SLOVENIA}

\section{Cankarjeva Zalozba dd}

Kopitarjeva 2, 1515 Ljubljana, SLOVENIA

Telephone: +38614323144• Fax: +38612301435

Email: import.books@cankarjeva-z.si •Web site: http://www.mladinska.com/cankarjeva_zalozba

\section{SPAIN}

Diaz de Santos, S.A.

Librerias Bookshop - Departamento de pedidos

Calle Albasanz 2, esquina Hermanos Garcia Noblejas 21, 28037 Madrid, SPAIN

Telephone: +34917434890 • Fax: +34917434023

Email: compras@diazdesantos.es•Web site: http://www.diazdesantos.es

\section{UNITED KINGDOM}

The Stationery Office Ltd. (TSO)

PO Box 29, Norwich, Norfolk, NR3 1PD, UNITED KINGDOM

Telephone: +448706005552

Email (orders): books.orders@tso.co.uk•(enquiries): book.enquiries@tso.co.uk•Web site: http://www.tso.co.uk

\section{UNITED STATES OF AMERICA}

\section{Bernan Associates}

4501 Forbes Blvd., Suite 200, Lanham, MD 20706-4391, USA

Telephone: +1 8008653457 • Fax: +1 8008653450

Email: orders@bernan.com•Web site: http://www.bernan.com

\section{Renouf Publishing Co. Ltd.}

812 Proctor Avenue, Ogdensburg, NY 13669, USA

Telephone: +1 8885517470 • Fax: +1 8885517471

Email: orders@renoufbooks.com•Web site: http://www.renoufbooks.com

\section{United Nations}

300 East $42^{\text {nd }}$ Street, IN-919J, New York, NY 1001, USA

Telephone: +1 2129638302 • Fax: 12129633489

Email: publications@un.org•Web site: http://www.unp.un.org

\section{Orders for both priced and unpriced publications may be addressed directly to:}

IAEA Publishing Section, Marketing and Sales Unit, International Atomic Energy Agency

Vienna International Centre, PO Box 100, 1400 Vienna, Austria

Telephone: +431260022529 or 22488 • Fax: +431260029302

Email: sales.publications@iaea.org•Web site: http://www.iaea.org/books 



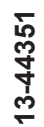




\section{RELATED PUBLICATIONS}

NON-HEU PRODUCTION TECHNOLOGIES FOR MOLYBDENUM-99

AND TECHNETIUM-99M

IAEA Nuclear Energy Series

STI/PUB/1589

ISBN 978-92-0-137710-4

Price: $€ 24.00$ 
Medical diagnostic imaging techniques using technetium-99m ( ${ }^{99 \mathrm{~m}} \mathrm{Tc}$ ) account for roughly 80 percent of all nuclear medicine procedures, representing over 30 million examinations worldwide every year. Disruptions in the supply chain of this medical isotope and its parent nuclide molybdenum-99 $\left({ }^{99} \mathrm{Mo}\right)$ can lead to cancellations or delays in important medical testing, so stability of supply is critical. Additionally, in keeping with global non-proliferation efforts, numerous States have decided to move away from using highly enriched uranium (HEU) in civilian applications, including for ${ }^{99} \mathrm{Mo}$ and ${ }^{99 \mathrm{~m}} \mathrm{Tc}$ production. To assist in stabilizing the production of ${ }^{99} \mathrm{Mo}$, and to promote the use of production methods that do not rely on the use of HEU, an IAEA coordinated research project (CRP) brought together participants to examine the feasibility of becoming small scale ${ }^{99}$ Mo producers using low enriched uranium or neutron activation. This summary of the CRP can serve as a model or guide for other States that may wish to pursue small scale ${ }^{99}$ Mo production. 